\title{
Guía de práctica clínica para el tratamiento de la enfermedad de Crohn en población adulta
}

\section{Clinical practice guidelines for the treatment of Crohn's disease in the adult population}

Fabián Juliao-Baños, ${ }^{1}$ Carlos Fernando Grillo-A., ${ }^{2}$ Luis Fernando Pineda, ${ }^{3}$ William Otero-Regino, ${ }^{4}$ María Teresa Galiano, ${ }^{5}$ Rafael GarcíaDuperly, ${ }^{6}$ María Teresa Vallejo-0., ${ }^{7}$ Marcela Torres-Amaya. ${ }^{8}$



\section{Resumen}

Objetivo: la enfermedad de Crohn es un trastorno inflamatorio idiopático de etiología desconocida con características genéticas, inmunológicas e influencias del medio ambiente. La incidencia y la prevalencia de la enfermedad de Crohn han aumentado en Colombia. El tratamiento de estos pacientes no es fácil y ha evolucionado en los últimos años; por lo tanto, es necesario desarrollar una guía de práctica clínica en Colombia, orientada al tratamiento de esta compleja enfermedad, para unificar criterios. Materiales y métodos: esta guía fue desarrollada por un equipo multidisciplinario con apoyo de la Asociación Colombiana de Gastroenterología, el Grupo Cochrane ITS y el Instituto de Investigaciones Clínicas de la Universidad Nacional de Colombia. Se desarrollaron preguntas clínicas relevantes a la entidad y se realizó la búsqueda de guías nacionales e internacionales en bases de datos especializadas. Las guías existentes fueron evaluadas en términos de calidad y aplicabilidad. El Grupo Cochrane realizó la búsqueda sistemática de la literatura. Las tablas de evidencia y recomendaciones fueron realizadas usando la metodología GRADE. Resultados: se realizó una guía de práctica clínica basada en la evidencia, para el tratamiento tanto médico como quirúrgico de la enfermedad de Crohn en población adulta en Colombia. Se diseñaron algoritmos de manejo teniendo en cuenta la actividad, el comportamiento y la localización de la enfermedad. Conclusiones: se estableció que una adecuada evaluación clínica, endoscópica e imagenológica, así como una estratificación de riesgo individual son importantes para el manejo, y se especificaron las indicaciones para el adecuado tratamiento tanto médico como quirúrgico de estos pacientes.

\section{Palabras clave}

Enfermedad de Crohn, comportamiento, extensión, cicatrización de la mucosa, terapia biológica, Crohn perianal, enfermedad de Crohn posquirúrgica.

\section{Abstract}

Objective: Crohn's disease is an idiopathic inflammatory disorder of unknown origin, influenced by genetic, immunological, and environmental factors. The incidence and prevalence of Crohn's disease have increased in Colombia. The treatment of these patients is not easy and has improved in recent years. Therefore, it is necessary to develop the Colombian Clinical Practice Guideline to guide the treatment of this complex disease and unify criteria. Materials and methods: The present guideline was carried out by a multidisciplinary team with support from the Asociación Colombiana de Gastroenterología, the Cochrane ITS Team, and the Clinical Research Institute of the Universidad Nacional de Colombia. Clinical questions regarding this disease were developed, and national and international guidelines were searched in specialized databases. The existing guidelines were evaluated in terms of quality and applicability. The Cochrane Group conducted a systematic search of the existing literature. Evidence tables were elaborated, and recommendations were made using the GRADE methodology. Results: An evidence-based clinical practice guideline was developed for the medical and surgical treatment of Crohn's disease in the adult population in Colombia. Treatment algorithms were designed, taking into account the activity, behavior, and location of the disease. Conclusions: It was established that proper clinical, endoscopic, and imaging assessment, as well as individual risk stratification, are important for treatment. Also, the indications for adequate medical and surgical treatment of these patients were specified.

\section{Keywords}

Crohn's disease, behavior, extension, mucosal healing, biological therapy, perianal Crohn's, postoperative Crohn's. 


\section{JUSTIFICACIÓN Y MARCO TEÓRICO}

La enfermedad inflamatoria intestinal (EII) comprende dos entidades, la enfermedad de Crohn (EC) y la colitis ulcerativa (CU), las cuales son patologías inflamatorias crónicas del tracto gastrointestinal, poco comunes, que afectan primordialmente al colon e intestino delgado. Su curso clínico se caracteriza por presentar múltiples recaídas y durante los últimos años se ha detectado un aumento en la frecuencia de aparición a nivel mundial $(1,2)$. Se desconoce la causa de la enfermedad, pero resulta de una interacción compleja entre el genotipo del huésped, la microbiota intestinal y los factores ambientales, que desencadenan una alteración en la respuesta inmunitaria intestinal (3). Aunque tradicionalmente se ha considerado que la EC es una enfermedad autoinmunitaria, no cumple los criterios de dichas enfermedades (4) y, por ello, algunos consideran que en realidad es una enfermedad autoinflamatoria $(5,6)$.

Históricamente, los estudios con mayor prevalencia de EII provienen de los países escandinavos, Reino Unido y Norteamérica. La EII afecta aproximadamente a 5 millones de personas en el mundo, entre ellos, 1,4 millones en Estados Unidos y cerca de 3 millones de personas en Europa (7). Una revisión sistemática de estudios epidemiológicos en EII encontró una prevalencia de EC en Europa de $0,6-322$ por cada 100.000 habitantes, de $16,7-318,5$ por cada 100.000 habitantes en Norteamérica y de 0,88-67,9 por cada 100.000 habitantes en Asia. Se demostró un incremento en la incidencia con el tiempo en el $75 \%$ de los estudios en EC (8). Una más reciente revisión sistemática de 147 estudios reportó altas tasas de prevalencia para EC en Europa (la más alta en Alemania, de 322 por cada 100.000 habitantes) y Norteamérica (la más alta en Canadá, de 319 por cada 100.000 habitantes), las cuales se han mantenido estables (9). Sin embargo, los estudios poblacionales realizados desde 1990 han demostrado un incremento en la incidencia y la prevalencia de EC en países en vía de desarrollo en Asia y en Suramérica, como en Brasil, México y Colombia (9-13). En Colombia se ha encontrado que la EC es menos frecuente que la CU. Uno de los primeros estudios se publicó en 1991, con 108 casos de EII, 98 con CU y 10 con EC, diagnosticados entre 1968 y 1990 en Bogotá (Colombia), para una razón CU/EC de 9,8:1 (14). En 2010, un trabajo del Hospital Pablo Tobón Uribe de Medellín (Colombia) encontró que en 202 pacientes con EII diagnosticados entre 2001-2009, la EC representó el $15,8 \%$, la CU el $80,7 \%$ y no clasificable el 3,5\%. La razón de CU/EC en este estudio fue 5,1:1 (15). Una actualización reciente en este mismo centro encontró, en 649 pacientes con EII, 478 individuos con CU (73,7\%), 159 pacientes con EC $(24,5 \%)$ y 12 con EII no clasificable $(1,8 \%)$, con una relación CU/EC de 3,0:1, con predominio de la EC en hombres (13). Otras series en Colombia también han documentado una proporción mayor de CU sobre EC (16, 17). Estos datos muestran que cada vez se diagnostican más pacientes con EC en el contexto de la EII, lo que semeja lo documentado en países desarrollados (18).

Por su baja prevalencia, la EC, a diferencia de la CU, cumple los criterios de una enfermedad huérfana. En Colombia, una enfermedad huérfana es aquella crónicamente debilitante, grave, que amenaza la vida y con una prevalencia (la medida de todos los individuos afectados por una enfermedad dentro de un período particular de tiempo) menor de 1 por cada 5000 personas (Ley 1392 de 2010/Ley 1438 de 2011) (19).

La EC usualmente se manifiesta entre la segunda y la cuarta década de la vida, con un pequeño pico adicional entre los 50 y 60 años (20). El diagnóstico se basa en la evaluación simultánea de síntomas clínicos, alteraciones de imágenes endoscópicas o radiológicas, bioquímicas e histopatológicas. Las alteraciones histológicas aisladas no hacen el diagnóstico. Las recientes guías de ECCO (European Crohn's and Colitis Organisation), han ratificado que no existe un "estándar de oro" para el diagnóstico de la EC. No recomiendan el uso de pruebas genéticas ni serológicas para el diagnóstico $(21,22)$. Clínicamente, es una entidad inflamatoria crónica del tracto gastrointestinal, que afecta principalmente al colon y al intestino delgado, aunque puede afectar a cualquier parte del tracto gastrointestinal desde la boca hasta el área perianal. Así mismo, puede afectar a los órganos extraintestinales, su curso clínico es variable con períodos alternantes de actividad y remisión de los síntomas. La inflamación es segmentaria, asimétrica y transmural, clínicamente es una entidad heterogénea, insidiosa y progresiva. Los síntomas más comunes son dolor abdominal, diarrea, sangrado gastrointestinal y pérdida de peso, dependiendo de la gravedad, la localización y el comportamiento (1). El tabaquismo, la vida urbana, la exposición a antibióticos y el uso de anticonceptivos orales son factores de riesgo documentados (23). Al examen físico se deben buscar signos de toxicidad sistémica, deshidratación, desnutrición, anemia y malabsorción, como también la presencia de dolor o masas en el abdomen. Examinar la región perianal es mandatorio, debido a que hasta un tercio de los pacientes presentan compromiso perianal (1). Los hallazgos de laboratorios más frecuentemente encontrados son anemia, trombocitosis, hipoalbuminemia y elevación de la proteína C-reactiva (PCR); este último no se correlaciona bien con los hallazgos endoscópicos y en un tercio de los pacientes nunca se incrementa $(21,24)$. Los biomarcadores fecales como la calprotectina se correlacionan con actividad inflamatoria por neutrófilos en el intestino, y están siendo utilizados como prueba de tamizaje, con alta sensibilidad y especificidad, para el diagnóstico de EII (25). Los pacientes con síntomas de síndrome de intestino irritable (SII), 
con una concentración de calprotectina fecal menor de 40 $\mu \mathrm{g} / \mathrm{g}$, tienen una probabilidad del $1 \%$ de padecer EII (26). Entre el $60 \%$ y el $70 \%$ de los pacientes con EC pueden tener niveles de anticuerpos antimicrobianos elevados, el más prevalente es el anti-Saccharomyces cerevisiae (ASCA); sin embargo, la sensibilidad y la especificidad de estos anticuerpos son demasiado bajas como para diagnosticar EC (27). Los hallazgos endoscópicos en ileocolonoscopia son claves para el diagnóstico de EC. La presencia de múltiples aftas inflamatorias con compromiso segmentario, asociado a úlceras longitudinales y serpentiginosas, son hallazgos típicos. Adicionalmente, la presencia de compromiso perianal, fístulas, ileítis y estenosis soporta el diagnóstico de EC (22, 28). En caso de ileocolonoscopia negativa y sospecha clínica de EC, está indicada la realización de cápsula endoscópica de intestino delgado, en ausencia de síntomas obstructivos o estenosis conocida (21). Histológicamente el compromiso inflamatorio es crónico, focal, discontinuo y transmural. El marcador histológico de EC es el granuloma epitelioide, pero se encuentra solamente en el $15 \%$ de las biopsias de mucosa y en el $70 \%$ de los especímenes quirúrgicos $(1,29)$. Estudios imagenológicos como la enterorresonancia nuclear magnética (entero-RNM) y la enterotomografía axial computarizada (entero-TAC) son de utilidad en el diagnóstico de EC, para definir la extensión de la enfermedad y descartar complicaciones como estenosis y fístulas; adicionalmente, pueden ser útiles en el seguimiento para medir la actividad de la enfermedad y la respuesta al tratamiento (30). Se prefiere la entero-RNM a la entero-TAC por la menor exposición a radiación. Para el estudio de EC perianal fistulizante se recomienda el uso de RNM de pelvis (30).

Una vez establecido el diagnóstico, se deben fenotipificar a los pacientes con EC según la clasificación de Montreal (31), para determinar la localización y el comportamiento clínico. La localización de la enfermedad tiende a ser estable, pero el comportamiento suele cambiar con el transcurso del tiempo (32).

\begin{tabular}{ll}
\hline Edad al diagnóstico (A) & A1: menor de 16 años \\
& A2: entre 17 y 40 años \\
& A3: mayor de 40 años \\
Localización (L) & L1: ileal \\
& L2: colónico \\
& L3: ileocolónico \\
& L4: digestivo superior aislado \\
Comportamiento (B) & B1: no estenosante, ni penetrante \\
& B2: estenosante \\
& B3: penetrante \\
& P: enfermedad perianal
\end{tabular}

Una revisión sistemática basada en estudios poblacionales encontró que el riesgo de cirugía en EC fue del 16,3\%, $33,3 \%$ y $46,6 \%$, a 1,5 y 10 años de seguimiento, respecti- vamente (33). Infortunadamente, la cirugía no es curativa: $50 \%$ de los pacientes reportan recurrencia clínica, $80 \%$ recurrencia endoscópica y $30 \%$ requieren manejo quirúrgico adicional (34). Adicionalmente, los pacientes con EC se estratifican según el riesgo de desarrollar complicaciones (35). Son alteraciones de mal pronóstico las siguientes: localización ileal aislada o ileocólica, compromiso digestivo superior grave o extenso de intestino delgado, lesiones perianales, compromiso rectal grave, úlceras profundas en colonoscopia, resecciones quirúrgicas intestinales previas, comportamiento estenosante y penetrante, requerimiento de esteroides al diagnóstico, edad joven al diagnóstico $(<30$ años) y sujetos fumadores $(35,36)$.

La finalidad actual del tratamiento es inducir y mantener la remisión clínica y endoscópica, para evitar la progresión de la enfermedad $(37,38)$. En el pasado, el objetivo era el control de los síntomas; sin embargo, estos no se correlacionan con la actividad inflamatoria de los sitios comprometidos. La evidencia de esta falta de correlación ha modificado los objetivos del tratamiento hacía la "remisión profunda", que incluye tanto la remisión clínica como la cicatrización endoscópica $(1,39)$. Cuando se logra la "remisión profunda”, hay menos recaídas, menos cirugías y menor daño intestinal (38). Teniendo en cuenta que la remisión profunda es la meta del tratamiento, se han identificado los blancos terapéuticos para el tratamiento ("Treat to Target") (40), y estudios recientes sugieren que esta estrategia debe impactar la progresión de la EC y mejorar los resultados, además de ser costo-efectiva (41).

Los medicamentos utilizados en el tratamiento de la EC tienen como objetivo atenuar o disminuir la inflamatoria crónica anormal, actuando sobre las vías inmunológicas de la enfermedad (1). Ninguno de los tratamientos disponibles cura la enfermedad. El arsenal terapéutico incluye 5-aminosalicilatos (5-ASA); esteroides sistémicos (prednisona, prednisolona) o tópicos (budesonida); inmunomoduladores (azatioprina, 6-mercaptopurina, metotrexato); terapia biológica (antifactor de necrosis tumoral alfa [anti-FNT- $\alpha$ ]): infliximab, adalimumab y certolizumab pegol; antiintegrinas: natalizumab, vedolizumab, anti-L12/23 subunidad p40, ustekinumab; probióticos, antibióticos (ciprofloxacina, metronidazol) y cirugía. La expiración de la patente de infliximab permitió la introducción de su biosimilar $(37,42-44)$.

Dada la complejidad de la entidad, es necesario un manejo por un equipo multidisciplinario, que además del gastroenterólogo, incluye la participación fundamental un cirujano de colon y recto experto en la entidad, así como también enfermera, radiólogo, patólogo, nutricionista y psicólogo, entre otros (45).

En el estándar de cuidado hace parte la educación del paciente y sus familiares, la prohibición absoluta del tabaquismo y la vacunación de los pacientes (46-49). 
Una vez que el diagnóstico se ha establecido, es fundamental descartar la existencia de enfermedades que puedan reaparecer o exacerbarse al iniciar un tratamiento inmunosupresor (esteroides, inmunomoduladores o terapia biológica) (50). Por lo anterior, es necesario realizar algunas pruebas, en las que se incluyen la prueba de tuberculina, radiografía de tórax, virus B: antígeno de superficie, anticuerpos antisuperficie, anticore total, antihepatitis $\mathrm{C}$, virus de la inmunodeficiencia humana (VIH), varicela zóster y virus de Epstein-Barr (51). Una preocupación de la terapia biológica es el riesgo de infección, infección seria e infección oportunista. Una infección seria es la que requiere hospitalización o antibióticos intravenosos y una infección oportunista es la que se produce por debilitamiento del sistema inmunitario y no en personas inmunocompetentes. Ejemplos de esta son Clostridium difficile, micobacteria, cándida, citomegalovirus y varicela zóster (50). La actividad de la EC, per se, también aumenta el riesgo de infecciones: cuando es moderada-grave, el riesgo de enfermedad seria aumenta dos veces. Por cada 100 puntos de actividad, el riesgo de infección seria aumenta $39 \%$ y las infecciones oportunistas, $31 \%$ (51).

El tratamiento de la EC involucra un esquema de inducción y posteriormente un régimen de mantenimiento. La escogencia de la medicación depende de la gravedad de la enfermedad, del uso de tratamiento previo y de la presencia de los factores de riesgo para desarrollar complicaciones $(35,37,52,53)$.

En la actualidad se cuenta con intervenciones farmacológicas y quirúrgicas para el manejo de la enfermedad; sin embargo, y pese a la existencia de múltiples estudios aleatorizados, algunas de las situaciones clínicas relacionadas con la entidad continúan siendo respondidas mediante el juicio clínico y la opinión de expertos, lo que se ha visto reflejado en las diferencias conceptuales para el tratamiento de estos pacientes. Por lo anterior, y tratándose de una enfermedad crónica que afecta en su mayoría a la población joven, con las consecuentes implicaciones sociales y económicas, es necesario desarrollar una guía de práctica clínica (GPC) nacional, que reúna la mejor y más reciente evidencia disponible, con el ánimo de unificar los criterios para el manejo acertado de la entidad, contando para ello con la participación de grupos multidisciplinarios. La amplia variedad de escenarios clínicos con circunstancias individuales y sociales tan diversas hace difícil el ejercicio médico en esta población de pacientes, lo cual es una de las justificaciones para elaborar esta guía, con el objetivo de disminuir la variabilidad injustificada de criterios para el tratamiento de los pacientes con EC. No obstante que los conceptos emitidos están basados en la mejor evidencia científica publicada, esta guía proporciona unas recomendaciones que serán utilizadas de acuerdo con el juicio clínico del médico tratante.

\section{OBJETIVOS}

Esta guía de práctica clínica se desarrolló con los siguientes objetivos:

- Generar recomendaciones informadas en la evidencia para el tratamiento de los pacientes con EC.

- Apoyar al tratamiento oportuno y seguro de los pacientes con EC, considerando la minimización de las secuelas y la hospitalización.

- Apoyar a los tomadores de decisiones a formular políticas para el manejo adecuado de la EC.

\section{POBLACIÓN}

\section{Grupos que se consideran}

Pacientes mayores de 16 años con diagnóstico de EC, independientemente del tiempo de evolución y del estado clínico de la enfermedad, sin importar el régimen de aseguramiento.

\section{Grupos que no se toman en consideración}

- Pacientes con colitis ulcerativa.

- Pacientes con enfermedad inflamatoria intestinal, no clasificable.

- Pacientes con manifestaciones extraintestinales de EC

- Pacientes con efectos secundarios y/o adversos del tratamiento para la EC.

- Pacientes con EC en gestación o lactancia.

- Pacientes con colitis infecciosa.

\section{USUARIOS DE LA GUÍA}

Esta guía está dirigida a los trabajadores del área de la salud, tales como gastroenterólogos, coloproctólogos, cirujanos gastrointestinales, médicos internistas, médicos familiares, médicos generales y pacientes y otros profesionales de la salud interesados en el manejo de los pacientes con EC.

\section{FINANCIACIÓN DE LA GUÍA DE PRÁCTICA CLÍNICA}

El desarrollo de la presente guía fue financiado por la Asociación Colombiana de Gastroenterología.

\section{DECLARACIÓN DE INDEPENDENCIA EDITORIAL}

La entidad financiadora brindó acompañamiento durante la elaboración de la guía garantizando con ello la transferibilidad y aplicabilidad de su contenido al contexto colombiano. El trabajo científico de investigación, así como la elaboración de las recomendaciones incluidas en el presente documento, fueron realizados de manera independiente 
por el grupo desarrollador de la guía (GDG). La entidad financiadora no influyó en el contenido de la guía.

\section{ALCANCE}

Esta guía de práctica clínica está dirigida a los profesionales de la salud que atienden directamente a los pacientes con EC, pero también indirectamente a quienes toman decisiones en salud tanto en el medio asistencial como en las aseguradoras, a los pagadores del gasto en salud y a quienes generan políticas en salud. Esta guía de práctica clínica pretende establecer los lineamientos para el tratamiento de la EC. La guía está limitada a la población diana.

\section{Ámbito asistencial}

La presente guía pretende apoyar al personal clínico asistencial que brinda cuidado a los pacientes mayores de 16 años con diagnóstico de EC en los diferentes niveles de atención en salud. El manejo de condiciones muy específicas por parte de los profesionales de la salud involucrados en la atención de los pacientes con Crohn amerita recomendaciones también específicas, que exceden el alcance de la presente guía.

Esta GPC ofrece recomendaciones para todos los niveles de atención que brindan asistencia a los pacientes con EC. La GPC suministra a los profesionales de la salud la información necesaria para brindar pautas para el manejo adecuado de la entidad.

\section{Aspectos clínicos centrales}

Aspectos clínicos abordados por la guía:

- La GPC hará referencia al tratamiento médico-quirúrgico de la $\mathrm{EC}$ y a los factores de mal pronóstico en pacientes mayores de 16 años.

- No se abordan los aspectos relacionados con el diagnóstico o la rehabilitación de los pacientes con EC debido a que, por su extensión, se consideran guías independientes que deben ser desarrolladas de novo (NICE, 2010).

\section{SOPORTE PARA AUDITORÍA EN LA GUÍA}

La guía de práctica clínica incorpora criterios de revisión e indicadores de evaluación.

\section{ACTUALIZACIÓN DE LA GUÍA}

Las recomendaciones de esta guía deben actualizarse en los próximos tres (3) años o previamente en caso de disponer de nuevas evidencias que modifiquen las recomendaciones aquí anotadas. Se espera que este proceso se lleve a cabo mediante la construcción de un panel de expertos que realice los cambios requeridos.

\section{NIVEL DE EVIDENCIA Y GRADO DE RECOMENDACIÓN}

\section{Nivel de evidencia}

\section{Calidad global de la evidencia GRADE

Calificación Juicio Características \\ A Alta Es muy poco probable que nuevos estudios $\oplus \oplus \oplus \oplus \quad$ cambien la confianza que se tiene en el resultado estimado. \\ B Moderada Es probable que nuevos estudios tengan $\oplus \oplus \oplus \mathbf{O}$ un impacto importante en la confianza que se tiene en el resultado estimado y que estos puedan modificar el resultado. \\ C Baja Es muy probable que nuevos estudios $\oplus \oplus \mathbf{O O}$ tengan un impacto importante en la confianza que se tiene en el resultado estimado y que estos puedan modificar el resultado. \\ D Muy baja Cualquier resultado estimado es muy $\oplus$ О०० incierto.}

\section{Grados de recomendación}

\section{Fuerza de la recomendación GRADE}

\begin{tabular}{|c|c|}
\hline $\begin{array}{l}\text { Fuerza de la } \\
\text { recomendación }\end{array}$ & Significado \\
\hline Fuerte a favor & $\begin{array}{l}\text { Las consecuencias deseables claramente } \\
\text { sobrepasan las consecuencias indeseables. } \\
\text { Se recomienda hacerlo }\end{array}$ \\
\hline Débil a favor & $\begin{array}{l}\text { Las consecuencias deseables probablemente } \\
\text { sobrepasan las consecuencias indeseables. } \\
\text { Se sugiere hacerlo }\end{array}$ \\
\hline Débil en contra & $\begin{array}{l}\text { Las consecuencias indeseables probablemente } \\
\text { sobrepasan las consecuencias deseables. } \\
\text { Se sugiere no hacerlo }\end{array}$ \\
\hline Fuerte en contra & $\begin{array}{l}\text { Las consecuencias indeseables claramente } \\
\text { sobrepasan las consecuencias deseables. } \\
\text { Se recomienda no hacerlo }\end{array}$ \\
\hline $\begin{array}{l}\text { Punto de buena } \\
\text { práctica }\end{array}$ & $\begin{array}{l}\text { Práctica recomendada, basada en la experiencia } \\
\text { clínica del grupo desarrollador de la guía. }\end{array}$ \\
\hline
\end{tabular}

\section{GLOSARIO}

- Enfermedad activa: la enfermedad clínicamente se clasifica como leve, moderada y grave. La graduación de la enfermedad se basa en el índice de actividad de la EC 
(CDAI). En la mayoría de los estudios clínicos se clasifica así: leve: $150-220$ puntos; moderada: $220-450$ puntos; $y$ grave: $>450$ puntos.

- Enfermedad dependiente de esteroides:

- pacientes incapaces de reducir la dosis de esteroides por debajo del equivalente a $10 \mathrm{mg} / \mathrm{d}$ de prednisona (budesonida $3 \mathrm{mg} / \mathrm{d}$ ) dentro de los primeros 3 meses de recibir los esteroides, sin recurrencia de la enfermedad; o

- pacientes que tienen recaída en los primeros 3 meses después de descontinuar los esteroides.

- la duración total del tratamiento con esteroides no debe exceder los 3 meses.

- Enfermedad extendida: compromiso intestinal por EC $>100 \mathrm{~cm}$, sin importar la localización. Incluye la suma de áreas inflamadas alternadas con áreas sin compromiso.

- Enfermedad localizada: afectación intestinal de la EC menor de $30 \mathrm{~cm}$.

- Enfermedad refractaria a esteroides: pacientes con actividad de la enfermedad a pesar de la administración de prednisona de hasta $1 \mathrm{mg} / \mathrm{kg} / \mathrm{d}$ durante un período de 4 semanas.

- Recaída: exacerbación de síntomas en un paciente con EC que había estado en remisión clínica, ya sea espontáneamente o después del tratamiento médico; un incremento de setenta puntos en el CDAI. Se sugiere en la práctica clínica confirmar recaída con laboratorios, estudios endoscópicos o radiológicos.

- Recaída temprana: exacerbación de síntomas en menos de 3 meses en un paciente con EC en remisión clínica bajo tratamiento médico.

- Recurrencia: reaparición de lesiones endoscópicas después de someterse a una resección quirúrgica.

- Recurrencia clínica: reaparición de los síntomas después de una resección macroscópica completa de la enfermedad, después de confirmar la recurrencia de lesiones. Es importante la confirmación de las lesiones, ya que hay entidades que pueden simular los síntomas de la EC (malabsorción de sales biliares, trastornos de la motilidad, sobrecrecimiento bacteriano, entre otras).

- Recurrencia morfológica: aparición de nuevas lesiones de EC después de resección macroscópica de la enfermedad, usualmente en el neoíleon terminal o en la anastomosis, y suele ser detectada por endoscopia, radiología o cirugía. La recurrencia endoscópica se clasifica según el puntaje de Rutgeerts: 0: no hay lesiones evidentes. 1: menos de 5 lesiones aftosas. 2: más de 5 lesiones con mucosa normal entre lesiones. 3: ileítis aftosa difusa con mucosa inflamada. 4: inflamación ileal con nódulos, úlceras y estenosis.

- Remisión clínica: CDAI <150 puntos. Se sugiere en la práctica clínica confirmar remisión clínica por pará- metros objetivos con laboratorios (calprotectina fecal, PCR), estudios endoscópicos o radiológicos.

- Respuesta a tratamiento: cambio de puntaje en el CDAI, disminución $\geq 100$ puntos en el CDAI.

\section{METODOLOGÍA}

Esta sección es una adaptación de la plantilla de la Organización Panamericana de la Salud (OPS), que se encuentra en la Directriz para el fortalecimiento de los programas nacionales de guías informadas por la evidencia, de 2018.

\section{Composición del grupo}

El GDG contó con la participación de expertos temáticos en gastroenterología, coloproctología, ginecología, epidemiología, química farmacéutica y salud pública. Adicionalmente, se contó con el soporte del Grupo Cochrane STI de Colombia. El Grupo Cochrane STI realizó para el GDG la búsqueda sistemática de la literatura, la obtención de los estudios en texto completo y la construcción de tablas GRADE.

\section{DECLARACIÓN DE CONFLICTOS DE INTERÉS}

Los responsables y participantes en la generación de las recomendaciones de esta guía declararán por escrito y de antemano sus conflictos de interés frente a estas.

Se realizó un análisis de los conflictos de interés y de acuerdo con el conflicto declarado se tomó la decisión de participación parcial o completa. Dos expertos temáticos fueron excluidos de la formulación de las recomendaciones relacionadas con medicamentos biológicos debido a que son ponentes de varios laboratorios farmacéuticos sobre el uso de medicamentos biológicos para EC. El análisis se encuentra en el Anexo 1.

\section{Definición de los alcances y objetivos de la guía de práctica clínica}

Los alcances y objetivos de esta guía fueron definidos por la Asociación Colombiana de Gastroenterología, con el propósito de servir de apoyo a los profesionales de la salud involucrados en el proceso de atención de los pacientes con EC y así brindar una atención médica homogénea, con calidad, equidad y eficiencia. Luego de la revisión de la literatura sobre el tema, el GDG redactó un documento considerando la heterogeneidad en la práctica clínica, la disponibilidad de nueva evidencia, la existencia de nuevas opciones terapéuticas, la inadecuada utilización de los recursos y los problemas de calidad en la práctica derivados 
de la atención en salud. También se definieron los temas abordados y no abordados, la población objeto de la guía y los aspectos clínicos centrales.

\section{Decisión sobre el desarrollo o la adaptación}

EL GDG procedió a realizar una búsqueda sistemática de la literatura con el objeto de identificar todas las GPC nacionales e internacionales que abordaran el manejo de pacientes con EC y que guardaran similitud con los alcances y objetivos propuestos para esta guía. Se evaluó la calidad de las GPC recuperadas con el instrumento AGREE II (54) y cada documento fue calificado independientemente por dos evaluadores con el fin de obtener la calidad global de la guía. Luego del proceso de calificación y de acuerdo con los lineamientos propuestos por desarrolladores de guías internacionales, se evaluaron los niveles de discrepancia para cada guía, para así identificar los dominios que necesitaban ser revisados. Esta discrepancia fue evaluada usando el sistema de calificación propuesto por el grupo AGREE (54).

Una vez se obtuvo la calidad global de cada guía y se identificaron los dominios que necesitaban ser revisados, se realizaron reuniones de consenso no formal pare establecer la posibilidad de adaptación o de desarrollo de novo. Para ello, el GDG tomó como insumo los criterios contenidos en la matriz de decisión de adaptación o desarrollo de novo de la GPC (55).

La matriz de decisión considera los siguientes aspectos:

- Las guías identificadas deben guardar relación con los alcances y objetivos de la GPC, objeto de desarrollo.

- Las guías identificadas fueron desarrolladas mediante metodologías basadas en la evidencia, disponen de tablas de evidencia y tienen menos de 5 años de publicación.

- Las guías deben obtener un puntaje adecuado en calidad metodológica e independencia editorial al ser evaluadas con la herramienta AGREE II.

- Las guías deben ser recomendadas por parte de ambos evaluadores.

Con base en los resultados de la matriz de decisión se consideró que ninguna de las guías elegibles cumplía la totalidad de los criterios para ser adaptada, por lo que se procedió a un desarrollo de novo.

\section{Formulación de preguntas clínicas de la guía de práctica clínica}

El GDG revisó los aspectos clínicos relevantes que debían ser incluidos y con base en estos formuló preguntas básicas, las cuales fueron posteriormente reestructuradas en formato PICO (población, intervención, comparación y desenlaces). Las preguntas resultantes se encuentran en el Anexo 2.
Identificación y graduación de los desenlaces de la guía de práctica clínica

\section{Búsqueda para el desarrollo de novo}

El primer paso desarrollado fue la búsqueda de revisiones sistemáticas de las siguientes bases de datos: MEDLINE (vía Ovid) EMBASE (vía embase.com) y Cochrane Library, la cual incluye Health Technology Assessment (HTA) database, Database of Abstracts of Reviews of Effects (DARE) y NHS Economic Evaluation Database (NHS EED).

El diseño y ejecución de las estrategias de búsqueda fue desarrollado por el coordinador de búsquedas del Grupo Cochrane STI con apoyo del GDG. Para esto, se usaron formatos de identificación de palabras relacionadas con las preguntas clínicas que permitieran la selección de términos de lenguaje controlado y lenguaje libre, con los cuales se crearon las sintaxis de búsqueda para cada plataforma consultada (Anexo 4). No se aplicaron restricciones de fecha o idioma en la búsqueda. Por otro lado, se incluyeron estudios clásicos y relevantes enviados por expertos temáticos. Las preguntas que no contaron con revisiones sistemáticas fueron contestadas mediante la inclusión de estudios primarios.

\section{Calificación de la evidencia}

La calificación de la evidencia se realizó de acuerdo con el tipo de evidencia. Las revisiones sistemáticas (RS) identificadas fueron evaluadas utilizando la lista de chequeo AMSTAR (56); además de esta lista, se evaluaron aspectos de contenido, calidad y relevancia clínica para identificar aquellas de mayor calidad metodológica, las cuales fueron incorporadas a la guía. En caso de no identificar revisiones sistemáticas de alta calidad, se procedió a la evaluación de estudios primarios utilizando la herramienta de riesgo de sesgos sugerida por Cochrane (57).

Para la síntesis de la evidencia encontrada se construyeron perfiles de evidencia a través del portal www.guidelinedevelopment.org y los niveles de evidencia fueron graduados según la clasificación GRADE, que califica la calidad de la evidencia en cuatro niveles (58).

\section{Juicio \\ Características}

Alta Es muy poco probable que nuevos estudios cambien la $\oplus \oplus \oplus \oplus \quad$ confianza que se tiene en el resultado estimado.

Moderada Es probable que nuevos estudios tengan un impacto $\oplus \oplus \oplus \mathbf{O}$ importante en la confianza que se tiene en el resultado estimado y que estos puedan modificar el resultado.

Baja Es muy probable que nuevos estudios tengan un impacto

$\oplus \oplus \mathbf{O}$ importante en la confianza que se tiene en el resultado estimado y que estos puedan modificar el resultado.

Muy baja Cualquier resultado estimado es muy incierto. 


\section{Graduación de la fuerza de las recomendaciones}

Las recomendaciones fueron formuladas en dos pasos. Primero, el GDG elaboró las recomendaciones preliminares considerando el balance riesgo-beneficio, las preferencias de los pacientes y el contexto colombiano. Posteriormente, las recomendaciones se discutieron y ajustaron en un panel de expertos con representantes de usuarios y de pacientes. Esta se determinó con base en el nivel de evidencia y otras consideraciones adicionales que fueron revisadas en pleno por el GDG, el ente gestor y el panel de expertos considerando los diferentes escenarios del contexto colombiano.

La metodología GRADE ofrece dos grados de fuerza de recomendación: "Fuerte" y "Débil". Una vez se contempló el balance riesgo-beneficio, la calidad de la evidencia, los valores y preferencias y el contexto colombiano, se determinó la fuerza de cada recomendación utilizando la siguiente estructura:

\begin{tabular}{|c|c|}
\hline $\begin{array}{l}\text { Fuerza de la } \\
\text { recomendación }\end{array}$ & Significado \\
\hline Fuerte a favor & $\begin{array}{l}\text { Las consecuencias deseables claramente } \\
\text { sobrepasan las consecuencias indeseables. } \\
\text { Se recomienda hacerlo }\end{array}$ \\
\hline Débil a favor & $\begin{array}{l}\text { Las consecuencias deseables probablemente } \\
\text { sobrepasan las consecuencias indeseables. } \\
\text { Se sugiere hacerlo }\end{array}$ \\
\hline Débil en contra & $\begin{array}{l}\text { Las consecuencias indeseables probablemente } \\
\text { sobrepasan las consecuencias deseables. } \\
\text { Se sugiere no hacerlo }\end{array}$ \\
\hline Fuerte en contra & $\begin{array}{l}\text { Las consecuencias indeseables claramente } \\
\text { sobrepasan las consecuencias deseables. } \\
\text { Se recomienda no hacerlo }\end{array}$ \\
\hline
\end{tabular}

Finalmente se verificó que el panel de expertos estuviera de acuerdo con las recomendaciones sugeridas y que estas incorporaran la perspectiva de los participantes. El grado de recomendación y cada recomendación fueron votadas.

\section{Buenas prácticas}

Las buenas prácticas son sugerencias operativas basadas en la experiencia del GDG y de las mesas de trabajo de GRADE donde participaron diferentes grupos de interés; aunque no son basadas en la evidencia, hacen parte de las buenas prácticas de diagnóstico, tratamiento o seguimiento de los pacientes. Las buenas prácticas tienen como objetivo apoyar las recomendaciones formuladas.

\section{Incorporación de costos y preferencias de pacientes}

En la presente guía no se realizó una evaluación de costoefectividad. Se identificaron las preferencias de los pacientes a través de una revisión sistemática de la literatura, donde se evaluaron los valores y las preferencias de tratamiento y la percepción de la EC, las cuales ayudaron a fortalecer las recomendaciones.

En la presente guía no se incluyeron consideraciones de costos dada la variabilidad del contexto latinoamericano, por lo que no se incluyen en la tabla de juicio de valor de las recomendaciones. Adicionalmente, no se identificó alguna recomendación cuya formulación se encontrará influenciada por los costos. Con respecto a las preferencias y los valores de los pacientes, se realizó una búsqueda que arrojó solo un estudio. Sin embargo, dada la patología, la estrategia de manejo y la población diana, existen pocas recomendaciones donde la preferencia de los padres o cuidadores pueda influenciar la recomendación.

\section{Formulación de preguntas por consenso de expertos}

Para las preguntas en las que no se encontró evidencia o esta fue controvertida, el GDG elaboró unas recomendaciones basadas en la experiencia profesional y en la buena práctica, que fueron sometidas a consenso formal en las mesas de trabajo de GRADE.

\section{PREGUNTAS CLÍNICAS}

\section{PREGUNTA 1. ¿CUÁLES SON LOS FACTORES QUE PERMITEN PREDECIR RECAÍDAS EN PACIENTES MAYORES DE 16 AÑOS CON ENFERMEDAD DE CROHN?}

\section{Lista de recomendaciones}

\begin{tabular}{|c|c|}
\hline Recomendación $n .^{\circ}$ & Resumen \\
\hline Fuerte a favor & $\begin{array}{l}\text { Se recomienda la medición de los niveles } \\
\text { de proteína C-reactiva (PCR) y el uso de } \\
\text { velocidad de sedimentación globular (VSG) } \\
\text { para predecir la recaída en los pacientes con } \\
\text { enfermedad de Crohn. } \\
\text { Calidad de la evidencia: muy baja } \oplus \text { }\end{array}$ \\
\hline Débil en contra & $\begin{array}{l}\text { No se sugiere la medición de ASCA para } \\
\text { predecir la recaída en pacientes con } \\
\text { enfermedad de Crohn. } \\
\text { Calidad de la evidencia: muy baja } \oplus \text { ○০০ }\end{array}$ \\
\hline Débil a favor & $\begin{array}{l}\text { Se sugiere la medición de los niveles de } \\
\text { calprotectina fecal para predecir la recaída en } \\
\text { pacientes con enfermedad de Crohn. } \\
\text { Calidad de la evidencia muy baja } \oplus \text { } \oplus \text { ○ }\end{array}$ \\
\hline $\begin{array}{l}\text { Punto de buena } \\
\text { práctica }\end{array}$ & $\begin{array}{l}\text { La periodicidad de la medición de } \\
\text { calprotectina fecal debe ser cada } 3 \text { a } 6 \text { meses. }\end{array}$ \\
\hline
\end{tabular}




\begin{tabular}{|ll}
$\begin{array}{l}\text { Punto de buena } \\
\text { práctica }\end{array}$ & $\begin{array}{l}\text { Se sugiere, para la medición de la } \\
\text { calprotectina fecal, tomar la primera muestra } \\
\text { del día y un punto de corte de } 250 \mu \mathrm{g} / \mathrm{g}\end{array}$ \\
& $\begin{array}{l}\text { es el valor más confiable para diferenciar } \\
\text { cicatrización de la mucosa de inflamación en } \\
\text { enfermedad de Crohn. Se considera un punto } \\
\text { de corte de } 100 \mu \mathrm{\mu g} / \mathrm{g} \text { como el valor predictor } \\
\text { de recurrencia en pacientes con enfermedad } \\
\text { de Crohn posquirúrgica. }\end{array}$ \\
\hline $\begin{array}{l}\text { Punto de buena } \\
\text { práctica }\end{array}$ & $\begin{array}{l}\text { En los pacientes con enfermedad de Crohn } \\
\text { que se encuentren en tratamiento con } \\
\text { infliximab se pueden medir los niveles séricos } \\
\text { del medicamento para predecir la remisión } \\
\text { clínica y endoscópica. }\end{array}$ \\
\hline Se sugiere utilizar la resonancia nuclear \\
magnética como prueba radiológica para \\
predecir la remisión profunda en pacientes \\
con enfermedad de Crohn perianal fistulizante. \\
Calidad de la evidencia muy baja $\oplus$ OOO
\end{tabular}

\section{Resumen de la evidencia}

\section{Proteína C-reactiva, velocidad de eritrosedimentación y ASCA}

Una revisión sistemática de la literatura (puntaje AMSTAR 8/11) evaluó la capacidad predictiva de la proteína C-reactiva (PCR), la velocidad de eritrosedimentación y los anticuerpos ASCA en pacientes con EC en período de remisión. El desenlace de interés fue el desarrollo de recaída, definida como el hallazgo de un puntaje CDAI >150; el valor pronóstico fue expresado en razones de daño (HR) o riesgos relativos (RR) (59).

Los estudios identificados en la revisión fueron heterogéneos en el reporte y en los puntos de corte evaluados, no siendo posible resumir la evidencia mediante técnicas de metaanálisis.

Proteína C-reactiva: un estudio de cohorte realizó un modelo de predicción de recaída basado en los parámetros biológicos de 101 participantes con EC fistulizante, inflamatoria o estenosante, intestinal o extraintestinal. Basados en este estudio se pudo establecer que, durante el primer año de seguimiento, el hallazgo de una PCR mayor de $10 \mathrm{mg} / \mathrm{L}$ incrementa de forma sustancial la probabilidad de recaída (HR: 1,5; intervalo de confianza [IC] 95\%: 1,1-1,9) durante los próximos 92 días. El modelo fue ajustado por enfermedad fistulizante, presencia de colitis y grado de estrés (60).
Un segundo estudio de cohorte evaluó, en esta ocasión, el valor pronóstico de la PCR en 71 pacientes con EC ileal, ileocolónica o colónica, utilizando como punto de corte 20 $\mathrm{mg} / \mathrm{L}$. Este estudio documentó que la positividad en este marcador aumenta notoriamente el riesgo de recaída (RR: 10,5; IC 95\%: 2,3-48,1) durante las próximas 6 semanas (61). Finalmente, un tercer estudio analizó el papel de la PCR junto con otras pruebas serológicas como marcadores predictivos en 53 pacientes con $\mathrm{EC}$ colónica. $\mathrm{Al}$ ajustar por los valores de calprotectina, género, hábito de fumar, extensión de la enfermedad y consumo de azatioprina, los autores no encontraron diferencias significativas en el riesgo de recurrencia cuando el valor de la PCR superó los $9 \mathrm{mg} / \mathrm{L}$ (HR: 9,1; IC 95\%: 0,5-53,3) (62).

Un metaanálisis ya mencionado (24) encontró una sensibilidad del 49\% (IC 95\%: 0,34-0,64) y una especificidad del 92\% (IC 95\%: 0,72-0,96) para la actividad endoscópica en enfermedad inflamatoria intestinal.

Velocidad de eritrosedimentación (VSG): un primer estudio de cohorte analizó el valor predictivo de diferentes pruebas biológicas en 101 pacientes con EC fistulizante, inflamatoria o estenosante, intestinal o extraintestinal. Al análisis bivariado no se encontró asociación entre los valores de VSG y el riesgo ulterior de recaída (HR: 1,3; IC 95\%: $1,0-1,7)(60)$. Por otra parte, un segundo estudio de cohorte con 71 participantes determinó la utilidad pronóstica de la VSG en pacientes con EC ileal, ileocolónica o colónica. Este estudio documentó que, cuando la VSG superó los 15 $\mathrm{mm}$, el riesgo de recaída se incrementó durante las próximas 6 semanas (RR: 6,1; IC 95\%: 1,9-18,9). Finalmente, este mismo estudio reportó que los niveles altos de PCR (>20 mg/L) y VSG (>15 mm) se asociaron de forma significativa a la reaparición de enfermedad activa en las próximas 6 semanas (RR: 9,9; IC 95\%: 3,3-29,7) (61).

Anticuerpos anti-Saccharomyces cerevisiae (ASCA): solo un estudio de cohorte determinó el papel de este marcador biológico como predictor de recaída en 101 pacientes con EC fistulizante, inflamatoria o estenosante, intestinal o extraintestinal. El análisis de este estudio falló en demostrar la asociación entre la positividad de este marcador y el desarrollo ulterior de enfermedad activa (HR: 1,2; IC 95\%: 0,54-2,5) (60).

\section{Calidad de la evidencia: muy baja $\oplus$ O००}

\section{Calprotectina fecal}

Una revisión sistemática con metaanálisis (63) (puntaje AMSTAR 8/11) evaluó la exactitud diagnóstica de la calprotectina fecal para predecir la recaída en pacientes con EC. El estándar de referencia fue la presencia de enfermedad activa, definida como CDAI $>150$ o índice Harvey-Bradshaw mayor de 4 y la exactitud diagnóstica fue reportada en valores de 
sensibilidad, especificidad, razones de verosimilitud positiva y negativa (LR+, LR-) y el área bajo la curva.

A partir de la información provista por los seis estudios incluidos, la revisión encontró que el hallazgo de un valor positivo en los niveles de calprotectina fecal (rango de positividad de $130 \mu \mathrm{g} / \mathrm{g}$ a $340 \mu \mathrm{g} / \mathrm{g}$ ) predice aceptablemente el desarrollo de recurrencia en pacientes con EC (sensibilidad, 75\%; IC 95\%: 64\%-84\%; especificidad, 71\%; IC 95\%: 64\%-76\%; LR+, 2,37; IC 95\%: 1,56-3,61; LR-, 0,41; IC 95\%: 0,27-0,61), con un área bajo la curva (AUC) de 0,79 (IC 95\%: 0,74-0,64). Desempeño de la prueba que fue bastante similar cuando se trató de pacientes con enfermedad colónica (sensibilidad, 76\%; IC 95\%: 59\%-88\%; especificidad, 77\%; IC 95\%: 69\%-83\%; LR+, 3,26; IC 95\%: 1,895,25; LR-, 0,34; IC 95\%: 0,19-0,60), con un AUC de 0,81 (IC 95\%: 0,76-0,86) (63).

Para recurrencia endoscópica posquirúrgica en EC, el valor de sensibilidad es de 0,90 y el de especificidad es de 0,36 , para un punto de corte de niveles de calprotectina de $50 \mu \mathrm{g} / \mathrm{g}$; de 0,81 y 0,57 , para un punto de corte de 100 $\mu \mathrm{g} / \mathrm{g}$; de 0,70 y 0,69 , para un punto de corte de $150 \mu \mathrm{g} / \mathrm{g}$; y de 0,55 y 0,71 , respectivamente, para un punto de corte de $200 \mu \mathrm{g} / \mathrm{g}$. Para EC de intestino delgado confirmada por cápsula endoscópica, la sensibilidad es de 0,83 y la especificidad es de 0,53, para un punto de corte de niveles de calprotectina de $50 \mu \mathrm{g} / \mathrm{g}$, y de 0,42 y 0,94 , respectivamente, para un punto de corte de $200 \mu \mathrm{g} / \mathrm{g}(64)$.

El estudio CALM, publicado recientemente, combinó calprotectina fecal y PCR y encontró una tasa de cicatrización de la mucosa en $79 \%$ de los pacientes con niveles de calprotectina $<250 \mu \mathrm{g} / \mathrm{g}$ y PCR $<5 \mathrm{mg} / \mathrm{L}$ (65).

\section{Calidad de la evidencia: muy baja $\oplus$ O००}

\section{Niveles séricos de infliximab}

Una revisión sistemática con metaanálisis (66) (puntaje AMSTAR 8/11) evaluó la utilidad pronóstica de los niveles séricos de infliximab en pacientes con enfermedad inflamatoria intestinal. El desenlace primario fue la frecuencia de remisión clínica, en tanto que los desenlaces secundarios fueron la proporción de pacientes con remisión endoscópica y el requerimiento de colectomía. La revisión recuperó 22 estudios observacionales, de los cuales, 11 fueron realizados de forma exclusiva en pacientes con EC, 4 en pacientes con colitis ulcerativa y 7 en participantes con enfermedad inflamatoria intestinal no especificada. Basados en los hallazgos de esta revisión sistemática, se pudo documentar que, cuando a las 14 semanas los niveles de infliximab superaron los $2 \mu \mathrm{g} / \mathrm{mL}$, los pacientes con enfermedad inflamatoria intestinal presentaron una mayor probabilidad de alcanzar la remisión (RR: 2,91; IC 95\%: 1,79-4,73) y de lograr la cicatrización de la mucosa intestinal (RR: 3,04; IC 95\%: 1,42-6,51). Finalmente, la presencia de valores indetectables de infliximab incrementó la probabilidad de requerir colectomía comparada frente a los pacientes con niveles detectables (RR: 5,4; IC 95\%: 3,10-9,30) (66).

Calidad de la evidencia: muy baja $\oplus$ O००

\section{Resonancia magnética nuclear para remisión profunda}

Un estudio de cohorte prospectiva (67) evaluó la utilidad de la resonancia magnética nuclear para predecir la remisión profunda en pacientes con EC fistulizante perianal. Los desenlaces de interés fueron la presencia de remisión y remisión profunda, la cual fue establecida mediante el índice de Van Assche, que evalúa la complejidad de la fístula, su extensión y localización, la captación del medio de contraste, el compromiso de la mucosa rectal y la presencia de abscesos; esta evaluación fue realizada de forma independiente por dos radiólogos expertos en imágenes de tracto gastrointestinal, quienes estuvieron enmascarados al cuadro clínico de los pacientes.

La cohorte incluyó 49 pacientes que se encontraban recibiendo terapia anti-FNT concomitantemente con inmunosupresores para inducir o mantener la remisión. Basados en este estudio, se pudo establecer que los factores asociados a la presencia de remisión fueron la ausencia de compromiso rectal a la resonancia magnética (OR: 4,7; IC 95\%: 1,2149,0) y la ausencia de cambio de anti-FNT (OR: 7,7; IC 95\%: no reportado; $p<0,05)$. En cuanto a la remisión profunda, se encontró que la ausencia de compromiso rectal a la resonancia se asoció fuertemente a la carencia de úlceras en el canal anal (OR: 4,6; IC 95\%: 1,03-20,5) (67).

Un metaanálisis de 12 estudios de entero-RNM con una nueva técnica con imagen ponderada por difusión (DWI) que, a diferencia de la técnica convencional, es más rápida y no requiere medio de contraste intravenoso, reportó una sensibilidad del 92,9\% (IC 95\%: 85,8\%-96,6\%) y una especificidad del 91\% (IC 95\%: 79,7\%-96,3\%) para detectar inflamación; sin embargo, se encontró heterogeneidad en los estudios y los autores concluyeron que puede haber sobreestimación de los resultados (68). Una reciente revisión considera esta nueva técnica una alternativa válida a la técnica convencional, menos invasiva, más rápida, que no requiere ayuno ni preparación intestinal (69).

\section{Calidad de la evidencia: muy baja $\oplus$ O००}

\section{Cápsula endoscópica para cicatrización de la mucosa de intestino delgado}

Una revisión sistemática y metaanálisis de 5 estudios observacionales, que incluyó 142 pacientes con EC, que completaron los criterios de inclusión, encontraron que un marcador de cicatrización de la mucosa en cápsula endoscópica (Niv o Lewis) se asoció a remisión clínica a 12 semanas y 24 meses de seguimiento (odds ratio [OR]: 11,06; IC 95\%: $3,74-32,73 ; p<0,001)(70)$. 


\section{Cicatrización de la mucosa}

Una revisión sistemática (38) (puntaje AMSTAR 8/11) evaluó el valor pronóstico de la cicatrización de la mucosa intestinal en la ocurrencia de desenlaces clínicos favorables en pacientes con EC. Los resultados considerados fueron la frecuencia de remisión clínica a largo plazo $(\mathrm{CDAI}<150)$, la necesidad de tratamiento quirúrgico y la tasa de cicatrización de la mucosa a largo plazo.

La revisión recuperó 12 estudios observacionales realizados en participantes con EC estenosante o fistulizante, localizada en intestino delgado, ileocolónica, colónica o perianal. Basados en esta revisión, se pudo documentar que la presencia de mucosa sana incrementa la posibilidad de continuar en remisión clínica por al menos 50 semanas (OR: 2,7; IC 95\%: 1,82-3,99; 304 pacientes), independientemente del tipo de tratamiento proporcionado (terapia biológica [OR: 2,89; IC 95\%: 1,82-4,59] o terapia no biológica [OR: 2,48; IC 95\%: 1,26-4,89]). Finalmente, la presencia de mucosa sana también se asoció a una mayor frecuencia de remisión endoscópica a largo plazo (OR: 14,3; IC 95\%: 5,57-36,74), sin que esto se viera reflejado en una mayor o menor frecuencia de requerir intervención quirúrgica (OR: 0,22; IC 95\%: 0,86-5,69) (38).

Calidad de la evidencia: muy baja $\oplus$ O००

\section{De la evidencia a la recomendación}

El panel expresó que los niveles de PCR y la VSG son de bajo costo y deben ser solicitados de forma simultánea. La fuerza de la recomendación es fuerte porque las pruebas deben realizarse como parte del manejo adecuado de la enfermedad, buscando los mejores desenlaces para los pacientes con EC.

La identificación de los niveles séricos de infliximab no se formuló como recomendación debido a su costo; se encontró evidencia de un solo medicamento biológico, que no está incluido en el plan de beneficios.

\begin{tabular}{|c|c|c|c|c|c|c|}
\hline & \multicolumn{6}{|c|}{ Juicio de valor } \\
\hline Problema & No & Probablemente no & Probablemente sí & Sí & Varía & No se conoce \\
\hline Efectos deseables & Triviales & Pequeños & Moderados & Grandes & Varía & No se conoce \\
\hline Efectos no deseados & Triviales & Pequeños & Moderados & Grandes & Varía & No se conoce \\
\hline Confianza en la evidencia & Muy baja & Baja & Moderada & Alta & & $\begin{array}{c}\text { No se encontró } \\
\text { evidencia }\end{array}$ \\
\hline Variabilidad & Alta incertidumbre & $\begin{array}{l}\text { Importante } \\
\text { variabilidad }\end{array}$ & $\begin{array}{l}\text { Variabilidad no } \\
\text { importante }\end{array}$ & $\begin{array}{l}\text { No se presenta } \\
\text { variabilidad }\end{array}$ & & No se conoce \\
\hline Balance de los efectos & $\begin{array}{l}\text { Favorece la } \\
\text { comparación }\end{array}$ & $\begin{array}{c}\text { Probablemente } \\
\text { favorece la } \\
\text { comparación }\end{array}$ & $\begin{array}{l}\text { No favorece } \\
\text { ninguna } \\
\text { intervención }\end{array}$ & $\begin{array}{l}\text { Probablemente } \\
\text { favorece la } \\
\text { intervención }\end{array}$ & $\begin{array}{l}\text { Favorece la } \\
\text { intervención }\end{array}$ & No se conoce \\
\hline $\begin{array}{l}\text { Calidad global de la } \\
\text { evidencia }\end{array}$ & Muy baja & Baja & Moderada & Alta & & $\begin{array}{c}\text { No se encontró } \\
\text { evidencia }\end{array}$ \\
\hline Equidad & Reducida & $\begin{array}{c}\text { Probablemente se } \\
\text { reduzca }\end{array}$ & $\begin{array}{c}\text { Probablemente } \\
\text { no tenga impacto }\end{array}$ & $\begin{array}{l}\text { Probablemente } \\
\text { se aumente }\end{array}$ & Se aumenta & No se conoce \\
\hline $\begin{array}{l}\text { Aceptabilidad de los } \\
\text { usuarios }\end{array}$ & No & Probablemente no & Probablemente sí & Sí & Varía & No se conoce \\
\hline $\begin{array}{l}\text { Factibilidad de } \\
\text { implementación }\end{array}$ & No & Probablemente no & Probablemente sí & Sí & Varía & No se conoce \\
\hline
\end{tabular}




\section{PREGUNTA 2. ¿CUÁLES SON LAS INTERVENCIONES NO BIOLÓGICAS MÁS SEGURAS Y EFECTIVAS PARA INDUCIR LA REMISIÓN EN PACIENTES MAYORES DE 16 AÑOS CON ENFERMEDAD DE CROHN?}

\section{Lista de recomendaciones}

\begin{tabular}{|c|c|}
\hline Recomendación $n .^{\circ}$ & Resumen \\
\hline Fuerte en contra & $\begin{array}{l}\text { No se recomienda el uso de probióticos } \\
\text { para inducir la remisión en pacientes con } \\
\text { enfermedad de Crohn activa. } \\
\text { Calidad de la evidencia muy baja } \oplus \text { ○০০ }\end{array}$ \\
\hline Débil en contra & $\begin{array}{l}\text { No se sugiere el uso de antibióticos para } \\
\text { inducir la remisión en pacientes con } \\
\text { enfermedad de Crohn activa. } \\
\text { Calidad de la evidencia baja } \oplus \oplus \bigcirc \bigcirc\end{array}$ \\
\hline Débil en contra & $\begin{array}{l}\text { No se sugiere la administración de } \\
\text { azatioprina o 6-mercaptopurina como } \\
\text { monoterapia para inducir la remisión en } \\
\text { pacientes con enfermedad de Crohn activa. } \\
\text { Calidad de la evidencia muy baja } \oplus \text { O० }\end{array}$ \\
\hline Fuerte a favor & $\begin{array}{l}\text { Se recomienda adicionar azatioprina en } \\
\text { pacientes con enfermedad de Crohn activa } \\
\text { que van a recibir terapia biológica con } \\
\text { infliximab, como terapia combinada, para } \\
\text { inducir la remisión. } \\
\text { Calidad de la evidencia muy baja } \oplus \text { ○০০ }\end{array}$ \\
\hline Débil en contra & $\begin{array}{l}\text { No se sugiere el uso de sulfasalazina ni } \\
\text { de mesalazina para inducir la remisión en } \\
\text { pacientes con enfermedad de Crohn activa. } \\
\text { Calidad de la evidencia muy baja } \oplus \text { ○০০ }\end{array}$ \\
\hline Fuerte en contra & $\begin{array}{l}\text { No se recomienda el uso de metotrexato } \\
\text { para inducir la remisión en pacientes con } \\
\text { enfermedad de Crohn activa. } \\
\text { Calidad de la evidencia muy baja } \oplus \text { ○০০ }\end{array}$ \\
\hline Débil a favor & $\begin{array}{l}\text { Se sugiere el uso de budesonida de } \\
\text { liberación ileal para inducir la remisión en } \\
\text { pacientes con enfermedad de Crohn activa. } \\
\text { Calidad de la evidencia baja } \oplus \oplus \bigcirc \bigcirc\end{array}$ \\
\hline $\begin{array}{l}\text { Punto de buena } \\
\text { práctica }\end{array}$ & $\begin{array}{l}\text { La dosis inicial recomendada de budesonida } \\
\text { es de } 9 \mathrm{mg} / \mathrm{d} \text {; a los } 2 \text { meses se disminuye a } 6 \\
\text { mg/d, y en los siguientes } 2 \text { meses se reduce } \\
\text { a } 3 \mathrm{mg} / \mathrm{d} \text {, para luego suspender. La duración } \\
\text { del tratamiento de inducción no debe ser } \\
\text { mayor de } 6 \text { meses. }\end{array}$ \\
\hline $\begin{array}{l}\text { Punto de buena } \\
\text { práctica }\end{array}$ & $\begin{array}{l}\text { Se deben monitorizar los eventos adversos } \\
\text { asociados al uso de esteroides sistémicos } \\
\text { luego de } 12 \text { semanas de uso. }\end{array}$ \\
\hline Fuerte a favor & $\begin{array}{l}\text { Se recomienda el uso de esteroides } \\
\text { sistémicos para inducir la remisión en } \\
\text { pacientes con enfermedad de Crohn activa. } \\
\text { Calidad de la evidencia baja } \oplus \oplus \bigcirc \bigcirc\end{array}$ \\
\hline
\end{tabular}

\begin{tabular}{|ll}
\hline $\begin{array}{l}\text { Punto de buena } \\
\text { práctica }\end{array}$ & $\begin{array}{l}\text { Los esteroides sistémicos son tratamiento } \\
\text { de primera elección en pacientes con } \\
\text { enfermedad de Crohn moderada a grave } \\
\text { ileocolónica, colónica o con compromiso } \\
\text { extenso de intestino delgado. }\end{array}$ \\
\hline $\begin{array}{l}\text { Punto de buena } \\
\text { práctica }\end{array}$ & $\begin{array}{l}\text { La dosis inicial recomendada de prednisolona } \\
\text { oral es } 40 \text { mg/d. }\end{array}$ \\
\hline $\begin{array}{l}\text { Punto de buena } \\
\text { práctica }\end{array}$ & $\begin{array}{l}\text { La respuesta con esteroides se debe evaluar } \\
\text { luego de 2 a 4 semanas de tratamiento. En } \\
\text { caso de falla terapéutica, se debe definir la } \\
\text { necesidad de modificar el tratamiento. }\end{array}$ \\
\hline Débil a favor & $\begin{array}{l}\text { Se sugiere como primera elección el uso de } \\
\text { esteroides orales sistémicos para inducir la } \\
\text { remisión en pacientes con enfermedad de } \\
\text { Crohn activa. }\end{array}$ \\
Calidad de la evidencia muy baja $\oplus$ OOO \\
Se sugiere el uso de budesonida de \\
práctica
\end{tabular}

\section{Resumen de la evidencia}

\section{Probióticos para inducir la remisión en pacientes con enfermedad de Crohn activa}

Una revisión sistemática de la literatura con metaanálisis (71) (puntaje AMSTAR 8/11) evaluó la efectividad del uso de probióticos para inducir la remisión en pacientes con EC. Para este estudio, el resultado evaluado fue la frecuencia de pacientes que lograron remisión clínica (definida como CDAI $<150$ o menos de 100 puntos con respecto al valor basal) durante los 3 a 24 meses de seguimiento. Esta revisión recuperó tres ensayos clínicos controlados que reclutaron 74 participantes. Basados en los hallazgos reportados, la administración de probióticos falló en incrementar la proporción de pacientes que alcanzaron la remisión, ya sea cuando se utilizaron en monoterapia (RR: 0,89; IC 95\%: 0,70-1,13) o como adyuvante al tratamiento convencional (RR: 0,89; IC 95\%: 0,70-1,13) (71). Una reciente revisión de Cochrane, que incluyó 2 estudios 
con probióticos en inducción de remisión en EC, concluyó que la evidencia disponible es muy incierta acerca de la eficacia o la seguridad de los probióticos, al compararlos con placebo, para la inducción de la remisión en la EC (72).

Calidad de la evidencia: muy baja $\oplus$ O००

\section{Antibióticos para inducir la remisión en pacientes con enfermedad de Crohn activa}

Una revisión sistemática de la literatura (73) (puntaje AMSTAR 7/11) evaluó la efectividad del uso de antibióticos para inducir la remisión en los pacientes con EC activa. Todos los estudios permitieron el uso concomitante de otras intervenciones (inmunomoduladores) y, para esta revisión, el desenlace reportado fue la proporción de pacientes que lograron mejoría clínica o remisión (CDAI $<150$ y/o disminución en CDAI $\geq 70$ o reducción $>50 \%$ en el número de las fístulas por al menos 4 semanas) durante el seguimiento.

La revisión recuperó tres ensayos clínicos aleatorios para un total de 222 participantes. Cuando se comparó frente al placebo, eel uso de antibióticos durante los 3 a 6 primeros meses, no incrementó la frecuencia de participantes que experimentaron mejoría clínica o remisión (RR: 1,15; IC 95\%: 0,56-2,36). Cuando se realizó un análisis de subgrupos acorde con el tipo de medicamento utilizado, se pudo evidenciar que tanto la administración de ciprofloxacina, rifaximina y de 5-nitroimidazoles mostró resultados similares (73).

Una reciente revisión de Cochrane de 13 estudios sugiere un beneficio modesto de los antibióticos en EC activa, y el beneficio en el mantenimiento de la remisión es incierto; por lo tanto, considera que no se pueden realizar conclusiones firmes con respecto a la eficacia de los antibióticos en EC (74).

\section{Calidad de la evidencia: baja $\oplus \oplus$ $\oplus$}

\section{Azatioprina o 6-mercaptopurina para inducir la remisión en pacientes con EC activa}

Una revisión sistemática de la literatura con metaanálisis (75) (puntaje AMSTAR 10/11) evaluó la efectividad y la seguridad del uso de azatioprina o 6-mercaptopurina para inducir la remisión en pacientes con EC. Para este estudio, el resultado evaluado fue la frecuencia de pacientes que lograron remisión o mejoría clínica (definidas como CDAI $<150$ puntos o HBI menor de 3), la proporción de pacientes en los que fue posible disminuir la dosis de esteroides (evaluado con prednisona en dosis $<10 \mathrm{mg} / \mathrm{d}$ ), que experimentaron mejoría o cierre de la fístula (cura de la lesión o disminución de la descarga) y, finalmente, la proporción de pacientes que presentaron eventos adversos serios o que abandonaron la terapia.
Nueve estudios evaluaron el efecto de esta intervención en comparación frente al placebo, para un total de 506 participantes. Basados en esta revisión, se pudo documentar que los pacientes asignados a recibir azatioprina o 6-mercaptopurina experimentaron una mayor frecuencia de mejoría clínica (RR: 1,53; IC 95\%: 1,05-2,22) y menores dosis de esteroides (RR: 1,34; IC 95\%: 1,02-1,77), sin que esto se viera reflejado en una mayor frecuencia de los pacientes que alcanzaron criterios clínicos de remisión (RR: 1,23; IC 95\%: 0,97-1,55) o que presentaron mejoría o cierre de la fístula (RR: 2,00; IC 95\%: 0,67-5,93). No obstante, el uso de azatioprina o 6-mercaptopurina tampoco incrementó el abandono de la terapia (RR: 1,70; IC 95\%: 0,94-3,08) o la frecuencia de eventos adversos (RR: 2,57; IC 95\%: 0,92-7,13) (75).

Un segundo análisis de esta revisión comparó la efectividad y la seguridad de la administración de azatioprina o 6-mercaptopurina frente a cualquier otra intervención farmacológica para inducir la remisión en pacientes con EC. Cuando se comparó frente al metotrexato, el uso de azatioprina o 6-mercaptopurina, no incrementó el número de pacientes que presentaron remisión libre del uso de esteroides (RR: 1,13; IC 95\%: 0,85-1,49; 2 estudios, 143 participantes) o en la frecuencia de abandono de la terapia (RR: 0,78; IC 95\%: 0,23-2,71; 2 estudios, 85 participantes). Por otra parte, cuando el grupo control recibió 5-aminosalicilatos o sulfasalazina, tampoco se encontraron diferencias estadísticamente significativas entre los grupos (remisión libre de esteroides [RR: 1,24; IC 95\%: 0,80-1,91] y abandono de la terapia [RR: 0,98; IC 95\%: 0,38-2,54]; 2 estudios, 156 pacientes) (75).

Ahora bien, cuando se comparó la administración de azatioprina frente al uso de infliximab ( 1 estudio, 339 participantes), el uso de azatioprina se asoció a una menor frecuencia de participantes que alcanzaron la remisión clínica (RR: 0,66; IC 95\%: 0,51-0,87), remisión libre de esteroides (RR: 0,68; IC 95\%: 0,51-0,90) o que presentaron mucosa de aspecto sano a la evaluación endoscópica (RR: 0,55; IC 95\%: 0,33-0,94), sin que la frecuencia de eventos adversos fuese diferente entre los grupos (RR: 1,47; IC 95\%: 0,96-2,23). Finalmente, cuando se comparó la terapia combinada con azatioprina más infliximab frente a la monoterapia con este medicamento biológico, el uso de la terapia combinada incrementó la proporción de pacientes que lograron la remisión clínica (RR: 1,26; IC 95\%: 1,031,54), remisión libre del uso de esteroides (RR: 1,23; IC 95\%: 1,02-1,47) o que presentaron mucosa de aspecto sano a la evaluación endoscópica (RR: 1,50; IC 95\%: 1,02$2,19)$, sin incrementar la frecuencia de eventos adversos (RR: 1,16; IC 95\%: 0,75-1,80) (75).

Calidad de la evidencia: muy baja $\oplus$ O०० 


\section{5-aminosalicilatos para inducir la remisión en pacientes con enfermedad de Crohn activa}

Una revisión sistemática de la literatura (76) (puntaje AMSTAR 10/11) evaluó la seguridad y la efectividad del uso de sulfasalazina para inducir la remisión en los pacientes con EC leve a moderada. Para esta revisión, el desenlace reportado fue la proporción de pacientes que lograron mejoría clínica o remisión (CDAI $<150$ o disminución en el índice $\mathrm{VHI}>25 \%$ ), la frecuencia de eventos adversos serios y el retiro de la terapia debido por efectos indeseables.

La revisión recuperó tres ensayos clínicos controlados, para un total de 289 participantes, que compararon el uso de esta intervención frente al placebo. Con base en los estudios recuperados, se pudo documentar que la administración de sulfasalazina incrementó la frecuencia de remisión (RR: 1,38; IC 95\%: 1,01-1,90), pero no de mejoría clínica (RR: 1,52; IC 95\%: 0,95-2,43), sin incrementar la incidencia de eventos adversos serios (RR: 0,35; IC 95\%: 0,01-8,38) o el retiro de la terapia (RR: 1,00; IC 95\%: 0,26-8,83). Un segundo análisis de esta revisión contrastó la efectividad y la seguridad de la administración de sulfasalazina frente a cualquier otra intervención farmacológica. Cuando se confrontó frente a la terapia con esteroides, el uso de sulfasalazina se asoció a una menor frecuencia de eventos adversos serios (RR: 0,43; IC 95\%: 0,22-0,82; 2 estudios, 159 participantes) a costa de una menor proporción de pacientes que lograron la remisión (RR: 0,68; IC 95\%: 0,51-0,91; 2 estudios, 260 pacientes). Los grupos no fueron diferentes entre sí en la incidencia de abandono de la terapia (RR: 0,72; IC 95\%: 0,33-1,59; 2 estudios, 260 pacientes) (76).

Por otra parte, cuando se comparó la monoterapia con 5 -aminosalicilatos frente a la terapia combinada de sulfasalazina con esteroides, se evidenció que el uso de sulfasalazina en monoterapia se asoció a una menor frecuencia de participantes que alcanzaron la remisión clínica (RR: 0,64; IC 95\%: 0,47-0,86; 1 estudio, 110 pacientes) sin evidencia estadísticamente significativa en la tasa de retiro de la terapia (RR: 0,52; IC 95\%: 0,05-5,55; 1 ensayo, 110 participantes). Finalmente, esta revisión realizó un análisis de subgrupo acorde al tipo de 5-aminosalicilatos. Cuando se comparó a la mesalazina con la sulfasalazina, no se encontraron diferencias entre los grupos en términos de efectividad (inducción de la remisión [RR: 1,02; IC 95\%: 0,841,24] o seguridad [eventos adversos serios: RR: 0,35; IC 95\%: 0,11-1,09]) (76).

Calidad de la evidencia: muy baja $\oplus$ $\bigcirc 00$

\section{Metotrexato para inducir la remisión en} pacientes con enfermedad de Crohn activa

Se recuperó una revisión sistemática (77) (AMSTAR 8/11) que evaluó la seguridad y la efectividad del uso de metotrexato para la inducción de la remisión en pacientes con EC. La pesquisa recuperó tres estudios que reclutaron 226 participantes. Cuando se comparó frente al placebo, los pacientes asignados al brazo de metotrexato no experimentaron una frecuencia mayor de remisión clínica (RR: 1,02; IC 95\%: 0,60-1,73), pero sí de abandono de la terapia (RR: 6,97; IC 95\%: 1,61-30,10) (77).

Calidad de la evidencia: muy baja $\oplus$ O००

\section{Budesonida para inducir la remisión en pacientes con enfermedad de Crohn activa}

Una revisión sistemática de la literatura con metaanálisis (78) (puntaje AMSTAR 10/11) evaluó la efectividad y la seguridad del uso de budesonida para inducir la remisión en pacientes con EC. Para este estudio, el resultado evaluado fue la frecuencia de pacientes que lograron la remisión (definida como CDAI $<150$ puntos), mejoría clínica (disminución en CDAI $>100$ o total $<150$ puntos) y la proporción de pacientes que abandonaron la terapia por eventos adversos serios. Tres estudios evaluaron el efecto de esta intervención en comparación frente al placebo, para un total de 379 participantes. Basados en esta revisión, se pudo documentar que los pacientes asignados a recibir budesonida experimentaron una mayor frecuencia de remisión (RR: 1,93; IC 95\%: 1,37-2,73, en dosis de 9 mg; RR: 2,25; IC 95\%: 1,35-3,76, en dosis de $15 \mathrm{mg}$ ) y de mejoría clínica (RR: 1,46; IC 95\%: 1,03-2,07, en dosis de 9 mg; RR: 2,34; IC 95\%: 0,83-6,63, en dosis de $15 \mathrm{mg}$ ), sin incrementar la proporción de pacientes que abandonaron la terapia (RR: 1,14; IC 95\%: 0,46-2,79, en dosis de 9 mg; RR: 1,55; IC 95\%: 0,45-5,34, en dosis de $15 \mathrm{mg}$ ).

Un segundo análisis de esta revisión comparó la efectividad y la seguridad de la administración de budesonida frente a cualquier otra intervención farmacológica para inducir la remisión en pacientes con EC. Cuando se comparó frente a mesalazina, el uso de budesonida en dosis de $9 \mathrm{mg}$ incrementó el número de pacientes que presentaron remisión a las 12 semanas (RR: 1,59; IC 95\%: 1,17-2,15; 1 estudio, 182 participantes) y 16 semanas de seguimiento (RR: 1,79; IC 95\%: 1,28-2,50; 1 estudio, 182 participantes), sin incrementar la frecuencia de mejoría clínica (RR: 1,18; IC 95\%: 0,99-1,42; 2 estudios, 489 pacientes) o de abandono de la terapia (RR: 0,43; IC 95\%: 0,18-1,03; 2 estudios, 489 pacientes). Por otra parte, cuando el grupo control recibió esteroides tradicionales, los pacientes asignados al brazo de budesonida en $9 \mathrm{mg}$ experimentaron una menor frecuencia de remisión a mediano (RR: 0,85; IC 95\%: 0,75-0,97; para 8 semanas), pero no a largo plazo (RR: 1,02; IC 95\%: 0,81-1,30; para 12 semanas). Finalmente, los pacientes que recibieron budesonida reportaron una menor proporción de eventos adversos 
(RR: 0,64; IC 95\%: 0,54-0,76) sin que esto se viera reflejado en una mayor o menor frecuencia de abandono de la terapia (RR: 0,57; IC 95\%: 0,18-1,84) (78).

Calidad de la evidencia: baja $\oplus \oplus \mathbf{O}$

\section{Corticoides orales o intravenosos para inducir la remisión en pacientes con EC activa}

Una revisión sistemática de la literatura (79) (puntaje AMSTAR 8/11) evaluó la efectividad y la seguridad del uso de los corticoides orales o intravenosos para inducir la remisión en pacientes con EC. Para este estudio, el resultado evaluado fue la frecuencia de pacientes que lograron la remisión (definida como CDAI $<150$ puntos) y la proporción de pacientes que abandonaron la terapia por eventos adversos serios. Dos estudios evaluaron el efecto de esta intervención en comparación frente al placebo, para un total de 267 participantes. Basados en esta revisión, se pudo documentar que los pacientes asignados a recibir corticoides experimentaron una mayor frecuencia de remisión (RR: 1,99; IC 95\%: 1,51-2,64), sin incrementar la proporción de pacientes que abandonaron la terapia (RR: 4,57; IC 95\%: 0,75-27,83). Por otra parte, un segundo análisis de esta revisión comparó la administración de esteroides frente a 5-aminosalicilatos. Comparados frente a esta intervención, los corticoides también se asociaron a una mayor frecuencia de remisión (RR: 1,65; IC 95\%: 1,33-2,03; 2 estudios, 332 participantes) sin que esto se viera reflejado en una mayor frecuencia de abandono (RR: 1,18; IC 95\%: 0,61-2,29; 6 ensayos, 478 pacientes) (79).

Calidad de la evidencia: baja $\oplus \oplus$ $\oplus$ O

\section{Seguridad y efectividad del uso de mesalazina, sulfasalazina, corticoesteroides y budesonida para inducir la remisión en pacientes con enfermedad de Crohn activa. Resultados de un metaanálisis en red} Una revisión sistemática con metaanálisis en red (80) (puntaje AMSTAR 8/11) evaluó la efectividad y la seguridad de diferentes estrategias para inducir la remisión en los pacientes con EC. Los participantes incluidos se caracterizaron por tener enfermedad activa (puntaje CDAI entre $150 \mathrm{y}$ 400) localizada en íleon, colon, ciego o recto. Se excluyeron estudios que permitieron la administración de terapia combinada o participantes con enfermedad posquirúrgica. Las intervenciones evaluadas fueron la administración de mesalazina, sulfasalazina, corticoesteroides o budesonida y los desenlaces reportados fueron inducción de la remisión (CDAI menor o igual a 150 o definido por el autor) y el retiro de la terapia debido a eventos adversos (evaluado de acuerdo con el criterio clínico).
La revisión recuperó 24 ensayos clínicos aleatorios. Cuando se comparó frente al placebo la administración de corticosteroides (OR: 3,86; IC 95\%: 2,51-6,06), budesonida (OR: 3,18; IC 95\%: 2,11-4,30; mayores de $6 \mathrm{mg} / \mathrm{d}$ ) o de mesalazina (OR: 2,11; IC 95\%: 1,39-3,31; mayores de $2,4 \mathrm{~g} / \mathrm{d}$ ) en altas dosis, fueron significativamente superiores al placebo cuando se trató de inducir la remisión. Sin embargo, la terapia con sulfasalazina no demostró un claro beneficio cuando se confrontó frente al placebo (OR: 1,56; IC 95\%: 0,83-2,88). Por su parte, cuando se trató de establecer qué intervención podría constituir la mejor opción terapéutica, los corticoides ocuparon el primer lugar, seguidos por budesonida en dosis $>6 \mathrm{mg} / \mathrm{d}$, mesalazina en dosis $>2,4 \mathrm{~g} / \mathrm{d}$ y, finalmente, con una probabilidad similar, budesonida en dosis bajas y sulfasalazina (80).

Los esteroides y las altas dosis de budesonida fueron significativamente superiores al uso de mesalazina, sulfasalazina o budesonida en dosis bajas. Los corticosteroides fueron superiores al uso de dosis altas de mesalazina (OR: 1,83; IC 95\%: 1,16-2,88), pero con una efectividad similar cuando se comparó frente a la terapia con dosis altas de budesonida (OR: 1,21; IC 95\%: 0,84-1,76). Finalmente, cuando se trató de abandono de la terapia, todas las intervenciones mostraron una frecuencia similar al placebo: mesalazina, baja (OR: 1,74; IC 95\%: 0,33-8,99) y en dosis altas (OR: 1,07; IC 95\%: 0,36-3,43), sulfasalazina (OR: 0,79; IC 95\%: 0,01-14,36), budesonida en dosis bajas (OR: 0,35; IC 95\%: 0,03-2,45) y en dosis altas (OR: 0,94; IC 95\%: 0,36-2,81) y, finalmente, corticosteroides (OR: 2,19; IC 95\%: 0,59-8,70). No obstante, los corticosteroides tuvieron un $93 \%$ y un $90 \%$ más de probabilidad de retiro por eventos adversos cuando se compararon frente a la terapia con budesonida o con mesalazina en dosis altas, respectivamente (80).

\section{Calidad de la evidencia: muy baja $\oplus 000$}

\section{Terapia con células madre}

Una revisión sistemática de la literatura con metaanálisis de proporciones (81) (puntaje AMSTAR 10/11) evaluó la eficacia y la seguridad de la terapia con células madre en pacientes con EC activa. Como intervenciones, los autores consideraron el uso de células madre mesenquimales provenientes de médula ósea, tejido adiposo o hematopoyéticas; como desenlaces, estimaron la eficacia clínica, definida como la respuesta o remisión clínica, la frecuencia de eventos adversos, la remisión endoscópica y la recurrencia clínica. La revisión recuperó 20 estudios prospectivos experimentales, con un total de 563 pacientes. La frecuencia global de respuesta clínica fue del 56\% (IC 95\%: 33\%-76\%), la de remisión endos- 
cópica fue del 15\% (IC 95\%: 0\%-50\%) y la de recurrencia fue del 16\% (IC 95\%: 4\%-34\%). La frecuencia global de eventos adversos fue del 12\% (IC 95\%: 0,06-0,23).

Cuando se realizó el análisis de subgrupos de acuerdo con la forma de administración, los pacientes que recibieron terapia sistémica tuvieron una frecuencia de respuesta del 66\% (IC 95\%: 39\%-86\%) y una remisión clínica del 46\% (IC 95\%: 25\%-69\%) (81).

Calidad de la evidencia: muy baja $\oplus$ O००

\section{De la evidencia a la recomendación}

El panel expresó la importancia de que este grupo de recomendaciones actualiza los lineamientos de agencias internacionales. De forma general, los medicamentos metotrexato, sulfasalazina y azatioprina no son recomendados para inducir la remisión. Los tiempos de uso de esteroides son reportados como buena práctica con el fin de darles un manejo adecuado, minimizando los efectos secundarios.

\begin{tabular}{|c|c|c|c|c|c|c|}
\hline & & & Juicio & e valor & & \\
\hline Problema & No & Probablemente no & Probablemente sí & Sí & Varía & No se conoce \\
\hline $\begin{array}{l}\text { Efectos } \\
\text { deseables }\end{array}$ & Triviales & Pequeños & Moderados & Grandes & Varía & No se conoce \\
\hline $\begin{array}{l}\text { Efectos no } \\
\text { deseados }\end{array}$ & Triviales & Pequeños & Moderados & Grandes & Varía & No se conoce \\
\hline $\begin{array}{l}\text { Confianza en la } \\
\text { evidencia }\end{array}$ & Muy baja & Baja & Moderada & Alta & & $\begin{array}{c}\text { No se encontró } \\
\text { evidencia }\end{array}$ \\
\hline Variabilidad & Alta incertidumbre & $\begin{array}{l}\text { Importante } \\
\text { variabilidad }\end{array}$ & $\begin{array}{l}\text { Variabilidad no } \\
\text { importante }\end{array}$ & $\begin{array}{l}\text { No se presenta } \\
\text { variabilidad }\end{array}$ & & No se conoce \\
\hline $\begin{array}{l}\text { Balance de los } \\
\text { efectos }\end{array}$ & $\begin{array}{l}\text { Favorece la } \\
\text { comparación }\end{array}$ & $\begin{array}{l}\text { Probablemente } \\
\text { favorece la } \\
\text { comparación }\end{array}$ & $\begin{array}{l}\text { No favorece } \\
\text { ninguna } \\
\text { intervención }\end{array}$ & $\begin{array}{l}\text { Probablemente } \\
\text { favorece la } \\
\text { intervención }\end{array}$ & $\begin{array}{l}\text { Favorece la } \\
\text { intervención }\end{array}$ & No se conoce \\
\hline $\begin{array}{l}\text { Calidad global } \\
\text { de la evidencia }\end{array}$ & Muy baja & Baja & Moderada & Alta & & $\begin{array}{c}\text { No se encontró } \\
\text { evidencia }\end{array}$ \\
\hline Equidad & Reducida & $\begin{array}{l}\text { Probablemente se } \\
\text { reduzca }\end{array}$ & $\begin{array}{l}\text { Probablemente no } \\
\text { tenga impacto }\end{array}$ & $\begin{array}{l}\text { Probablemente se } \\
\text { aumente }\end{array}$ & Se aumenta & No se conoce \\
\hline $\begin{array}{l}\text { Aceptabilidad } \\
\text { de los usuarios }\end{array}$ & No & Probablemente no & Probablemente sí & Sí & Varía & No se conoce \\
\hline $\begin{array}{l}\text { Factibilidad de } \\
\text { implementación }\end{array}$ & No & Probablemente no & Probablemente sí & Sí & Varía & No se conoce \\
\hline
\end{tabular}




\section{PREGUNTA 3. ¿CUÁLES SON LAS INTERVENCIONES NO BIOLÓGICAS MÁS SEGURAS Y EFECTIVAS PARA MANTENER EN REMISIÓN A LOS PACIENTES MAYORES DE 16 AÑOS CON ENFERMEDAD DE CROHN?}

\section{Lista de recomendaciones}

Recomendación $n .^{\circ}$

Resumen

Fuerte en contra $\quad$ No se recomienda el uso de mesalazina para mantener la remisión en pacientes con enfermedad de Crohn.

Calidad de la evidencia baja $\oplus \oplus 00$

$\begin{array}{ll}\text { Débil a favor } & \begin{array}{l}\text { Se sugiere el uso de azatioprina o } \\ \text { 6-mercaptopurina para mantener la remisión } \\ \text { en pacientes con enfermedad de Crohn en } \\ \text { quienes se logró inducir la remisión con el } \\ \text { uso de esteroides sistémicos. } \\ \text { Calidad de la evidencia muy baja } \oplus \text { OOO }\end{array} \\ \begin{array}{l}\text { Punto de buena } \\ \text { práctica }\end{array} & \begin{array}{l}\text { La dosis recomendada de azatioprina es de } \\ \text { de } 0,75 \mathrm{a} 2,5 \mathrm{mg} / \mathrm{kg} / \mathrm{d} \text { y de } 6 \text {-mercaptopurina es } / \mathrm{kg} / \mathrm{d} .\end{array}\end{array}$

Punto de buena Se puede realizar la medición de la actividad práctica de la enzima tiopurinametiltransferasa (TPMT) antes del inicio de tiopurinas; esto permite identificar a los pacientes que pueden desarrollar inmunosupresión grave con el uso de estos medicamentos.

\begin{tabular}{|c|c|}
\hline Débil en contra & $\begin{array}{l}\text { No se sugiere el uso de budesonida para } \\
\text { mantener la remisión en pacientes con } \\
\text { enfermedad de Crohn. } \\
\text { Calidad de la evidencia muy baja } \oplus \text { O০০ }\end{array}$ \\
\hline Débil a favor & $\begin{array}{l}\text { Se sugiere el uso de metotrexato para } \\
\text { mantener la remisión en pacientes con } \\
\text { enfermedad de Crohn que logran la remisión } \\
\text { con esteroides. } \\
\text { Calidad de la evidencia muy baja } \oplus \text { O০০ }\end{array}$ \\
\hline $\begin{array}{l}\text { Punto de buena } \\
\text { práctica }\end{array}$ & $\begin{array}{l}\text { Los pacientes con enfermedad de Crohn } \\
\text { dependientes de esteroides deben ser } \\
\text { tratados inicialmente con tiopurinas o } \\
\text { metotrexato como "ahorradores" de } \\
\text { esteroides. }\end{array}$ \\
\hline $\begin{array}{l}\text { Punto de buena } \\
\text { práctica }\end{array}$ & $\begin{array}{l}\text { Se debe considerar el uso de metotrexato } \\
\text { en lugar de tiopurinas en pacientes jóvenes } \\
\text { hombres <35 años, por el riesgo de linfoma } \\
\text { hepatoesplénico, lo mismo que en sujetos } \\
\text { intolerantes o que presenten efectos } \\
\text { adversos a las tiopurinas. }\end{array}$ \\
\hline $\begin{array}{l}\text { Punto de buena } \\
\text { práctica }\end{array}$ & $\begin{array}{l}\text { La dosis recomendada de mantenimiento } \\
\text { de metotrexato es de } 25 \mathrm{mg} / \mathrm{semana} \text { vía } \\
\text { intramuscular. }\end{array}$ \\
\hline
\end{tabular}

\begin{tabular}{|c|c|}
\hline Fuerte en contra & $\begin{array}{l}\text { No se recomienda el uso de nutrición } \\
\text { elemental para mantener la remisión en } \\
\text { pacientes con enfermedad de Crohn. } \\
\text { Calidad de la evidencia muy baja } \oplus \text { O০০ }\end{array}$ \\
\hline Fuerte en contra & $\begin{array}{l}\text { No se recomienda el uso de probióticos } \\
\text { para mantener la remisión en pacientes con } \\
\text { enfermedad de Crohn. } \\
\text { Calidad de la evidencia baja } \oplus \oplus \text { O० }\end{array}$ \\
\hline Fuerte en contra & $\begin{array}{l}\text { No se recomienda el uso de esteroides } \\
\text { sistémicos para mantener la remisión en } \\
\text { pacientes con enfermedad de Crohn. } \\
\text { Calidad de la evidencia muy baja } \oplus \text { ○০০ }\end{array}$ \\
\hline
\end{tabular}

Resumen de la evidencia: generalidades

\section{5-aminosalicilatos para mantener en remisión a los pacientes con enfermedad de Crohn}

Una revisión sistemática de la literatura (82) (puntaje AMSTAR 9/11) evaluó la seguridad y la efectividad del uso de 5-aminosalicilatos para mantener en remisión a los pacientes con EC. Para esta revisión, los desenlaces evaluados fueron la recurrencia clínica o endoscópica a los 12 o 24 meses de seguimiento (definida como CDAI $>150$ o el incremento en más de 60 puntos o $\mathrm{HBI}>4$ ) y la proporción de pacientes que experimentaron eventos adversos serios o que suspendieron la terapia a causa de este.

La revisión recuperó 11 ensayos clínicos aleatorios para un total de 2014 participantes. Cuando se comparó frente al placebo, el uso de 5-aminosalicilatos no se asoció a una menor recurrencia clínica o endoscópica a mediano (RR: 0,98; IC 95\%: 0,91-1,07; para los 12 meses) o a largo plazo (RR: 0,99; IC 95\%: 0,80-1,23; para los 24 meses), al igual que tampoco incrementó la frecuencia de eventos adversos serios (RR: 1,43; IC 95\%: 0,24-8,44) o de suspensión de la terapia (RR: 1,11; IC 95\%: 0,88-1,38) (82).

\section{Calidad de la evidencia: baja $\oplus \oplus \mathrm{O}$}

\section{Azatioprina o 6-mercaptopurina para mantener en remisión a los pacientes con enfermedad de Crohn}

Una revisión sistemática de la literatura (83) (puntaje AMSTAR 9/11) evaluó la seguridad y la efectividad del uso de azatioprina o 6-mercaptopurina para mantener en remisión a los pacientes con EC. En esta ocasión, los desenlaces evaluados fueron la proporción de pacientes que permanecieron en remisión (evaluado con CDAI $<150$ ), la disminución en la dosis de esteroides y la frecuencia de eventos adversos serios o de pacientes que abandonaron la terapia.

La revisión recuperó ocho ensayos clínicos controlados que compararon el uso de esta intervención frente al placebo y que reclutó 532 participantes. Con base en la 
evidencia recuperada, se pudo establecer que el uso de azatioprina o 6-mercaptopurina incrementó la proporción de pacientes que continuaron en período de remisión (RR: 1,25; IC 95\%: 1,11-1,42) a expensas de una mayor frecuencia de eventos adversos serios (RR: 2,45 ; IC 95\%: 1,22-4.90) o de abandono de la terapia (RR: 3,12; IC 95\%: $1,59-6,09)$, sin modificar la proporción de pacientes en los que fue factible reducir la dosis de esteroide (RR: 1,59; IC 95\%: 0,97-2,61) (83).

Un segundo análisis realizado al interior de esta revisión comparó en esta ocasión la administración de azatioprina o 6-mercaptopurina frente a la terapia con mesalazina o sulfasalazina. Cuando se comparó frente al uso de 5-aminosalicilatos, la terapia con azatioprina o 6-mercaptopurina no se asoció a una mayor o menor frecuencia de pacientes que permanecieron en remisión (RR: 1,09; IC 95\%: 0,88-1,34) o que experimentaron abandono de la terapia (RR: 1,86 ; IC 95\%: 0,87-3,97), pero sí con una mayor incidencia de eventos adversos serios (RR: 9,37; IC 95\%: 1,84-47,72). Finalmente, el último estudio recuperado comparó la terapia combinada con azatioprina más infliximab frente a la monoterapia con este medicamento biológico. El uso de terapia combinada no fue superior a la hora de incrementar la proporción de pacientes que continuaron en remisión (RR: 1,02; IC 95\%: 0,74-1,40). No obstante, tampoco aumentó la frecuencia de eventos adversos serios (RR: 2,42; IC 95\%: 0,10-56,46) o de abandono de la terapia (RR: 2,42; IC 95\%: 0,10-56,46) (83).

Calidad de la evidencia: muy baja $\oplus$ O००

\section{Budesonida para mantener en remisión a los pacientes con enfermedad de Crohn}

Una revisión sistemática de la literatura (84) (puntaje AMSTAR 10/11) evaluó la seguridad y la efectividad de la administración de budesonida para mantener en remisión a los pacientes con EC. Para este estudio, los desenlaces evaluados fueron la proporción de pacientes que continuaron en remisión (evaluado con CDAI <150), el cambio en el puntaje CDAI con respecto a la línea de base, los días transcurridos al primer episodio de recaída y, finalmente, la frecuencia de pacientes que abandonaron la terapia como consecuencia de un evento adverso.

La revisión recuperó cinco ensayos clínicos aleatorizados que compararon el uso de esta intervención frente al placebo y que reclutaron 420 pacientes. Con base en la evidencia recuperada, se pudo establecer que el uso de budesonida en dosis de $6 \mathrm{mg} / \mathrm{d}$ no incrementó la frecuencia de pacientes en remisión a mediano o a largo plazo (RR: 1,15; IC 95\%: 0,95-1,39; y RR: 1,13; IC 95\%: 0,94-1,35; para los 6 y 12 meses, respectivamente), aunque sí dismi- nuyó la actividad de la enfermedad a mediano y largo plazo (DM puntaje CDAI a los 6 meses: $-24,30$; IC 95\%: $-2,29$ a $-46,31$; y puntaje CDAI a los 12 meses: $-23,49$; IC $95 \%$ : $-0,32$ a $-46,65)$ y prolongó el tiempo al primer episodio de recaída (DM: 59,93 días; IC 95\%; 19,02-100,84 días), sin incrementar la frecuencia de abandono de la terapia (RR: 1,08; IC 95\%; 0,60-1,95) (84).

Cuando se realizó el análisis de subgrupos acorde con la dosis de budesonida, se observó que el aumento en la posología ( 6 versus $9 \mathrm{mg}$ ) no incrementó la frecuencia de pacientes en el período de remisión (RR: 1,07; IC 95\%: 0,91-1,26) ni modificó los índices de actividad de la enfermedad (DM puntaje CDAI: -18; IC 95\%: -41,06-5,06), pero tampoco incrementó la frecuencia de pacientes que abandonaron la terapia (RR: 0,31; IC 95\%: 0,03-2,94). Finalmente, cuando se comparó la terapia con budesonida frente al uso de prednisolona $40 \mathrm{mg} / \mathrm{d}$, no se encontraron diferencias entre los grupos en términos de la tasa de remisión a 6 (RR: 0,79; IC 95\%: 0,56-1,12) o a 12 meses (RR: 0,79; IC 95\%: 0,55-1,13) o en la frecuencia de eventos adversos (RR: 8,62; IC 95\%: 0,48-155,52) (84).

Calidad de la evidencia: muy baja $\oplus$ O००

\section{Metotrexato para mantener en remisión a los pacientes con enfermedad de Crohn}

Una revisión sistemática con metaanálisis (85) (puntaje AMSTAR 8/11) evaluó la efectividad de la terapia con metotrexato para mantener en remisión a los pacientes con EC. Para esta revisión, el desenlace analizado fue la proporción de pacientes que continuaron en remisión con un rango de seguimiento de 30 a 76 semanas (remisión definida como CDAI $<150$ ). Siete ensayos clínicos controlados con un total de 306 participantes compararon la administración de esta terapia frente al uso de cualquier otra intervención. Cuando se comparó frente al placebo, la administración de metotrexato incrementó la tasa de pacientes que permanecieron en remisión (RR: 1,57; IC 95\%: 1,10$2,23)$, sin que estos hallazgos fueran consistentes cuando se comparó frente al uso de 6-mercaptopurina (RR: 1,36; IC 95\%: 0,92-2,00), 5-aminosalicilatos (RR: 2,62; IC 95\%: $0,23-29,79)$ o a la terapia combinada con infliximab (RR: 1,02; IC 95\%: 0,76-1,38) (85).

Calidad de la evidencia: muy baja $\oplus$ $\bigcirc$ ○०

\section{Nutrición elemental para mantener en remisión a los pacientes con enfermedad de Crohn}

Una revisión sistemática de la literatura (86) (puntaje AMSTAR 7/11) evaluó la efectividad de la nutrición elemental para mantener en remisión a los pacientes con EC. Para este estudio, los desenlaces evaluados fueron man- 
tenimiento de la remisión (puntaje CDAI $\leq 150$ solo o Rutgeerts $<2$ ), recaída (puntaje CDAI $\geq 200$ o que se incrementa en 100 puntos, o puntaje IOIBD $\geq 2$ o incremento en la dosis de esteroides), necesidad de intervención quirúrgica, retiro de esteroides y calidad de vida (evaluada con la escala Inflammatory Bowel Disease Questionnaire [IBDQ]).

La revisión recuperó dos ensayos clínicos controlados para un total de 116 participantes. Cuando se comparó frente a la no intervención, la nutrición elemental no modificó la proporción de pacientes que continuaron en remisión a corto (RR: 1,21; IC 95\%: 0,92-1,58; a 6 meses), mediano (RR: 1,37; IC 95\%: 0,86-2,17; a 12 meses) o largo plazo (RR: 2,06; IC 95\%: 1,00-4,43; a 24 meses) o que requirieron intervención quirúrgica (RR: 1,03; IC 95\%: 0,06-15,79). No obstante, el uso de esta intervención sí redujo la frecuencia de episodios de recaída durante el primer y segundo año (RR: 0,57; IC 95\%: 0,38-0,84) e incrementó los índices de calidad de vida durante el primer año de seguimiento (DM, puntaje 4,9 en la escala IBDQ; IC 95\%: 6,3-16,1) (86).

Por otra parte, otro de los estudios recuperados en esta revisión comparó la efectividad del uso de la nutrición elemental frente a la terapia con 6-mercaptopurina. No se encontraron diferencias entre los grupos en términos de mantenimiento de la remisión a corto (RR: 1,05; IC 95\%: 0,83-1,33; a 6 meses), mediano (RR: 0,93; IC 95\%: 0,64-1,35; a 12 meses) o largo plazo (RR: 0,77; IC 95\%: 0,46-1,27), la frecuencia de episodios de recaída (RR: 1,61; IC 95\%: 0,73-3,53) o los requerimientos de intervención quirúrgica (RR: 0,93; IC 95\%: 0,06-14,32). Finalmente, tampoco se encontró diferencia en la frecuencia de pacientes que toleraron el desmonte de esteroides cuando se comparó la administración de dieta elemental frente a la nutrición polimérica (RR: 0,98; IC 95\%: 0,44-2,19) (86).

Una revisión de Cochrane más reciente, que comparó nutrición enteral con corticoides en población adulta, demostró diferencia significativa a favor de los corticoides en cuanto a las tasas de remisión en EC (45\% vs. 73\%) (RR: 0,65; IC 95\%: 0,52-0,82), con calidad de evidencia muy baja (87).

Calidad de la evidencia: muy baja $\oplus$ O००
Probióticos para mantener en remisión a los pacientes con enfermedad de Crohn

Una revisión sistemática de la literatura (88) (puntaje AMSTAR 9/11) evaluó la efectividad y la seguridad del uso de probióticos para mantener en remisión a los pacientes con EC. Para esta revisión, los resultados analizados fueron la frecuencia de recaídas a 12 meses (CDAI $>220$ o $150-220$ con un incremento de $\geq 70$ sobre el valor basal) y la incidencia de eventos adversos derivados de la intervención. Se incluyeron cuatro ensayos clínicos aleatorios con un total de 233 participantes. Cuando se comparó frente al placebo, la administración de probióticos no redujo la frecuencia de episodios de recaída (RR: 1,03; IC 95\%: 0,70$1,51)$, pero tampoco incrementó la frecuencia de eventos adversos (RR: 1,05; IC 95\%: 0,80-1,37) (88).

Calidad de la evidencia: baja $\oplus \oplus \mathrm{O}$

\section{Corticoides para mantener en remisión a los pacientes con enfermedad de Crohn}

Una revisión sistemática de la literatura (89) (puntaje AMSTAR 8/11) evaluó la efectividad del uso de corticoides para mantener en remisión a los pacientes con EC. Para esta revisión, el desenlace reportado fue la frecuencia de recaída a los 6, 12 y 24 meses (CDAI > 150 acompañado de síntomas sugestivos). Se incluyeron tres ensayos clínicos aleatorios con un total de 303 participantes. Cuando se comparó frente al placebo, la administración de corticoides no redujo la frecuencia de episodios de recaída a corto (RR: 0,71; IC 95\%: 0,38-1,31), mediano (RR: 0,82; IC 95\%: 0,47-1,44) o a largo plazo (RR: 0,72; IC 95\%: 0,39-1,35) (89).

Calidad de la evidencia: muy baja $\oplus$ O००

\section{De la evidencia a la recomendación}

Colombia no cuenta con la prueba de la enzima tiopurinametiltransferasa (TPMT); sin embargo, sería ideal realizarla debido a que los pacientes con tiopurinas pueden presentar inmunosupresión. A futuro se sugiere su inclusión en el plan de beneficios. 


\begin{tabular}{|c|c|c|c|c|c|c|}
\hline \multirow[b]{2}{*}{ Problema } & \multicolumn{6}{|c|}{ Juicio de valor } \\
\hline & No & Probablemente no & Probablemente sí & Sí & Varía & No se conoce \\
\hline $\begin{array}{l}\text { Efectos } \\
\text { deseables }\end{array}$ & Triviales & Pequeños & Moderados & Grandes & Varía & No se conoce \\
\hline $\begin{array}{l}\text { Efectos no } \\
\text { deseados }\end{array}$ & Triviales & Pequeños & Moderados & Grandes & Varía & No se conoce \\
\hline $\begin{array}{l}\text { Confianza en la } \\
\text { evidencia }\end{array}$ & Muy baja & Baja & Moderada & Alta & & $\begin{array}{c}\text { No se encontró } \\
\text { evidencia }\end{array}$ \\
\hline Variabilidad & Alta incertidumbre & $\begin{array}{l}\text { Importante } \\
\text { variabilidad }\end{array}$ & $\begin{array}{l}\text { Variabilidad no } \\
\text { importante }\end{array}$ & $\begin{array}{l}\text { No se presenta } \\
\text { variabilidad }\end{array}$ & & No se conoce \\
\hline $\begin{array}{l}\text { Balance de los } \\
\text { efectos }\end{array}$ & $\begin{array}{l}\text { Favorece la } \\
\text { comparación }\end{array}$ & $\begin{array}{l}\text { Probablemente } \\
\text { favorece la } \\
\text { comparación }\end{array}$ & $\begin{array}{l}\text { No favorece } \\
\text { ninguna } \\
\text { intervención }\end{array}$ & $\begin{array}{l}\text { Probablemente } \\
\text { favorece la } \\
\text { intervención }\end{array}$ & $\begin{array}{l}\text { Favorece la } \\
\text { intervención }\end{array}$ & No se conoce \\
\hline $\begin{array}{l}\text { Calidad global de } \\
\text { la evidencia }\end{array}$ & Muy baja & Baja & Moderada & Alta & & $\begin{array}{c}\text { No se encontró } \\
\text { evidencia }\end{array}$ \\
\hline Equidad & Reducida & $\begin{array}{c}\text { Probablemente se } \\
\text { reduzca }\end{array}$ & $\begin{array}{l}\text { Probablemente no } \\
\text { tenga impacto }\end{array}$ & $\begin{array}{c}\text { Probablemente se } \\
\text { aumente }\end{array}$ & Se aumenta & No se conoce \\
\hline $\begin{array}{l}\text { Aceptabilidad de } \\
\text { los usuarios }\end{array}$ & No & Probablemente no & Probablemente sí & Sí & Varía & No se conoce \\
\hline $\begin{array}{l}\text { Factibilidad de } \\
\text { implementación }\end{array}$ & No & Probablemente no & Probablemente sí & Sí & Varía & No se conoce \\
\hline
\end{tabular}

\section{PREGUNTA 4. ¿CUÁL ES LA SEGURIDAD Y LA EFECTIVIDAD DEL USO DE MEDICAMENTOS BIOLÓGICOS PARA EL TRATAMIENTO DE LOS PACIENTES MAYORES DE 16 AÑOS CON ENFERMEDAD DE CROHN MODERADA A GRAVE?}

\section{Lista de recomendaciones}

\begin{tabular}{|c|c|}
\hline Recomendación $n .^{\circ}$ & Resumen \\
\hline Fuerte a favor & $\begin{array}{l}\text { Se recomienda el uso de infliximab, } \\
\text { adalimumab, certolizumab, vedolizumab } \\
\text { o ustekinumab para inducir y mantener la } \\
\text { remisión en pacientes con enfermedad de } \\
\text { Crohn luminal moderada a grave. } \\
\text { Calidad de la evidencia muy baja } \oplus \text { ○০০ }\end{array}$ \\
\hline $\begin{array}{l}\text { Punto de buena } \\
\text { práctica }\end{array}$ & $\begin{array}{l}\text { Se deben elegir, como primera opción, } \\
\text { los medicamentos anti-FNT (infliximab, } \\
\text { adalimumab o certolizumab pegol) sobre } \\
\text { otros biológicos para el manejo inicial de la } \\
\text { enfermedad de Crohn moderada a grave. }\end{array}$ \\
\hline $\begin{array}{l}\text { Punto de buena } \\
\text { práctica }\end{array}$ & $\begin{array}{l}\text { Los pacientes mayores de } 65 \text { años en } \\
\text { tratamiento con anti-FNT tienen mayor riesgo } \\
\text { de infección }(90) \text {. }\end{array}$ \\
\hline
\end{tabular}

\begin{tabular}{|c|c|}
\hline $\begin{array}{l}\text { Punto de buena } \\
\text { práctica }\end{array}$ & $\begin{array}{l}\text { En pacientes masculinos menores de } 35 \text { años } \\
\text { no se recomienda el uso de terapia combinada } \\
\text { de anti-FNT con tiopurinas por el riesgo } \\
\text { de linfoma hepatoesplénico, lo mismo en } \\
\text { pacientes con historia de malignidad. En este } \\
\text { caso, debe usarse monoterapia con anti-FNT. }\end{array}$ \\
\hline $\begin{array}{l}\text { Punto de buena } \\
\text { práctica }\end{array}$ & $\begin{array}{l}\text { En pacientes con contraindicaciones para } \\
\text { el uso de anti-FNT (falla cardíaca grave, } \\
\text { enfermedad desmielinizante, entre otras) se } \\
\text { debe considerar el uso de vedolizumab o } \\
\text { ustekinumab. }\end{array}$ \\
\hline $\begin{array}{l}\text { Punto de buena } \\
\text { práctica }\end{array}$ & $\begin{array}{l}\text { Los pacientes con enfermedad de Crohn } \\
\text { deben ser evaluados en } 12-14 \text { semanas } \\
\text { luego del inicio de la inducción con terapia } \\
\text { biológica para determinar la respuesta y la } \\
\text { necesidad de modificar el tratamiento. }\end{array}$ \\
\hline Débil a favor & $\begin{array}{l}\text { Se sugiere el uso de medicamentos anti-FNT } \\
\text { (infliximab o adalimumab) para el tratamiento } \\
\text { de los pacientes con enfermedad de Crohn } \\
\text { fistulizante perianal. } \\
\text { Calidad de la evidencia baja } \oplus \oplus \text { O० }\end{array}$ \\
\hline $\begin{array}{l}\text { Punto de buena } \\
\text { práctica }\end{array}$ & $\begin{array}{l}\text { La eficacia del infliximab podría } \\
\text { incrementarse cuando se administra en } \\
\text { conjunto con tiopurinas. }\end{array}$ \\
\hline
\end{tabular}




\begin{tabular}{|c|c|}
\hline Débil a favor & $\begin{array}{l}\text { Se sugiere el uso de ustekinumab para } \\
\text { inducir la remisión en pacientes con } \\
\text { enfermedad de Crohn moderada a grave, que } \\
\text { hayan presentado falla terapéutica a anti-FNT. } \\
\text { Calidad de la evidencia muy baja } \oplus \text { O०० }\end{array}$ \\
\hline $\begin{array}{l}\text { Punto de buena } \\
\text { práctica }\end{array}$ & $\begin{array}{l}\text { La dosis inicial recomendada de inducción de } \\
\text { ustekinumab es } 260 \mathrm{mg} \text { intravenosos (hasta } \\
55 \mathrm{~kg} \text { de peso), } 390 \mathrm{mg} \text { (entre } 56 \text { y } 85 \mathrm{~kg} \text { ) y } \\
520 \mathrm{mg} \text { (mayor de } 85 \mathrm{~kg} \text { ). Para el tratamiento } \\
\text { de mantenimiento se recomienda continuar } \\
\text { con } 90 \text { mg subcutáneos cada } 8 \text { semanas. }\end{array}$ \\
\hline Débil a favor & $\begin{array}{l}\text { Se sugiere la vigilancia clínica de las } \\
\text { infecciones oportunistas en los pacientes con } \\
\text { enfermedad de Crohn que reciban terapia } \\
\text { biológica. } \\
\text { Calidad de la evidencia muy baja } \oplus \text { ○૦૦ }\end{array}$ \\
\hline $\begin{array}{l}\text { Punto de buena } \\
\text { práctica }\end{array}$ & $\begin{array}{l}\text { Se debe contraindicar el uso de tratamiento } \\
\text { con anti-FNT en pacientes con infección } \\
\text { activa. }\end{array}$ \\
\hline $\begin{array}{l}\text { Punto de buena } \\
\text { práctica }\end{array}$ & $\begin{array}{l}\text { Previo al inicio de la terapia biológica se debe } \\
\text { indagar la presencia de síntomas respiratorios } \\
\text { y se debe realizar una radiografía de tórax y } \\
\text { una prueba de tuberculina, dado el riesgo de } \\
\text { reactivación de tuberculosis latente. }\end{array}$ \\
\hline $\begin{array}{l}\text { Punto de buena } \\
\text { práctica }\end{array}$ & $\begin{array}{l}\text { Previo al inicio de la terapia biológica se debe } \\
\text { solicitar serología para hepatitis } B, C \text { y prueba } \\
\text { de VIH. }\end{array}$ \\
\hline $\begin{array}{l}\text { Punto de buena } \\
\text { práctica }\end{array}$ & $\begin{array}{l}\text { Los pacientes con enfermedad de Crohn } \\
\text { deben ser vacunados contra influenza, } \\
\text { neumococo, hepatitis B, varicela (al menos } 3 \\
\text { semanas antes del inicio del inmunosupresor) } \\
\text { y virus del papiloma humano (previo al inicio } \\
\text { de los medicamentos inmunosupresores } \\
\text { esteroides, tiopurinas y biológicos). }\end{array}$ \\
\hline Débil a favor & $\begin{array}{l}\text { Se sugiere utilizar un segundo anti-FNT } \\
\text { cuando no haya respuesta primaria o } \\
\text { posterior a la pérdida secundaria de } \\
\text { respuesta a un primer anti-FNT. } \\
\text { Calidad de la evidencia muy baja } \oplus \text { O० }\end{array}$ \\
\hline $\begin{array}{l}\text { Punto de buena } \\
\text { práctica }\end{array}$ & $\begin{array}{l}\text { Se debe individualizar el cambio de } \\
\text { tratamiento de acuerdo con los resultados de } \\
\text { los niveles séricos y de anticuerpos contra el } \\
\text { medicamento anti-FNT. }\end{array}$ \\
\hline $\begin{array}{l}\text { Punto de buena } \\
\text { práctica }\end{array}$ & $\begin{array}{l}\text { Pacientes con niveles adecuados de anti-FNT } \\
\text { y con anticuerpos }(+) \text { deben tratarse con otro } \\
\text { tipo de anti-FNT u otra clase de biológico. }\end{array}$ \\
\hline $\begin{array}{l}\text { Punto de buena } \\
\text { práctica }\end{array}$ & $\begin{array}{l}\text { En sujetos con niveles subterapéuticos de } \\
\text { anti-FNT y anticuerpos (-) debe acortarse el } \\
\text { intervalo o incrementarse la dosis del anti-FNT. }\end{array}$ \\
\hline
\end{tabular}

\begin{tabular}{|c|c|}
\hline Débil a favor & $\begin{array}{l}\text { Se sugiere el uso de biosimilar de infliximab } \\
\text { para inducir y mantener la remisión en } \\
\text { pacientes con enfermedad de Crohn. } \\
\text { Calidad de la evidencia muy baja } \oplus \text { ○০০ }\end{array}$ \\
\hline $\begin{array}{l}\text { Punto de buena } \\
\text { práctica }\end{array}$ & $\begin{array}{l}\text { Los pacientes en tratamiento con infliximab } \\
\text { innovador pueden continuar el tratamiento } \\
\text { con el biosimilar si vienen respondiendo al } \\
\text { anterior. }\end{array}$ \\
\hline $\begin{array}{l}\text { Punto de buena } \\
\text { práctica }\end{array}$ & $\begin{array}{l}\text { No se debe realizar el intercambio entre las } \\
\text { dos moléculas en caso de falla terapéutica } \\
\text { inicial con cualquiera de ellas. }\end{array}$ \\
\hline $\begin{array}{l}\text { Punto de buena } \\
\text { práctica }\end{array}$ & $\begin{array}{l}\text { En caso de realizarse el intercambio no } \\
\text { médico entre un biológico innovador con } \\
\text { un biosimilar, debe informársele al médico } \\
\text { tratante para farmacovigilancia y se debe } \\
\text { contar con el consentimiento por parte del } \\
\text { paciente. }\end{array}$ \\
\hline Fuerte a favor & $\begin{array}{l}\text { Se recomienda el uso de infliximab, infliximab } \\
\text { más azatioprina, adalimumab o vedolizumab } \\
\text { para inducir la remisión en pacientes con } \\
\text { enfermedad de Crohn. } \\
\text { Calidad de la evidencia muy baja } \oplus \text { ○০০ }\end{array}$ \\
\hline Fuerte a favor & $\begin{array}{l}\text { Se recomienda el uso de azatioprina, } \\
\text { metotrexato, infliximab, infliximab más } \\
\text { azatioprina, adalimumab o vedolizumab para } \\
\text { mantener en remisión a los pacientes con } \\
\text { enfermedad de Crohn. } \\
\text { Calidad de la evidencia muy baja } \oplus \text { }\end{array}$ \\
\hline
\end{tabular}

\section{Resumen de la evidencia: generalidades}

\section{Anti-FNT (infliximab, adalimumab o certolizumab pegol) 0 antiintegrinas (natalizumab o vedolizumab) 0 anti-IL-12/23 (ustekinumab) comparados con placebo para inducir o mantener en remisión a los pacientes con enfermedad de Crohn luminal moderada o grave}

Una revisión sistemática de la literatura con metaanálisis en red (91) (puntaje AMSTAR 9/11) evaluó la eficacia del uso de medicamentos Anti-FNT (infliximab, adalimumab o certolizumab pegol) o antiintegrinas (natalizumab o vedolizumab) o antiinterleucina 12/23 (anti-IL-12/23; ustekinumab) comparado con el uso de placebo para inducir o mantener en remisión a los pacientes con EC luminal moderada o grave de localización en colon, íleon o ileocólica. Todos los estudios incluidos permitieron el uso concomitante de inmunomoduladores, corticoesteroides y/o 5-aminosalicilatos. Los desenlaces evaluados fueron la inducción de la remisión clínica (CDAI $<150$ o disminución en el puntaje CDAI en más de 100 o 70 puntos) y el mantenimiento de la remisión (CDAI $<150$ o una dismi- 
nución en el puntaje CDAI en más de 100 o 70 puntos con respecto a la línea de base).

La revisión recuperó 11 ensayos clínicos aleatorizados, para un total de 2530 pacientes. Al comparar el uso de los medicamentos biológicos versus placebo, una mayor proporción de pacientes alcanzó la remisión clínica (RR: 1,44; IC 95\%: 1,19-1,75) y se mantuvieron en remisión (RR: 2,06; IC 95\%: 1,73-2,45). Cuando se realizó el análisis de subgrupos y el desenlace de interés fue la inducción de la remisión, se observó que el uso de anti-FNT incrementó la proporción de pacientes que lograron este desenlace (OR: 1,63; IC 95\%: 1,24-2,14), hallazgos que no fueron estadísticamente significativos cuando se trató de la familia antiintegrinas (OR: 1,20; IC 95\%: 0,97-1,49) o inhibidor de IL-12/23 ustekinumab (OR: 0,79; IC 95\%: 0,44-1,39). Cuando se realizó el análisis en red se documentó que infliximab (RR: 6,11; IC 95\%: 2,49-18,29) y adalimumab (RR: 2,98; IC 95\%; 1,12-8,18) fueron superiores al placebo en términos de inducción de la remisión, hallazgo que no fue documentado para certolizumab pegol (RR: 1,48; IC 95\%: 0,76-2,93), natalizumab (RR: 1,36; IC 95\%: 0,692,86 ), vedolizumab (RR: 1,40 ; IC $95 \%$ : 0,63-3,28) o ustekinumab (RR: 0,61; IC 95\%: 0,15-2,49). El infliximab tuvo el $86 \%$ de probabilidad de ser la mejor alternativa seguido por adalimumab, con una probabilidad del 16\% (91).

Por su parte, el análisis de subgrupos para el desenlace de mantenimiento de la remisión documentó que, cuando se trató de medicamentos anti-FNT (OR: 2,18; IC 95\%: 1,65-2,88) o de anti-IL-12/23 ustekinumab (OR: 2,09; IC 95\%: 1,49-2,92), una mayor proporción de pacientes continuaron en este estadio clínico. Estos hallazgos no fueron observados cuando se trató de antiintegrinas (OR: 1,52; IC 95\%: 0,96-2,42). Cuando se realizó el análisis en red, se documentó que adalimumab (RR: 5,16; IC 95\%: 1,78$18,00)$ fue superior al placebo, en tanto que infliximab (RR: 3,31; IC 95\%: 0,98-14,01), certolizumab pegol (RR: 2,26; IC 95\%: 0,38-13,57), natalizumab (RR: 4,26; IC 95\%: 0,71-25,49), vedolizumab (RR: 2,20; IC 95\%: 0,3713,54) y ustekinumab (RR: 0,91; IC 95\%: 0,31-12,31) no lo fueron. El adalimumab tuvo una probabilidad del $48 \%$ de ser la mejor alternativa terapéutica, seguido por natalizumab, con un $29 \%$, e infliximab, con un $11 \%$ (91).

Calidad de la evidencia: muy baja $\oplus$ $\bigcirc 00$

Una revisión sistemática reciente comparó la eficacia y la seguridad de biológicos (infliximab, adalimumab, certolizumab, vedolizumab y ustekinumab) como terapia de primera línea ("naive") y segunda línea (exposición previa a anti-FNT) en pacientes con EC moderada a grave. Se incluyeron 8 estudios (ensayos clínicos aleatorizados; RCT) con biológicos como agentes de primera línea, 6 estudios con biológicos como agentes de segunda línea y 9 estudios con biológicos como terapia de mantenimiento. No se encontraron estudios comparativos cabeza a cabeza. Los autores determinaron la superficie bajo la clasificación acumulativa (SUCRA), que representa el porcentaje de eficacia o seguridad alcanzado por un agente comparado con un agente imaginario que siempre es el mejor sin incertidumbre (es decir, SUCRA $=100 \%)$. Los autores concluyeron que infliximab (SUCRA, 0,93) y adalimumab (SUCRA, 0,75) tuvieron la más alta calificación para la inducción de la remisión clínica en EC (calidad de la evidencia moderada). En pacientes con previa exposición a anti-FNT (segunda línea), adalimumab (SUCRA, 0,91) y ustekinumab (SUCRA, 0,71) lograron la mayor calificación para la inducción de la remisión (calidad de la evidencia baja). Para el mantenimiento de la remisión, adalimumab (SUCRA, 0,97) e infliximab (SUCRA, 0,68) tuvieron la mejor puntuación. Ustekinumab tuvo el más bajo riesgo para eventos adversos (SUCRA, 0,72 ) e infección (SUCRA, 0,71) (92).

\section{Efectividad del uso de un segundo anti-FNT en pacientes con enfermedad inflamatoria intestinal y falla o intolerancia a un primer biológico}

Una revisión sistemática de la literatura (93) (puntaje AMSTAR 8/11) evaluó la efectividad del uso de un segundo anti-FNT en pacientes con enfermedad inflamatoria intestinal y falla primaria o secundaria a un anti-FNT o intolerancia a un biológico. Los pacientes incluidos se caracterizaron por tener enfermedad luminal o fistulizante con CDAI de 220 a 450 puntos o HBI $\geq 7$ o "con enfermedad moderada a grave" o con enfermedad "dependiente de esteroides" o con "fallo a inmunomoduladores". De los estudios, 32 evaluaron el cambio de infliximab a adalimumab, 4 evaluaron el cambio de infliximab a certolizumab y 1 evaluó el cambio de adalimumab a infliximab.

Los desenlaces evaluados fueron las tasas globales de remisión o respuesta a falla primaria de infliximab a adalimumab, de infliximab a adalimumab o certolizumab pegol y, finalmente, la tasa global de remisión o respuesta secundaria en caso de intolerancia a infliximab. Basados en este metaanálisis, se pudo establecer que el porcentaje de remisión a corto, mediano y largo plazo fue del 18\%, 30\% y $28 \%$, respectivamente. Cuando se trató de la respuesta, las fracciones alcanzadas correspondieron al 35\%, 67\% y $42 \%$ para los mismos períodos de observación en los pacientes que presentaron falla primaria a infliximab y en quienes se realizó el cambio a adalimumab (93).

Ahora bien, cuando se trató de la falla primaria a infliximab con la administración posterior a adalimumab o certolizumab, se observó una tasa de remisión del 41\%, 38\% y $60 \%$ a corto, mediano y largo plazo y de respuesta del $66 \%$ y $42 \%$ a mediano y largo plazo. Finalmente, la frecuencia de remisión fue del $50 \%, 60 \%$ y $83 \%$ y de respuesta del $70 \%$ y $77 \%$ a 
corto, mediano y largo plazo, cuando se trató del cambio de infliximab a adalimumab por intolerancia. Este metaanálisis no reportó la frecuencia de eventos adversos (93).

Calidad de la evidencia: muy baja $\oplus$ O००

\section{Anti-FNT (infliximab o adalimumab) comparado con placebo en pacientes con enfermedad de Crohn fistulizante}

Una revisión sistemática de la literatura (94) (puntaje AMSTAR 8/11) evaluó la eficacia del uso de medicamentos anti-FNT (infliximab o adalimumab) para el tratamiento de los pacientes con EC y fístula perianal o enterocutánea o enteroenteral. Los participantes recibieron 5 $\mathrm{mg} / \mathrm{kg}$ de infliximab o $40 \mathrm{mg}$ a $80 \mathrm{mg}$ de adalimumab, y los desenlaces evaluados fueron el cierre completo o parcial de la fístula. La revisión recuperó cuatro ensayos clínicos aleatorizados, para un total de 288 pacientes; cuando se comparó frente al placebo, los pacientes asignados al brazo de anti-FNT experimentaron una mayor frecuencia de cierre completo de la fístula (RR; 2,40 ; IC 95\%: 1,36-4,22), pero no de cierre parcial (RR: 1,27; IC 95\%: 0,51-3,14) (94).

Calidad de la evidencia: muy baja $\oplus$ O००

\section{Anti-IL-12/23p40 comparado con placebo para inducir la remisión en pacientes con enfermedad de Crohn moderada a grave}

Una revisión sistemática de la literatura (95) (puntaje AMSTAR 9/11) evaluó la seguridad y la efectividad del uso de anti-IL-12/23p40 comparado frente al placebo para inducir la remisión en pacientes con EC. Los pacientes asignados al manejo con ustekinumab o briakinumab presentaban EC moderada a grave y fallo previo a anti-FNT o corticosteroides o inmunosupresores. Los desenlaces evaluados fueron la falla para inducir la remisión clínica (puntaje CDAI $<150$ ) o respuesta clínica (reducción en el puntaje CDAI $\geq 100$ ) y la frecuencia de eventos adversos serios o de retiro debido a eventos adversos serios.

La revisión recuperó cuatro ensayos clínicos aleatorizados, para un total de 2023 participantes. Al comparar el uso de briakinumab frente al placebo, se observó que el uso de esta intervención no se asoció a una menor frecuencia de falla para alcanzar la remisión (RR: 0,92; IC 95\%: 0,83-1,03). No obstante, cuando se trató de la proporción de pacientes que no lograron la respuesta clínica, el uso de briakinumab se asoció a una menor frecuencia para este desenlace (RR: 0,82; IC 95\%: 0,67-0,99). No hubo diferencias entre los grupos en cuanto a la frecuencia de eventos adversos serios (RR: 0,64; IC 95\%: 0,26-1,56) o de retiro por eventos adversos (RR: 0,47; IC 95\%: 0,15-1,53) (95).

Ahora bien, cuando se trató de ustekinumab, se observó que los pacientes asignados a esta intervención tuvieron una menor frecuencia de falla en alcanzar la remisión clínica (RR: 0,91; IC 95\%: 0,86-0,95) o de no lograr la respuesta clínica (RR: 0,73; IC 95\%: 0,66-0,81) cuando se comparó frente al placebo. De otra parte, también se observó que los grupos no fueron diferentes en relación con la presencia de eventos adversos serios (RR: 0,83; IC 95\%: 0,58-1,20) o de retiro debido a eventos adversos (RR: 0,44; IC 95\%: 0,18-1,05) (95).

Calidad de la evidencia: muy baja $\oplus 000$

Una reciente revisión sistemática de Cochrane evaluó la eficacia y la seguridad de los anticuerpos anti-IL-12/23p40 para el mantenimiento de la remisión en la EC. Tres ensayos controlados aleatorizados (646 participantes) cumplieron los criterios de inclusión. Dos ensayos evaluaron la eficacia de ustekinumab (542 participantes). Se evaluaron todos los estudios incluidos como de riesgo de sesgo bajo. Un estudio $(\mathrm{n}=145)$ comparó ustekinumab subcutáneo (90 mg) administrado a las 8 y 16 semanas con placebo. El $58 \%(42 / 72)$ de los participantes del grupo ustekinumab no lograron mantener la remisión clínica a las 22 semanas en comparación con el 73\% (53/73) de los participantes del grupo placebo (RR: 0,80; IC 95\%: 0,63-1,02; evidencia de certeza moderada). Un segundo estudio $(n=388)$ comparó ustekinumab subcutáneo $(90 \mathrm{mg}$ ) administrado cada 8 o 12 semanas con placebo durante 44 semanas. El $49 \%(126 / 257)$ de los participantes del grupo ustekinumab no logró mantener la remisión clínica a las 44 semanas en comparación con el 64\% (84/131) de los participantes del grupo placebo (RR: 0,76; IC 95\%: 0,64-0,91; evidencia de certeza moderada). La evidencia de certeza moderada indica que es probable que el uso de ustekinumab sea efectivo para el mantenimiento de la remisión clínica y la respuesta en pacientes con EC de moderada a grave en remisión, sin un mayor riesgo de eventos adversos (evidencia de certeza alta) o eventos adversos graves (evidencia de certeza moderada) en comparación con el placebo (96).

\section{Seguridad de la terapia biológica en pacientes con enfermedad inflamatoria intestinal moderada a grave} Una revisión sistemática de la literatura (97) (puntaje AMSTAR 10/11) evaluó el riesgo de desarrollar patología infecciosa o neoplásica en pacientes con EC que recibían terapia biológica con adalimumab, certolizumab pegol, golimumab, infliximab, natalizumab o vedolizumab. Para este estudio, los desenlaces reportados fueron la frecuencia de infecciones serias (que requieren hospitalización, uso de antibióticos intravenosos o que terminan en muerte), oportunistas (presencia de Mycobacterium tuberculosis, infección por Nocardia, citomegalovirus o Epstein-Barr, infección oral o esofágica por cándida, infección por varicela-zóster o herpes zóster, infección por Pneumocystis jirovecii o Histoplasma capsulatum o neumonía por Legionella, 
o infección por herpes simple o cualquier otra infección considerada oportunista) o de cualquier tipo, al igual que el desarrollo de tuberculosis (diagnóstico confirmado, reactivación, miliaria o cavitaria pulmonar o de cualquier otro órgano) o malignidad.

Se incluyeron 47 estudios observacionales, para un total de 14.440 participantes. A partir de esta revisión. se pudo documentar que el uso de medicamentos biológicos incrementó la frecuencia de infecciones oportunistas (OR: 1,90; IC 95\%: 1,21-3,01) y de cualquier otro tipo de infección (OR: 1,19; IC 95\%: 1,10-1,29), pero no la de infecciones serias (OR: 0,89; IC 95\%: 0,71-1,12), tuberculosis (OR: 2,04; IC 95\%: 0,71-5,89) o de malignidad (OR: 0,90; IC 95\%: 0,54-1,50). Cuando se realizó el análisis de subgrupos acorde con el tipo de medicamento, no se observaron diferencias entre anti-FNT y antiintegrinas en cuanto a la tasa de infecciones serias (anti-FNT: OR: 0,90; IC 95\%: 0,69-1,17; vs. antiintegrina: OR: 0,87; IC 95\%: 0,54-1,39; valor de $p$ para diferencia de subgrupos de 0,89 ), infecciones oportunistas (anti-FNT: OR: 1,89; IC 95\%: 1,15-3,12; vs. antiintegrina: OR: 1,99; IC 95\%: 0,64-6,18; valor de $p$ para diferencia de subgrupos $=0,94)$ o para cualquier otro tipo de infección (anti-FNT: OR: 1,21; IC 95\%: 1,10-1,33; vs. antiintegrina: OR: 1,14; IC 95\%: 0,99-1,32; valor de $p$ para diferencia de subgrupos $=0,49)(97)$.

\section{Calidad de la evidencia: muy baja $\oplus$ O००}

Una revisión sistemática evaluó el riesgo de infecciones con biológicos y terapia inmunosupresora en enfermedad inflamatoria intestinal en general, en 15 estudios observacionales. Comparados con monoterapia con anti-FNT, el riesgo de infección se incrementa con la combinación con inmunosupresores (RR: 1,19; IC 95\%: 1,03-1,37) con esteroides (RR: 1,64; IC 95\%: 1,33-2,03) y con la combinación de los tres medicamentos (RR: 1,35; IC 95\%: 1,04-1,77). Por el contrario, el riesgo de un agente inmunosupresor fue menor comparado con anti-FNT (RR: 0,61; IC 95\%: 0,44$0,84)$ o con la combinación anti-FNT con un inmunosupresor (RR: 0,56; IC 95\%: 0,39-0,81) (98).

\section{Seguridad y efectividad del uso de CT-P13 (biosimilar infliximab) en pacientes con enfermedad de Crohn moderada a grave}

Una revisión sistemática con metaanálisis (99) (puntaje AMSTAR 9/11) evaluó la seguridad y la efectividad del uso del biosimilar CT-P13 en pacientes con EC localizada en íleon terminal, colon, íleon y colon, o en el tracto gastrointestinal superior. Ninguno de los estudios incluidos realizó una comparación cabeza a cabeza entre el biosimilar y el anti-FNT infliximab, y para la totalidad de ellos, los pacientes fueron tratados en primera instancia con infliximab para luego recibir el biosimilar.
Para esta revisión, los desenlaces evaluados fueron la tasa de respuesta clínica (evaluada con disminución en el puntaje de la escala CDAI $\geq 25 \%$ o $\geq 70$ con respecto al puntaje inicial o, en caso de ser fistulizante, $\geq 50 \%$ de disminución en el número o en el tamaño de las fístulas), la tasa de remisión (evaluada con CDAI $<150$ o, en caso de enfermedad fistulizante, cierre completo de la fístula o $\mathrm{HBI}<5$ y fístulas no activas) y, finalmente, la frecuencia de eventos adversos (evaluada con las reacciones a la infusión, la tuberculosis latente o el desarrollo de infecciones) (99).

La revisión recuperó siete estudios observacionales tipo cohorte, para un total de 225 pacientes. Cuando el desenlace evaluado fue la tasa de respuesta clínica, la proporción de pacientes que continuaron en remisión a corto plazo (seguimiento de 8 a 14 semanas) fue del 79\% (IC 95\%: 65\%88\%) para enfermedad no fistulizante y del 67\% (IC 95\%: 27\%-92\%) para fistulizante. Cuando el desenlace fue evaluado a mediano plazo (seguimiento de 24 a 30 semanas), se observó una respuesta del 77\% (IC 95\%: 63\%-86\%) para no fistulizante y del 67\% (IC 95\%: 27\%-92\%) para enfermedad fistulizante. Finalmente, cuando este desenlace fue valorado a largo plazo (seguimiento a 48 a 63 semanas), la tasa de respuesta fue del 75\% (IC 95\%: 44\%-92\%). No se recuperó información para enfermedad fistulizante (99).

Por otra parte, con respecto a la tasa de remisión a corto plazo (seguimiento de 8 a 14 semanas), esta fue del $66 \%$ (IC 95\%: 53\%-77\%) para no fistulizante y del 33\% (IC 95\%: 8\%-73\%) para enfermedad fistulizante. Cuando este desenlace fue analizado a mediano plazo (seguimiento de 24 a 30 semanas), se observó una proporción del 60\% (IC 95\%: 49\%-70\%) para no fistulizante y del 50\% (IC 95\%: $17 \%-83 \%)$ para fistulizante. No se recuperó información para el seguimiento a largo plazo. Cuando se trató de los eventos adversos, se observó una tasa global del 10\% (IC 95\%: 2\%-31\%) (99).

Calidad de la evidencia: muy baja $\oplus$ O००

\section{Seguridad y efectividad de diferentes estrategias para inducir y mantener en remisión a los pacientes con enfermedad de Crohn. Resultados de un metaanálisis en red}

Una revisión sistemática con metaanálisis en red (100) (puntaje AMSTAR 7/11) evaluó la efectividad y la seguridad de diferentes estrategias para inducir y mantener en remisión a los pacientes con EC. Los pacientes incluidos se caracterizaron por tener enfermedad activa (puntaje CDAI entre 150 y 450 o $\mathrm{HBI}>7$ ) o refractaria o dependiente a esteroide, o bien, refractaria a azatioprina.

Las intervenciones evaluadas fueron la administración de azatioprina/6-mercaptopurina, metotrexato, infliximab, adalimumab, certolizumab y vedolizumab como monoterapia o como parte de la terapia combinada. No se incluyó 
al natalizumab, en consideración a que los estudios disponibles reclutaron pacientes con fallo a anti-FNT. Los desenlaces evaluados fueron inducción de la remisión (CDAI menor o igual a 150 o definido por el autor), mantenimiento de la remisión (CDAI menor o igual a 150 o definido por el autor) y el retiro de la terapia debido a eventos adversos (evaluado de acuerdo con el criterio clínico) (100).

La revisión recuperó 24 ensayos clínicos aleatorios para un total de 4694 participantes. Cuando se comparó frente al placebo, el uso de azatioprina/6-mercaptopurina o de metotrexato no incrementó la probabilidad de inducir remisión (OR: 1,2; IC 95\%: 0,76-2,1; y OR: 1,5; IC 95\%: $0,72-3,2$; respectivamente) en los pacientes con EC. Por otra parte, la administración de infliximab en monoterapia (OR: 2,8; IC 95\%: 1,4 -7,2), infliximab más azatioprina (OR: 4,3; IC 95\%: 2,0-9,8), adalimumab en monoterapia (OR: 2,9 ; IC 95\%: 1,6-5,5) y vedolizumab en monoterapia (OR: 2,0; IC 95\%: 1,2-3,3) incrementó la proporción de pacientes en los cuales se alcanzó la remisión clínica. Estas intervenciones tuvieron más de un $99 \%$ de probabilidad de ser superiores al placebo (100).

Cuando el desenlace de interés fue el mantenimiento de la remisión, todas las intervenciones evaluadas demostraron ser superiores al placebo: azatioprina/6-mercaptopurina (OR: 1,7; IC 95\%: 1,3-2,6), metotrexato en monoterapia (OR: 2,4; IC 95\%: 1,1-4,8), infliximab en monoterapia (OR: 2,8;
IC 95\%: 1,8-4,5), certolizumab en monoterapia (OR: 2,0; IC 95\%: 1,4-3,0), infliximab más azatioprina (OR: 5,2; IC 95\%: 2,8-11,0), adalimumab en monoterapia (OR: 5,1; IC 95\%: $3,3-8,1$ ) y vedolizumab en monoterapia (OR: 2,2 ; IC 95\%: 1,3-3,7). Estas intervenciones tuvieron más de un $99 \%$ de probabilidad de ser superiores al placebo (100).

Finalmente, cuando se evaluó la frecuencia de eventos adversos, esta resultó ser mayor para las intervenciones de azatioprina/6-mercaptopurina (OR: 3,9; IC 95\%: 2,4-6,4), metotrexato en monoterapia (OR: 13; IC 95\%: 3,2-109), infliximab en monoterapia (OR: 2,7; IC 95\%: 1,6-4,7) e infliximab más azatioprina (OR: 3,2; IC 95\%: 1,6-6,1). Ninguna de las otras opciones, ya sea en monoterapia o como parte de la terapia combinada, se asociaron a una mayor o menor frecuencia de eventos adversos cuando se compararon frente al placebo (100).

Calidad de la evidencia: muy baja $\oplus 000$

\section{De la evidencia a la recomendación}

El panel expresó la necesidad de un uso adecuado de los medicamentos biológicos dado que deben ser utilizados considerando las preferencias de los pacientes y su historia clínica y el seguimiento de los eventos adversos potenciales con vigilancia clínica. El uso de biosimilares permitirá acceder con mayor facilidad al tratamiento.

\begin{tabular}{|c|c|c|c|c|c|c|}
\hline \multirow[b]{2}{*}{ Problema } & \multicolumn{6}{|c|}{ Juicio de valor } \\
\hline & No & Probablemente no & Probablemente sí & Sí & Varía & No se conoce \\
\hline Efectos deseables & Triviales & Pequeños & Moderados & Grandes & Varía & No se conoce \\
\hline Efectos no deseados & Triviales & Pequeños & Moderados & Grandes & Varía & No se conoce \\
\hline $\begin{array}{l}\text { Confianza en la } \\
\text { evidencia }\end{array}$ & Muy baja & Baja & Moderada & Alta & & $\begin{array}{c}\text { No se encontró } \\
\text { evidencia }\end{array}$ \\
\hline Variabilidad & Alta incertidumbre & $\begin{array}{l}\text { Importante } \\
\text { variabilidad }\end{array}$ & $\begin{array}{l}\text { Variabilidad no } \\
\text { importante }\end{array}$ & $\begin{array}{l}\text { No se presenta } \\
\text { variabilidad }\end{array}$ & & No se conoce \\
\hline $\begin{array}{l}\text { Balance de los } \\
\text { efectos }\end{array}$ & $\begin{array}{l}\text { Favorece la } \\
\text { comparación }\end{array}$ & $\begin{array}{l}\text { Probablemente } \\
\text { favorece la } \\
\text { comparación }\end{array}$ & $\begin{array}{l}\text { No favorece } \\
\text { ninguna } \\
\text { intervención }\end{array}$ & $\begin{array}{l}\text { Probablemente } \\
\text { favorece la } \\
\text { intervención }\end{array}$ & $\begin{array}{l}\text { Favorece la } \\
\text { intervención }\end{array}$ & No se conoce \\
\hline $\begin{array}{l}\text { Calidad global de la } \\
\text { evidencia }\end{array}$ & Muy baja & Baja & Moderada & Alta & & $\begin{array}{c}\text { No se encontró } \\
\text { evidencia }\end{array}$ \\
\hline Equidad & Reducida & $\begin{array}{c}\text { Probablemente se } \\
\text { reduzca }\end{array}$ & $\begin{array}{l}\text { Probablemente no } \\
\text { tenga impacto }\end{array}$ & $\begin{array}{l}\text { Probablemente se } \\
\text { aumente }\end{array}$ & Se aumenta & No se conoce \\
\hline $\begin{array}{l}\text { Aceptabilidad de los } \\
\text { usuarios }\end{array}$ & No & Probablemente no & Probablemente sí & Sí & Varía & No se conoce \\
\hline $\begin{array}{l}\text { Factibilidad de la } \\
\text { implementación }\end{array}$ & No & Probablemente no & Probablemente sí & Sí & Varía & No se conoce \\
\hline
\end{tabular}




\section{PREGUNTA 5. ¿CUÁLES SON LAS INTERVENCIONES MÁS SEGURAS Y EFECTIVAS PARA EL TRATAMIENTO DE LA ENFERMEDAD DE CROHN PERIANAL EN PACIENTES MAYORES DE 16 AÑOS?}

\section{Lista de recomendaciones}

Recomendación $\quad$ n. $^{\circ}$

Resumen

Débil a favor Se sugiere manejo con ciprofloxacina como terapia adjunta al manejo quirúrgico o inmunosupresor para el tratamiento de pacientes con enfermedad de Crohn con fístulas perianales.

Calidad de la evidencia baja $\oplus \oplus 0$ O

$\begin{array}{ll}\begin{array}{l}\text { Punto de buena } \\ \text { práctica }\end{array} & \begin{array}{l}\text { El uso de antibióticos en conjunto } \\ \text { con la cirugía y la terapia biológica es } \\ \text { recomendable para intentar el cierre de las } \\ \text { fístulas perianales. }\end{array} \\ \begin{array}{ll}\text { Punto de buena } \\ \text { práctica }\end{array} & \begin{array}{l}\text { Debe realizarse resonancia nuclear } \\ \text { magnética de pelvis o endosonografía rectal } \\ \text { previo al drenaje. }\end{array}\end{array}$

Punto de buena Los pacientes con fístulas perianales simples práctica sintomáticos deben ser manejados con fistulotomía o colocación de setón asociadas a manejo con antibióticos (ciprofloxacina en 500 $\mathrm{mg}$, cada 12 horas, y/o metronidazol en 500 $\mathrm{mg}$, cada 8 horas, durante 6-8 semanas).

\begin{tabular}{|c|c|}
\hline $\begin{array}{l}\text { Punto de buena } \\
\text { práctica }\end{array}$ & $\begin{array}{l}\text { Se deben clasificar las fístulas perianales en: } \\
\text { - simples: superficiales o bajas } \\
\text { interesfintéricas o bajas transesfintéricas, } \\
\text { con un solo orificio externo; } \\
\text { - complejas: altas interesfintéricas, altas } \\
\text { transesfintéricas o supraesfintéricas, } \\
\text { rectovaginales, con absceso perianal, } \\
\text { actividad inflamatoria en mucosa rectal o } \\
\text { estenosis anorrectal. }\end{array}$ \\
\hline $\begin{array}{l}\text { Punto de buena } \\
\text { práctica }\end{array}$ & $\begin{array}{l}\text { Debe realizarse resonancia nuclear } \\
\text { magnética de pelvis o endosonografía rectal } \\
\text { ante la sospecha de enfermedad de Crohn } \\
\text { perianal para el diagnóstico y el seguimiento. }\end{array}$ \\
\hline Débil a favor & $\begin{array}{l}\text { Se sugiere el uso de infliximab para el } \\
\text { mantenimiento de la remisión de fístulas } \\
\text { perianales complejas en pacientes con } \\
\text { enfermedad de Crohn. } \\
\text { Calidad de la evidencia muy baja } \oplus \text { O০০ }\end{array}$ \\
\hline $\begin{array}{l}\text { Punto de buena } \\
\text { práctica }\end{array}$ & $\begin{array}{l}\text { Se debe iniciar infliximab siempre en terapia } \\
\text { combinada con tiopurinas, a no ser que esta } \\
\text { última este contraindicada. }\end{array}$ \\
\hline $\begin{array}{l}\text { Punto de buena } \\
\text { práctica }\end{array}$ & $\begin{array}{l}\text { Se debe adicionar ciprofloxacina en } 500 \text { mg, } \\
\text { cada } 12 \text { horas, durante } 12 \text { semanas, a la } \\
\text { terapia anti-FNT para mejorar los resultados } \\
\text { a corto plazo en pacientes con fístulas } \\
\text { perianales complejas. }\end{array}$ \\
\hline
\end{tabular}

\begin{tabular}{|c|c|}
\hline Fuerte a favor & $\begin{array}{l}\text { Se recomienda la terapia combinada, } \\
\text { anti-FNT más colocación de setón, en el } \\
\text { tratamiento de la enfermedad de Crohn } \\
\text { fistulizante perianal compleja, para } \\
\text { incrementar el cierre completo de la fístula. } \\
\text { Calidad de la evidencia muy baja } \oplus \text { } \odot \text { O }\end{array}$ \\
\hline $\begin{array}{l}\text { Punto de buena } \\
\text { práctica }\end{array}$ & $\begin{array}{l}\text { En fístulas complejas debe realizarse drenaje } \\
\text { quirúrgico de abscesos antes de iniciar el } \\
\text { tratamiento médico con anti-FNT. }\end{array}$ \\
\hline $\begin{array}{l}\text { Punto de buena } \\
\text { práctica }\end{array}$ & $\begin{array}{l}\text { Se debe retirar el setón de drenaje una vez } \\
\text { se controle la infección, para permitir el cierre } \\
\text { de la fístula perianal. }\end{array}$ \\
\hline $\begin{array}{l}\text { Punto de buena } \\
\text { práctica }\end{array}$ & $\begin{array}{l}\text { Los pacientes con enfermedad de } \\
\text { Crohn perianal requieren de manejo } \\
\text { multidisciplinario con coloproctología. }\end{array}$ \\
\hline Débil a favor & $\begin{array}{l}\text { Se sugiere el uso de tacrólimus para el } \\
\text { tratamiento de la enfermedad de Crohn } \\
\text { fistulizante en pacientes refractarios } \\
\text { al tratamiento con terapia biológica y } \\
\text { antibióticos. } \\
\text { Calidad de la evidencia muy baja } \oplus \text { }\end{array}$ \\
\hline Fuerte en contra & $\begin{array}{l}\text { No se recomienda el uso de pegantes de } \\
\text { fibrina en el tratamiento de los pacientes con } \\
\text { enfermedad de Crohn perianal. } \\
\text { Calidad de la evidencia muy baja } \oplus \text { ○০০ }\end{array}$ \\
\hline Débil a favor & $\begin{array}{l}\text { Se sugiere el abordaje transrectal o } \\
\text { transvaginal para el cierre de las fístulas } \\
\text { rectovaginales en las pacientes con } \\
\text { enfermedad de Crohn. } \\
\text { Calidad de la evidencia muy baja } \oplus \text { ○০০ }\end{array}$ \\
\hline $\begin{array}{l}\text { Punto de buena } \\
\text { práctica }\end{array}$ & $\begin{array}{l}\text { Se debe escoger el abordaje transrectal } \\
\text { como primera alternativa para el cierre de las } \\
\text { fístulas rectovaginales. }\end{array}$ \\
\hline $\begin{array}{l}\text { Punto de buena } \\
\text { práctica }\end{array}$ & $\begin{array}{l}\text { No debe haber actividad endoscópica en el } \\
\text { recto durante al menos dos años, antes de } \\
\text { considerar realizar el cierre quirúrgico de la } \\
\text { fístula. }\end{array}$ \\
\hline Débil a favor & $\begin{array}{l}\text { Se sugiere la derivación fecal como terapia } \\
\text { de rescate en los pacientes con enfermedad } \\
\text { de Crohn perianal con falla al manejo } \\
\text { convencional médico y quirúrgico. } \\
\text { Calidad de la evidencia muy baja } \oplus \text { }\end{array}$ \\
\hline Débil a favor & $\begin{array}{l}\text { Se sugiere la aplicación de células madre } \\
\text { local para el manejo de los pacientes con } \\
\text { enfermedad de Crohn perianal refractaria al } \\
\text { tratamiento médico. } \\
\text { Calidad de la evidencia muy baja } \oplus \text { O০০ }\end{array}$ \\
\hline
\end{tabular}




\section{Resumen de la evidencia: generalidades}

\section{Uso de antibióticos}

Una revisión sistemática de la literatura (73) (puntaje AMSTAR 7/11) evaluó la efectividad del uso de antibióticos para inducir la remisión en los pacientes con fístulas perianales secundarias a EC. Todos los estudios permitieron el uso concomitante de otras intervenciones (inmunomoduladores) y fueron comparados bien sea contra placebo o contra tratamiento inmunomodulador solo o contra inmunomodulador más placebo. Como desenlace de efectividad reportado, se consideró la proporción de pacientes que logró mejoría clínica o remisión (CDAI $<150$ y/o disminución en CDAI $\geq 70$ o una reducción mayor al $50 \%$ en el número de las fístulas por al menos 4 semanas) durante el seguimiento. La revisión recuperó quince ensayos clínicos aleatorios para un total de 1407 participantes. Para el subgrupo de fístula perianales, se encontró que el uso de ciprofloxacina se asoció a la mejoría de las lesiones a corto plazo (RR: 1,64; IC 95\%: 1,16-2,32; 3 estudios, 63 pacientes) (73).

Calidad de la evidencia: baja $\oplus \oplus \mathbf{O}$

\section{Monoterapia con biológicos}

El ensayo clínico aleatorizado doble ciego ACCENT II (101) evaluó la eficacia y la seguridad del uso de infliximab comparado con placebo en pacientes con EC fistulizante que no habían recibido tratamiento previo con infliximab. Los participantes se distribuyeron en dos grupos, acorde con si experimentaron o no respuesta a la terapia inicial; a su vez, en cada uno de los grupos, los participantes fueron aleatorizados a recibir infliximab en $5 \mathrm{mg} / \mathrm{kg}$, cada 8 semanas, por 32 semanas adicionales, o a placebo. Los desenlaces de eficacia fueron medidos a través del índice de actividad de enfermedad de Crohn (CDAI), el período libre de drenaje por la fístula y la calidad de vida (medida con el cuestionario Inflammatory Bowel Disease Questionnaire), en tanto que la seguridad fue establecida mediante la frecuencia de eventos adversos. El tiempo de seguimiento fue de 54 semanas posterior al inicio de la terapia.

Como resultado, fueron aleatorizados 282 pacientes con una frecuencia de EC perianal fistulizante similar entre los grupos (82\% al 87\%). En el grupo de participantes que habían obtenido remisión a las 14 semanas, el estudio documentó que la terapia de mantenimiento con infliximab incrementó el período libre de drenaje en la fístula (40 semanas $v$ s. 14 semanas; $p<0,001)$ y el puntaje de calidad de vida (mediana de incremento infliximab 14 vs. mediana incremento placebo 4; $p=0,002$ ) al tiempo que redujo la probabilidad de experimentar recaídas ( $R R$ estimado: 0,66; IC 95\%: 0,5-0,88) (101).

Por otro lado, cuando se trató del grupo no respondedores, se pudo observar que continuar con la terapia con infliximab no se asoció a una mayor posibilidad de alcanzar la remisión clínica (RR estimado: 1,31; IC 95\%: 0,53$3,21)$. La frecuencia de eventos adversos serios no fue diferente entre los grupos (RR estimado: 0,6; IC 95\%: 0,35-1) al igual que tampoco lo fue la proporción de pacientes que requirieron abandonar el tratamiento (RR estimado: 0,43; IC 95\%: 0,15-1,2) (101).

\section{Calidad de la evidencia: muy baja $\oplus$ OO०}

\section{Terapia combinada anti-FNT más drenaje de setón comparados con monoterapia en pacientes con fístula perianal y enfermedad de Crohn}

Una revisión sistemática de la literatura (94) (puntaje AMSTAR 8/11) evaluó la efectividad del uso de la terapia combinada anti-FNT más drenaje de setón para el tratamiento de los pacientes con fístula perianal y EC. El medicamento administrado fue infliximab y tres de los cuatro estudios permitieron la administración de otros tratamientos médicos concomitantes. Los desenlaces evaluados fueron el cierre completo o parcial y la frecuencia de recurrencia de la fístula, con un rango de seguimiento de 4 meses a 30 meses.

La revisión recuperó tres estudios observacionales para un total de 293 participantes. Con base en esta revisión sistemática se pudo establecer que del $45 \%$ al $100 \%$ de los pacientes que recibieron terapia combinada presentaron cierre completo de la fístula, en contraste a un $17 \%$ a $70 \%$ de los que recibieron monoterapia con setón, y del $63 \%$ al $82 \%$ con anti-FNT. Por otra parte, cuando se trató de cierre parcial, los pacientes expuestos a terapia combinada mostraron un rango de efecto del $14 \%$ al $88 \%$ frente a un $20 \%$ a $72 \%$ con monoterapia de setón y del $27 \%$ con anti-FNT. Finalmente, cuando se trató de recurrencia de la fístula, esta se presentó en el $18 \%$ al $44 \%$ de los pacientes con terapia combinada frente a un $42 \%$ a $78 \%$ anti-FNT y del $42 \%$ con terapia de setón (94).

Calidad de la evidencia: muy baja $\oplus$ O००

\section{Tacrólimus}

Una revisión sistemática (102) (puntaje AMSTAR 7/11) evaluó la efectividad del uso de tacrólimus en pacientes con EC luminal o perianal. Como intervención de interés, los autores incluyeron estudios con administración oral, intravenosa o tópica y realizaron análisis de subgrupos de acuerdo con el sitio de presentación de la EC. Como desenlaces, los autores reportaron la mejoría clínica, definida como el cierre de al menos el 50\% de la fístula, la remisión, definida como el cierre completo de la lesión, y la frecuencia de eventos adversos.

Para la EC perianal, los autores detectaron un ensayo clínico aleatorizado de tacrólimus vía oral comparado con placebo (103). Este ensayo encontró diferencias a favor 
del uso del tacrólimus en cuanto a la frecuencia de mejoría clínica (OR ajustado: 7,74; IC 95\%: 1,28-46,8), sin documentar diferencias en la frecuencia de remisión ( $R R$ calculado: 1,19; IC 95\%: 0,18-7,74) o de eventos adversos serios (tacrólimus 5\% vs. placebo 0\%; $p=0,46)(102,103)$.

\section{Calidad de la evidencia: muy baja $\oplus$ O००}

\section{Pegante de fibrina versus tratamiento quirúrgico}

Una revisión sistemática con metaanálisis (104) (puntaje AMSTAR 7/11) evaluó la efectividad del uso de pegamento de fibrina para el manejo de los pacientes con EC perianal. La población incluida se caracterizó por tener fístulas de origen anal simples, complejas y transesfintéricas; los autores no reportaron información adicional sobre las características clínicas. En cuanto a las intervenciones realizadas, la revisión incluyó el uso de inyecciones de pegantes de fibrina ( 81 pacientes en total) frente a cualquier otra intervención quirúrgica (fistulotomía, dren de setón, avances de colgajos). Como desenlaces, los autores reportaron la recurrencia de la fístula y la incontinencia anal. La revisión incluyó 3 estudios ( 2 ensayos clínicos y 1 estudio con grupo control no aleatorizado) para un total de 311 participantes. No se encontraron diferencias estadísticamente significativas entre los grupos en términos de recurrencia de la fístula (OR: 0,33; IC 95\%: 0,03-3,66) o la frecuencia de incontinencia fecal (OR: 1,00; IC 95\%: 0,43-2,34) (104).

Calidad de la evidencia: muy baja $\oplus$ O००

\section{Colgajos rectovaginales en pacientes con fístulas perianales}

Una revisión sistemática de la literatura con metaanálisis (105) (puntaje AMSTAR 7/11) evaluó la efectividad y la seguridad de la aproximación transrectal comparada con la transvaginal para el tratamiento de las fístulas rectovaginales en pacientes con EC, sin otra especificación reportada por los autores. Como desenlaces, los autores consideraron el cierre primario de la fístula, el cierre secundario y la recurrencia de la fístula. La revisión incluyó 11 estudios no aleatorizados para un total de 224 procedimientos. No se encontraron diferencias significativas entre las aproximaciones en cuanto a la frecuencia de cierre primario (OR calculado: 1,02; IC 95\%: 0,33-3,21), cierre global (OR calculado: 1,14; IC 95\%: 0,45-2,91) o recurrencia (OR calculado: 0,36; IC 95\%: 0,03-3,84) (105).

Calidad de la evidencia: muy baja $\oplus 000$

\section{Derivación fecal en pacientes con enfermedad de Crohn perianal refractaria}

Una revisión sistemática de la literatura con metaanálisis de proporciones (106) (puntaje AMSTAR 9/11) determinó la efectividad de la derivación fecal temporal en pacientes con
EC perianal. Se incluyó población adulta y pediátrica con EC perianal con o sin enfermedad colónica. Como desenlace primario, los autores consideraron la proporción de restauración exitosa de la continuidad intestinal y como desenlaces secundarios se contempló la mejoría clínica temprana y la necesidad de cirugía adicional. La revisión incluyó 15 estudios no aleatorizados. De los pacientes que fueron sometidos a derivación fecal temporal, el 63,8\% (IC 95\%: 54\%-73\%; 373 pacientes) presentó respuesta clínica temprana; el 16.6\% tuvo continuidad intestinal exitosa luego de la derivación ( IC 95\%: 11,8\%-22,9\%; 15 estudios, 545 pacientes); el 26,5\% requirió una nueva derivación (IC 95\%: 14,1\%-44,2\%); y el 41,6\% fue llevado a proctocolectomía luego de la derivación (IC 95\%: 32,6\%-51,2\%) (106).

Calidad de la evidencia: muy baja $\oplus$ O००

\section{Terapia con células madre}

\section{Uso de células madre óseas, de tejido adiposo o hematopoyéticas}

Una revisión sistemática de la literatura con metaanálisis de proporciones (81) (puntaje AMSTAR 10/11) evaluó la eficacia y la seguridad de la terapia con células madre en pacientes con EC activa. Como intervenciones, los autores consideraron el uso de células madre mesenquimales provenientes de médula ósea, tejido adiposo o hematopoyéticas; como desenlaces estimaron la eficacia clínica, definida como la respuesta o la remisión clínica, la curación de la fístula, la frecuencia de eventos adversos, la remisión endoscópica y la recurrencia clínica.

La revisión recuperó, para EC perianal, 13 estudios prospectivos experimentales. Cuando se realizó el análisis de subgrupos de acuerdo con el tipo celular usado, se encontró que los pacientes que recibieron células de médula ósea presentaron una respuesta clínica del 59\% (IC 95\%: 34\%-80\%; 6 estudios) con una probabilidad de cierre de la fístula del 60\% (IC 95\%: 44\%-75\%). Por otro lado, las poblaciones tratadas con células provenientes de tejido adiposo lograron una respuesta clínica del 56\% (IC 95\%: 13\%$88 \%$ ), con un $23 \%$ de remisión clínica (IC 95\%: 7\%-54\%; 4 estudios). En los pacientes en quienes se usaron células hematopoyéticas, se encontró un $73 \%$ de remisión clínica (IC 95\%: 36\%-93\%; 4 estudios) y una frecuencia de eventos adversos del 35\% (IC 95\%: 5\%-86\%) (81).

En cuanto al análisis de la vía de administración, los pacientes que recibieron tratamiento sistémico para el manejo de la enfermedad perianal presentaron un $29 \%$ de curación de la fístula (IC 95\%: 3\%-85\%), mientras que los pacientes que recibieron células madre de forma local tuvieron una frecuencia de curación de la fístula del $60 \%$ (IC 95\%: 47\%-72\%) (81). 


\section{Células madre mesenquimales estromales} comparadas contra placebo para el tratamiento de las fístulas en enfermedad de Crohn

Una revisión sistemática con metaanálisis (107) (puntaje AMSTAR 7/11) evaluó la eficacia del uso de células madre mesenquimales comparadas frente a placebo para el tratamiento de las fístulas asociadas a la EC. La revisión incluyó estudios comparativos en pacientes con enfermedad activa (puntaje promedio CDAI $<450$ en presencia de fístulas) y el desenlace evaluado fue la frecuencia de curación de la fístula, sin contemplar los desenlaces de seguridad. Los autores compilaron 14 estudios con un total de 477 pacientes. Basados en este estudio, se pudo establecer que los pacientes asignados a la terapia con células madre experimentaron una menor proporción de fístula persistente (OR: 0,21; IC 95\%: 0,09-0,32) (107).

Calidad de la evidencia: muy baja $\oplus$ $\bigcirc$ ००

Una segunda revisión sistemática incluyó 11 estudios que cumplieron los criterios de inclusión e incluyeron solo 3 estudios con grupo control para el metaanálisis. La terapia con células madre mesenquimales se asoció a una mayor cicatrización clínica de las fístulas perianales comparada con los sujetos controles a las 6 y 24 semanas (OR: 3,06; IC $95 \%: 1,05-8,90 ; p=0,04)$ y a las 24 y 52 semanas (OR: 2,37; IC 95\%: 0,90-6,25; $p=0,08)$. No hubo incremento en los eventos adversos (OR: 1,07; IC 95\%: 0,61-1,89; $p=$ 0.81 ), ni en los eventos adversos serios (OR: 0,53; IC 95\%: $0,28-0,98 ; p=0,04)$ en los pacientes tratados con células madre mesenquimales (108).

\section{Eficacia de la terapia médica para enfermedad de Crohn fistulizante}

Una revisión sistemática de 21 estudios en EC fistulizante encontró una calidad de la evidencia moderada que soporta la eficacia de anti-FNT (RR: 2,01; IC 95\%: 1,362,97), particularmente infliximab, ustekinumab (RR, 1,77; IC 95\%: 0,93-3,37) y terapia con células madre mesenquimales (RR: 1,31; IC 95\%: 0,98-1,73) para la inducción de la remisión de las fístulas. Los autores encontraron baja calidad de la evidencia para vedolizumab e inmunosupresores. Para el mantenimiento de la remisión, se encontró una calidad de la evidencia moderada para los anti-FNT comparados con placebo (RR: 1,94; IC 95\%: $1,25-3,02 ; p=0,003)(109)$.

\section{De la evidencia a la recomendación}

\begin{tabular}{|c|c|c|c|c|c|c|}
\hline \multirow[b]{2}{*}{ Problema } & \multicolumn{6}{|c|}{ Juicio de valor } \\
\hline & No & Probablemente no & Probablemente sí & Sí & Varía & No se conoce \\
\hline Efectos deseables & Triviales & Pequeños & Moderados & Grandes & Varía & No se conoce \\
\hline Efectos no deseados & Triviales & Pequeños & Moderados & Grandes & Varía & No se conoce \\
\hline Confianza en la evidencia & Muy baja & Baja & Moderada & Alta & & $\begin{array}{c}\text { No se encontró } \\
\text { evidencia }\end{array}$ \\
\hline Variabilidad & Alta incertidumbre & $\begin{array}{l}\text { Importante } \\
\text { variabilidad }\end{array}$ & $\begin{array}{l}\text { Variabilidad no } \\
\text { importante }\end{array}$ & $\begin{array}{l}\text { No se presenta } \\
\text { variabilidad }\end{array}$ & & No se conoce \\
\hline Balance de los efectos & $\begin{array}{l}\text { Favorece la } \\
\text { comparación }\end{array}$ & $\begin{array}{c}\text { Probablemente } \\
\text { favorece la } \\
\text { comparación }\end{array}$ & $\begin{array}{l}\text { No favorece } \\
\text { ninguna } \\
\text { intervención }\end{array}$ & $\begin{array}{c}\text { Probablemente } \\
\text { favorece la } \\
\text { intervención }\end{array}$ & $\begin{array}{l}\text { Favorece la } \\
\text { intervención }\end{array}$ & No se conoce \\
\hline $\begin{array}{l}\text { Calidad global de la } \\
\text { evidencia }\end{array}$ & Muy baja & Baja & Moderada & Alta & & $\begin{array}{c}\text { No se encontró } \\
\text { evidencia }\end{array}$ \\
\hline Equidad & Reducida & $\begin{array}{l}\text { Probablemente se } \\
\text { reduzca }\end{array}$ & $\begin{array}{c}\text { Probablemente no } \\
\text { tenga impacto }\end{array}$ & $\begin{array}{c}\text { Probablemente se } \\
\text { aumente }\end{array}$ & Se aumenta & No se conoce \\
\hline $\begin{array}{l}\text { Aceptabilidad de los } \\
\text { usuarios }\end{array}$ & No & Probablemente no & Probablemente sí & Sí & Varía & No se conoce \\
\hline $\begin{array}{l}\text { Factibilidad de la } \\
\text { implementación }\end{array}$ & No & Probablemente no & Probablemente sí & Sí & Varía & No se conoce \\
\hline
\end{tabular}




\section{PREGUNTA 6. ¿CUÁLES SON LAS INTERVENCIONES MÁS SEGURAS Y EFECTIVAS PARA EL ABORDAJE QUIRÚRGICO Y ENDOSCÓPICO DE LOS PACIENTES MAYORES DE 16 AÑOS CON ENFERMEDAD DE CROHN?}

\section{Lista de recomendaciones}

\begin{tabular}{|c|c|}
\hline Recomendación $n .^{\circ}$ & Resumen \\
\hline Débil a favor & $\begin{array}{l}\text { Se sugiere no contraindicar el procedimiento } \\
\text { quirúrgico en los pacientes con enfermedad } \\
\text { de Crohn que reciben terapia biológica. } \\
\text { Calidad de la evidencia muy baja } \oplus \text { ○૦० }\end{array}$ \\
\hline Débil a favor & $\begin{array}{l}\text { Se sugiere continuar la azatioprina previo al } \\
\text { procedimiento quirúrgico en pacientes con } \\
\text { enfermedad de Crohn. } \\
\text { Calidad de la evidencia muy baja } \oplus \text { ○০০ }\end{array}$ \\
\hline $\begin{array}{l}\text { Punto de buena } \\
\text { práctica }\end{array}$ & $\begin{array}{l}\text { Si el procedimiento es diferible, se debe } \\
\text { realizar la intervención quirúrgica antes } \\
\text { del inicio de la siguiente dosis de terapia } \\
\text { biológica. }\end{array}$ \\
\hline $\begin{array}{l}\text { Punto de buena } \\
\text { práctica }\end{array}$ & $\begin{array}{l}\text { Se debe vigilar la posibilidad de infecciones } \\
\text { en el período postoperatorio. }\end{array}$ \\
\hline Débil a favor & $\begin{array}{l}\text { Se sugiere el tratamiento quirúrgico en } \\
\text { pacientes con abscesos intraabdominales } \\
\text { asociados a enfermedad de Crohn, solo en } \\
\text { caso de no respuesta al tratamiento médico } \\
\text { y/o radiológico inicial. } \\
\text { Calidad de la evidencia muy baja } \oplus \text { ○০০ }\end{array}$ \\
\hline $\begin{array}{l}\text { Punto de buena } \\
\text { práctica }\end{array}$ & $\begin{array}{l}\text { Los abscesos menores de } 3 \mathrm{~cm} \text { deben recibir } \\
\text { solo tratamiento antibiótico. Los pacientes } \\
\text { con abscesos mayores de } 3 \mathrm{~cm} \text { requieren, } \\
\text { adicionalmente, drenaje radiológico } \\
\text { percutáneo. }\end{array}$ \\
\hline $\begin{array}{l}\text { Punto de buena } \\
\text { práctica }\end{array}$ & $\begin{array}{l}\text { En caso de no respuesta al tratamiento médico } \\
\text { o de que los abscesos no puedan ser drenados } \\
\text { percutáneamente (tabicados o de difícil acceso), } \\
\text { se debe realizar tratamiento quirúrgico. }\end{array}$ \\
\hline Fuerte a favor & $\begin{array}{l}\text { Se recomienda el uso de la dilatación } \\
\text { neumática endoscópica con balón en } \\
\text { los pacientes con estenosis asociadas a } \\
\text { enfermedad de Crohn. } \\
\text { Calidad de la evidencia muy baja } \oplus \text { ○০০ }\end{array}$ \\
\hline $\begin{array}{l}\text { Punto de buena } \\
\text { práctica }\end{array}$ & $\begin{array}{l}\text { Se consideran indicaciones de dilatación } \\
\text { neumática endoscópica: } \\
\text { - longitud de la estenosis menor de } 4 \mathrm{~cm} \text {; } \\
\text { - presencia de estenosis en íleon terminal o } \\
\text { en la anastomosis ileocólica; } \\
\text { - estenosis únicas. }\end{array}$ \\
\hline $\begin{array}{l}\text { Punto de buena } \\
\text { práctica }\end{array}$ & $\begin{array}{l}\text { La presencia de fístulas o abscesos } \\
\text { en el área de la estenosis representa } \\
\text { una contraindicación para la dilatación } \\
\text { endoscópica. }\end{array}$ \\
\hline
\end{tabular}

\begin{tabular}{|ll}
\hline $\begin{array}{l}\text { Punto de buena } \\
\text { práctica }\end{array}$ & $\begin{array}{l}\text { Se debe intentar determinar por imágenes } \\
\text { diagnósticas si el componente de la estenosis } \\
\text { es fibrótico o inflamatorio. }\end{array}$ \\
\hline Fuerte a favor & $\begin{array}{l}\text { Se recomienda realizar la estricturoplastia } \\
\text { en pacientes con enfermedad de Crohn } \\
\text { estenosante de intestino delgado. } \\
\text { Calidad de la evidencia muy baja } \oplus \text { O०० }\end{array}$ \\
\hline Punto de buena & $\begin{array}{l}\text { La estricturoplastia es altamente } \\
\text { recomendable en pacientes con estenosis } \\
\text { múltiples, menores de 10 cm, para evitar } \\
\text { las resecciones extensas del intestino } \\
\text { delgado y disminuir el riesgo de síndrome de } \\
\text { intestino corto. Esta debe ser realizada por } \\
\text { especialistas con experiencia en este tipo de } \\
\text { patología. }\end{array}$ \\
\hline Se sugiere la laparoscopia o la cirugía \\
punterta para el tratamiento quirúrgico de los \\
práctica
\end{tabular}

Resumen de la evidencia: generalidades

\section{Medicamentos biológicos y frecuencia de complicaciones postoperatorias en pacientes con enfermedad inflamatoria intestinal}

Una revisión sistemática de la literatura (110) (puntaje AMSTAR 9/11) evaluó la frecuencia de complicaciones postoperatorias en pacientes con EC sometidos a cirugía abierta o laparoscópica, que recibieron anti-FNT durante los tres meses previos a la intervención. De los estudios incluidos, 11 de ellos reclutaron pacientes exclusivamente con EC y 3 de ellos, pacientes con cualquier tipo de enfermedad inflamatoria intestinal. En esta oportunidad, los desenlaces reportados fueron la frecuencia de complicaciones 
relacionadas con la anastomosis (presencia de dehiscencia, fístula, absceso intraabdominal o desarrollo de fístula entérica), la proporción de pacientes que presentaron una complicación médica mayor (definida como que amenaza la vida o que requiere hospitalización e incluye patología trombótica, renal o cardiovascular) o menor (infección de sitio operatorio, íleo prolongado, adherencias, sangrado gástrico o dehiscencia de la herida), la necesidad de reintervención quirúrgica y, finalmente, la mortalidad asociada.

La revisión recuperó 13 estudios observacionales, para un total de 2046 pacientes. Nueve de los estudios incluidos administraron infliximab, en tanto que cuatro proporcionaron adalimumab o certolizumab. La totalidad de los participantes recibieron de forma concomitante esteroides e inmunomoduladores. Fundamentado en los hallazgos de esta revisión, se pudo documentar que la administración de medicamentos biológicos durante los meses previos a la intervención no se asoció a una mayor o menor frecuencia de complicaciones relacionadas con la anastomosis (OR: 0,91; IC 95\%: 0,56-1,47) o de reintervención quirúrgica (OR: 1,09; IC 95\%: 0,61-1,95), pero sí de complicaciones médicas mayores (OR: 1,97; IC 95\%: 1,23-3,14) y menores (OR: 1,40; IC 95\%: 1,05-1,85). No obstante, la frecuencia de estos eventos adversos no se acompañó de un incremento de la mortalidad (OR: 4,80; IC 95\%: 0,66-34,82) (110).

Calidad de la evidencia: muy baja $\oplus$ O००

Una revisión sistemática evaluó el efecto del tiempo de la infusión de anti-FNT previo a la cirugía y el riesgo de infección en el sitio quirúrgico en el postoperatorio. Veintisiete estudios fueron incluidos y no se encontraron diferencias significativas en infecciones en la herida quirúrgica, formación de abscesos, ni en filtración de anastomosis en pacientes con EC cuando se aplicó el anti-FNT en las 4, 8 o 12 semanas previas a la cirugía, en comparación con los grupos controles (111).

\section{Inmunomoduladores previos a una resección intestinal en pacientes con enfermedad de Crohn y riesgo de complicaciones}

Una revisión sistemática de la literatura (112) (puntaje AMSTAR 7/11) evaluó la seguridad del uso de inmunomoduladores previos a la resección intestinal en pacientes con EC. En 14 de los estudios incluidos, los participantes recibieron anti-FNT; en 13, recibieron corticoides; en 8 , recibieron tiopurinas; y en 6 , recibieron el uso concomitante de dos inmunosupresores, durante los 3 meses previos a la intervención. El desenlace de interés para esta revisión fue la proporción de pacientes con infección postoperatoria, definida como la presencia de un foco infeccioso en tejidos blandos o el desarrollo de dehiscencia en la herida, o bien, tener un diagnóstico de absceso intraabdominal, sepsis, neumonía, peritonitis o bacteriemia.

La revisión recuperó 21 estudios observacionales tipo cohorte y de casos y controles, para un total de 648 pacientes. Basados en esta revisión sistemática, se pudo establecer que el uso previo de anti-FNT, así como de corticoides, incrementó la proporción de pacientes que experimentaron infección postoperatoria (RR: 1,42; IC 95\%: 1,05-1,92; y RR: 1,45; IC 95\%: 1,01-2,08; para anti-FNT y corticoides, respectivamente). No obstante, esto no se observó cuando se trató del uso de tiopurinas (RR: 1,23; IC 95\%: 0,66$2,29)$. Estos hallazgos permanecieron constantes cuando se realizó el análisis de subgrupos, excluyendo los estudios que reclutaron a los pacientes con enfermedad inflamatoria intestinal diferente a EC (RR: 1,31; IC 95\%: 1,06-1,64, para anti-FNT; y RR: 1,45; IC 95\%: 1,13-1,87, para corticoides) (112).

Calidad de la evidencia: muy baja $\oplus 000$

\section{Tratamiento quirúrgico versus manejo médico en abscesos intrabdominales}

Una revisión sistemática con metaanálisis (113) (puntaje AMSTAR 5/11) evaluó la efectividad del manejo médico (antibióticos o antibióticos y drenaje percutáneo) comparado contra el abordaje quirúrgico (laparotomía con o sin resección intestinal) en pacientes con abscesos intrabdominales secundarios a EC. La revisión no especificó la localización de la enfermedad, ni documentó el tipo de antibiótico o la distribución de las técnicas quirúrgicas usadas. En cuanto a los desenlaces, los autores evaluaron la resolución del absceso, el tiempo de mejoría, el número de pacientes que requirieron la realización de estomas y la estancia hospitalaria; el período de seguimiento de los estudios fue de al menos 1 año, excepto en un estudio, en el cual el seguimiento fue de 3 meses.

La revisión encontró 9 estudios observacionales retrospectivos. Los autores reportaron diferencias a favor del tratamiento quirúrgico en la resolución de los abscesos (OR: 3,44; IC 95\%: 1,8-6,58) y en la mejoría antes del año (OR: 4,58; IC 95\%: 2,02-10,36). En cuanto a la necesidad de crear estomas, el grupo que fue sometido a tratamiento quirúrgico tuvo una mayor frecuencia en comparación con el tratamiento médico (OR: 3,35; IC 95\%: 1,43-7,87). Para el desenlace de estancia hospitalaria, los autores indicaron de forma descriptiva que esta fue menor en el grupo que recibió tratamiento médico (datos cuantitativos no proporcionados) (113).

Calidad de la evidencia: muy baja $\oplus$ O०० 


\section{Dilatación neumática endoscópica \\ en enfermedad de Crohn}

Una revisión sistemática de la literatura con metaanálisis de proporciones (114) (puntaje AMSTAR 8/11) evaluó la efectividad de la dilatación neumática endoscópica en pacientes adultos con ROHN estenosante. La revisión no reportó la distribución anatómica de la enfermedad e incluyó un total de 1089 pacientes con 790 estenosis y la realización de 2664 dilataciones. Como desenlaces, los autores consideraron la respuesta sintomática y endoscópica y la presencia de complicaciones postoperatorias. La mediana de seguimiento fue de 83,5 meses (rango de 12 a 172 meses). Como resultados, la revisión incluyó 25 estudios, de los cuales, 16 incluyeron como desenlace la respuesta sintomática, cuya frecuencia agrupada fue del 70,2\% (IC 95\%: 60\%-78,8\%); en cuanto a la respuesta endoscópica, esta fue del 90,6\% (IC 95\%: 87,8\%-92,8\%; 22 estudios) y la tasa de perforación fue del 3\% (IC 95\%: 2,2\%-4\%) (114).

Calidad de la evidencia: muy baja $\oplus$ $\bigcirc 00$

\section{Plastia de la estenosis (estricturoplastia) versus resección intestinal en pacientes con enfermedad de Crohn de intestino delgado}

Una revisión sistemática con metaanálisis (115) (puntaje AMSTAR 8/11) evaluó la efectividad y la seguridad de la estricturoplastia de la estenosis (strictureplasty) comparada con la resección intestinal con o sin dilatación en pacientes con EC de intestino delgado, sin otra especificación. Como desenlaces de efectividad, los autores evaluaron la recurrencia quirúrgica y médica; como desenlaces de seguridad, la obstrucción intestinal, la hemorragia, las complicaciones infecciosas y las complicaciones globales. La revisión logró identificar siete estudios no aleatorizados que reclutaron población pediátrica $y$ adulta. En el tiempo libre de recurrencia, los autores encontraron diferencias a favor de la estricturoplastia (HR: 1,08; IC 95\%: 1,02-1,15), sin documentar diferencias en la recurrencia global (OR: 1,36; IC 95\%: 0,96-1,93) o en la frecuencia de complicaciones globales (OR: 0,60; IC 95\%: 0,31-1,16). Tampoco se encontraron diferencias entre los grupos para los desenlaces de recurrencia quirúrgica y médica (OR: 1,36; IC 95\%: 0,96-1,93), obstrucción intestinal (OR: 0,8; IC 95\%: 0,09-1,93), hemorragia (OR: 0,51; IC 95\%: 0,13-2,0) o sepsis (OR: 0,67; IC 95\%: 0,27-1,67) (115).

\section{Calidad de la evidencia: muy baja $\oplus 000$}

\section{Laparoscopia versus cirugía abierta}

Una revisión sistemática (116) (puntaje AMSTAR 10/11) evaluó la efectividad y las tasas de reoperación y recurrencia asociadas al uso de laparoscopia en comparación con la técnica abierta en pacientes con EC localizada en intestino delgado. Los pacientes incluidos fueron mayores de 16 años sometidos a cirugía electiva con resección ileocólica y anastomosis o resección de intestino delgado más anastomosis o estricturoplastia de estenosis intestinales (strictureplasty). Los autores consideraron como desenlaces primarios la morbilidad perioperatoria y la reintervención por recurrencia de la enfermedad; como desenlaces secundarios, el dolor postoperatorio, la duración del íleo, la estancia hospitalaria postoperatoria, la duración del procedimiento, la pérdida sanguínea, la mortalidad y la tasa de conversión. La mediana de seguimiento de los estudios estuvo entre 3 meses luego de la cirugía y los 10,9 años. La revisión encontró 4 ensayos clínicos aleatorizados con un total de 120 pacientes. En los análisis agrupados, no se encontraron diferencias estadísticamente significativas en la tasa de infecciones (OR: 0,25; IC 95\%: 0,03-2,39), de fugas en las anastomosis (OR: 0,97; IC 95\%: 0,13-6,98), de abscesos intrabdominales (OR: 0,19; IC 95\%: 0,11-74,12), la tasa de reintervención a 30 días (OR: 0,57; IC 95\%: 0,07-4,46) o a largo plazo (OR: 0,85; IC 95\%. 0,32-2,27). Tampoco se encontraron diferencias en la estancia hospitalaria (OR: 0,7; IC 95\%: 0,28-1,73), el íleo (OR: 0,55; IC 95\%: 0,13-2,43), las pérdidas sanguíneas (cirugía: $133 \pm 70 \mathrm{~mL}$ versus laparoscopia: $173 \pm 123 \mathrm{~mL}$; $p=0,25)$. Se encontró una tasa de conversión menor al $3 \%$ y no se reportaron casos de muerte en los estudios (116).

Calidad de la evidencia: muy baja $\oplus$ O००

\section{Tipos de anastomosis en resección ileocólica}

Una revisión sistemática con metaanálisis (117) (puntaje AMSTAR 8/11) evaluó la efectividad y la seguridad de la anastomosis laterolateral comparada con la terminoterminal en pacientes con EC sometidos a resección ileocólica. Como desenlaces, la revisión evaluó la frecuencia de complicaciones, la estancia hospitalaria, la mortalidad, la recurrencia y la necesidad de reintervención. La revisión incluyó tres ensayos clínicos aleatorizados y cinco estudios no aleatorizados para un total de 821 pacientes. En cuanto a la frecuencia de las complicaciones, los autores encontraron diferencias a favor de la anastomosis laterolateral (complicaciones globales: OR: 0,54; IC 95\%: 0,32-0,93), sin que estas diferencias fueran significativas al ser desagrupadas en fuga de la anastomosis, infección de la herida, embolismo pulmonar, absceso intrabdominal, obstrucción o estenosis intestinal. En cuanto a la recurrencia, la revisión encontró diferencias estadísticamente significativas a favor de la anastomosis laterolateral (OR: 0,20; IC 95\%: 0,070,55 ), al igual que en la frecuencia de reintervenciones (OR: 0,18 ; IC 95\%: 0,07-0,45). No se encontraron diferencias en los días de estancia hospitalaria (diferencia ponderada de medias: $-0,59$; IC 95\%: $-1,87$ a 0,68$)$ ni en el riesgo de mortalidad (OR: 1,94; IC 95\%: 0,30-12,48) (117).

Calidad de la evidencia: muy baja $\oplus 000$ 


\section{Resección quirúrgica en pacientes con enfermedad de Crohn localizada del colon}

Una revisión sistemática con metaanálisis (118) (puntaje AMSTAR 7/11) evaluó la efectividad y la seguridad de la colectomía segmentaria comparada con la colectomía subtotal o total en pacientes con EC colónica. La revisión reclutó a los pacientes con diagnóstico de EC, definida por los criterios de Price y Morson, con compromiso inicial de colon de forma exclusiva o enfermedad activa en colon, e incluyó población pediátrica y adulta. Uno de los estudios incluyó pacientes con enfermedad ileocolónica. Como desenlaces de interés, los autores consideraron recurrencia quirúrgica, recurrencia global, complicaciones postoperatorias y necesidad de realizar un estoma permanente. La revisión logró identificar 6 estudios observacionales comparativos, los cuales no reportaron diferencias entre las intervenciones para recurrencia quirúrgica (OR: 1,08; IC 95\%: 0,39-2,95), recurrencia global (OR: 1,01; IC 95\%: 0,49-2,06), complicaciones postoperatorias (OR: 1,43; IC 95\%: 0,16-12,74) o en la necesidad de un estoma permanente (OR: 2,75; IC 95\%: 0,78-9,71) (118).

Calidad de la evidencia: muy baja $\oplus$ O००

\section{De la evidencia a la recomendación}

\begin{tabular}{|c|c|c|c|c|c|c|}
\hline & \multicolumn{6}{|c|}{ Juicio de valor } \\
\hline Problema & No & Probablemente no & Probablemente sí & Sí & Varía & No se conoce \\
\hline Efectos deseables & Triviales & Pequeños & Moderados & Grandes & Varía & No se conoce \\
\hline Efectos no deseados & Triviales & Pequeños & Moderados & Grandes & Varía & No se conoce \\
\hline $\begin{array}{l}\text { Confianza en la } \\
\text { evidencia }\end{array}$ & Muy baja & Baja & Moderada & Alta & & $\begin{array}{c}\text { No se encontró } \\
\text { evidencia }\end{array}$ \\
\hline Variabilidad & Alta incertidumbre & $\begin{array}{l}\text { Importante } \\
\text { variabilidad }\end{array}$ & $\begin{array}{l}\text { Variabilidad no } \\
\text { importante }\end{array}$ & $\begin{array}{l}\text { No se presenta } \\
\text { variabilidad }\end{array}$ & & No se conoce \\
\hline Balance de los efectos & $\begin{array}{l}\text { Favorece la } \\
\text { comparación }\end{array}$ & $\begin{array}{c}\text { Probablemente } \\
\text { favorece la } \\
\text { comparación }\end{array}$ & $\begin{array}{l}\text { No favorece } \\
\text { ninguna } \\
\text { intervención }\end{array}$ & $\begin{array}{l}\text { Probablemente } \\
\text { favorece la } \\
\text { intervención }\end{array}$ & $\begin{array}{l}\text { Favorece la } \\
\text { intervención }\end{array}$ & No se conoce \\
\hline $\begin{array}{l}\text { Calidad global de la } \\
\text { evidencia }\end{array}$ & Muy baja & Baja & Moderada & Alta & & $\begin{array}{c}\text { No se encontró } \\
\text { evidencia }\end{array}$ \\
\hline Equidad & Reducida & $\begin{array}{l}\text { Probablemente se } \\
\text { reduzca }\end{array}$ & $\begin{array}{l}\text { Probablemente no } \\
\text { tenga impacto }\end{array}$ & $\begin{array}{c}\text { Probablemente se } \\
\text { aumente }\end{array}$ & Se aumenta & No se conoce \\
\hline $\begin{array}{l}\text { Aceptabilidad de los } \\
\text { usuarios }\end{array}$ & No & Probablemente no & Probablemente sí & Sí & Varía & No se conoce \\
\hline $\begin{array}{l}\text { Factibilidad de la } \\
\text { implementación }\end{array}$ & No & Probablemente no & Probablemente sí & Sí & Varía & No se conoce \\
\hline
\end{tabular}




\section{PREGUNTA 7. ¿CUÁLES SON LAS INTERVENCIONES MÁS SEGURAS Y EFECTIVAS PARA PREVENIR LA RECURRENCIA EN LOS PACIENTES MAYORES DE 16 AÑOS CON ENFERMEDAD DE CROHN POSQUIRÚRGICA?}

\section{Lista de recomendaciones}

\begin{tabular}{|c|c|}
\hline Recomendación $n .^{\circ}$ & Resumen \\
\hline Fuerte en contra & $\begin{array}{l}\text { No se recomienda el uso de probióticos para } \\
\text { prevenir la recurrencia de la enfermedad de } \\
\text { Crohn posquirúrgica. } \\
\text { Calidad de la evidencia muy baja } \oplus \text { ○০০ }\end{array}$ \\
\hline $\begin{array}{l}\text { Punto de buena } \\
\text { práctica }\end{array}$ & $\begin{array}{l}\text { En todo paciente con enfermedad de } \\
\text { Crohn sometido a resección quirúrgica se } \\
\text { debe identificar la presencia de factores de } \\
\text { riesgo para la recaída posquirúrgica, con el } \\
\text { ánimo de implementar las intervenciones } \\
\text { farmacológicas preventivas. } \\
\text { - factores de alto riesgo: edad }<30 \text { años, } \\
\text { tabaquismo, }>2 \text { cirugías por EC penetrante } \\
\text { (B3); } \\
\text { - factores de bajo riesgo: edad }>50 \text { años, no } \\
\text { fumadores, primera cirugía, estenosis corta } \\
<10-20 \mathrm{~cm} \text {, duración EC }>10 \text { años. }\end{array}$ \\
\hline
\end{tabular}

Punto de buena Se debe realizar ileocolonoscopia de 6 a 12 práctica meses después de la cirugía para identificar la recaída endoscópica.

\begin{tabular}{|c|c|}
\hline Débil a favor & $\begin{array}{l}\text { Se sugiere el uso de antibióticos para } \\
\text { prevenir la recurrencia de la enfermedad de } \\
\text { Crohn posquirúrgica. } \\
\text { Calidad de la evidencia baja } \oplus \oplus \bigcirc \bigcirc\end{array}$ \\
\hline $\begin{array}{l}\text { Punto de buena } \\
\text { práctica }\end{array}$ & $\begin{array}{l}\text { El antibiótico que se debe utilizar es } \\
\text { metronidazol, en dosis de } 15 \text { a } 20 \mathrm{mg} / \mathrm{kg} \text {, } \\
\text { por un tiempo de } 3 \text { meses. Cuando se use } \\
\text { este medicamento, se debe monitorizar } \\
\text { estrechamente la tolerancia y la aparición de } \\
\text { eventos adversos, especialmente neuropatía } \\
\text { periférica. }\end{array}$ \\
\hline $\begin{array}{l}\text { Punto de buena } \\
\text { práctica }\end{array}$ & $\begin{array}{l}\text { En pacientes de bajo riesgo, se recomienda } \\
\text { un curso de } 3 \text { meses con metronidazol } \\
\text { o hacer una monitorización estrecha sin } \\
\text { medicamentos en casos de intolerancia. }\end{array}$ \\
\hline $\begin{array}{l}\text { Punto de buena } \\
\text { práctica }\end{array}$ & $\begin{array}{l}\text { En todo paciente con enfermedad de Crohn } \\
\text { que haya sido intervenido quirúrgicamente se } \\
\text { debe evitar el consumo de tabaco. }\end{array}$ \\
\hline Débil a favor & $\begin{array}{l}\text { Se sugiere el uso de azatioprina o } \\
6 \text {-mercaptopurina para prevenir la recurrencia } \\
\text { en pacientes con enfermedad de Crohn } \\
\text { posquirúrgica. } \\
\text { Calidad de la evidencia muy baja } \oplus \text { ○০০ }\end{array}$ \\
\hline
\end{tabular}

\begin{tabular}{|c|c|}
\hline $\begin{array}{l}\text { Punto de buena } \\
\text { práctica }\end{array}$ & $\begin{array}{l}\text { En pacientes de alto riesgo de recaída, las } \\
\text { tiopurinas pueden usarse concomitantemente } \\
\text { con anti-FNT, con o sin metronidazol, durante } \\
\text { los primeros } 3 \text { meses. Se debe monitorizar la } \\
\text { tolerancia al medicamento. }\end{array}$ \\
\hline Débil a favor & $\begin{array}{l}\text { Se sugiere el uso de } 5 \text {-ASA para prevenir } \\
\text { la recurrencia clínica en pacientes con } \\
\text { enfermedad de Crohn posquirúrgica. } \\
\text { Calidad de la evidencia baja } \oplus \oplus \bigcirc \bigcirc\end{array}$ \\
\hline $\begin{array}{l}\text { Punto de buena } \\
\text { práctica }\end{array}$ & $\begin{array}{l}\text { El uso de mesalazina debe considerarse } \\
\text { solo en pacientes de bajo riesgo de recaída } \\
\text { posquirúrgica o en aquellos que tengan } \\
\text { contraindicación absoluta o relativa para } \\
\text { tiopurinas o anti-FNT. }\end{array}$ \\
\hline Débil en contra & $\begin{array}{l}\text { No se sugiere el uso de budesonida para } \\
\text { prevenir la recurrencia en pacientes con } \\
\text { enfermedad de Crohn posquirúrgica. } \\
\text { Calidad de la evidencia baja } \oplus \oplus \bigcirc \bigcirc\end{array}$ \\
\hline Débil a favor & $\begin{array}{l}\text { Se sugiere el uso de anti-FNT como terapia } \\
\text { de primera línea para prevenir la recurrencia } \\
\text { endoscópica en pacientes con enfermedad de } \\
\text { Crohn posquirúrgica de alto riesgo. } \\
\text { Calidad de la evidencia baja } \oplus \oplus \bigcirc \bigcirc\end{array}$ \\
\hline $\begin{array}{l}\text { Punto de buena } \\
\text { práctica }\end{array}$ & $\begin{array}{l}\text { En pacientes con alto riesgo de recurrencia } \\
\text { se recomienda iniciar el tratamiento durante } \\
6 \text { meses con anti-FNT } \pm \text { tiopurinas, si no hay } \\
\text { contraindicación, asociado o no a terapia con } \\
\text { metronidazol ( } 3 \text { meses). }\end{array}$ \\
\hline Fuerte a favor & $\begin{array}{l}\text { Se recomienda el uso de medicamentos anti- } \\
\text { FNT para tratar las recaídas en pacientes con } \\
\text { enfermedad de Crohn posquirúrgica. } \\
\text { Calidad de la evidencia muy baja } \oplus \text { ○০০ }\end{array}$ \\
\hline $\begin{array}{l}\text { Punto de buena } \\
\text { práctica }\end{array}$ & $\begin{array}{l}\text { En pacientes con recurrencia posquirúrgica } \\
\text { de bajo riesgo se recomienda el uso inicial de } \\
\text { tiopurinas } \pm \text { metronidazol (este último durante } \\
3 \text { meses); en caso de no respuesta, se debe } \\
\text { manejar con terapia anti-FNT. }\end{array}$ \\
\hline Fuerte a favor & $\begin{array}{l}\text { Se recomienda que a los pacientes con } \\
\text { enfermedad de Crohn se les informe claramente } \\
\text { sobre el manejo de la enfermedad y las opciones } \\
\text { de tratamiento, con sus riesgos y beneficios. } \\
\text { Calidad de la evidencia muy baja } \oplus \text { O০০ }\end{array}$ \\
\hline Fuerte a favor & $\begin{array}{l}\text { Se recomienda que se evalué la presencia de } \\
\text { signos de depresión o pérdida de la calidad } \\
\text { de vida, y si es necesario, se remita a grupos } \\
\text { de apoyo y de ayuda especializada. } \\
\text { Calidad de la evidencia muy baja } \oplus \text { ○૦ }\end{array}$ \\
\hline
\end{tabular}


Resumen de la evidencia: generalidades

\section{Probióticos para prevenir la recurrencia en los pacientes con enfermedad de Crohn posquirúrgica} Una revisión sistemática de la literatura (71) (puntaje AMSTAR 9/11) evaluó la efectividad y la seguridad del uso de probióticos para mantener en remisión a los pacientes con EC. Para esta revisión, los resultados analizados fueron la frecuencia de recaída clínica a 12 meses (CDAI $>150$ o un incremento de $\geq 70$ sobre el valor basal) o endoscópica (puntaje Rutgeerts $>2$ ). Cuando se comparó frente al placebo, la administración de probióticos no redujo la incidencia de recaídas clínicas (RR: 1,06; IC 95\%: 0,591,92) o endoscópicas (RR: 1,04; IC 95\%: 0,82-1,31). Esta revisión no evaluó la frecuencia de eventos adversos para esta población.

Una segunda revisión sistemática de la literatura (88) (puntaje AMSTAR 8/11) también evaluó la efectividad del uso de probióticos para mantener en remisión a los pacientes con EC posquirúrgica. En esta ocasión, el desenlace reportado fue la incidencia de recaída endoscópica (puntaje de Rutgeerts) con un rango de seguimiento de 3 a 24 meses. Tres estudios con 200 participantes compararon el uso de esta intervención frente al placebo. No se encontraron diferencias estadísticamente significativas entre los grupos (RR: 1,08; IC 95\%: 0,67-1,74).

Calidad de la evidencia: muy baja $\oplus$ O००

\section{Antibióticos para prevenir la recurrencia en los pacientes con enfermedad de Crohn posquirúrgica}

Una revisión sistemática de la literatura (73) (puntaje AMSTAR 7/11) evaluó la efectividad del uso de antibióticos para inducir la remisión en los pacientes con EC posquirúrgica. Todos los estudios permitieron el uso concomitante de otras intervenciones (inmunomoduladores) y para esta revisión, el desenlace reportado fue la proporción de pacientes que logró la mejoría clínica o la remisión (CDAI $<150$ y/o disminución en CDAI $\geq 70$ o reducción $>50 \%$ en el número de las fístulas por al menos 4 semanas) durante el seguimiento. La revisión recuperó un ensayo clínico aleatorio para un total de 33 participantes. Cuando se comparó frente al placebo, el uso de antibióticos no incrementó durante los 3 a 6 primeros meses la frecuencia de los participantes que permanecieron en remisión (RR: 1,13; IC 95\%: 0,43-2,98) (53).

\section{Calidad de la evidencia: baja $\oplus \oplus$}

Una segunda revisión sistemática (119) (puntaje AMSTAR 9/11) incluyó dos ensayos clínicos controlados en donde se evaluó la tasa de recurrencia endoscópica grave (seguimiento a 3 meses y evaluada con puntaje Rutgeerts puntaje I 2 o mayor) y de abandono de la terapia por eventos adversos serios con el uso de 5-nitroimidazoles. Cuando se comparó frente al placebo, el uso de esta intervención disminuyó la recurrencia endoscópica grave (RR: 0,44; IC 95\%: 0,26-0,74), a expensas de una mayor frecuencia de eventos adversos (RR: 3,00; IC 95\%: 1,37-6,58) (119).

\section{Calidad de la evidencia: baja $\oplus \oplus \mathrm{O}$}

\section{Azatioprina o 6-mercaptopurina para prevenir la recurrencia en los pacientes con enfermedad de Crohn posquirúrgica}

Una revisión sistemática de la literatura con metaanálisis (120) (puntaje AMSTAR 9/11) evaluó la seguridad y la efectividad del uso de diferentes intervenciones para mantener en remisión a los pacientes con EC posquirúrgica. En esta ocasión, los desenlaces evaluados fueron la proporción de pacientes que experimentaron recaída clínica (CDAI > 200 o que requiere esteroides o CDAI de más de 60 puntos con respecto al basal) o endoscópica (puntaje Rutgeerts $>2$ ) y la frecuencia de abandono de la terapia por eventos adversos al tratamiento.

La revisión recuperó dos ensayos clínicos controlados que compararon el uso de esta intervención frente al placebo, que reclutaron 168 participantes. Con base en la evidencia recuperada se pudo establecer que el uso de azatioprina o 6-mercaptopurina redujo la incidencia de recaída clínica (RR: 0,74; IC 95\%: 0,58-0,94) y endoscópica (RR: 0,40; IC 95\%: 0,19-0,83) durante los 3 a 12 meses de seguimiento, sin incrementar la frecuencia de abandono de la terapia (RR: 1,33; IC 95\%: 0,59-2,98). Otra de las comparaciones realizadas en esta revisión fue la terapia con azatioprina o 6-mercaptopurina frente a la administración de 5-aminosalicilatos. Cinco estudios con 425 pacientes compararon la seguridad y la efectividad de estas intervenciones. No se encontraron diferencias entre los grupos en términos de recaída clínica (RR: 1,14; IC 95\%: 0,93-1,41) o endoscópica (RR: 0,55; IC 95\%: 0,23-1,32); no obstante, una mayor proporción de pacientes asignados al brazo de azatioprina o 6-mercaptopurina abandonaron la terapia como consecuencia de los eventos adversos (RR: 2,07; IC 95\%: 1,26-33,90) (120).

Finalmente, la última comparación recuperada fue frente al uso de medicamento anti-FNT. Cuando se trató de infliximab, no se encontraron diferencias en la tasa de recaída clínica (RR: 2,00; IC 95\%: 0,21-18,98), endoscópica (RR: 4,40; IC 95\%: 0,59-33,07) o en la frecuencia de abandono de la terapia (RR: 3,00; IC 95\%: 0,14-66,53). Sin embargo, el uso de azatioprina o 6-mercaptopurina incrementó de forma significativa la tasa de recaídas (RR: 5,18; IC 95\%: 1,35-19,83, clínica; y RR: 10,35; IC 95\%: 1,50-71,32, endoscópica) cuando se comparó contra adalimumab. La frecuencia de suspensión de la terapia fue similar entre los grupos (RR: 1,88; IC 95\%: 0,19-18,80) (120).

Calidad de la evidencia: muy baja $\oplus$ O०० 
5-aminosalicilatos para prevenir la recurrencia en los pacientes con enfermedad de Crohn posquirúrgica

Se recuperó una revisión sistemática (121) (puntaje AMSTAR 8/11) que evaluó la efectividad y la seguridad del uso de 5-aminosalicilatos para mantener en remisión a los pacientes con EC posquirúrgica. Para esta revisión, los resultados analizados fueron la frecuencia de recaída clínica durante los dos primeros años de seguimiento (CDAI $>150$ o >200 o aumento en más de 60 puntos con respecto al basal) y la frecuencia de eventos adversos relacionados con la intervención. Se incluyeron ocho estudios, que reclutaron 1061 participantes. Cuando se comparó frente al placebo, la administración de 5-aminosalicilatos redujo la frecuencia de recaídas (RR: 0,71; IC 95\%: 0,54-0,94), pero no la de eventos adversos (RR: 1,06; IC 95\%: 0,61-1,85) (121).

Calidad de la evidencia: baja $\oplus \oplus \circ \mathrm{O}$

\section{Budesonida para prevenir la recurrencia en los pacientes con enfermedad de Crohn posquirúrgica}

Un metaanálisis, resultado de una búsqueda sistemática de la literatura (119) (puntaje AMSTAR 9/11), recuperó dos ensayos clínicos controlados en donde se evaluó la tasa de recurrencia endoscópica grave (seguimiento a 12 meses y evaluada con puntaje Rutgeerts puntaje I2 o mayor) y de abandono de la terapia por eventos adversos serios con el uso de budesonida. Cuando se comparó frente al placebo, el uso de esta intervención no redujo la incidencia de recaída endoscópica grave (RR: 0,87; IC 95\%: 0,50-1,49), pero tampoco incrementó el abandono de la terapia relacionada con la presencia de eventos adversos (RR: 1,01; IC 95\%: 0,37-2,78) (119).

Calidad de la evidencia: baja $\oplus \oplus \mathbf{O}$

\section{Anti-FNT comparado con terapia convencional para prevenir la recurrencia en los pacientes con enfermedad de Crohn posquirúrgica}

Una segunda revisión sistemática de la literatura (122) (puntaje AMSTAR 7/11) comparó la eficacia de la administración de infliximab durante las 2 a 4 primeras semanas posteriores al procedimiento, con el ánimo de prevenir la recurrencia histológica definida con base en los criterios modificados de D'Haens. Esta revisión recuperó un estudio con 24 participantes en los que se evaluó la presencia de este desenlace. Cuando se comparó frente a la administración de mesalamina o 6-mercaptopurina, la terapia con infliximab incrementó la proporción de pacientes que no experimentaron un episodio de recurrencia histológica durante las primeras 54 semanas de seguimiento (RR: 6,00; IC 95\%: 1,02-35,37) (122).

Calidad de la evidencia: baja $\oplus \oplus 0 \mathrm{O}$
Seguridad y efectividad de las diferentes estrategias para prevenir la recurrencia en los pacientes con enfermedad de Crohn posquirúrgica. Resultados de un metaanálisis en red

Una revisión sistemática de la literatura (123) (puntaje AMSTAR 8/11) evaluó la seguridad y la efectividad de las diferentes intervenciones farmacológicas para prevenir la recaída clínica (CDAI mayor o igual a 150) o endoscópica (Rutgeerts I2-I4 o la combinación de recaída endoscópica y por imagen o por estudios de bario) en pacientes con EC posquirúrgica. Los pacientes incluidos en esta revisión se caracterizaron por tener enfermedad establecida, historia de resección intestinal microscópicamente satisfactoria y por haber iniciado la intervención profiláctica en los primeros tres meses posteriores a la resección intestinal.

Los resultados de este metaanálisis en red mostraron que, comparado frente al placebo (o no intervención), la administración de mesalazina (RR: 0,60; IC 95\%: 0,37-0,88), antibióticos (RR: 0,26; IC 95\%: 0,08-0,61), inmunomodulador en monoterapia (RR: 0,36; IC 95\%: 0,17-0,63), combinación inmunomodulador con antibiótico (RR: 0,11; IC 95\%: 0,020,51 ) y el uso de anti-FNT en monoterapia (RR: 0,04; IC 95\%: 0,00-0,14) fueron intervenciones efectivas en cuanto a la disminución de los episodios de recaída clínica. No obstante, la administración de budesonida no parece ser superior al placebo (RR: 0,93; IC 95\%: 0,40-1,84). Por otra parte, cuando el desenlace evaluado fue la recaída endoscópica, el metaanálisis documentó que el uso de antibióticos (RR: 0,41; IC 95\%: 0,15-0,92), la monoterapia con inmunomodulador (RR: 0,33; IC 95\%: 0,13-0,68), la terapia combinada inmunomoduladora con antibióticos (RR: 0,16; IC 95\%: 0,04-0,48) y el tratamiento con anti-FNT en monoterapia (RR: 0,01; IC 95\%: 0,00-0,05) fueron superiores al placebo, hallazgos que no son consistentes cuando se trató de mesalazina (RR: 0,67; IC 95\%: 0,39-1,08) o de budesonida (RR: 0,86; IC 95\%: 0,61-1,22) (123).

Ahora bien, esta revisión desarrolló un segundo análisis con el objetivo de determinar cuál de las intervenciones farmacológicas disponibles se comportaba como la más eficaz a la hora de prevenir la recaída clínica. El análisis en red mostró que la monoterapia con anti-FNT fue superior al uso de inmunomoduladores en monoterapia (RR: 0,11; IC 95\%: 0,01-0,40). Por otra parte, la administración de anti-FNT en monoterapia también fue superior al uso de antibióticos, pero este estimador se basó fundamentalmente en evidencia indirecta (RR: 0,20; IC 95\%: 0,01-0,84). También se observó que la combinación de inmunomodulador y antibióticos no fue significativamente diferente de la monoterapia con inmunomodulador (RR: 0,34; IC 95\%: 0,05-1,20) o del antibiótico en monoterapia (RR: 0,48; IC 95\%: 0,08-1,46). La monoterapia con inmu- 
nomodulador no fue superior a la terapia con antibiótico (RR: 1,92; IC 95\%: 0,93-4,00) (123).

Finalmente, esta revisión también pretendió determinar cuál de las intervenciones terapéuticas podría ser la mejor a la hora de prevenir una recaída endoscópica. Basados en los resultados de este metaanálisis en red, la monoterapia con anti-FNT fue superior a todas las demás estrategias: versus mesalazina (RR: 0,02; IC 95\%: 0,00-0,07), antibióticos (RR: 0,03; IC 95\%: 0,00-0,15), monoterapia con inmunomodulador (RR: 0,04; IC 95\%: 0,00-0,14), inmunomodulador combinado con antibióticos (RR: 0,03; IC 95\%: 0,00-0,49) y budesonida (RR: 0,005; IC 95\%: 0,00-0,08). La combinación de inmunomodulador y antibióticos no fue significativamente diferente de la monoterapia con inmunomodulador (RR: 0,54; IC 95\%: 0,12-1,59) o de antibióticos (RR: 0,43; IC 95\%: 0,10-1,19). Adicionalmente, la monoterapia con inmunomodulador no fue significativamente diferente de la monoterapia con antibióticos en la reducción del riesgo de recaída endoscópica (RR: 0,97; IC 95\%: 0,26-2,53) (123).

Calidad de la evidencia: baja $\oplus \oplus$ $\oplus$

Una revisión sistemática y metaanálisis de 10 estudios con 751 pacientes analizó la recurrencia endoscópica posquirúrgica de pacientes con EC a 12 meses de seguimiento. La monoterapia con anti-FNT fue significativamente mejor que placebo para prevenir la recurrencia endoscópica (RR: 0,13;
IC 95\%: 0,04-0,39). Lo mismo se obtuvo cuando se combinó con medicamentos 5-ASA (RR: 0,30; IC 95\%: 0,12-0,75) o con nitroimidazoles (RR: 0,40; IC 95\%: 0,23-0,69). La terapia combinada con tiopurinas y metronidazol también fue más efectiva que placebo (RR: 0,56; IC 95\%: 0,40-0,80), lo mismo que la monoterapia con tiopurinas (RR: 0,84; IC 95\%: 0,74-0,94). Los nitroimidazoles y los medicamentos 5-ASA no fueron superiores a placebo para prevenir la recurrencia endoscópica en EC posquirúrgica (124).

\section{Anti-FNT comparado con inmunomoduladores para tratar las recaídas en los pacientes con enfermedad de Crohn posquirúrgica}

Una revisión sistemática de la literatura (125) (puntaje AMSTAR 8/11) evaluó la eficacia de administrar medicamentos anti-FNT para tratar la recaída en pacientes con EC posquirúrgica. El desenlace reportado fue la frecuencia de remisión endoscópica (puntaje Rutgeerts $<2$ ) con un rango de seguimiento de 6 a 12 meses y se recuperaron dos ensayos clínicos aleatorizados, para un total de 50 pacientes. Cuando se comparó frente al uso de inmunomoduladores, se observó que la terapia con anti-FNT incrementó la proporción de pacientes que lograron la remisión endoscópica (OR: 16,64; IC 95\%: 2,51-110,27) (125).

Calidad de la evidencia: muy baja $\oplus$ O००

\section{De la evidencia a la recomendación}

\begin{tabular}{|c|c|c|c|c|c|c|}
\hline & & & Juicio & le valor & & \\
\hline Problema & No & Probablemente no & Probablemente sí & Sí & Varía & No se conoce \\
\hline Efectos deseables & Triviales & Pequeños & Moderados & Grandes & Varía & No se conoce \\
\hline $\begin{array}{l}\text { Efectos no } \\
\text { deseados }\end{array}$ & Triviales & Pequeños & Moderados & Grandes & Varía & No se conoce \\
\hline $\begin{array}{l}\text { Confianza en la } \\
\text { evidencia }\end{array}$ & Muy baja & Baja & Moderada & Alta & & $\begin{array}{c}\text { No se encontró } \\
\text { evidencia }\end{array}$ \\
\hline Variabilidad & Alta incertidumbre & $\begin{array}{l}\text { Importante } \\
\text { variabilidad }\end{array}$ & $\begin{array}{l}\text { Variabilidad no } \\
\text { importante }\end{array}$ & $\begin{array}{l}\text { No se presenta } \\
\text { variabilidad }\end{array}$ & & No se conoce \\
\hline $\begin{array}{l}\text { Balance de los } \\
\text { efectos }\end{array}$ & $\begin{array}{l}\text { Favorece la } \\
\text { comparación }\end{array}$ & $\begin{array}{c}\text { Probablemente } \\
\text { favorece la } \\
\text { comparación }\end{array}$ & $\begin{array}{l}\text { No favorece } \\
\text { ninguna } \\
\text { intervención }\end{array}$ & $\begin{array}{l}\text { Probablemente } \\
\text { favorece la } \\
\text { intervención }\end{array}$ & $\begin{array}{l}\text { Favorece la } \\
\text { intervención }\end{array}$ & No se conoce \\
\hline $\begin{array}{l}\text { Calidad global de la } \\
\text { evidencia }\end{array}$ & Muy baja & Baja & Moderada & Alta & & $\begin{array}{c}\text { No se encontró } \\
\text { evidencia }\end{array}$ \\
\hline Equidad & Reducida & $\begin{array}{c}\text { Probablemente se } \\
\text { reduzca }\end{array}$ & $\begin{array}{l}\text { Probablemente no } \\
\text { tenga impacto }\end{array}$ & $\begin{array}{c}\text { Probablemente se } \\
\text { aumente }\end{array}$ & Se aumenta & No se conoce \\
\hline $\begin{array}{l}\text { Aceptabilidad de } \\
\text { los usuarios }\end{array}$ & No & Probablemente no & Probablemente sí & Sí & Varía & No se conoce \\
\hline $\begin{array}{l}\text { Factibilidad de la } \\
\text { implementación }\end{array}$ & No & Probablemente no & Probablemente sí & Sí & Varía & No se conoce \\
\hline
\end{tabular}


VALORES Y PREFERENCIAS DE LOS PACIENTES

\section{¿Cuáles son las necesidades de los pacientes en relación con la enfermedad de Crohn?}

Resumen de las recomendaciones

\begin{tabular}{|c|c|}
\hline Recomendación $\quad n .^{\circ}$ & Resumen \\
\hline Fuerte a favor & $\begin{array}{l}\text { Se recomienda que a los pacientes con } \\
\text { enfermedad de Crohn se les informe } \\
\text { claramente sobre el manejo de la enfermedad } \\
\text { y las opciones de manejo con sus riesgos y } \\
\text { beneficios. } \\
\text { Calidad de la evidencia muy baja } \oplus \text { } ૦ ০\end{array}$ \\
\hline Fuerte a favor & $\begin{array}{l}\text { Se recomienda que se evalué la presencia de } \\
\text { signos de depresión o pérdida de la calidad } \\
\text { de vida y, si es necesario, se remita a grupos } \\
\text { de apoyo y ayuda especializada. } \\
\text { Calidad de la evidencia muy baja } \oplus \text { } \bigcirc ০\end{array}$ \\
\hline
\end{tabular}

\section{Valores y preferencias}

La enfermedad inflamatoria intestinal (EII) tiene un gran impacto en la calidad de vida y en el bienestar psicológico de los pacientes. Se ha identificado un componente emocional que puede afectar el resultado de la terapia en los pacientes.

Una revisión sistemática cualitativa (126) (AMSTAR 7/11) exploró cómo apoyar la mejoría de estos desenlaces en los pacientes con EII, la cual incluyó 36 estudios en población adulta. Se identificó que los pacientes con mecanismos psicológicos de ajuste a nuevas situaciones (pacientes con red de apoyo familiar y fortaleza individual) presentaron una mejoría más rápida que los pacientes con dificultades de ajuste psicológico (pacientes que se enfocan más en las situaciones negativas).

La RS identificó que, en promedio, el $43 \%$ de los pacientes con EII sufren algún grado de depresión de acuerdo con las escalas especializadas con énfasis en los dominios de "soledad", "resiliencia" y "actividad de la enfermedad". La RS incluyó un estudio con 49 pacientes, el cual identificó que el grado de depresión es predictor del efecto positivo de la terapia. Un metaanálisis con 50 pacientes identificó los efectos de la terapia psicológica en la enfermedad a los 12 meses, pero ningún efecto a los 6 meses. Un estudio cualitativo con 31 pacientes con EII grave encontró que los cambios en la alimentación, las redes de apoyo, el control de la situación, los cambios positivos en la actitud hacia la enfermedad, las técnicas de relajación, las distracciones de la enfermedad y el conocimiento de la enfermedad contribuían a un mejoramiento del bienestar y de los síntomas. La RS concluye que los pacientes con EII deben acompañar con terapia el manejo emocional de la enfermedad (126).

\section{Valores y preferencias}

La mayoría de los pacientes con EC requiere cirugía dentro de los 10 años del diagnóstico inicial. La resección intestinal es la operación más frecuente, aunque afecta la calidad de vida de los pacientes.

Una revisión sistemática (127) (AMSTAR 7/11) evaluó el efecto del impacto de la recesión intestinal en la calidad de vida de acuerdo con la escala HRQOL e identificó los predictores de calidad de vida relacionada con la salud (CVRS) del postoperatorio y la satisfacción del paciente con la cirugía. Se incluyeron 9 estudios que reclutaron 1108 pacientes con EC, que fueron sometidos a resección intestinal. El rango medio de edad fue entre 29 y 41 años. La resección ileocólica fue la cirugía más frecuente relacionada con obstrucción intestinal, perforación y falla a la terapia farmacológica. Los resultados de CVRS encontraron que todos los pacientes (a los 30 días después de la operación) reportaron una mejoría en la calidad de vida. De forma general, el efecto en CVRS duró entre 2 y 5 años. La RS analizó adicionalmente los factores predictores de CVRS. Se encontró que los pacientes mayores de 49 años reportaron menores mejoras en CVRS a los 9 meses del postoperatorio. Los pacientes fumadores presentaron menor mejoría en CVRS comparados con los no fumadores. No se encontraron diferencias por género y técnica quirúrgica. En relación con la satisfacción de los pacientes, el $80 \%$ reportó encontrarse satisfecho con la cirugía y la realizaría de nuevo si fuera necesario. El 92\% de los pacientes reportaron preferir la cirugía laparoscópica (127).

\section{Valores y preferencias}

La EC perianal puede afectar la calidad de vida a lo largo de los aspectos físicos, funcionales y psicológicos.

Un estudio de corte transversal (128) determinó los factores que afectan de forma positiva o negativa la calidad de vida y su impacto en los síntomas de 69 pacientes con EC con enfermedad perianal. La media de edad fue de 42,7 años y $62 \%$ fueron mujeres. El $80 \%$ de los pacientes fue sometido a cirugía antes de la encuesta. El dolor anal e incomodidad fueron considerados los síntomas más importantes por el $41 \%$ los pacientes. El 39\% reportó como "muy importante de manejar para mejorar la calidad de vida" la dificultad para dormir, la restricción de la actividad física y la sensación de suciedad. El 85\% de los pacientes recibiría un estoma para mejorar los síntomas.

Las mujeres reportaron como síntoma más importante el dolor anal comparadas con los hombres (53\% vs. 19\%). La presencia de drenaje se reportó como el mayor predictor de incontinencia, sensación de suciedad y confianza en salir a la calle. El estudio concluyó que los síntomas físicos son los 
más importantes para los pacientes con enfermedad perianal y que los drenajes afectan la calidad de vida (98).

\section{Valores y preferencias}

El manejo de la EC presenta desafíos en la selección de la terapia más adecuada. Es por ello por lo que las preferencias de los pacientes pueden orientar la selección de la terapia.

Un estudio cualitativo (99) comparó las preferencias de 300 pacientes con EC con la de 92 cirujanos y 74 gastroenterólogos en Australia. El estudio encontró que las preferencias de los pacientes no son las mismas que las de los especialistas. Los pacientes están más interesados en mejoras en su calidad de vida dados los riesgos y beneficios de las terapias presentadas. El 37\% de los cirujanos buscan no realizar la cirugía de resección ileocólica comparado con un $39 \%$ de los pacientes $(p<0,01)$. Los pacientes prefieren el uso de estoma permanente que la cirugía colorrectal ( $85 \%$ vs. $56 \% ; p>0,01$ ). Sin embargo, cuando se preguntó sobre las preferencias entre proctocolectomía restaurativa y estoma permanente, los pacientes y los cirujanos tuvieron la misma preferencia $(50 \% ; p>0,05)$

Cuando se compararon las preferencias de los pacientes con las de los gastroenterólogos, se encontraron diferencias en las preferencias quirúrgicas. Los pacientes prefirieron la resección ileocólica en mayor porcentaje que los gastroenterólogos. No se encontraron diferencias con respecto a la selección de la terapia farmacológica $(p>0,05)(129)$.

\section{RESUMEN DE LAS RECOMENDACIONES}

ASPECTO CLÍNICO: PRONÓSTICO

\section{Pregunta 1. ¿Cuáles son los factores que permiten predecir recaídas en pacientes mayores de 16 años con enfermedad de Crohn?}

\begin{tabular}{|c|c|}
\hline Recomendación $n$. & Resumen \\
\hline Fuerte a favor & $\begin{array}{l}\text { Se recomienda la medición de los niveles } \\
\text { de proteína C-reactiva (PCR) y el uso de } \\
\text { velocidad de sedimentación globular (VSG) } \\
\text { para predecir la recaída en los pacientes con } \\
\text { enfermedad de Crohn. } \\
\text { Calidad de la evidencia: muy baja } \oplus \text { O০০ }\end{array}$ \\
\hline Débil en contra & $\begin{array}{l}\text { No se sugiere la medición de ASCA para } \\
\text { predecir la recaída en pacientes con } \\
\text { enfermedad de Crohn. } \\
\text { Calidad de la evidencia: muy baja } \oplus \text { O০০ }\end{array}$ \\
\hline Débil a favor & $\begin{array}{l}\text { Se sugiere la medición de los niveles de } \\
\text { calprotectina fecal para predecir la recaída en } \\
\text { pacientes con enfermedad de Crohn. } \\
\text { Calidad de la evidencia muy baja } \oplus \text { ○০০ }\end{array}$ \\
\hline
\end{tabular}

\begin{tabular}{|c|c|}
\hline $\begin{array}{l}\text { Punto de buena } \\
\text { práctica }\end{array}$ & $\begin{array}{l}\text { La periodicidad de la medición de } \\
\text { calprotectina fecal debe ser cada } 3 \text { a } 6 \\
\text { meses. }\end{array}$ \\
\hline $\begin{array}{l}\text { Punto de buena } \\
\text { práctica }\end{array}$ & $\begin{array}{l}\text { Se sugiere, para la medición de la } \\
\text { calprotectina fecal, tomar la primera muestra } \\
\text { del día y un punto de corte de } 250 \mu \mathrm{g} / \mathrm{g} \\
\text { es el valor más confiable para diferenciar } \\
\text { cicatrización de la mucosa de inflamación en } \\
\text { enfermedad de Crohn. Se considera un punto } \\
\text { de corte de } 100 \mu \mathrm{g} / \mathrm{g} \text { como valor predictor de } \\
\text { recurrencia en pacientes con enfermedad de } \\
\text { Crohn posquirúrgica. }\end{array}$ \\
\hline $\begin{array}{l}\text { Punto de buena } \\
\text { práctica }\end{array}$ & $\begin{array}{l}\text { En los pacientes con enfermedad de Crohn } \\
\text { que se encuentren en tratamiento con } \\
\text { infliximab se pueden medir los niveles séricos } \\
\text { del medicamento para predecir la remisión } \\
\text { clínica y endoscópica. }\end{array}$ \\
\hline Débil a favor & $\begin{array}{l}\text { Se sugiere utilizar la resonancia nuclear } \\
\text { magnética como prueba radiológica para } \\
\text { predecir la remisión profunda en pacientes } \\
\text { con enfermedad de Crohn perianal } \\
\text { fistulizante. } \\
\text { Calidad de la evidencia muy baja } \oplus \text { }\end{array}$ \\
\hline Débil a favor & $\begin{array}{l}\text { Se sugiere implementar la cicatrización de } \\
\text { la mucosa como objetivo terapéutico en } \\
\text { pacientes con enfermedad de Crohn. } \\
\text { Calidad de la evidencia muy baja } \oplus \text { ○০০ }\end{array}$ \\
\hline $\begin{array}{l}\text { Punto de buena } \\
\text { práctica }\end{array}$ & $\begin{array}{l}\text { Se sugiere el estudio con cápsula } \\
\text { endoscópica para determinar la cicatrización } \\
\text { de la mucosa del intestino delgado. }\end{array}$ \\
\hline
\end{tabular}

Pregunta 2. ¿Cuáles son las intervenciones no biológicas más seguras y efectivas para inducir la remisión en pacientes mayores de 16 años con enfermedad de Crohn?

\begin{tabular}{|c|c|}
\hline Recomendación $n .^{\circ}$ & Resumen \\
\hline Fuerte en contra & $\begin{array}{l}\text { No se recomienda el uso de probióticos } \\
\text { para inducir la remisión en pacientes con } \\
\text { enfermedad de Crohn activa. } \\
\text { Calidad de la evidencia muy baja } \oplus \text { ○০০ }\end{array}$ \\
\hline Débil en contra & $\begin{array}{l}\text { No se sugiere el uso de antibióticos para } \\
\text { inducir la remisión en pacientes con } \\
\text { enfermedad de Crohn activa. } \\
\text { Calidad de la evidencia baja } \oplus \oplus \bigcirc \bigcirc\end{array}$ \\
\hline Débil en contra & $\begin{array}{l}\text { No se sugiere la administración de azatioprina } \\
\text { o 6-mercaptopurina como monoterapia } \\
\text { para inducir la remisión en pacientes con } \\
\text { enfermedad de Crohn activa. } \\
\text { Calidad de la evidencia muy baja } \oplus \text { ○০০ }\end{array}$ \\
\hline
\end{tabular}




\begin{tabular}{|c|c|}
\hline Fuerte a favor & $\begin{array}{l}\text { Se recomienda adicionar azatioprina en } \\
\text { pacientes con enfermedad de Crohn activa } \\
\text { que van a recibir terapia biológica con } \\
\text { infliximab, como terapia combinada, para } \\
\text { inducir la remisión. } \\
\text { Calidad de la evidencia muy baja } \oplus \text { } \bigcirc ০\end{array}$ \\
\hline Débil en contra & $\begin{array}{l}\text { No se sugiere el uso de sulfasalazina ni } \\
\text { de mesalazina para inducir la remisión en } \\
\text { pacientes con enfermedad de Crohn activa. } \\
\text { Calidad de la evidencia muy baja } \oplus \text { ○০০ }\end{array}$ \\
\hline Fuerte en contra & $\begin{array}{l}\text { No se recomienda el uso de metotrexato } \\
\text { para inducir la remisión en pacientes con } \\
\text { enfermedad de Crohn activa. } \\
\text { Calidad de la evidencia muy baja } \oplus \text { ○০০ }\end{array}$ \\
\hline Débil a favor & $\begin{array}{l}\text { Se sugiere el uso de budesonida de liberación } \\
\text { ileal para inducir la remisión en pacientes con } \\
\text { enfermedad de Crohn activa. } \\
\text { Calidad de la evidencia baja } \oplus \oplus \text { ○० }\end{array}$ \\
\hline $\begin{array}{l}\text { Punto de buena } \\
\text { práctica }\end{array}$ & $\begin{array}{l}\text { La dosis inicial recomendada de budesonida } \\
\text { es de } 9 \mathrm{mg} / \mathrm{d} \text {; a los } 2 \text { meses se disminuye a } 6 \\
\mathrm{mg} / \mathrm{d} \text {, y en los siguientes } 2 \text { meses se reduce a } \\
3 \mathrm{mg} / \mathrm{d} \text {, para luego suspender. La duración del } \\
\text { tratamiento de inducción no debe ser mayor } \\
\text { de } 6 \text { meses. }\end{array}$ \\
\hline $\begin{array}{l}\text { Punto de buena } \\
\text { práctica }\end{array}$ & $\begin{array}{l}\text { Se deben monitorizar los eventos adversos } \\
\text { asociados al uso de esteroides sistémicos } \\
\text { luego de } 12 \text { semanas de uso. }\end{array}$ \\
\hline Fuerte a favor & $\begin{array}{l}\text { Se recomienda el uso de esteroides } \\
\text { sistémicos para inducir la remisión en } \\
\text { pacientes con enfermedad de Crohn activa. } \\
\text { Calidad de la evidencia baja } \oplus \oplus \text {. }\end{array}$ \\
\hline $\begin{array}{l}\text { Punto de buena } \\
\text { práctica }\end{array}$ & $\begin{array}{l}\text { Los esteroides sistémicos son tratamiento } \\
\text { de primera elección en pacientes con } \\
\text { enfermedad de Crohn moderada a grave } \\
\text { ileocolónica, colónica o con compromiso } \\
\text { extenso de intestino delgado. }\end{array}$ \\
\hline $\begin{array}{l}\text { Punto de buena } \\
\text { práctica }\end{array}$ & $\begin{array}{l}\text { La dosis inicial recomendada de prednisolona } \\
\text { oral es } 40 \mathrm{mg} / \mathrm{d} \text {. }\end{array}$ \\
\hline $\begin{array}{l}\text { Punto de buena } \\
\text { práctica }\end{array}$ & $\begin{array}{l}\text { La respuesta con esteroides se debe evaluar } \\
\text { luego de } 2 \text { a } 4 \text { semanas de tratamiento. En } \\
\text { caso de falla terapéutica, se debe definir la } \\
\text { necesidad de modificar el tratamiento. }\end{array}$ \\
\hline Débil a favor & $\begin{array}{l}\text { Se sugiere como primera elección el uso de } \\
\text { esteroides orales sistémicos para inducir la } \\
\text { remisión en pacientes con enfermedad de } \\
\text { Crohn activa. } \\
\text { Calidad de la evidencia muy baja } \oplus \text { O০০ }\end{array}$ \\
\hline Débil a favor & $\begin{array}{l}\text { Se sugiere el uso de budesonida de liberación } \\
\text { ileal como primera alternativa para el manejo } \\
\text { de los pacientes con enfermedad de Crohn } \\
\text { ileal o ileocecal de bajo riesgo. } \\
\text { Calidad de la evidencia muy baja } \oplus \text { ○০০ }\end{array}$ \\
\hline
\end{tabular}

\begin{tabular}{|c|c|}
\hline $\begin{array}{l}\text { Punto de buena } \\
\text { práctica }\end{array}$ & $\begin{array}{l}\text { En caso de no disponer de budesonida, se } \\
\text { pueden usar corticoides sistémicos, como la } \\
\text { prednisolona. }\end{array}$ \\
\hline Débil a favor & $\begin{array}{l}\text { Se sugiere el uso de trasplante de células } \\
\text { madre autólogo para el manejo de pacientes } \\
\text { con enfermedad de Crohn refractarios a } \\
\text { tratamiento médico. } \\
\text { Calidad de la evidencia muy baja } \oplus \text { ○০০ }\end{array}$ \\
\hline $\begin{array}{l}\text { Punto de buena } \\
\text { práctica }\end{array}$ & $\begin{array}{l}\text { El trasplante de células madre debe hacerse } \\
\text { en centros con experiencia. }\end{array}$ \\
\hline
\end{tabular}

Pregunta 3. ¿Cuáles son las intervenciones no biológicas más seguras y efectivas para mantener en remisión a los pacientes mayores de 16 años con enfermedad de Crohn?

\begin{tabular}{|c|c|}
\hline Recomendación $n .^{\circ}$ & Resumen \\
\hline Fuerte en contra & $\begin{array}{l}\text { No se recomienda el uso de mesalazina } \\
\text { para mantener la remisión en pacientes con } \\
\text { enfermedad de Crohn. } \\
\text { Calidad de la evidencia baja } \oplus \oplus \text { O০ }\end{array}$ \\
\hline Débil a favor & $\begin{array}{l}\text { Se sugiere el uso de azatioprina o } \\
6 \text {-mercaptopurina para mantener la remisión } \\
\text { en pacientes con enfermedad de Crohn en } \\
\text { quienes se logró inducir la remisión con el } \\
\text { uso de esteroides sistémicos. } \\
\text { Calidad de la evidencia muy baja } \oplus \text { } ๑ \text { ○ }\end{array}$ \\
\hline $\begin{array}{l}\text { Punto de buena } \\
\text { práctica }\end{array}$ & $\begin{array}{l}\text { La dosis recomendada de azatioprina es de } \\
2,0 \text { a } 2,5 \mathrm{mg} / \mathrm{kg} / \mathrm{d} \text { y de } 6 \text {-mercaptopurina es } \\
\text { de } 0,75 \text { a } 1,5 \mathrm{mg} / \mathrm{kg} / \mathrm{d} \text {. }\end{array}$ \\
\hline $\begin{array}{l}\text { Punto de buena } \\
\text { práctica }\end{array}$ & $\begin{array}{l}\text { Se puede realizar la medición de la actividad } \\
\text { de la enzima tiopurinametiltransferasa } \\
\text { (TPMT) antes del inicio de tiopurinas; esto } \\
\text { permite identificar a los pacientes que pueden } \\
\text { desarrollar inmunosupresión grave con el uso } \\
\text { de estos medicamentos. }\end{array}$ \\
\hline Débil en contra & $\begin{array}{l}\text { No se sugiere el uso de budesonida para } \\
\text { mantener la remisión en pacientes con } \\
\text { enfermedad de Crohn. } \\
\text { Calidad de la evidencia muy baja } \oplus \text { ○০০ }\end{array}$ \\
\hline Débil a favor & $\begin{array}{l}\text { Se sugiere el uso de metotrexato para } \\
\text { mantener la remisión en pacientes con } \\
\text { enfermedad de Crohn que logran la remisión } \\
\text { con esteroides. } \\
\text { Calidad de la evidencia muy baja } \oplus \text { ○০০ }\end{array}$ \\
\hline $\begin{array}{l}\text { Punto de buena } \\
\text { práctica }\end{array}$ & $\begin{array}{l}\text { Los pacientes con enfermedad de Crohn } \\
\text { dependientes de esteroides deben ser } \\
\text { tratados inicialmente con tiopurinas o } \\
\text { metotrexato como "ahorradores" de } \\
\text { esteroides. }\end{array}$ \\
\hline
\end{tabular}




\begin{tabular}{ll}
$\begin{array}{l}\text { Punto de buena } \\
\text { práctica }\end{array}$ & $\begin{array}{l}\text { Se debe considerar el uso de metotrexato } \\
\text { en lugar de tiopurinas en pacientes jóvenes } \\
\text { hombres }<35 \text { años, por el riesgo de linfoma } \\
\text { hepatoesplénico, lo mismo que en sujetos } \\
\text { intolerantes o que presenten efectos } \\
\text { adversos a las tiopurinas. }\end{array}$ \\
\hline $\begin{array}{l}\text { Punto de buena } \\
\text { práctica }\end{array}$ & $\begin{array}{l}\text { La dosis recomendada de mantenimiento } \\
\text { de metotrexato es de } 25 \text { mg/semana vía } \\
\text { intramuscular. }\end{array}$ \\
\hline Fuerte en contra & $\begin{array}{l}\text { No se recomienda el uso de nutrición } \\
\text { elemental para mantener la remisión en } \\
\text { pacientes con enfermedad de Crohn. }\end{array}$ \\
Calidad de la evidencia muy baja $\oplus$ O००
\end{tabular}

Pregunta 4. ¿Cuál es la seguridad y la efectividad del uso de medicamentos biológicos para el tratamiento de los pacientes mayores de 16 años con enfermedad de Crohn moderada a grave?

\begin{tabular}{|c|c|}
\hline Recomendación $n .^{\circ}$ & Resumen \\
\hline Fuerte a favor & $\begin{array}{l}\text { Se recomienda el uso de infliximab, } \\
\text { adalimumab, certolizumab, vedolizumab } \\
\text { o ustekinumab para inducir y mantener la } \\
\text { remisión en pacientes con enfermedad de } \\
\text { Crohn luminal moderada a grave. } \\
\text { Calidad de la evidencia muy baja } \oplus \text { } ૦ ૦\end{array}$ \\
\hline $\begin{array}{l}\text { Punto de buena } \\
\text { práctica }\end{array}$ & $\begin{array}{l}\text { Se debe elegir, como primera opción, } \\
\text { los medicamentos anti-FNT (infliximab, } \\
\text { adalimumab o certolizumab pegol) sobre } \\
\text { otros biológicos para el manejo inicial de la } \\
\text { enfermedad de Crohn moderada a grave. }\end{array}$ \\
\hline $\begin{array}{l}\text { Punto de buena } \\
\text { práctica }\end{array}$ & $\begin{array}{l}\text { Los pacientes mayores de } 65 \text { años en } \\
\text { tratamiento con anti-FNT tienen mayor riesgo } \\
\text { de infección. }\end{array}$ \\
\hline $\begin{array}{l}\text { Punto de buena } \\
\text { práctica }\end{array}$ & $\begin{array}{l}\text { En pacientes masculinos menores de } 35 \\
\text { años no se recomienda el uso de terapia } \\
\text { combinada de anti-FNT con tiopurinas por el } \\
\text { riesgo de linfoma hepatoesplénico, lo mismo } \\
\text { en pacientes con historia de malignidad. En } \\
\text { este caso, debe usarse monoterapia con } \\
\text { anti-FNT. }\end{array}$ \\
\hline
\end{tabular}

\begin{tabular}{|c|c|}
\hline $\begin{array}{l}\text { Punto de buena } \\
\text { práctica }\end{array}$ & $\begin{array}{l}\text { En pacientes con contraindicaciones para } \\
\text { el uso de anti-FNT (falla cardiaca grave, } \\
\text { enfermedad desmielinizante, entre otras) se } \\
\text { debe considerar el uso de vedolizumab o } \\
\text { ustekinumab. }\end{array}$ \\
\hline $\begin{array}{l}\text { Punto de buena } \\
\text { práctica }\end{array}$ & $\begin{array}{l}\text { Los pacientes con enfermedad de Crohn } \\
\text { deben ser evaluados en 12-14 semanas luego } \\
\text { del inicio de la inducción con terapia biológica } \\
\text { para determinar la respuesta y la necesidad } \\
\text { de modificar el tratamiento. }\end{array}$ \\
\hline Débil a favor & $\begin{array}{l}\text { Se sugiere el uso de medicamentos anti-FNT } \\
\text { (infliximab o adalimumab) para el tratamiento } \\
\text { de los pacientes con enfermedad de Crohn } \\
\text { fistulizante perianal. } \\
\text { Calidad de la evidencia baja } \oplus \oplus \text { O० }\end{array}$ \\
\hline $\begin{array}{l}\text { Punto de buena } \\
\text { práctica }\end{array}$ & $\begin{array}{l}\text { La eficacia del infliximab podría incrementarse } \\
\text { cuando se administra en conjunto con } \\
\text { tiopurinas. }\end{array}$ \\
\hline Débil a favor & $\begin{array}{l}\text { Se sugiere el uso de ustekinumab para inducir } \\
\text { la remisión en pacientes con enfermedad } \\
\text { de Crohn moderada a grave, que hayan } \\
\text { presentado falla terapéutica a anti-FNT. } \\
\text { Calidad de la evidencia muy baja } \oplus \text { ○০ }\end{array}$ \\
\hline $\begin{array}{l}\text { Punto de buena } \\
\text { práctica }\end{array}$ & $\begin{array}{l}\text { La dosis inicial recomendada de inducción de } \\
\text { ustekinumab es } 260 \mathrm{mg} \text { intravenosos (hasta } \\
55 \mathrm{~kg} \text { de peso), } 390 \mathrm{mg} \text { (entre } 56 \text { y } 85 \mathrm{~kg} \text { ) y } \\
520 \mathrm{mg} \text { (mayor de } 85 \mathrm{~kg} \text { ). Para el tratamiento } \\
\text { de mantenimiento se recomienda continuar } \\
\text { con } 90 \mathrm{mg} \text { subcutáneos cada } 8 \text { semanas. }\end{array}$ \\
\hline Débil a favor & $\begin{array}{l}\text { Se sugiere la vigilancia clínica de las } \\
\text { infecciones oportunistas en los pacientes con } \\
\text { enfermedad de Crohn que reciban terapia } \\
\text { biológica. } \\
\text { Calidad de la evidencia muy baja } \oplus \text { ○০০ }\end{array}$ \\
\hline $\begin{array}{l}\text { Punto de buena } \\
\text { práctica }\end{array}$ & $\begin{array}{l}\text { Se debe contraindicar el uso de tratamiento } \\
\text { con anti-FNT en pacientes con sepsis activa. }\end{array}$ \\
\hline $\begin{array}{l}\text { Punto de buena } \\
\text { práctica }\end{array}$ & $\begin{array}{l}\text { Previo al inicio de la terapia biológica se debe } \\
\text { indagar la presencia de síntomas respiratorios } \\
\text { y se debe realizar una radiografía de tórax y } \\
\text { una prueba de tuberculina, dado el riesgo de } \\
\text { reactivación de tuberculosis latente. }\end{array}$ \\
\hline $\begin{array}{l}\text { Punto de buena } \\
\text { práctica }\end{array}$ & $\begin{array}{l}\text { Previo al inicio de la terapia biológica se debe } \\
\text { solicitar serología para hepatitis } B, C \text { y prueba } \\
\text { de VIH. }\end{array}$ \\
\hline $\begin{array}{l}\text { Punto de buena } \\
\text { práctica }\end{array}$ & $\begin{array}{l}\text { Los pacientes con enfermedad de Crohn } \\
\text { deben ser vacunados contra influenza, } \\
\text { neumococo, hepatitis B, varicela (al menos } 3 \\
\text { semanas antes del inicio del inmunosupresor) } \\
\text { y virus del papiloma humano (previo al inicio } \\
\text { de los medicamentos inmunosupresores } \\
\text { esteroides, tiopurinas y biológicos). }\end{array}$ \\
\hline
\end{tabular}




\begin{tabular}{|c|c|}
\hline Débil a favor & $\begin{array}{l}\text { Se sugiere utilizar un segundo anti-FNT } \\
\text { cuando no haya respuesta primaria o posterior } \\
\text { a la pérdida secundaria de respuesta a un } \\
\text { primer anti-FNT. } \\
\text { Calidad de la evidencia muy baja } \oplus \text { O০০ }\end{array}$ \\
\hline $\begin{array}{l}\text { Punto de buena } \\
\text { práctica }\end{array}$ & $\begin{array}{l}\text { Se debe individualizar el cambio de } \\
\text { tratamiento de acuerdo con los resultados de } \\
\text { los niveles séricos y de anticuerpos contra el } \\
\text { medicamento anti-FNT. }\end{array}$ \\
\hline $\begin{array}{l}\text { Punto de buena } \\
\text { práctica }\end{array}$ & $\begin{array}{l}\text { Pacientes con niveles adecuados de anti-FNT } \\
\text { y con anticuerpos }(+) \text { deben tratarse con otro } \\
\text { tipo de anti-FNT u otra clase de biológico. }\end{array}$ \\
\hline $\begin{array}{l}\text { Punto de buena } \\
\text { práctica }\end{array}$ & $\begin{array}{l}\text { En sujetos con niveles subterapéuticos de } \\
\text { anti-FNT y anticuerpos (-) debe acortarse el } \\
\text { intervalo o incrementarse la dosis del anti- } \\
\text { FNT. }\end{array}$ \\
\hline Débil a favor & $\begin{array}{l}\text { Se sugiere el uso de biosimilar de infliximab } \\
\text { para inducir y mantener la remisión en } \\
\text { pacientes con enfermedad de Crohn. } \\
\text { Calidad de la evidencia muy baja } \oplus \text { O০০ }\end{array}$ \\
\hline $\begin{array}{l}\text { Punto de buena } \\
\text { práctica }\end{array}$ & $\begin{array}{l}\text { Los pacientes en tratamiento con infliximab } \\
\text { innovador pueden continuar el tratamiento } \\
\text { con el biosimilar si vienen respondiendo al } \\
\text { anterior. }\end{array}$ \\
\hline $\begin{array}{l}\text { Punto de buena } \\
\text { práctica }\end{array}$ & $\begin{array}{l}\text { No se debe realizar intercambio entre las dos } \\
\text { moléculas en caso de falla terapéutica inicial } \\
\text { con cualquiera de ellas. }\end{array}$ \\
\hline $\begin{array}{l}\text { Punto de buena } \\
\text { práctica }\end{array}$ & $\begin{array}{l}\text { En caso de realizarse el intercambio no } \\
\text { médico entre un biológico innovador con } \\
\text { un biosimilar, debe informársele al médico } \\
\text { tratante para farmacovigilancia y se debe } \\
\text { contar con el consentimiento por parte del } \\
\text { paciente. }\end{array}$ \\
\hline Fuerte a favor & $\begin{array}{l}\text { Se recomienda el uso de infliximab, infliximab } \\
\text { más azatioprina, adalimumab o vedolizumab } \\
\text { para inducir la remisión en pacientes con } \\
\text { enfermedad de Crohn. } \\
\text { Calidad de la evidencia muy baja } \oplus \text { ○০০ }\end{array}$ \\
\hline Fuerte a favor & $\begin{array}{l}\text { Se recomienda el uso de azatioprina, } \\
\text { metotrexato, infliximab, infliximab más } \\
\text { azatioprina, adalimumab o vedolizumab para } \\
\text { mantener en remisión a los pacientes con } \\
\text { enfermedad de Crohn. } \\
\text { Calidad de la evidencia muy baja } \oplus \text { ○০০ }\end{array}$ \\
\hline
\end{tabular}

Pregunta 5. ¿Cuáles son las intervenciones más seguras y efectivas para el tratamiento de la enfermedad de Crohn perianal en pacientes mayores de 16 años?

Recomendación $\quad \mathrm{n}^{0} \quad$ Resumen

Débil a favor Se sugiere manejo con ciprofloxacina como terapia adjunta al manejo quirúrgico o inmunosupresor para el tratamiento de pacientes con enfermedad de Crohn con fístulas perianales. Calidad de la evidencia baja $\oplus \oplus \mathrm{O}$

\begin{tabular}{|c|c|}
\hline $\begin{array}{l}\text { Punto de buena } \\
\text { práctica }\end{array}$ & $\begin{array}{l}\text { El uso de antibióticos en conjunto } \\
\text { con la cirugía y la terapia biológica es } \\
\text { recomendable para intentar el cierre de las } \\
\text { fístulas perianales. }\end{array}$ \\
\hline $\begin{array}{l}\text { Punto de buena } \\
\text { práctica }\end{array}$ & $\begin{array}{l}\text { Debe realizarse resonancia nuclear } \\
\text { magnética de pelvis o endosonografía rectal } \\
\text { previo al drenaje. }\end{array}$ \\
\hline $\begin{array}{l}\text { Punto de buena } \\
\text { práctica }\end{array}$ & $\begin{array}{l}\text { Los pacientes con fístulas perianales simples } \\
\text { sintomáticos deben ser manejados con } \\
\text { fistulotomía o colocación de setón asociadas a } \\
\text { manejo con antibióticos (ciprofloxacina en } 500 \\
\text { mg, cada } 12 \text { horas, y/o metronidazol en } 500 \\
\text { mg, cada } 8 \text { horas, durante 6-8 semanas). }\end{array}$ \\
\hline $\begin{array}{l}\text { Punto de buena } \\
\text { práctica }\end{array}$ & $\begin{array}{l}\text { Se deben clasificar las fístulas perianales en: } \\
\text { - simples: superficiales o bajas } \\
\text { interesfintéricas o bajas transesfintéricas, } \\
\text { con un solo orificio externo; } \\
\text { - complejas: altas interesfintéricas, altas } \\
\text { transesfintéricas o supraesfintéricas, } \\
\text { rectovaginales, con absceso perianal, } \\
\text { actividad inflamatoria en mucosa rectal o } \\
\text { estenosis anorrectal. }\end{array}$ \\
\hline $\begin{array}{l}\text { Punto de buena } \\
\text { práctica }\end{array}$ & $\begin{array}{l}\text { Debe realizarse resonancia nuclear } \\
\text { magnética de pelvis o endosonografía rectal } \\
\text { ante la sospecha de enfermedad de Crohn } \\
\text { perianal para el diagnóstico y el seguimiento. }\end{array}$ \\
\hline Débil a favor & $\begin{array}{l}\text { Se sugiere el uso de infliximab para el } \\
\text { mantenimiento de la remisión de fístulas } \\
\text { perianales complejas en pacientes con } \\
\text { enfermedad de Crohn. } \\
\text { Calidad de la evidencia muy baja } \oplus \text { ○০০ }\end{array}$ \\
\hline $\begin{array}{l}\text { Punto de buena } \\
\text { práctica }\end{array}$ & $\begin{array}{l}\text { Se debe iniciar infliximab siempre en terapia } \\
\text { combinada con tiopurinas, a no ser que esta } \\
\text { última esté contraindicada. }\end{array}$ \\
\hline
\end{tabular}




\begin{tabular}{|c|c|}
\hline $\begin{array}{l}\text { Punto de buena } \\
\text { práctica }\end{array}$ & $\begin{array}{l}\text { Se debe adicionar ciprofloxacina en } 500 \text { mg, } \\
\text { cada } 12 \text { horas, durante } 12 \text { semanas, a la } \\
\text { terapia anti-FNT para mejorar los resultados } \\
\text { a corto plazo en pacientes con fístulas } \\
\text { perianales complejas. }\end{array}$ \\
\hline Fuerte a favor & $\begin{array}{l}\text { Se recomienda la terapia combinada, } \\
\text { anti-FNT más colocación de setón, en } \\
\text { el tratamiento de la enfermedad de } \\
\text { Crohn fistulizante perianal compleja, } \\
\text { para incrementar el cierre completo de la } \\
\text { fístula. } \\
\text { Calidad de la evidencia muy baja } \oplus \text { } \oplus \text { ○০ }\end{array}$ \\
\hline $\begin{array}{l}\text { Punto de buena } \\
\text { práctica }\end{array}$ & $\begin{array}{l}\text { En fístulas complejas debe realizarse } \\
\text { drenaje quirúrgico de abscesos antes de } \\
\text { iniciar el tratamiento médico con anti-FNT. }\end{array}$ \\
\hline $\begin{array}{l}\text { Punto de buena } \\
\text { práctica }\end{array}$ & $\begin{array}{l}\text { Se debe retirar el setón de drenaje una vez } \\
\text { se controle la infección, para permitir el } \\
\text { cierre de la fístula perianal. }\end{array}$ \\
\hline $\begin{array}{l}\text { Punto de buena } \\
\text { práctica }\end{array}$ & $\begin{array}{l}\text { Los pacientes con enfermedad de } \\
\text { Crohn perianal requieren de manejo } \\
\text { multidisciplinario con coloproctología. }\end{array}$ \\
\hline Débil a favor & $\begin{array}{l}\text { Se sugiere el uso de tacrólimus para el } \\
\text { tratamiento de la enfermedad de Crohn } \\
\text { fistulizante en pacientes refractarios } \\
\text { al tratamiento con terapia biológica y } \\
\text { antibióticos. } \\
\text { Calidad de la evidencia muy baja } \oplus \text { ○০০ }\end{array}$ \\
\hline Fuerte en contra & $\begin{array}{l}\text { No se recomienda el uso de pegantes de } \\
\text { fibrina en el tratamiento de los pacientes con } \\
\text { enfermedad de Crohn perianal. } \\
\text { Calidad de la evidencia muy baja } \oplus \text { ○০০ }\end{array}$ \\
\hline Débil a favor & $\begin{array}{l}\text { Se sugiere el abordaje transrectal o } \\
\text { transvaginal para el cierre de las fístulas } \\
\text { rectovaginales en las pacientes con } \\
\text { enfermedad de Crohn. } \\
\text { Calidad de la evidencia muy baja } \oplus \text { ○০০ }\end{array}$ \\
\hline $\begin{array}{l}\text { Punto de buena } \\
\text { práctica }\end{array}$ & $\begin{array}{l}\text { Se debe escoger el abordaje transrectal } \\
\text { como primera alternativa para el cierre de las } \\
\text { fístulas rectovaginales. }\end{array}$ \\
\hline $\begin{array}{l}\text { Punto de buena } \\
\text { práctica }\end{array}$ & $\begin{array}{l}\text { No debe haber actividad endoscópica en el } \\
\text { recto durante al menos dos años, antes de } \\
\text { considerar realizar el cierre quirúrgico de la } \\
\text { fístula. }\end{array}$ \\
\hline Débil a favor & $\begin{array}{l}\text { Se sugiere la derivación fecal como } \\
\text { terapia de rescate en los pacientes } \\
\text { con enfermedad de Crohn perianal con } \\
\text { falla al manejo convencional médico } \\
\text { quirúrgico. } \\
\text { Calidad de la evidencia muy baja } \oplus \text { } \odot \text { ○০ }\end{array}$ \\
\hline
\end{tabular}



Pregunta 6. ¿Cuáles son las intervenciones más seguras y efectivas para el abordaje quirúrgico y endoscópico de los pacientes mayores de 16 años con enfermedad de Crohn?

\section{Recomendación $n .^{\circ} \quad$ Resumen}

Débil a favor

Se sugiere no contraindicar el procedimiento quirúrgico en los pacientes con enfermedad de Crohn que reciben terapia biológica. Calidad de la evidencia muy baja $\oplus$ O००

Débil a favor Se sugiere continuar la azatioprina previo al procedimiento quirúrgico en pacientes con enfermedad de Crohn.

Calidad de la evidencia muy baja $\oplus$ O००

Punto de buena Si el procedimiento es diferible, se debe práctica realizar la intervención quirúrgica antes del inicio de la siguiente dosis de terapia biológica.

Punto de buena Se debe vigilar la posibilidad de infecciones práctica en el período postoperatorio.

Débil a favor

Se sugiere el tratamiento quirúrgico en pacientes con abscesos intraabdominales asociados a enfermedad de Crohn, solo en caso de no respuesta al tratamiento médico y/o radiológico inicial. Calidad de la evidencia muy baja $\oplus$ ○૦०

Punto de buena práctica

Los abscesos menores de $3 \mathrm{~cm}$ deben recibir solo tratamiento antibiótico. Los pacientes con abscesos mayores de $3 \mathrm{~cm}$ requieren, adicionalmente, drenaje radiológico percutáneo.

Punto de buena En caso de no respuesta al tratamiento médico práctica o de que los abscesos no puedan ser drenados percutáneamente (tabicados o de difícil acceso), se debe realizar tratamiento quirúrgico.

Fuerte a favor Se recomienda el uso de la dilatación neumática endoscópica con balón en los pacientes con estenosis asociadas a enfermedad de Crohn.

Calidad de la evidencia muy baja $\oplus$ O००

$\begin{array}{ll}\begin{array}{ll}\text { Punto de buena } \\ \text { práctica }\end{array} & \text { Se consideran indicaciones de dilatación } \\ & \text { neumática endoscópica: } \\ & \text { - longitud de la estenosis menor de } 4 \mathrm{~cm} ; \\ & \text { en la anastomosis ileocólica; } \\ & \text { - estenosis únicas. }\end{array}$




\begin{tabular}{|c|c|}
\hline $\begin{array}{l}\text { Punto de buena } \\
\text { práctica }\end{array}$ & $\begin{array}{l}\text { La presencia de fístulas o abscesos } \\
\text { en el área de la estenosis representa } \\
\text { una contraindicación para la dilatación } \\
\text { endoscópica. }\end{array}$ \\
\hline $\begin{array}{l}\text { Punto de buena } \\
\text { práctica }\end{array}$ & $\begin{array}{l}\text { Se debe intentar determinar por imágenes } \\
\text { diagnósticas si el componente de la estenosis } \\
\text { es fibrótico o inflamatorio. }\end{array}$ \\
\hline Fuerte a favor & $\begin{array}{l}\text { Se recomienda realizar la estricturoplastia } \\
\text { en pacientes con enfermedad de Crohn } \\
\text { estenosante de intestino delgado. } \\
\text { Calidad de la evidencia muy baja } \oplus \text { ○০০ }\end{array}$ \\
\hline $\begin{array}{l}\text { Punto de buena } \\
\text { práctica }\end{array}$ & $\begin{array}{l}\text { La estricturoplastia es altamente recomendable } \\
\text { en pacientes con estenosis múltiples, menores } \\
\text { de } 10 \mathrm{~cm} \text {, para evitar las resecciones extensas } \\
\text { del intestino delgado y disminuir el riesgo de } \\
\text { síndrome de intestino corto. Esta debe ser } \\
\text { realizada por especialistas con experiencia en } \\
\text { este tipo de patología. }\end{array}$ \\
\hline Débil a favor & $\begin{array}{l}\text { Se sugiere la laparoscopia o la cirugía abierta } \\
\text { para el tratamiento quirúrgico de los pacientes } \\
\text { con enfermedad de Crohn. La selección de la } \\
\text { técnica será de acuerdo con la experiencia local. } \\
\text { Calidad de la evidencia muy baja } \oplus \text { ○০০ }\end{array}$ \\
\hline $\begin{array}{l}\text { Punto de buena } \\
\text { práctica }\end{array}$ & $\begin{array}{l}\text { Siempre que sea factible, se debe preferir la } \\
\text { cirugía mínimamente invasiva por menor riesgo } \\
\text { de adherencias y mejores resultados estéticos. }\end{array}$ \\
\hline $\begin{array}{l}\text { Punto de buena } \\
\text { práctica }\end{array}$ & $\begin{array}{l}\text { La cirugía mínimamente invasiva debe } \\
\text { realizarse en centros con experiencia, con un } \\
\text { volumen adecuado de pacientes. }\end{array}$ \\
\hline Fuerte a favor & $\begin{array}{l}\text { Se recomienda la realización de anastomosis } \\
\text { laterolaterales en los pacientes con } \\
\text { enfermedad de Crohn sometidos a resección } \\
\text { quirúrgica. } \\
\text { Calidad de la evidencia muy baja } \oplus \text { } \odot \text { ○০ }\end{array}$ \\
\hline Débil a favor & $\begin{array}{l}\text { Se sugiere la resección segmentaria en } \\
\text { pacientes con enfermedad de Crohn } \\
\text { localizada del colon }(<30 \mathrm{~cm}) \text {. } \\
\text { Calidad de la evidencia muy baja } \oplus \text { ○০০ }\end{array}$ \\
\hline
\end{tabular}

\section{Pregunta 7. ¿Cuáles son las intervenciones más seguras y efectivas para prevenir la recurrencia en los pacientes mayores de 16 años con enfermedad de Crohn posquirúrgica?}

\begin{tabular}{|c|c|}
\hline Recomendación $n .^{\circ}$ & Resumen \\
\hline Fuerte en contra & $\begin{array}{l}\text { No se recomienda el uso de probióticos para } \\
\text { prevenir la recurrencia de la enfermedad de } \\
\text { Crohn posquirúrgica. } \\
\text { Calidad de la evidencia muy baja } \oplus \text { O०० }\end{array}$ \\
\hline
\end{tabular}

$\begin{array}{ll}\begin{array}{l}\text { Punto de buena } \\ \text { práctica }\end{array} & \text { En todo paciente con enfermedad de } \\ & \text { Crohn sometido a resección quirúrgica se } \\ & \text { debe identificar la presencia de factores de } \\ \text { riesgo para la recaída posquirúrgica, con el } & \text { ánimo de implementar las intervenciones } \\ \text { farmacológicas preventivas. } \\ \text { - factores de alto riesgo: edad }<30 \text { años, } \\ \text { tabaquismo, }>2 \text { cirugias por EC penetrante (B3); } \\ \text { - factores de bajo riesgo: edad }>50 \text { años, no } \\ \text { fumadores, primera cirugía, estenosis corta } \\ <10-20 \mathrm{~cm} \text {, duración } \mathrm{EC}>10 \text { años. }\end{array}$

Punto de buena práctica

Se debe realizar ileocolonoscopia de 6 a 12 meses después de la cirugía para identificar la recaída endoscópica.
Débil a favor Se sugiere el uso de antibióticos para prevenir la recurrencia de la enfermedad de Crohn posquirúrgica.
Calidad de la evidencia baja $\oplus \oplus 00$
Punto de buena El antibiótico que se debe utilizar es práctica metronidazol, en dosis de 15 a $20 \mathrm{mg} / \mathrm{kg}$, por un tiempo de 3 meses. Cuando se use este medicamento, se debe monitorizar estrechamente la tolerancia y la aparición de eventos adversos, especialmente neuropatía periférica.

\begin{tabular}{|c|c|}
\hline $\begin{array}{l}\text { Punto de buena } \\
\text { práctica }\end{array}$ & $\begin{array}{l}\text { En pacientes de bajo riesgo, se recomienda } \\
\text { un curso de } 3 \text { meses con metronidazol } \\
\text { o hacer una monitorización estrecha sin } \\
\text { medicamentos en casos de intolerancia. }\end{array}$ \\
\hline $\begin{array}{l}\text { Punto de buena } \\
\text { práctica }\end{array}$ & $\begin{array}{l}\text { En todo paciente con enfermedad de Crohn } \\
\text { que haya sido intervenido quirúrgicamente se } \\
\text { debe evitar el consumo de tabaco. }\end{array}$ \\
\hline Débil a favor & $\begin{array}{l}\text { Se sugiere el uso de azatioprina o } \\
\text { 6-mercaptopurina para prevenir la recurrencia } \\
\text { en pacientes con enfermedad de Crohn } \\
\text { postquirúrgica. } \\
\text { Calidad de la evidencia muy baja } \oplus \text { ○০০ }\end{array}$ \\
\hline $\begin{array}{l}\text { Punto de buena } \\
\text { práctica. }\end{array}$ & $\begin{array}{l}\text { En pacientes de alto riesgo de recaída, las } \\
\text { tiopurinas pueden usarse concomitantemente } \\
\text { con anti-FNT, con o sin metronidazol, durante } \\
\text { los primeros } 3 \text { meses. Se debe monitorizar la } \\
\text { tolerancia al medicamento. }\end{array}$ \\
\hline Débil a favor & $\begin{array}{l}\text { Se sugiere el uso de 5-ASA para prevenir } \\
\text { la recurrencia clínica en pacientes con } \\
\text { enfermedad de Crohn posquirúrgica. } \\
\text { Calidad de la evidencia baja } \oplus \oplus \bigcirc \bigcirc\end{array}$ \\
\hline $\begin{array}{l}\text { Punto de buena } \\
\text { práctica }\end{array}$ & $\begin{array}{l}\text { El uso de mesalazina debe considerarse } \\
\text { solo en pacientes de bajo riesgo de recaída } \\
\text { posquirúrgica o en aquellos que tengan } \\
\text { contraindicación absoluta o relativa para } \\
\text { tiopurinas o anti-FNT. }\end{array}$ \\
\hline
\end{tabular}




\begin{tabular}{|c|c|}
\hline Débil en contra & $\begin{array}{l}\text { No se sugiere el uso de budesonida para } \\
\text { prevenir la recurrencia en pacientes con } \\
\text { enfermedad de Crohn posquirúrgica. } \\
\text { Calidad de la evidencia baja } \oplus \oplus \bigcirc \bigcirc\end{array}$ \\
\hline Débil a favor & $\begin{array}{l}\text { Se sugiere el uso de anti-FNT como terapia } \\
\text { de primera línea para prevenir la recurrencia } \\
\text { endoscópica en pacientes con enfermedad de } \\
\text { Crohn posquirúrgica de alto riesgo. } \\
\text { Calidad de la evidencia baja } \oplus \oplus \bigcirc \bigcirc\end{array}$ \\
\hline $\begin{array}{l}\text { Punto de buena } \\
\text { práctica }\end{array}$ & $\begin{array}{l}\text { En pacientes con alto riesgo de recurrencia } \\
\text { se recomienda iniciar el tratamiento durante } \\
6 \text { meses con anti-FNT } \pm \text { tiopurinas, si no hay } \\
\text { contraindicación, asociado o no a terapia con } \\
\text { metronidazol ( } 3 \text { meses). }\end{array}$ \\
\hline Fuerte a favor & $\begin{array}{l}\text { Se recomienda el uso de medicamentos anti- } \\
\text { FNT para tratar las recaídas en pacientes con } \\
\text { enfermedad de Crohn posquirúrgica. } \\
\text { Calidad de la evidencia muy baja } \oplus \text { } \\
\text { ○० }\end{array}$ \\
\hline
\end{tabular}

\begin{tabular}{|c|c|}
\hline $\begin{array}{l}\text { Punto de buena } \\
\text { práctica }\end{array}$ & $\begin{array}{l}\text { En pacientes con recurrencia posquirúrgica } \\
\text { de bajo riesgo se recomienda el uso inicial de } \\
\text { tiopurinas } \pm \text { metronidazol (este último durante } \\
3 \text { meses); en caso de no respuesta, se debe } \\
\text { manejar con terapia anti-FNT. }\end{array}$ \\
\hline Fuerte a favor & $\begin{array}{l}\text { Se recomienda que a los pacientes con } \\
\text { enfermedad de Crohn se les informe } \\
\text { claramente sobre el manejo de la enfermedad } \\
\text { y las opciones de tratamiento, con sus riesgos } \\
\text { y beneficios. } \\
\text { Calidad de la evidencia muy baja } \oplus \text { ○০০ }\end{array}$ \\
\hline Fuerte a favor & $\begin{array}{l}\text { Se recomienda que se evalué la presencia de } \\
\text { signos de depresión o pérdida de la calidad de } \\
\text { vida, y si es necesario, se remita a grupos de } \\
\text { apoyo y de ayuda especializada. } \\
\text { Calidad de la evidencia muy baja } \oplus \text { } \bigcirc \text { }\end{array}$ \\
\hline
\end{tabular}

\section{ALGORITMOS}

\section{ALGORITMO 1}

\section{Tratamiento de la enfermedad de Crohn luminal}

Determinar la actividad de la EC por clínica, hallazgos endoscópicos y biomarcadores (PCR, calprotectina). Determinar la presencia de factores de riesgo de EC complicada*. En EC activa, se sugiere la monitorización estricta de la respuesta clínica cada 3 meses, PCR y calprotectina cada 3-6 meses e ileocolonoscopia (o RNM, si no es posible) cada 6-9 meses. En caso de no respuesta, se debe escalar el tratamiento.
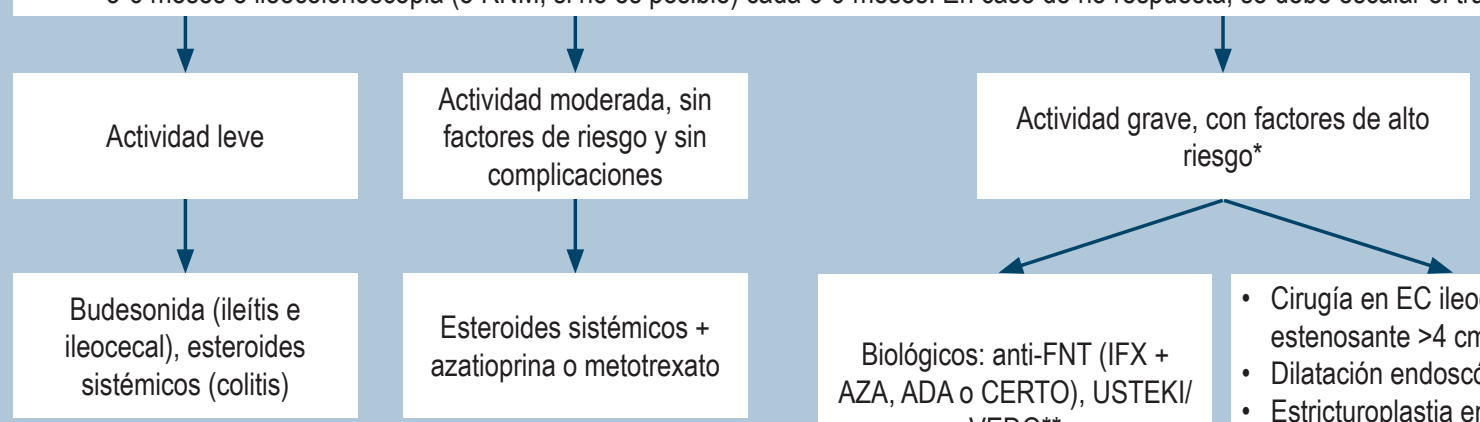

- Cirugía en EC ileocecal localizada

Esteroides sistémicos + sistémicos (colitis)

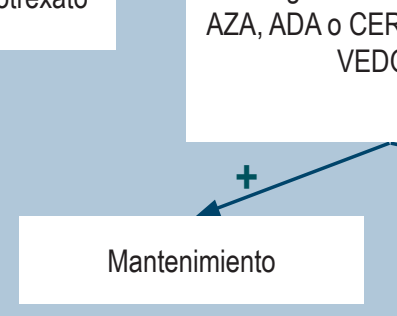

*Factores de alto riesgo: EC extensa intestino delgado, EC grave superior, compromiso rectal, lesiones perianales, comportamiento estenosante y penetrante (B2, B3), lesiones endoscópicas graves, tabaquismo y edad joven al diagnóstico (<40 años)

**En $>65$ años por riesgo de infección, hombres $<35$ años por riesgo de linfoma e historia de malignidad: monoterapia, antifactor de necrosis tumoral (anti-FNT), vedolizumab o ustekinumab) estenosante $>4 \mathrm{~cm}$

- Dilatación endoscópica en $<4 \mathrm{~cm}$

- Estricturoplastia en estenosis en intestino delgado $4-10 \mathrm{~cm}$, resección $>10 \mathrm{~cm}$
Optimizar la dosis (ideal niveles y anticuerpos), en no respuesta primaria o pérdida de respuesta $2^{\circ}$, cambiar dentro o fuera de clase de biológico

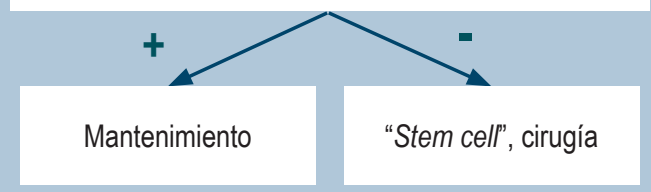




\section{ALGORITMO 2}

\section{Tratamiento de la EC fistulizante perianal}

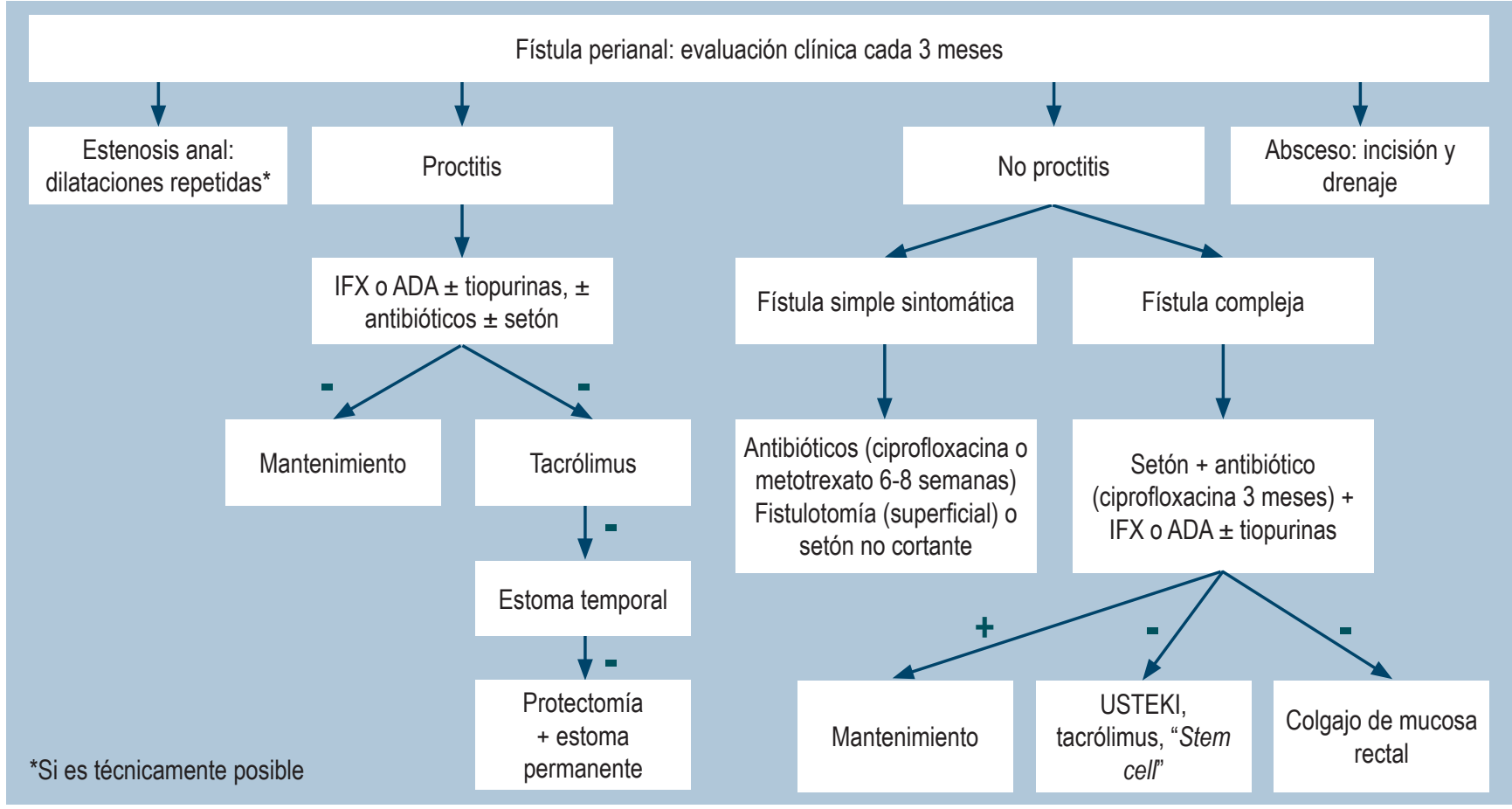

\section{ALGORITMO 3}

\section{Tratamiento de la EC posquirúrgica}

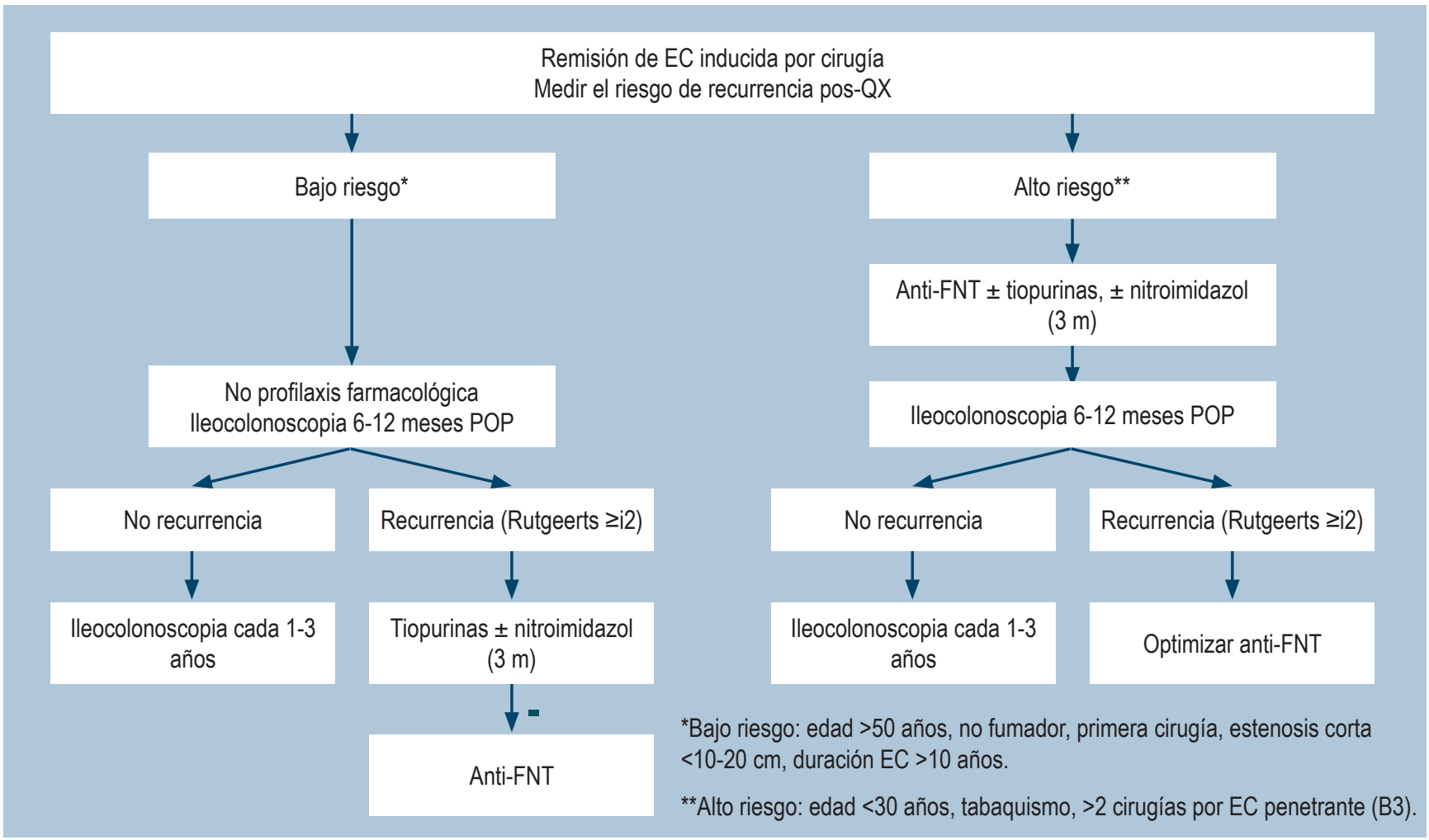




\section{MÓDULO DE IMPLEMENTACIÓN}

Con el fin de apoyar la implementación de esta guía, se recomienda utilizar el Manual para la implementación de guías en el marco del aseguramiento colombiano (MSPS, 2014).

A continuación, se presentan las consideraciones que deben tenerse en cuenta para los diferentes actores del sistema de salud al momento de implementar la guía.

\section{ACTORES RESPONSABLES DE LA IMPLEMENTACIÓN DE LAS RECOMENDACIONES DE LA GPC}

Es importante identificar a los responsables de apoyar o ejecutar las actividades de implementación a nivel nacional o en las instituciones prestadoras de servicios de salud (ISPSS). Los principales actores del proceso de implementación de la guía de tratamiento de la enfermedad de Crohn son:

- Entes gubernamentales:

- Ministerio de Salud y Protección Social

- Cuenta de alto costo

- Entidades territoriales

- Superintendencia de salud

- Instituciones:

- Entidades promotoras de salud

- Sociedades científicas

- Asociación Colombiana de Gastroenterología

- Instituciones prestadoras de servicios de salud

- Asociaciones de pacientes y representantes de la sociedad civil

- Usuarios:

- Gastroenterólogos

- Cirujanos

- Coloproctólogos

- Pacientes

\section{RECOMENDACIONES CLAVE DE LA IMPLEMENTACIÓN}

Con el fin de identificar las recomendaciones de mayor impacto en la guía y sobre las cuales se pueden priorizar los esfuerzos de implementación, el GDG seleccionó las siguientes recomendaciones:

- Se recomienda la medición de los niveles de proteína C-reactiva (PCR) y el uso de velocidad de sedimentación globular (VSG) para predecir la recaída en pacientes con enfermedad de Crohn.

- Se sugiere implementar la cicatrización de la mucosa como objetivo terapéutico en pacientes con enfermedad de Crohn.

- Se sugiere la vigilancia clínica de las infecciones oportunistas en los pacientes con enfermedad de Crohn que reciban terapia biológica.
- No se recomienda el uso de esteroides sistémicos para mantener la remisión en pacientes con enfermedad de Crohn.

- Se sugiere el uso de biosimilar de infliximab para inducir y mantener la remisión en pacientes con enfermedad de Crohn.

- Se recomienda el uso de azatioprina, metotrexato, infliximab, infliximab más azatioprina, adalimumab o vedolizumab para mantener en remisión a los pacientes con enfermedad de Crohn.

- Se recomienda la terapia combinada, anti-FNT más colocación de setón, en el tratamiento de la enfermedad de Crohn fistulizante perianal compleja, para incrementar el cierre completo de la fístula.

- Se recomienda que se evalué la presencia de signos de depresión o pérdida de la calidad de vida, y si es necesario, se remita a grupos de apoyo y de ayuda especializada.

\section{IDENTIFICACIÓN DE BARRERAS Y FACILITADORES}

Con el fin de facilitar el uso de la guía en el contexto colombiano, se deben identificar las barreras, los facilitadores y las estrategias de implementación.

\begin{tabular}{|c|c|}
\hline Barreras & Facilitadores/estrategias \\
\hline $\begin{array}{l}\text { Desconocimiento de las } \\
\text { recomendaciones de } \\
\text { la guía }\end{array}$ & $\begin{array}{l}\text { Desarrollo de jornadas de capacitación } \\
\text { a nivel institucional, gremial y } \\
\text { gubernamental. Las capacitaciones } \\
\text { pueden ser presenciales o virtuales con } \\
\text { el fin de facilitar el entrenamiento de } \\
\text { los profesionales para el manejo de la } \\
\text { enfermedad de Crohn. } \\
\text { - Inclusión de recordatorios de las } \\
\text { recomendaciones clave que deben } \\
\text { implementarse en cada institución y en } \\
\text { las historias clínicas de los pacientes } \\
\text { diagnosticados con enfermedad de } \\
\text { Crohn. } \\
\text { Inclusión de la guía dentro de los } \\
\text { programas curriculares de las facultades } \\
\text { de Medicina. }\end{array}$ \\
\hline $\begin{array}{l}\text { Acceso limitado a la } \\
\text { guía }\end{array}$ & $\begin{array}{l}\text { - Desarrollar diferentes formas de } \\
\text { diseminación de las recomendaciones } \\
\text { de la guía, tales como: publicación } \\
\text { de artículos científicos, distribución } \\
\text { de algoritmos de manejo y uso de } \\
\text { aplicaciones móviles. } \\
\text { - Disponibilidad de la guía en el portal } \\
\text { de la Asociación Colombiana de } \\
\text { Gastroenterología. } \\
\text { - Distribución de la guía a los grupos de } \\
\text { interés y potenciales usuarios dentro del } \\
\text { marco de congresos y cátedras. }\end{array}$ \\
\hline
\end{tabular}




\begin{tabular}{|c|c|}
\hline $\begin{array}{l}\text { Percepción de que no } \\
\text { existen políticas de } \\
\text { apoyo }\end{array}$ & $\begin{array}{l}\text { - Implementar las políticas de atención } \\
\text { en salud de las enfermedades } \\
\text { huérfanas, como el Decreto } 1954 \\
\text { de } 2012 \text { (reporte a los sistemas de } \\
\text { información), la Ley } 1392 \text { de } 2010 \\
\text { (garantía de atención a enfermedades } \\
\text { huérfanas), la Circular } 011 \text { de } 2016 \\
\text { Supersalud (establece instrucciones } \\
\text { para el tratamiento de los pacientes } \\
\text { con enfermedades raras por parte } \\
\text { de las EAPB, las IPS y las entidades } \\
\text { territoriales). } \\
\text { - Plantear políticas que permitan } \\
\text { implementar la guía a nivel institucional. }\end{array}$ \\
\hline $\begin{array}{l}\text { Baja presencia de la } \\
\text { guía en los sistemas } \\
\text { electrónicos de apoyo a } \\
\text { la toma de decisiones }\end{array}$ & $\begin{array}{l}\text { - La guía puede ser incluida dentro } \\
\text { de aplicaciones móviles, boletines } \\
\text { electrónicos institucionales o en páginas } \\
\text { especializadas para apoyar el proceso de } \\
\text { consulta rápida. }\end{array}$ \\
\hline $\begin{array}{l}\text { No existencia de } \\
\text { responsables de la } \\
\text { implementación de la } \\
\text { guía en IPS }\end{array}$ & $\begin{array}{l}\text { Esta estrategia busca que cada IPS } \\
\text { tenga un responsable que se encargue } \\
\text { de verificar la adherencia a las } \\
\text { recomendaciones de las guías, incluida la } \\
\text { de enfermedad de Crohn. }\end{array}$ \\
\hline $\begin{array}{l}\text { No existencia de apoyo } \\
\text { administrativo en la } \\
\text { implementación de las } \\
\text { guías }\end{array}$ & $\begin{array}{l}\text { - La gerencia de cada IPS debe apoyar } \\
\text { las actividades de implementación de } \\
\text { las GPC con el fin de que estas puedan } \\
\text { realizarse adecuadamente. }\end{array}$ \\
\hline $\begin{array}{l}\text { Baja adherencia a las } \\
\text { recomendaciones de } \\
\text { la guía }\end{array}$ & $\begin{array}{l}\text { - Usar estrategias para aumentar } \\
\text { el conocimiento de la guía entre } \\
\text { gastroenterólogos, proctólogos y } \\
\text { pacientes. } \\
\text { - Diseñar estrategias de manejo } \\
\text { multidisciplinario. } \\
\text { - Mejorar la relación médico-paciente. } \\
\text { - Considerar la baja adherencia a la guía } \\
\text { por parte de los pacientes de acuerdo } \\
\text { con los predictores fuertes, tales como: } \\
\text { la preocupación por los efectos adversos } \\
\text { y la percepción del tratamiento, para } \\
\text { incluirlas en el manejo de la enfermedad. } \\
\text { - Usar los algoritmos de manejo. }\end{array}$ \\
\hline Altos costos & $\begin{array}{l}\text { - Incluir todas las opciones terapéuticas en } \\
\text { el plan de beneficios. }\end{array}$ \\
\hline
\end{tabular}

\section{INDICADORES}

A continuación, se presentan los indicadores de proceso y resultado de la implementación de la GPC. Algunos son parte del consenso internacional para la evaluación de la calidad de la atención de enfermedad de Crohn.

\section{Elemento}

Característica

\begin{tabular}{|c|c|}
\hline Indicador 1 & $\begin{array}{l}\text { Proporción de pacientes tamizados para } \\
\text { tuberculosis antes de iniciar la terapia anti-FNT }\end{array}$ \\
\hline Tipo de indicador & Proceso, indicador internacional de calidad \\
\hline Método de cálculo & $\begin{array}{l}\text { Número de pacientes tamizados para } \\
\text { tuberculosis antes de iniciar la terapia anti-FNT/ } \\
\text { número de pacientes tratados con anti-FNT * } 100\end{array}$ \\
\hline $\begin{array}{l}\text { Periodicidad } \\
\text { (frecuencia de } \\
\text { medición) }\end{array}$ & Semestral \\
\hline $\begin{array}{l}\text { Responsable (del } \\
\text { seguimiento) }\end{array}$ & IPS, entes gubernamentales \\
\hline Meta & $100 \%$ \\
\hline
\end{tabular}

\begin{tabular}{ll}
\multicolumn{1}{c}{ Elemento } & \multicolumn{1}{c|}{ Característica } \\
\hline Indicador 2 & $\begin{array}{l}\text { Proporción de pacientes con prueba de TPMT } \\
\text { antes de la terapia con tiopurinas }\end{array}$ \\
\hline $\begin{array}{l}\text { Tipo de indicador } \\
\text { Método de cálculo }\end{array}$ & $\begin{array}{l}\text { Púmero de pacientes con prueba de TPMT antes } \\
\text { de la terapia con tiopurinas/número de pacientes } \\
\text { tratados con tiopurinas * 100 }\end{array}$ \\
\hline $\begin{array}{l}\text { Periodicidad } \\
\text { (frecuencia de } \\
\text { medición) }\end{array}$ & Semestral \\
\hline $\begin{array}{l}\text { Responsable (del } \\
\text { seguimiento) }\end{array}$ & IPS, entes gubernamentales \\
\hline Meta & $100 \%$
\end{tabular}

Elemento Característica

Indicador 3 Proporción de pacientes con enfermedad de Crohn tratados con azatioprina activa y que van a recibir terapia biológica con infliximab para inducir la remisión

\begin{tabular}{ll} 
Tipo de indicador & Proceso \\
Método de cálculo & $\begin{array}{l}\text { Número de pacientes con enfermedad de } \\
\text { Crohn activa tratados con infliximab para } \\
\text { inducir la remisión y que previamente recibieron } \\
\text { azatioprina/número de pacientes con enfermedad } \\
\text { de Crohn activa tratados con infliximab para } \\
\text { inducir la remisión * 100 }\end{array}$ \\
\hline $\begin{array}{l}\text { Periodicidad } \\
\text { (frecuencia de } \\
\text { medición) }\end{array}$ & $\begin{array}{l}\text { Semestral } \\
\text { Responsable (del } \\
\text { seguimiento) }\end{array}$ \\
\hline \begin{tabular}{l} 
Meta \\
\hline
\end{tabular}
\end{tabular}




\begin{tabular}{ll|}
\hline \multicolumn{1}{c|}{ Elemento } & \multicolumn{1}{c|}{ Característica } \\
\hline Indicador 4 & $\begin{array}{l}\text { Proporción de pacientes en remisión sin terapia } \\
\text { con esteroides }\end{array}$ \\
\hline $\begin{array}{l}\text { Tipo de indicador } \\
\text { Método de cálculo }\end{array}$ & $\begin{array}{l}\text { Resultado, indicador internacional de calidad } \\
\text { Númeroides/númentes en remisión sin terapia con } \\
\text { esterientes en remisión * }\end{array}$ \\
\hline $\begin{array}{l}\text { Periodicidad } \\
\text { (frecuencia de } \\
\text { medición) }\end{array}$ & Semestral \\
\hline $\begin{array}{l}\text { Responsable (del } \\
\text { seguimiento) }\end{array}$ & IPS, entes gubernamentales \\
\hline Meta & $100 \%$ \\
\hline
\end{tabular}

\begin{tabular}{|c|c|}
\hline Elemento & Característica \\
\hline Indicador 5 & $\begin{array}{l}\text { Proporción de pacientes hospitalizados por } \\
\text { enfermedad de Crohn al año }\end{array}$ \\
\hline Tipo de indicador & Resultado \\
\hline Método de cálculo & $\begin{array}{l}\text { Número de pacientes hospitalizados por } \\
\text { enfermedad de Crohn al año/número de } \\
\text { pacientes con enfermedad de Crohn al año * } 100\end{array}$ \\
\hline $\begin{array}{l}\text { Periodicidad } \\
\text { (frecuencia de } \\
\text { medición) }\end{array}$ & Anual \\
\hline $\begin{array}{l}\text { Responsable (del } \\
\text { seguimiento) }\end{array}$ & IPS, entes gubernamentales \\
\hline
\end{tabular}

\section{ANEXOS}

\section{ANEXO 1}

\section{Análisis de conflicto de intereses}

\begin{tabular}{|c|c|c|c|c|c|}
\hline $\begin{array}{c}\text { Integrante del } \\
\text { GDG }\end{array}$ & $\begin{array}{l}\text { ¿Presenta } \\
\text { conflicto de } \\
\text { interés de tipo } \\
\text { económico } \\
\text { personal? }\end{array}$ & $\begin{array}{l}\text { ¿Presenta } \\
\text { conflicto de } \\
\text { interés de tipo } \\
\text { económico no } \\
\text { personal? }\end{array}$ & $\begin{array}{l}\text { ¿Presenta } \\
\text { conflicto de } \\
\text { interés de tipo } \\
\text { no económico } \\
\text { personal? }\end{array}$ & $\begin{array}{l}\text { ¿Tiene algún } \\
\text { familiar de primer } \\
\text { grado con conflicto } \\
\text { de interés de tipo } \\
\text { económico? }\end{array}$ & Análisis y decisión \\
\hline Fabián Juliao & Sí & No & Sí & No & $\begin{array}{l}\text { - Presenta conflicto por ser "speaker" de } \\
\text { medicamentos biológicos para la enfermedad } \\
\text { de Crohn a nombre de laboratorios } \\
\text { farmacéuticos. } \\
\text { - Exclusión parcial en preguntas de } \\
\text { medicamentos biológicos. }\end{array}$ \\
\hline William Otero & No & No & No & No & - Participación total \\
\hline Luis Pineda & No & No & No & No & $\begin{array}{l}\text { - Ha trabajado con la industria farmacéutica, pero } \\
\text { no con enfermedad de Crohn. } \\
\text { - Participación total }\end{array}$ \\
\hline $\begin{array}{l}\text { María T. } \\
\text { Galeano }\end{array}$ & Sí & No & Sí & No & $\begin{array}{l}\text { - Presenta conflicto por ser "speaker" de } \\
\text { medicamentos biológicos para enfermedad de } \\
\text { Crohn a nombre de laboratorios farmacéuticos. } \\
\text { - Exclusión parcial en preguntas de } \\
\text { medicamentos biológicos. }\end{array}$ \\
\hline $\begin{array}{l}\text { Carlos } \\
\text { Fernando Grillo }\end{array}$ & Ninguno & Ninguno & Ninguno & Ninguno & - Participación total \\
\hline $\begin{array}{l}\text { Ana Marcela } \\
\text { Torres }\end{array}$ & Ninguno & Ninguno & Ninguno & Ninguno & - Participación total \\
\hline $\begin{array}{l}\text { María Teresa } \\
\text { Vallejo }\end{array}$ & Ninguno & Ninguno & Ninguno & Ninguno & - Participación total \\
\hline
\end{tabular}




\section{ANEXO 2}

\section{Preguntas desarrolladas en formato PICO}

1. ¿Cuáles son los factores que permiten predecir recaídas en pacientes mayores de 16 años con enfermedad de Crohn?

\begin{tabular}{|c|c|c|}
\hline Población & $\begin{array}{l}\text { Prueba diagnóstical } \\
\text { comparador }\end{array}$ & Desenlaces \\
\hline $\begin{array}{l}\text { - Población mayor de } 16 \text { años con enfermedad } \\
\text { de Crohn en remisión }\end{array}$ & $\begin{array}{l}\text { - PCR } \\
\text { - MRI (índice de María) } \\
\text { - Calprotectina } \\
\text { - Colonoscopia } \\
\text { - Lactoferrina } \\
\text { - Ecografía } \\
\text { - Cápsula endoscópica } \\
\text { - ASCA }\end{array}$ & $\begin{array}{l}\text { - Actividad de la enfermedad } \\
\text { - Calidad de vida } \\
\text { - Recaída endoscópica } \\
\text { - Recurrencia de fístulas } \\
\text { - Hospitalización } \\
\text { - Cirugía }\end{array}$ \\
\hline
\end{tabular}

\section{2. ¿Cuáles son las intervenciones no biológicas más seguras y efectivas para inducir} la remisión en pacientes mayores de 16 años con enfermedad de Crohn?

\begin{tabular}{|c|c|c|}
\hline Población & $\begin{array}{l}\text { Intervención/ } \\
\text { comparador }\end{array}$ & Desenlaces \\
\hline $\begin{array}{l}\text { - Población mayor de } 16 \text { años con diagnóstico } \\
\text { de enfermedad de Crohn ileocecal } \\
\text { - Población mayor de } 16 \text { años con diagnóstico } \\
\text { de enfermedad de Crohn colónica } \\
\text { - Población mayor de } 16 \text { años con diagnóstico } \\
\text { de enfermedad de Crohn de intestino delgado } \\
\text { aislado } \\
\text { - Población mayor de } 16 \text { años con diagnóstico } \\
\text { de enfermedad de Crohn de vía digestiva } \\
\text { superior }\end{array}$ & $\begin{array}{l}\text { - Esteroides intravenosos } \\
\text { - Esteroides orales (prednisolona, prednisona, } \\
\text { budesonida de liberación ileal, budesonida } \\
\text { MMX) } \\
\text { - } 5 \text {-aminosalicilatos } \\
\text { - Azatioprina } \\
\text { - 6-mercaptopurina } \\
\text { - Metotrexato } \\
\text { - Probióticos } \\
\text { - Antibióticos (ciprofloxacina, metronidazol, } \\
\text { rifaximina) }\end{array}$ & $\begin{array}{l}\text { - Ausencia de síntomas clínicos } \\
\text { - Tasa de remisión } \\
\text { - Actividad de la enfermedad } \\
\text { - Mejoría endoscópica (cicatrización de la } \\
\text { mucosa) } \\
\text { - Tasa de cirugía } \\
\text { - Tasa de hospitalización } \\
\text { - Retiro o suspensión del tratamiento por } \\
\text { - eventos adversos (adherencia al tratamiento) } \\
\text { - Ealidad de vida } \\
\text { Eventos adversos }\end{array}$ \\
\hline
\end{tabular}

\section{3. ¿Cuáles son las intervenciones no biológicas más seguras y efectivas para mantener} en remisión a los pacientes mayores de 16 años con enfermedad de Crohn?

\begin{tabular}{|c|c|c|}
\hline Población & $\begin{array}{l}\text { Intervención/ } \\
\text { comparador }\end{array}$ & Desenlaces \\
\hline $\begin{array}{l}\text { - Población mayor de } 16 \text { años con diagnóstico } \\
\text { de enfermedad de Crohn ileocecal } \\
\text { - Población mayor de } 16 \text { años con diagnóstico } \\
\text { de enfermedad de Crohn colónica } \\
\text { - Población mayor de } 16 \text { años con diagnóstico } \\
\text { de enfermedad de Crohn de intestino delgado } \\
\text { aislado } \\
\text { - Población mayor de } 16 \text { años con diagnóstico } \\
\text { de enfermedad de Crohn de vía digestiva } \\
\text { superior }\end{array}$ & $\begin{array}{l}\text { - Esteroides orales (prednisolona, prednisona, } \\
\text { budesonida de liberación de intestino } \\
\text { delgado, budesonida MMX) } \\
\text { - } 5 \text {-aminosalicilatos } \\
\text { - Azatioprina } \\
\text { - 6-mercaptopurina } \\
\text { - Metotrexato } \\
\text { - Probióticos } \\
\text { - Antibióticos (ciprofloxacina, metronidazol, } \\
\text { rifaximina) }\end{array}$ & $\begin{array}{l}\text { - Ausencia de síntomas clínicos } \\
\text { - Tasa de remisión } \\
\text { - Actividad de la enfermedad } \\
\text { - Mejoría endoscópica (cicatrización de la } \\
\text { mucosa) } \\
\text { - Tasa de cirugía } \\
\text { - Tasa de hospitalización } \\
\text { - Retiro o suspensión del tratamiento por } \\
\text { - eventos adversos (adherencia al tratamiento) } \\
\text { - Ealidad de vida } \\
\text { - Supentos adversos }\end{array}$ \\
\hline
\end{tabular}


4. ¿Cuál es la seguridad y la efectividad del uso de medicamentos biológicos para el tratamiento de los pacientes mayores de 16 años con enfermedad de Crohn moderada a grave?

\begin{tabular}{|c|c|c|}
\hline Población & $\begin{array}{l}\text { Intervención/ } \\
\text { comparador }\end{array}$ & Desenlaces \\
\hline $\begin{array}{l}\text { - Población mayor de } 16 \text { años con diagnóstico } \\
\text { - Pe enfermedad de Crohn ileocecal } \\
\text { de enfermedad de Crohn colónica } \\
\text { - Población mayor de } 16 \text { años con diagnóstico } \\
\text { de enfermedad de Crohn de intestino delgado } \\
\text { aislado } \\
\text { - Población mayor de } 16 \text { años con diagnóstico } \\
\text { de enfermedad de Crohn de vía digestiva } \\
\text { superior }\end{array}$ & $\begin{array}{l}\text { - Monoterapia: } \\
\text { - Infliximab } \\
\text { - Adalimumab } \\
\text { - Vedolizumab } \\
\text { - Certolizumab pegol } \\
\text { - Ustekinumab } \\
\text { - Terapia biológica sola o combinada con } \\
\text { - } \text { metotrexato o azatioprina } \\
\text { - Biosimilares (infliximab, adalimumab) }\end{array}$ & $\begin{array}{l}\text { - Ausencia de síntomas clínicos } \\
\text { - Tasa de remisión } \\
\text { - Actividad de la enfermedad } \\
\text { - Mejoría endoscópica (cicatrización de la } \\
\text { mucosa) } \\
\text { - Tasa de cirugía } \\
\text { - Tasa de hospitalización } \\
\text { - Retiro o suspensión del tratamiento pro } \\
\text { - eventos adversos (adherencia al tratamiento) } \\
\text { - Ealidad de vida } \\
\text { - Eventos adversos }\end{array}$ \\
\hline
\end{tabular}

5. ¿Cuáles son las intervenciones más seguras y efectivas para el tratamiento de la enfermedad de Crohn perianal en pacientes mayores de 16 años?

\begin{tabular}{|c|c|c|}
\hline Población & $\begin{array}{l}\text { Intervención/ } \\
\text { comparador }\end{array}$ & Desenlaces \\
\hline $\begin{array}{l}\text { - Población mayor de } 16 \text { años con enfermedad } \\
\text { de Crohn perianal }\end{array}$ & $\begin{array}{l}\text { - Tratamiento quirúrgico } \\
\text { - Metronidazol } \\
\text { - Ciprofloxacina } \\
\text { - Esteroides intravenosos } \\
\text { - Esteroides orales (prednisolona, prednisona, } \\
\text { budesonida) } \\
\text { - } 5 \text {-aminosalicilatos } \\
\text { - Azatioprina } \\
\text { - } 6 \text {-mercaptopurina } \\
\text { - Metotrexato } \\
\text { - Probióticos } \\
\text { - Terapia biológica sola o combinada }\end{array}$ & $\begin{array}{l}\text { - Actividad de la enfermedad } \\
\text { - Calidad de vida } \\
\text { - Recaída endoscópica } \\
\text { - Recurrencia de fístulas } \\
\text { - Hospitalización } \\
\text { - Cirugía } \\
\text { - Eventos adversos }\end{array}$ \\
\hline
\end{tabular}

\section{6. ¿Cuáles son las intervenciones más seguras y efectivas para el abordaje quirúrgico y} endoscópico de los pacientes mayores de 16 años con enfermedad de Crohn?

\begin{tabular}{lll}
\multicolumn{1}{c}{ Población } & \multicolumn{1}{c}{$\begin{array}{c}\text { Intervención/ } \\
\text { comparador }\end{array}$} & \multicolumn{1}{c}{ Desenlaces } \\
- Población mayor de 16 años con diagnóstico & \multicolumn{1}{c}{ - Resección intestinal } & - Actividad de la enfermedad \\
de enfermedad de Crohn ileocecal & - Drenaje percutáneo & - Calidad de vida \\
- Población mayor de 16 años con diagnóstico & - Plastia de la estenosis & - Recaída endoscópica \\
de enfermedad de Crohn colónica & - Anastomosis intestinal & - Recurrencia de fístulas \\
- Población mayor de 16 años con diagnóstico & - Laparoscopia operatoria & - Hospitalización \\
de enfermedad de Crohn de intestino delgado & - Dilatación endoscópica & - Reintervención quirúrgica \\
aislado & - Fistulotomía & - Mortalidad \\
- Población mayor de 16 años con diagnóstico & & Complicaciones perioperatorias \\
de enfermedad de Crohn de vía digestiva & & \\
superior & & \\
- Población mayor de 16 años con diagnóstico & & \\
de enfermedad de Crohn fistulizante & &
\end{tabular}


7. ¿Cuáles son las intervenciones más seguras y efectivas para mantener en remisión a los pacientes mayores de 16 años con enfermedad de Crohn posquirúrgica?

\begin{tabular}{|c|c|c|}
\hline Población & $\begin{array}{l}\text { Intervención/ } \\
\text { comparador }\end{array}$ & Desenlaces \\
\hline $\begin{array}{l}\text { Población mayor de } 16 \text { años con diagnóstico } \\
\text { de enfermedad de Crohn que requirió } \\
\text { tratamiento quirúrgico }\end{array}$ & $\begin{array}{l}\text { - Esteroides orales (prednisolona, prednisona, } \\
\text { budesonida de liberación en intestino } \\
\text { delgado, budesonida MMX) } \\
\text { - } 5 \text {-aminosalicilatos } \\
\text { - Azatioprina } \\
\text { - } 6 \text {-mercaptopurina } \\
\text { - Metotrexato } \\
\text { - Metronidazol } \\
\text { - Manejo nutricional } \\
\text { - Probióticos } \\
\text { - Antibióticos (ciprofloxacina, metronidazol, } \\
\text { rifaximina) }\end{array}$ & $\begin{array}{l}\text { - Ausencia de síntomas clínicos } \\
\text { - Tasa de remisión } \\
\text { - Actividad de la enfermedad } \\
\text { - Mejoría endoscópica (cicatrización de la } \\
\text { mucosa) } \\
\text { - Tasa de cirugía } \\
\text { - Tasa de hospitalización } \\
\text { - Retiro o suspensión del tratamiento pro } \\
\text { - eventos adversos (adherencia al tratamiento) } \\
\text { - Ealidad de vida } \\
\text { Eventos adversos }\end{array}$ \\
\hline
\end{tabular}




\section{ANEXO 3}

\section{Bitácoras de búsqueda}

\section{Pronóstico}

\section{Reporte de búsqueda electrónica \#1}

\begin{tabular}{|c|c|c|}
\hline Tipo de búsqueda & \multicolumn{2}{|l|}{ Nueva } \\
\hline Bases de datos & \multicolumn{2}{|l|}{$\begin{array}{l}\text { - } \text { MEDLINE } \\
\text { - } \text { MEDLINE In-Process \& Other Non-Indexed Citations } \\
\text { - } \text { MEDLINE Daily Update }\end{array}$} \\
\hline Plataforma & \multicolumn{2}{|l|}{ Ovid } \\
\hline Fecha de búsqueda & \multicolumn{2}{|l|}{$16 / 08 / 2017$} \\
\hline Fecha de actualización (autoalerta) & \multicolumn{2}{|l|}{ Indefinida } \\
\hline Rango de fecha de búsqueda & \multicolumn{2}{|l|}{$2012-2017$} \\
\hline Restricciones de lenguaje & \multicolumn{2}{|l|}{ Ninguna } \\
\hline Otros límites & \multicolumn{2}{|l|}{ Ninguno } \\
\hline $\begin{array}{l}\text { Estrategia de búsqueda } \\
\text { (resultados) }\end{array}$ & $\begin{array}{l}\text { 1. exp C-Reactive Protein/ (40622) } \\
\text { 2. (c adj5 reacti\$ adj5 protein).tw. ( } 57641) \\
\text { 3. (creactive adj5 protein).tw. (68) } \\
\text { 4. crp.tw. (39222) } \\
\text { 5. exp Magnetic Resonance Imaging/ (388612) } \\
\text { 6. (magnetic adj5 resonance adj5 tomography).tw. } \\
\text { ( } 28751) \\
\text { 7. (magnetization adj5 transfer adj5 imaging).tw. (853) } \\
\text { 8. (imaging adj5 magnetic adj5 resonance).tw. } \\
\text { (199952) } \\
\text { 9. (imaging } \$ \text { adj5 chemical adj5 shift).tw. (1176) } \\
\text { 10. (tomography adj5 mr\$).tw. (8914) } \\
\text { 11. (tomography adj5 proton adj5 spin).tw. (42) } \\
\text { 12. (spin ajd5 echo adj5 imaging).tw. (0) } \\
\text { 13. zeugmatography.tw. (23) } \\
\text { 14. nmr.tw. (150492) } \\
\text { 15. mri.tw. (197942) } \\
\text { 16. (mr adj5 imaging).tw. (43265) } \\
\text { 17. (maria adj5 score).tw. (13) } \\
\text { 18. exp Leukocyte L1 Antigen Complex/ (1830) } \\
\text { 19. calgranulin.tw. (278) } \\
\text { 20. calprotectin.tw. (1989) } \\
\text { 21. (calcium-binding adj5 protein).tw. (5779) } \\
\text { 22. (L1 adj5 antigen).tw. (264) } \\
\text { 23. (L1 adj5 protein).tw. (2034) } \\
\text { 24. ((migratory adj5 inhibitory) and (factor-related adj5 } \\
\text { protein)).tw. (0) } \\
\text { 25. exp Lactoferrin/ (5666) } \\
\text { 26. lactoferrin\$.tw. ( } 7191) \\
\text { 27. lactotransferrin.tw. ( } 252)\end{array}$ & $\begin{array}{l}\text { 28. exp Ultrasonography/ (400680) } \\
\text { 29. exp Ultrasonography, Doppler/ (66581) } \\
\text { 30. echogra } \$ . t w . ~(10041) \\
\text { 31. ultraso\$.tw. (323134) } \\
\text { 32. sonography.tw. (30920) } \\
\text { 33. echotomography.tw. (623) } \\
\text { 34. doptone.tw. (12) } \\
\text { 35. echoscopy.tw. (51) } \\
\text { 36. echosound.tw. (1) } \\
\text { 37. sonogram.tw. (1492) } \\
\text { 38. exp Capsule Endoscopy/ (2452) } \\
\text { 39. (capsule adj5 endoscop\$).tw. (3577) } \\
\text { 40. (capsule adj5 enteroscopy).tw. (405) } \\
\text { 41. ASCA\$.tw. (11244) } \\
\text { 42. or/1-41 (1271843) } \\
\text { 43. exp Crohn Disease/ (35815) } \\
\text { 44. crohn\$.tw. (40956) } \\
\text { 45. (regional\$ adj5 enter\$).tw. (1167) } \\
\text { 46. (regional adj5 ileiti\$).tw. (295) } \\
\text { 47. (regional adj5 colitis).tw. (182) } \\
\text { 48. (enteritis adj5 granulomatous).tw. (196) } \\
\text { 49. (colitis adj5 granulomatous).tw. (442) } \\
\text { 50. ileocolitis.tw. (415) } \\
\text { 51. (terminal adj5 ileitis).tw. (416) } \\
\text { 52. (cleron adj5 disease).tw. (0) } \\
\text { 53. or/43-52 (50141) } \\
\text { 54. } 42 \text { and } 53 \text { (4966) } \\
\text { 55. limit } 54 \text { to (yr="2012 - 2017" and "reviews (best } \\
\quad \text { balance of sensitivity and specificity)") (407) }\end{array}$ \\
\hline \# de referencias identificadas & 407 & \\
\hline \# de referencias sin duplicados & 352 (véase archivo EndNote) & \\
\hline
\end{tabular}




\section{Reporte de búsqueda electrónica \#2}

\begin{tabular}{|c|c|c|}
\hline Tipo de búsqueda & \multicolumn{2}{|l|}{ Nueva } \\
\hline Base de datos & \multicolumn{2}{|l|}{ EMBASE } \\
\hline Plataforma & \multicolumn{2}{|l|}{ EMBASE.com } \\
\hline Fecha de búsqueda & \multicolumn{2}{|l|}{$16 / 08 / 2017$} \\
\hline Fecha de actualización (autoalerta) & \multicolumn{2}{|l|}{ Indefinida } \\
\hline Rango de fecha de búsqueda & \multicolumn{2}{|l|}{$2012-2017$} \\
\hline Restricciones de lenguaje & \multicolumn{2}{|l|}{ Ninguna } \\
\hline Otros límites & \multicolumn{2}{|l|}{ Ninguno } \\
\hline $\begin{array}{l}\text { Estrategia de búsqueda } \\
\text { (resultados) }\end{array}$ & 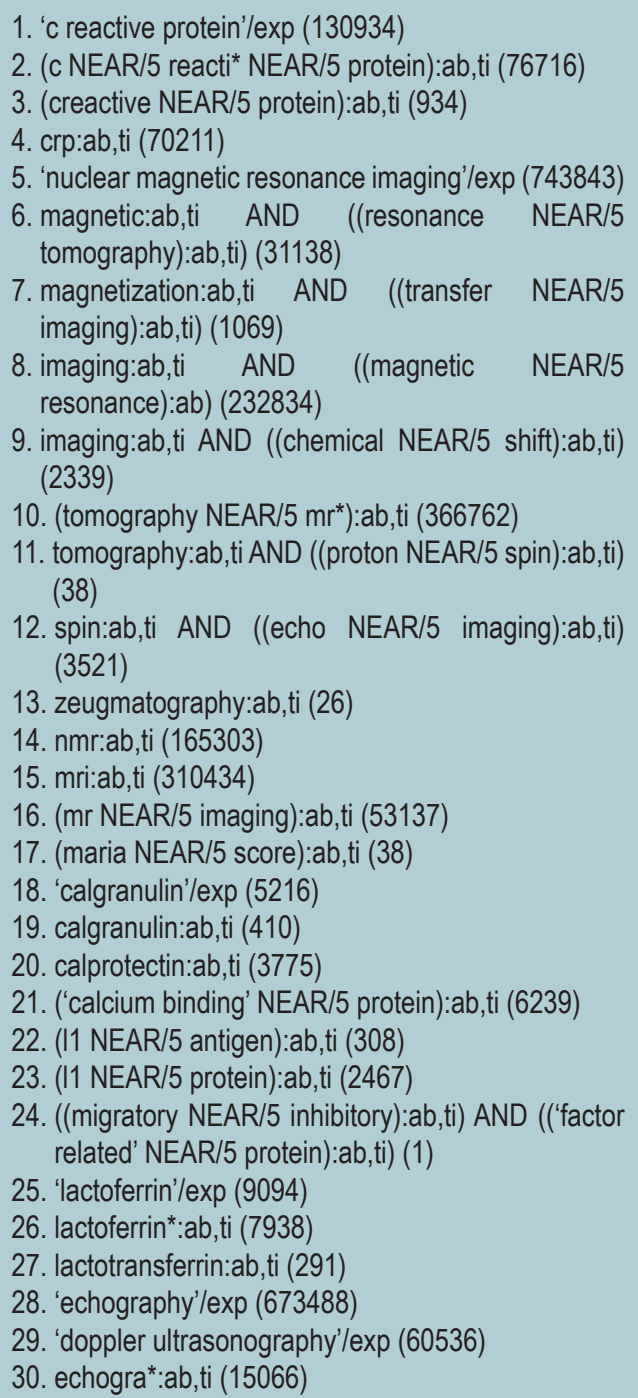 &  \\
\hline \# de referencias identificadas & \multicolumn{2}{|l|}{147} \\
\hline \# de referencias sin duplicados & \multicolumn{2}{|l|}{145 (véase archivo EndNote) } \\
\hline
\end{tabular}




\section{Reporte de búsqueda electrónica \#3}

\begin{tabular}{|c|c|c|}
\hline Tipo de búsqueda & \multicolumn{2}{|l|}{ Nueva } \\
\hline Base de datos & \multicolumn{2}{|l|}{$\begin{array}{l}\text { Cochrane Library } \\
\text { http://onlinelibrary.wiley.com/cochranelibrary/search/quick }\end{array}$} \\
\hline Plataforma & \multicolumn{2}{|l|}{ Wiley } \\
\hline Fecha de búsqueda & \multicolumn{2}{|l|}{ 07/07/2017 } \\
\hline Fecha de actualización (autoalerta) & \multicolumn{2}{|l|}{ Indefinida } \\
\hline Rango de fecha de búsqueda & \multicolumn{2}{|l|}{ Sin restricción } \\
\hline Restricciones de lenguaje & \multicolumn{2}{|l|}{ Ninguna } \\
\hline Otros límites & \multicolumn{2}{|l|}{ Ninguno } \\
\hline $\begin{array}{l}\text { Estrategia de búsqueda } \\
\text { (resultados) }\end{array}$ & 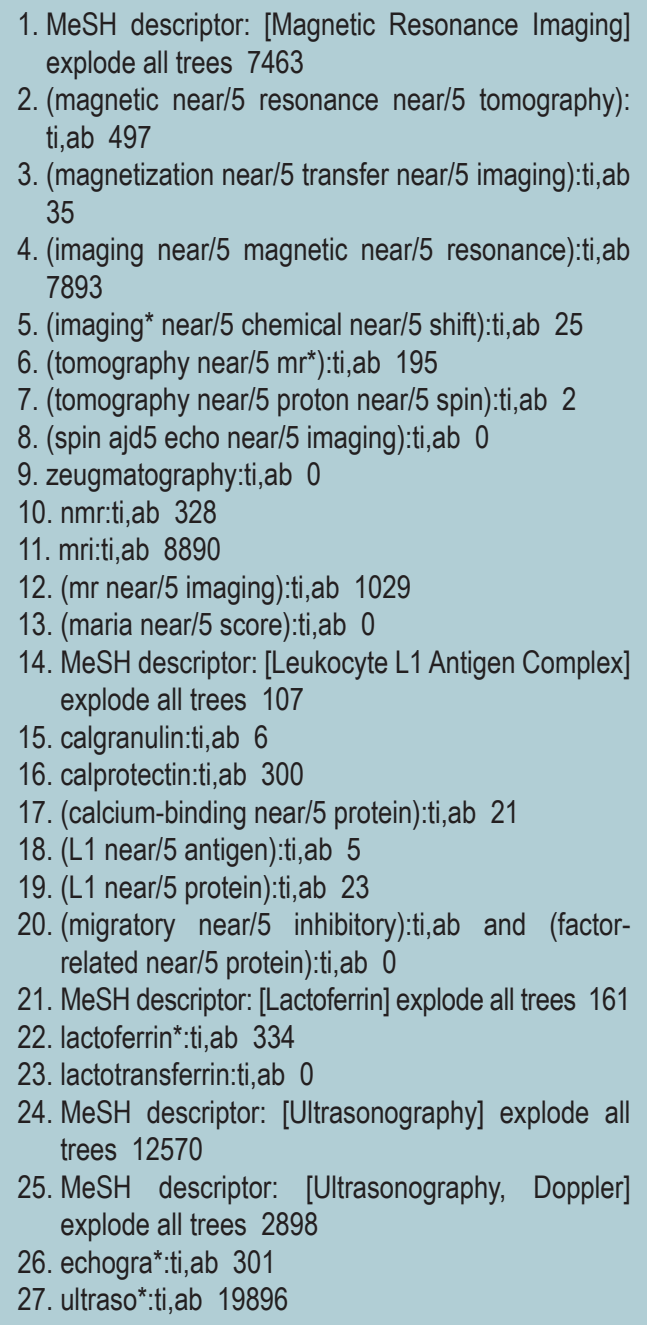 & 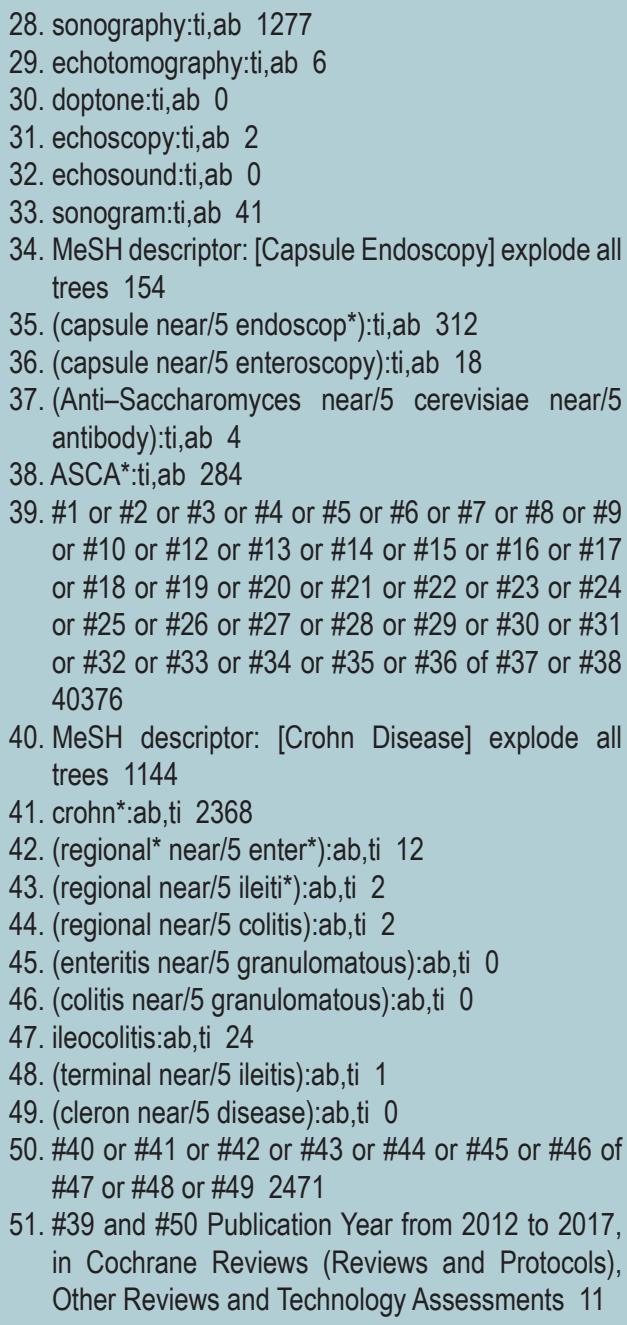 \\
\hline \# de referencias identificadas & 11 & \\
\hline \# de referencias sin duplicados & 11 (véase archivo End & \\
\hline
\end{tabular}


Medicamentos no biológicos

Reporte de búsqueda electrónica \#1

\begin{tabular}{|c|c|c|}
\hline Tipo de búsqueda & \multicolumn{2}{|l|}{ Nueva } \\
\hline Bases de datos & \multicolumn{2}{|c|}{$\begin{array}{l}\text { - } \text { MEDLINE } \\
\text { - } \text { MEDLINE In-Process \& Other Non-Indexed Citations } \\
\text { - } \text { MEDLINE Daily Update }\end{array}$} \\
\hline Plataforma & \multicolumn{2}{|l|}{ Ovid } \\
\hline Fecha de búsqueda & \multicolumn{2}{|l|}{$16 / 08 / 2017$} \\
\hline Fecha de actualización (autoalerta) & \multicolumn{2}{|l|}{ Indefinida } \\
\hline Rango de fecha de búsqueda & \multicolumn{2}{|l|}{$2012-2017$} \\
\hline Restricciones de lenguaje & \multicolumn{2}{|l|}{ Ninguna } \\
\hline Otros límites & \multicolumn{2}{|l|}{ Ninguno } \\
\hline Estrategia de búsqueda (resultados) & $\begin{array}{l}\text { 56. exp Crohn Disease/ (35795) } \\
\text { 57. crohn\$.tw. (40970) } \\
\text { 58. (regional\$ adj5 enter\$).tw. (1167) } \\
\text { 59. (regional adj5 ileiti\$).tw. ( } 295) \\
\text { 60. (regional adj5 colitis).tw. (182) } \\
\text { 61. (enteritis adj5 granulomatous).tw. (196) } \\
\text { 62. (colitis adj5 granulomatous).tw. (442) } \\
\text { 63. ileocolitis.tw. (415) } \\
\text { 64. (terminal adj5 ileitis).tw. (416) } \\
\text { 65. (cleron adj5 disease).tw. (0) } \\
\text { 66. or/1-10 (50154) } \\
\text { 67. exp Adrenal Cortex Hormones/ (382543) } \\
\text { 68. cortic\$.tw. (378388) } \\
\text { 69. (adren\$ adj5 cort\$).tw. (30413) } \\
\text { 70. (adren\$ adj5 steroid\$).tw. (8473) } \\
\text { 71. adrenocorticosteroid.tw. (142) } \\
\text { 72. (adreno\$ adj5 hormone\$).tw. (12527) } \\
\text { 73. exp Glucocorticoids/ (184091) } \\
\text { 74. gl?cocort\$.tw. (64780) } \\
\text { 75. exp Prednisone/ (38793) } \\
\text { 76. predniso\$.tw. (48789) } \\
\text { 77. exp Methylprednisolone/ (18648) } \\
\text { 78. methylpredniso\$.tw. (14683) } \\
\text { 79. exp Betamethasone/ (7082) } \\
\text { 80. betamet?a.tw. (4614) } \\
\text { 81. (beta adj5 methason\$).tw. (144) } \\
\text { 82. betadexamethasone.tw. (0) } \\
\text { 83. flubenisolone.tw. (0) } \\
\text { 84. exp Budesonide/ (4165) }\end{array}$ & $\begin{array}{l}\text { 85. budesonide.tw. (4741) } \\
\text { 86. dexbudesonide.tw. (0) } \\
\text { 87. exp Mesalamine/ (3214) } \\
\text { 88. mesala?ine.tw. (2122) } \\
\text { 89. meta-aminosalicylic.tw. (0) } \\
\text { 90. 5-aminosalicyli\$.tw. (1752) } \\
\text { 91. 5-asa.tw. (1422) } \\
\text { 92. exp Azathioprine/ (14342) } \\
\text { 93. az?thiop\$.tw. (14633) } \\
\text { 94. exp 6-Mercaptopurine/ (19317) } \\
\text { 95. mercaptopurine.tw. (4326) } \\
\text { 96. exp Methotrexate/ (36982) } \\
\text { 97. meth?otrexat\$.tw. (38521) } \\
\text { 98. metot?rexate.tw. (65) } \\
\text { 99. methohexate.tw. (0) } \\
\text { 100. amethopterin.tw. (407) } \\
\text { 101. methylaminopterin\$.tw. (8) } \\
\text { 102. mtx.tw. (11536) } \\
\text { 103. exp Probiotics/ (12966) } \\
\text { 104. probiotic\$.tw. (16678) } \\
\text { 105. exp Ciprofloxacin/ (12241) } \\
\text { 106. ciprofloxacin.tw. (22416) } \\
\text { 107. exp Metronidazole/ (12192) } \\
\text { 108. metronidazol\$.tw. (14418) } \\
\text { 109. rifaximin.tw. (944) } \\
\text { 110. or/12-54 (854013) } \\
\text { 111. 11 and } 55 \text { (7187) } \\
\text { 112. limit } 56 \text { to (yr="2012 -Current" and "reviews (best } \\
\quad \text { balance of sensitivity and specificity)") (507) }\end{array}$ \\
\hline \# de referencias identificadas & 507 & \\
\hline \# de referencias sin duplicados & 429 (véase archivo EndNote) & \\
\hline
\end{tabular}




\begin{tabular}{|c|c|c|}
\hline Tipo de búsqueda & Nueva & \\
\hline Base de datos & EMBASE & \\
\hline Plataforma & EMBASE.com & \\
\hline Fecha de búsqueda & $16 / 08 / 2017$ & \\
\hline Fecha de actualización (autoalerta) & Indefinida & \\
\hline Rango de fecha de búsqueda & $2012-2017$ & \\
\hline Restricciones de lenguaje & Ninguna & \\
\hline Otros límites & Ninguno & \\
\hline Estrategia de búsqueda (resultados) & 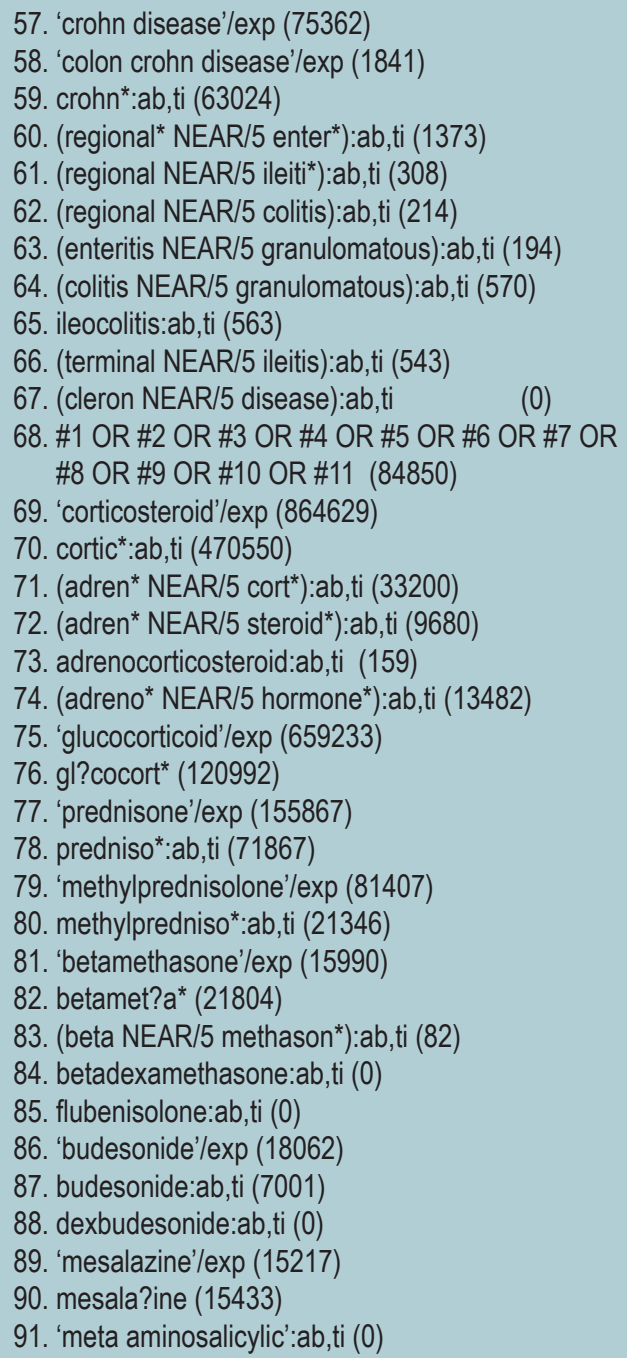 & 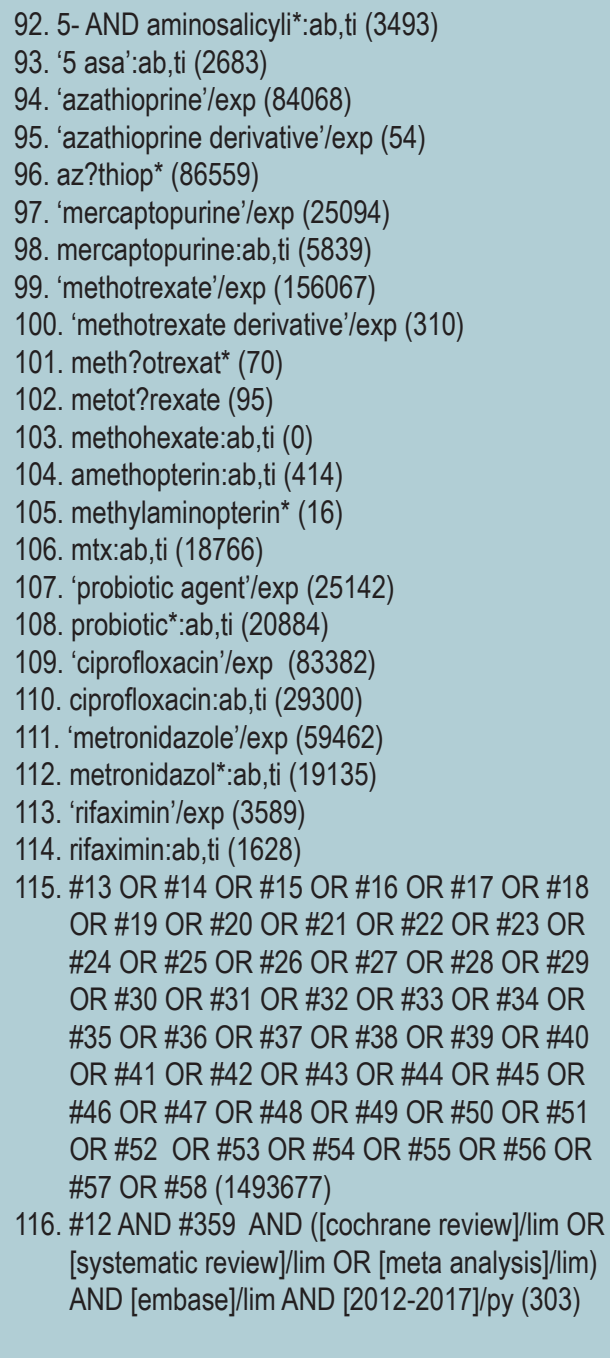 \\
\hline \# de referencias identificadas & 303 & \\
\hline \# de referencias sin duplicados & 300 (véase archivo EndNote) & \\
\hline
\end{tabular}




\section{Reporte de búsqueda electrónica \#3}

\begin{tabular}{|c|c|c|}
\hline Tipo de búsqueda & \multicolumn{2}{|l|}{ Nueva } \\
\hline Base de datos & \multicolumn{2}{|l|}{$\begin{array}{l}\text { Cochrane Library } \\
\text { http://onlinelibrary.wiley.com/cochranelibrary/search/quick }\end{array}$} \\
\hline Plataforma & \multicolumn{2}{|l|}{ Wiley } \\
\hline Fecha de búsqueda & \multicolumn{2}{|l|}{$07 / 07 / 2017$} \\
\hline Fecha de actualización (autoalerta) & \multicolumn{2}{|l|}{ Indefinida } \\
\hline Rango de fecha de búsqueda & \multicolumn{2}{|l|}{ Sin restricción } \\
\hline Restricciones de lenguaje & \multicolumn{2}{|l|}{ Ninguna } \\
\hline Otros límites & \multicolumn{2}{|l|}{ Ninguno } \\
\hline Estrategia de búsqueda (resultados) & $\begin{array}{l}\text { 52. MeSH descriptor: [Crohn Disease] explode all } \\
\text { trees (1144) } \\
\text { 53. crohn*:ab,ti (2368) } \\
\text { 54. (regional* near/5 enter*):ab,ti (12) } \\
\text { 55. (regional near/5 ileiti*):ab,ti (2) } \\
\text { 56. (regional near/5 colitis):ab,ti (2) } \\
\text { 57. (enteritis near/5 granulomatous):ab,ti (0) } \\
\text { 58. (colitis near/5 granulomatous):ab,ti (0) } \\
\text { 59. ileocolitis:ab,ti (24) } \\
\text { 60. (terminal near/5 ileitis):ab,ti (1) } \\
\text { 61. (cleron near/5 disease):ab,ti (0) } \\
\text { 62. \#1 or \#2 or \#3 or \#4 or \#5 or \#6 or \#7 or \#8 or \#9 } \\
\text { or \#10 (2471) } \\
\text { 63. MeSH descriptor: [Adrenal Cortex Hormones] } \\
\text { explode all trees (13079) } \\
\text { 64. cortic*:ti,ab (18763) } \\
\text { 65. (adren* near/5 cortt):ti,ab (1292) } \\
\text { 66. (adren* near/5 steroid*):ti,ab (197) } \\
\text { 67. adrenocorticosteroid:ti,ab (11) } \\
\text { 68. (adreno* near/5 hormone*):ti,ab (822) } \\
\text { 69. MeSH descriptor: [Glucocorticoids] explode all } \\
\text { trees (4091) } \\
\text { 70. gl?cocort*:ti,ab (3204) } \\
\text { 71. MeSH descriptor: [Prednisone] explode all trees } \\
\text { (2944) } \\
\text { 72. predniso*:ti,ab (8028) } \\
\text { 73. MeSH descriptor: [Methylprednisolone] explode } \\
\text { all trees (1702) } \\
\text { 74. methylpredniso*:ti,ab (2334) } \\
\text { 75. MeSH descriptor: [Betamethasone] explode all } \\
\text { trees (1096) } \\
\text { 76. betamet?a*:ti,ab (398) } \\
\text { 77. (beta near/5 methason*):ti,ab ( } 26 \text { ) } \\
\text { 78. betadexamethasone:ti,ab (0) } \\
\text { 79. flubenisolone:ti,ab (0) } \\
\text { 80. MeSH descriptor: [Budesonide] explode all trees } \\
\text { (1320) } \\
\text { 81. budesonide:ti,ab (3147) } \\
\text { 82. dexbudesonide:ti,ab (0) } \\
\text { 83. MeSH descriptor: [Mesalamine] explode all trees (441) }\end{array}$ &  \\
\hline \# de referencias identificadas & 37 & \\
\hline \# de referencias sin duplicados & 37 (véase archivo EndNote) & \\
\hline
\end{tabular}


Reporte de búsqueda electrónica \#1

\begin{tabular}{|c|c|c|}
\hline Tipo de búsqueda & \multicolumn{2}{|l|}{ Nueva } \\
\hline Bases de datos & \multicolumn{2}{|l|}{$\begin{array}{l}\text { - MEDLINE } \\
\text { - MEDLINE In-Process \& Other Non-Indexed Citations } \\
\text { - MEDLINE Daily Update }\end{array}$} \\
\hline Plataforma & \multicolumn{2}{|l|}{ Ovid } \\
\hline Fecha de búsqueda & \multicolumn{2}{|l|}{$28 / 06 / 2017$} \\
\hline Fecha de actualización (autoalerta) & \multicolumn{2}{|l|}{ Indefinida } \\
\hline Rango de fecha de búsqueda & \multicolumn{2}{|l|}{ 2012-2017 } \\
\hline Restricciones de lenguaje & \multicolumn{2}{|l|}{ Ninguna } \\
\hline Otros límites & \multicolumn{2}{|l|}{ Ninguno } \\
\hline Estrategia de búsqueda (resultados) & 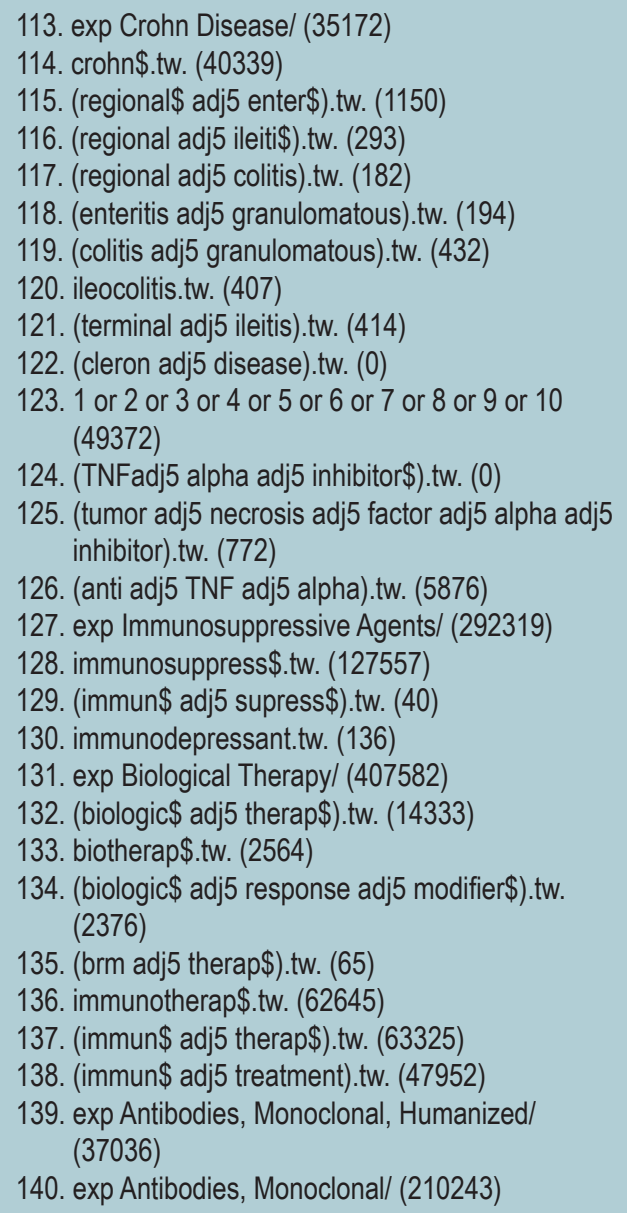 &  \\
\hline \# de referencias identificadas & 969 & \\
\hline \# de referencias sin duplicados & 913 (véase archivo EndNote) & \\
\hline
\end{tabular}


Reporte de búsqueda electrónica \#2

\begin{tabular}{|c|c|c|}
\hline Tipo de búsqueda & \multicolumn{2}{|l|}{ Nueva } \\
\hline Base de datos & \multicolumn{2}{|l|}{ EMBASE } \\
\hline Plataforma & \multicolumn{2}{|l|}{ EMBASE.com } \\
\hline Fecha de búsqueda & \multicolumn{2}{|l|}{$28 / 06 / 2017$} \\
\hline Fecha de actualización (autoalerta) & \multicolumn{2}{|l|}{ Indefinida } \\
\hline Rango de fecha de búsqueda & \multicolumn{2}{|l|}{ 2012-2017 } \\
\hline Restricciones de lenguaje & \multicolumn{2}{|l|}{ Ninguna } \\
\hline Otros límites & \multicolumn{2}{|l|}{ Ninguno } \\
\hline Estrategia de búsqueda (resultados) & $\begin{array}{l}\text { 117. 'crohn disease'/exp (74811) } \\
\text { 118. 'colon crohn disease'/exp (1830) } \\
\text { 119. crohn*:ab,ti ( } 62562) \\
\text { 120. (regional NEAR/5 enter*):ab,ti (1371) } \\
\text { 121. (regional NEAR/5 ileiti*):ab,ti (308) } \\
\text { 122. (regional NEAR/5 colitis):ab,ti (214) } \\
\text { 123. (enteritis NEAR/5 granulomatous):ab,ti (191) } \\
\text { 124. (colitis NEAR/5 granulomatous):ab,ti (570) } \\
\text { 125. ileocolitis:ab,ti (562) } \\
\text { 126. (terminal NEAR/5 ileitis):ab,ti (540) } \\
\text { 127. (cleron NEAR/5 disease):ab,ti (0) } \\
\text { 128. \#1 OR \#2 OR \#3 OR \#4 OR \#5 OR \#6 OR \#7 } \\
\text { OR \#8 OR \#9 OR \#10 OR \#11 (84213) } \\
\text { 129. 'tumor necrosis factor alpha inhibitor'lexp } \\
\text { (67178) } \\
\text { 130. (tnf NEAR/5 alpha):ab,ti AND inhibitor*:ab,ti } \\
\text { (5067) } \\
\text { 131. (tumor NEAR/5 necrosis):ab,ti AND (factor } \\
\text { NEAR/5 alpha):ab,ti AND inhibitor:ab,ti (2535) } \\
\text { 132. (anti NEAR/5 tnf):ab,ti AND alpha:ab,ti (3165) } \\
\text { 133. 'immunosuppressive agent'/exp (830811) } \\
\text { 134. immunosuppress*:ab,ti (176239) } \\
\text { 135. (immu* NEAR/5 supress*):ab,ti (155) } \\
\text { 136. immunodepressant:ab,ti (215) } \\
\text { 137. 'biological therapy'lexp (1401311) } \\
\text { 138. (biologic* NEAR/5 therap*):ab,ti (22249) } \\
\text { 139. biotherap*:ab,ti ( } 3617) \\
\text { 140. (biologic* NEAR/5 response):ab,ti AND } \\
\text { modifier*:ab,ti ( } 2772 \text { ) } \\
\text { 141. (brm NEAR/5 therap*):ab,ti (111) } \\
\text { 142. 'immunotherapy'lexp (164044) } \\
\text { 143. immunotherap*:ab,ti (86340) } \\
\text { 144. (immun* NEAR/5 therap*):ab,ti ( } 88930) \\
\text { 145. (immun* NEAR/5 treatment):ab,ti (66616) }\end{array}$ & 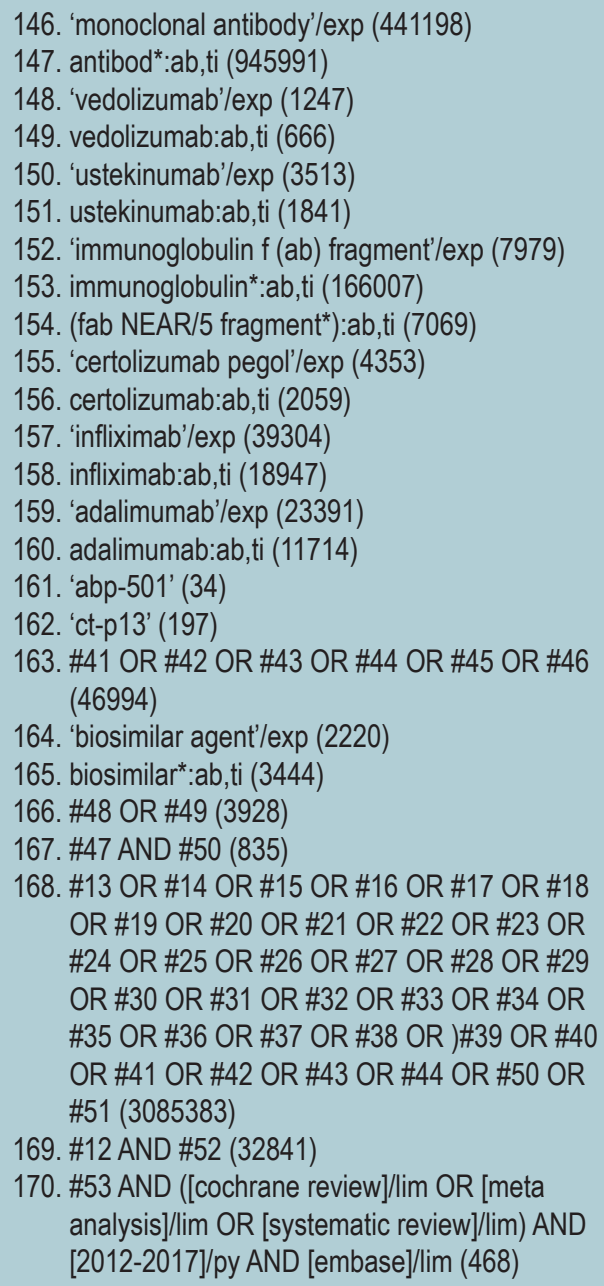 \\
\hline \# de referencias identificadas & 468 & \\
\hline \# de referencias sin duplicados & 373 (véase archivo EndNote) & \\
\hline
\end{tabular}




\section{Reporte de búsqueda electrónica \#3}

\begin{tabular}{|c|c|c|}
\hline Tipo de búsqueda & \multicolumn{2}{|l|}{ Nueva } \\
\hline Base de datos & \multicolumn{2}{|l|}{$\begin{array}{l}\text { Cochrane Library } \\
\text { http://onlinelibrary.wiley.com/cochranelibrary/search/quick }\end{array}$} \\
\hline Plataforma & \multicolumn{2}{|l|}{ Wiley } \\
\hline Fecha de búsqueda & \multicolumn{2}{|l|}{ 28/06/2017 } \\
\hline Fecha de actualización (autoalerta) & \multicolumn{2}{|l|}{ Indefinida } \\
\hline Rango de fecha de búsqueda & \multicolumn{2}{|l|}{ Sin restricción } \\
\hline Restricciones de lenguaje & \multicolumn{2}{|l|}{ Ninguna } \\
\hline Otros límites & \multicolumn{2}{|l|}{ Ninguno } \\
\hline Estrategia de búsqueda (resultados) &  & $\begin{array}{l}\text { 29. antibod*:ti,ab (18526) } \\
\text { 30. vedolizumab:ti,ab (104) } \\
\text { 31. MeSH descriptor: [Ustekinumab] explode all } \\
\text { trees (56) } \\
\text { 32. ustekinumab:ti,ab (247) } \\
\text { 33. MeSH descriptor: [Immunoglobulin Fab } \\
\text { Fragments] explode all trees (669) } \\
\text { 34. immunoglobulin*:ti,ab (4113) } \\
\text { 35. (fab near/5 fragment):ti,ab (65) } \\
\text { 36. MeSH descriptor: [Certolizumab Pegol] explode } \\
\text { all trees (70) } \\
\text { 37. certolizumab:ti,ab (282) } \\
\text { 38. MeSH descriptor: [Infliximab] explode all trees } \\
\text { (465) } \\
\text { 39. infliximab:ti,ab (1229) } \\
\text { 40. MeSH descriptor: [Adalimumab] explode all trees } \\
\text { (285) } \\
\text { 41. adalimumab:ti,ab (1189) } \\
\text { 42. abp-501:ti,ab (7) } \\
\text { 43. ct-p13:ti,ab (31) } \\
\text { 44. \#38 or \#39 or \#40 or \#41 or \#42 or \#43 (2205) } \\
\text { 45. MeSH descriptor: [Biosimilar Pharmaceuticals] } \\
\text { explode all trees ( } 33 \text { ) } \\
\text { 46. biosimilar*:ab,ti ( } 273 \text { ) } \\
47 . \# 45 \text { or \#46 ( } 276 \text { ) } \\
\text { 48. \#44 and \#47 ( } 84 \text { ) } \\
\text { 49. \#12 or \#13 or \#14 or \#15 or \#16 or \#17 or \#18 or } \\
\# 19 \text { or \#20 or \#21 or \#22 or \#23 or \#24 or \#25 or } \\
\# 26 \text { or \#27 or \#28 or \#29 or \#30 or \#31 or \#32 or } \\
\# 33 \text { or \#34 or \#35 or \#36 of \#37 or \#38 or \#39 or } \\
40 \text { or \#41 or \#48 ( } 163231) \\
\text { 50. \#11 and \#49 Publication, in Cochrane Reviews } \\
\text { (Reviews and Protocols), Other Reviews and } \\
\text { Technology Assessments (105) }\end{array}$ \\
\hline \# de referencias identificadas & 63 & \\
\hline \# de referencias sin duplicados & 52 (véase archivo EndNote) & \\
\hline
\end{tabular}


Reporte de búsqueda electrónica \#1

\begin{tabular}{|c|c|c|}
\hline Tipo de búsqueda & \multicolumn{2}{|l|}{ Nueva } \\
\hline Bases de datos & \multicolumn{2}{|c|}{$\begin{array}{l}\text { - MEDLINE } \\
\text { - MEDLINE In-Process \& Other Non-Indexed Citations } \\
\text { - MEDLINE Daily Update }\end{array}$} \\
\hline Plataforma & \multicolumn{2}{|l|}{ Ovid } \\
\hline Fecha de búsqueda & \multicolumn{2}{|l|}{$15 / 08 / 2017$} \\
\hline Fecha de actualización (autoalerta) & \multicolumn{2}{|l|}{ Indefinida } \\
\hline Rango de fecha de búsqueda & \multicolumn{2}{|l|}{ Sin límite } \\
\hline Restricciones de lenguaje & \multicolumn{2}{|l|}{ Ninguna } \\
\hline Otros límites & \multicolumn{2}{|l|}{ Ninguno } \\
\hline Estrategia de búsqueda (resultados) & $\begin{array}{l}\text { 164. exp Crohn Disease/ (35805) } \\
\text { 165. crohn\$.tw. (40988) } \\
\text { 166. (regional\$ adj5 enter\$).tw. (1167) } \\
\text { 167. (regional adj5 ileiti\$).tw. (295) } \\
\text { 168. (regional adj5 colitis).tw. (182) } \\
\text { 169. (enteritis adj5 granulomatous).tw. (196) } \\
\text { 170. (colitis adj5 granulomatous).tw. (442) } \\
\text { 171. ileocolitis.tw. (416) }\end{array}$ & $\begin{array}{l}\text { 172. (terminal adj5 ileitis).tw. (416) } \\
\text { 173. (cleron adj5 disease).tw. (0) } \\
\text { 174. or/1-10 ( } 50174) \\
\text { 175. perianal.tw. (6225) } \\
\text { 176. } 11 \text { and } 12 \text { (1534) } \\
\text { 177. limit } 13 \text { to "reviews (best balance of sensitivity } \\
\quad \text { and specificity)" }\end{array}$ \\
\hline \# de referencias identificadas & \multicolumn{2}{|l|}{320} \\
\hline \# de referencias sin duplicados & \multicolumn{2}{|l|}{307 (véase archivo EndNote) } \\
\hline
\end{tabular}

\section{Reporte de búsqueda electrónica \#2}

\begin{tabular}{lll} 
Tipo de búsqueda & Nueva & \\
\hline Base de datos & EMBASE & \\
\hline Plataforma & EMBASE.com & \\
\hline Fecha de búsqueda & $16 / 08 / 2017$ & \\
\hline Fecha de actualización (autoalerta) & Indefinida & \\
\hline Rango de fecha de búsqueda & Sin límite & \\
Restricciones de lenguaje & Ninguna & 180. (terminal NEAR/5 ileitis):ab,ti (543) \\
\hline Otros límites & Ninguno & 181. (cleron NEAR/5 disease):ab,ti \\
Estrategia de búsqueda (resultados) & 171. 'crohn disease'lexp (75362) & 182. \#1 OR \#2 OR \#3 OR \#4 OR \#5 OR \#6 OR \#7 \\
& 172. 'colon crohn disease'/exp (1841) & OR \#8 OR \#9 OR \#10 OR \#11 (84850) \\
& 173. crohn*:ab,ti (63024) & 183. perianal:ab,ti (9455) \\
& 174. (regional* NEAR/5 enter*):ab,ti (1373) & 184. \#12 AND \#13 AND ([cochrane review]/lim OR \\
[systematic review]/lim OR [meta analysis]/lim) & AND [embase]/lim AND [2012-2017]/py (62)
\end{tabular}




\section{Reporte de búsqueda electrónica \#3}

\begin{tabular}{|c|c|c|}
\hline Tipo de búsqueda & \multicolumn{2}{|l|}{ Nueva } \\
\hline Base de datos & \multicolumn{2}{|c|}{$\begin{array}{l}\text { Cochrane Library } \\
\text { http://onlinelibrary.wiley.com/cochranelibrary/search/quick }\end{array}$} \\
\hline Plataforma & \multicolumn{2}{|l|}{ Wiley } \\
\hline Fecha de búsqueda & \multicolumn{2}{|l|}{$16 / 08 / 2017$} \\
\hline Fecha de actualización (autoalerta) & \multicolumn{2}{|l|}{ Indefinida } \\
\hline Rango de fecha de búsqueda & \multicolumn{2}{|l|}{ Sin restricción } \\
\hline Restricciones de lenguaje & \multicolumn{2}{|l|}{ Ninguna } \\
\hline Otros límites & \multicolumn{2}{|l|}{ Ninguno } \\
\hline Estrategia de búsqueda (resultados) &  & $\begin{array}{l}\text { 116. (terminal near/5 ileitis):ab,ti } 1 \\
\text { 117. (cleron near/5 disease):ab,ti } 0 \\
\text { 118. \#1 or \#2 or \#3 or \#4 or \#5 or \#6 or \#7 or \#8 or } \\
\# 9 \text { or } \# 102471 \\
\text { 119. perianal:ti,ab } 398 \\
\text { 120. \#11 and \#12 in Cochrane Reviews (Reviews } \\
\text { and Protocols), Other Reviews and Technology } \\
\text { Assessments } 3\end{array}$ \\
\hline \# de referencias identificadas & 3 & \\
\hline \# de referencias sin duplicados & 3 (véase archivo EndNote) & \\
\hline
\end{tabular}

\section{Tratamiento quirúrgico y endoscópico}

\begin{tabular}{|c|c|c|}
\hline \multicolumn{3}{|c|}{ Reporte de búsqueda electrónica \#1 } \\
\hline Bases de datos & $\begin{array}{l}\text { - MEDLINE } \\
\text { - MEDLINE In-Process \& Other Non-Indexed Ci } \\
\text { - MEDLINE Daily Update }\end{array}$ & \\
\hline Plataforma & Ovid & \\
\hline Fecha de búsqueda & 06/067/2017 & \\
\hline Fecha de actualización (autoalerta) & Indefinida & \\
\hline Rango de fecha de búsqueda & Sin restricción & \\
\hline Restricciones de lenguaje & Ninguna & \\
\hline Otros límites & Ninguno & \\
\hline Estrategia de búsqueda (resultados) & $\begin{array}{l}\text { 178. exp Crohn Disease/ (35172) } \\
\text { 179. crohn\$.tw. ( } 40339) \\
\text { 180. (regional\$ adj5 enter\$).tw. (1150) } \\
\text { 181. (regional adj5 ileiti\$).tw. ( } 293) \\
\text { 182. (regional adj5 colitis).tw. (182) } \\
\text { 183. (enteritis adj5 granulomatous).tw. (194) } \\
\text { 184. (colitis adj5 granulomatous).tw. (432) } \\
\text { 185. ileocolitis.tw. (407) } \\
\text { 186. (terminal adj5 ileitis).tw. (414) } \\
\text { 187. (cleron adj5 disease).tw. (0) } \\
\text { 188. } 1 \text { or } 2 \text { or } 3 \text { or } 4 \text { or } 5 \text { or } 6 \text { or } 7 \text { or } 8 \text { or } 9 \text { or } 10 \\
\text { (49372) } \\
\text { 189. exp General Surgery/ (128) } \\
\text { 190. surg\$.tw. (182708) } \\
\text { 191. (operative adj5 intervention).tw. (644) } \\
\text { 192. (operative adj5 repair).tw. ( } 273 \text { ) } \\
\text { 193. (operative adj5 treatment).tw. (2017) } \\
\text { 194. resection.tw. ( } 28549)\end{array}$ & $\begin{array}{l}\text { 195. exp Drainage/ (23) } \\
\text { 196. (drainage adj5 percutaneous).tw. ( } 770) \\
\text { 197. exp Laparoscopy/ (63) } \\
\text { 198. (laparoscop\$ adj5 surg\$).tw. ( } 4544) \\
\text { 199. strictureplasty.tw. (30) } \\
\text { 200. bypass.tw. ( } 9612) \\
\text { 201. exp Dilatation/ (1) } \\
\text { 202. dilat\$.tw. (11489) } \\
\text { 203. exp Anastomosis, Surgical/ (41) } \\
\text { 204. anastomo\$.tw. (6062) } \\
\text { 205. exp Endoscopy/ (213) } \\
\text { 206. (endoscop\$ adj5 surgical).tw. (1072) } \\
\text { 207. (endoscop\$ adj5 interventional).tw. (143) } \\
\text { 208. fistulotomy.tw. (39) } \\
\text { 209. or/12-31 (207914) } \\
\text { 210. } 11 \text { and } 32 \text { (965) } \\
\text { 211. limit } 33 \text { to "reviews (best balance of sensitivity } \\
\quad \text { and specificity)" (129) }\end{array}$ \\
\hline \# de referencias identificadas & 129 & \\
\hline \# de referencias sin duplicados & 123 (véase archivo EndNote) & \\
\hline
\end{tabular}




\section{Reporte de búsqueda electrónica \#2}

\begin{tabular}{|c|c|c|}
\hline Tipo de búsqueda & Nueva & \\
\hline Base de datos & EMBASE & \\
\hline Plataforma & EMBASE.com & \\
\hline Fecha de búsqueda & 07/07/2017 & \\
\hline Fecha de actualización (autoalerta) & Indefinida & \\
\hline Rango de fecha de búsqueda & 2012-2017 & \\
\hline Restricciones de lenguaje & Ninguna & \\
\hline Otros límites & Ninguno & \\
\hline Estrategia de búsqueda (resultados) & $\begin{array}{l}\text { 185. 'crohn disease'/exp (74942) } \\
\text { 186. 'colon crohn disease'/exp (1831) } \\
\text { 187. crohn*:ab,ti (62691) } \\
\text { 188. (regional* NEAR/5 enter*):ab,ti (1372) } \\
\text { 189. (regional NEAR/5 ileiti):ab,ti (308) } \\
\text { 190. (regional NEAR/5 colitis):ab,ti (214) } \\
\text { 191. (enteritis NEAR/5 granulomatous):ab,ti (192) } \\
\text { 192. (colitis NEAR/5 granulomatous):ab,ti (570) } \\
\text { 193. ileocolitis:ab,ti (563) } \\
\text { 194. (terminal NEAR/5 ileitis):ab,ti (541) } \\
\text { 195. (cleron NEAR/5 disease):ab,ti } \\
\text { 196. \#1 OR \#2 OR \#3 OR \#4 OR \#5 OR \#6 OR\#7 } \\
\text { OR \#8 OR \#9 OR \#10 OR \#11 (4384) } \\
\text { 197. 'surgery'lexp ( } 4189568) \\
\text { 198. surg*:ab,ti (2160909) } \\
\text { 199. (operative NEAR/5 intervention):ab,ti (7362) } \\
\text { 200. (operative NEAR/5 repair):ab,ti (3653) } \\
\text { 201. (operative NEAR/5 treatment):ab,ti (23505) } \\
\text { 202. resection:ab,ti (330309) } \\
\text { 203. 'percutaneous drainage'lexp (6191) }\end{array}$ & $\begin{array}{l}\text { 204. (drainage NEAR/5 percutaneous):ab,ti (9303) } \\
\text { 205. 'laparoscopy'lexp (130180) } \\
\text { 206. (laparoscop* NEAR/5 surg*):ab,ti ( } 49130) \\
\text { 207. strictureplasty:ab,ti (330) } \\
\text { 208. bypass:ab,ti (151156) } \\
\text { 209. 'dilatation'/exp (14473) } \\
\text { 210. dilat*:ab,ti (180987) } \\
\text { 211. 'anastomosis'lexp (159915) } \\
\text { 212. anastomo*:ab,ti (101621) } \\
\text { 213. 'endoscopic therapy'lexp (13188) } \\
\text { 214. (endoscop* NEAR/5 surgical):ab,ti (11591) } \\
\text { 215. (endoscop* NEAR/5 interventional):ab,ti (1374) } \\
\text { 216. fistulotomy:ab,ti ( } 720) \\
\text { 217. \#13 OR \#14 OR \#15 OR \#16 OR \#17 OR \#18 } \\
\text { OR \#19 OR \#20 OR \#21 OR \#22 OR \#23 OR } \\
\text { \#24 OR \#25 OR \#26 OR \#27 OR \#28 OR \#29 } \\
\text { OR \#30 OR \#31 OR \#32 (4985128) } \\
\text { 218. \#12 AND \#33 ( } 25329) \\
\text { 219. \#34 AND ([cochrane review]/lim OR [meta } \\
\text { analysis]/lim OR [systematic review]/lim) AND } \\
\text { [embase]/lim (565) }\end{array}$ \\
\hline \# de referencias identificadas & 565 & \\
\hline \# de referencias sin duplicados & 550 (véase archivo EndNote) & \\
\hline
\end{tabular}




\section{Reporte de búsqueda electrónica \#3}

\begin{tabular}{|c|c|c|}
\hline Tipo de búsqueda & \multicolumn{2}{|l|}{ Nueva } \\
\hline Base de datos & \multicolumn{2}{|l|}{$\begin{array}{l}\text { Cochrane Library } \\
\text { http://onlinelibrary.wiley.com/cochranelibrary/search/quick }\end{array}$} \\
\hline Plataforma & \multicolumn{2}{|l|}{ Wiley } \\
\hline Fecha de búsqueda & \multicolumn{2}{|l|}{ 07/07/2017 } \\
\hline Fecha de actualización (autoalerta) & \multicolumn{2}{|l|}{ Indefinida } \\
\hline Rango de fecha de búsqueda & \multicolumn{2}{|l|}{ Sin restricción } \\
\hline Restricciones de lenguaje & \multicolumn{2}{|l|}{ Ninguna } \\
\hline Otros límites & \multicolumn{2}{|l|}{ Ninguno } \\
\hline Estrategia de búsqueda (resultados) & $\begin{array}{l}\text { 121. MeSH descriptor: [Crohn Disease] explode all } \\
\text { trees (1134) } \\
\text { 122. crohn*:ab,ti ( } 2347) \\
\text { 123. (regional* near/5 enter*):ab,ti (12) } \\
\text { 124. (regional near/5 ileiti*):ab,ti ( } 2 \text { ) } \\
\text { 125. (regional near/5 colitis):ab,ti ( } 2 \text { ) } \\
\text { 126. (enteritis near/5 granulomatous):ab,ti (0) } \\
\text { 127. (colitis near/5 granulomatous):ab,ti (8) } \\
\text { 128. ileocolitis:ab,ti ( } 24) \\
\text { 129. (terminal near/5 ileitis):ab,ti (1) } \\
\text { 130. (cleron near/5 disease):ab,ti ( } 0) \\
\text { 131. \#1 or \#2 or \#3 or \#4 or \#5 or \#6 or \#7 or \#8 or } \\
\text { \#9 or \#10 ( } 2450) \\
\text { 132. MeSH descriptor: [General Surgery] explode all } \\
\text { trees ( } 365) \\
\text { 133. surg*ti,ab (116447) } \\
\text { 134. (operative near/5 intervention):ab,ti (271) } \\
\text { 135. (operative near/5 repair):ab,ti (148) } \\
\text { 136. (operative near/5 treatment):ab,ti (1317) } \\
\text { 137. resection:ti,ab (10916) } \\
\text { 138. MeSH descriptor: [Drainage] explode all trees } \\
\text { (2735) } \\
\text { 139. (drainage near/5 percutaneous):ab,ti (202) }\end{array}$ & $\begin{array}{l}\text { 140. MeSH descriptor: [Laparoscopy] explode all } \\
\text { trees ( } 6088) \\
\text { 141. (laparoscop* near/5 surg*):ab,ti ( } 5454) \\
\text { 142. strictureplasty:ab,ti }(6) \\
\text { 143. bypass:ab,ti (12893) } \\
\text { 144. MeSH descriptor: [Dilatation] explode all trees } \\
\text { (406) } \\
\text { 145. dilat*:ab,ti (7654) } \\
\text { 146. MeSH descriptor: [Anastomosis, Surgical] } \\
\text { explode all trees ( } 2378) \\
\text { 147. anastomo*:ab,ti ( } 2680) \\
\text { 148. MeSH descriptor: [Endoscopy] explode all trees } \\
\text { (17762) } \\
\text { 149. (endoscop* near/5 surgical):ab,ti ( } 398) \\
\text { 150. (endoscop* near/5 interventional):ab,ti ( } 40 \text { ) } \\
\text { 151. fistulotomy:ab,ti ( } 49) \\
\text { 152. \#12 or \#13 or \#14 or \#15 or \#16 or \#17 or \#18 } \\
\text { or \#19 or \#20 or \#21 or \#22 or \#23 or \#24 or } \\
\# 25 \text { or \#26 or \#27 or \#28 or \#29 or \#30 or \#31 } \\
\text { 144793 } \\
\text { 153. \#11 and \#32 in Cochrane Reviews (Reviews } \\
\text { and Protocols), Other Reviews and Technology } \\
\text { Assessments ( } 43 \text { ) }\end{array}$ \\
\hline \# de referencias identificadas & 43 & \\
\hline \# de referencias sin duplicados & 43 (véase archivo EndNote) & \\
\hline
\end{tabular}











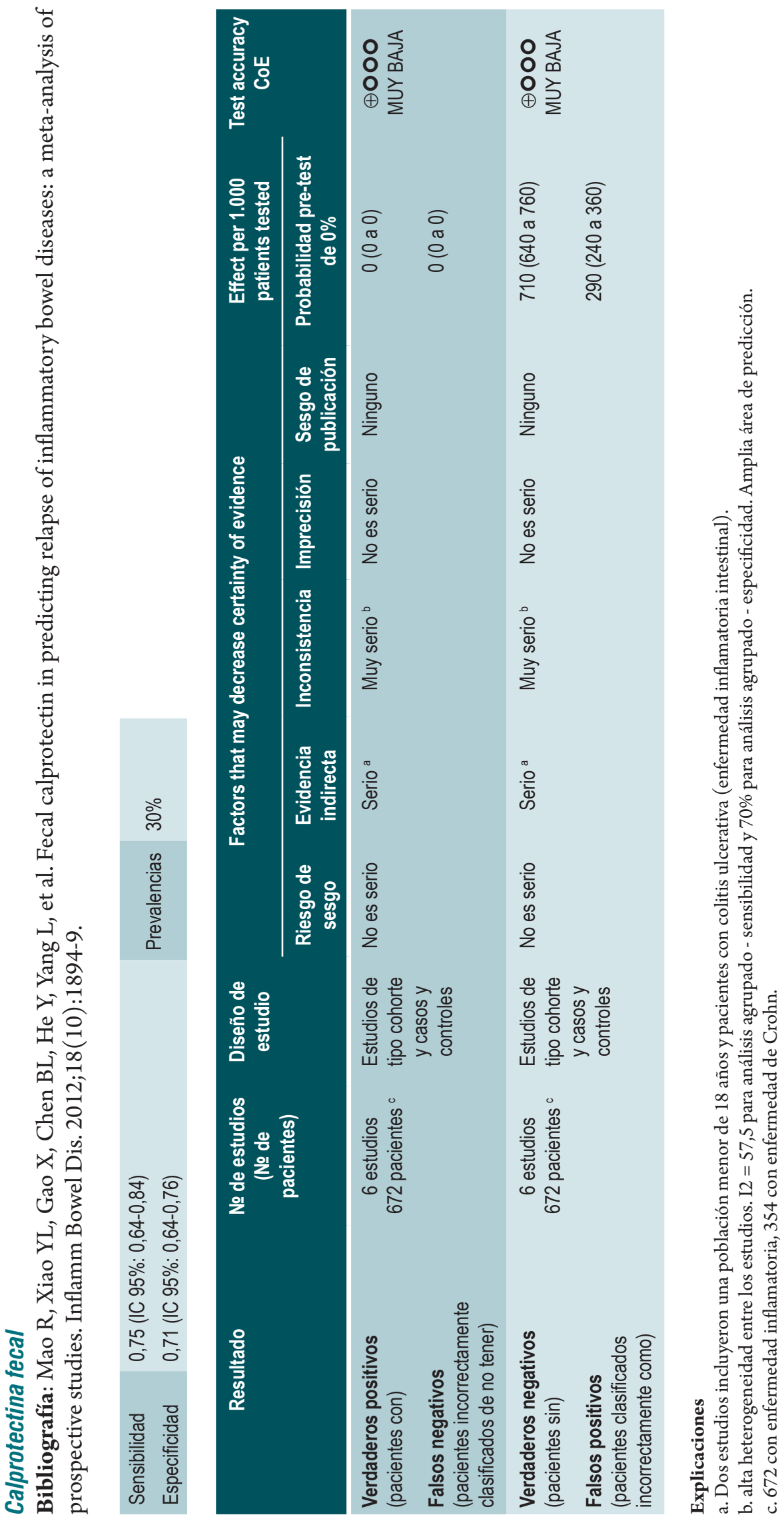









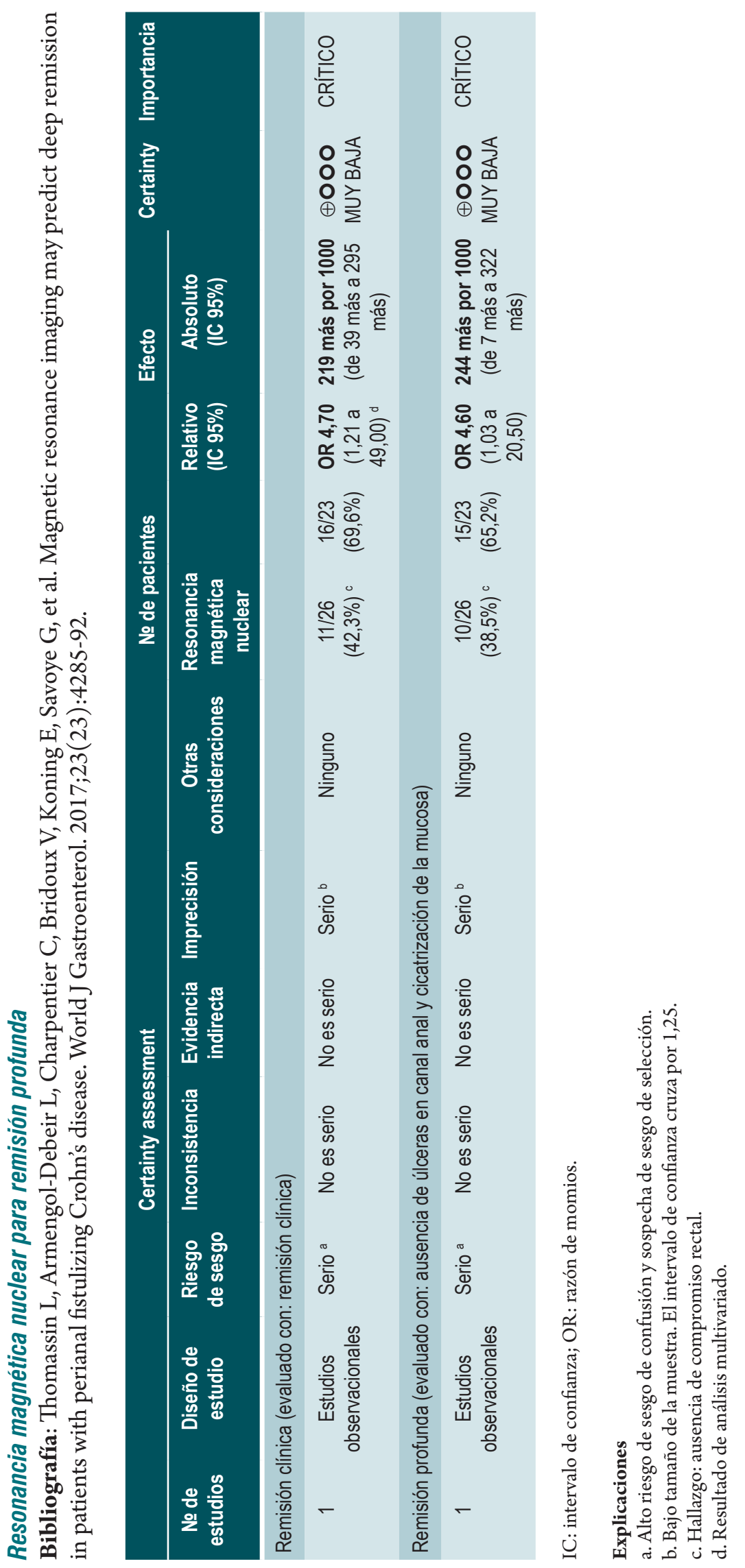




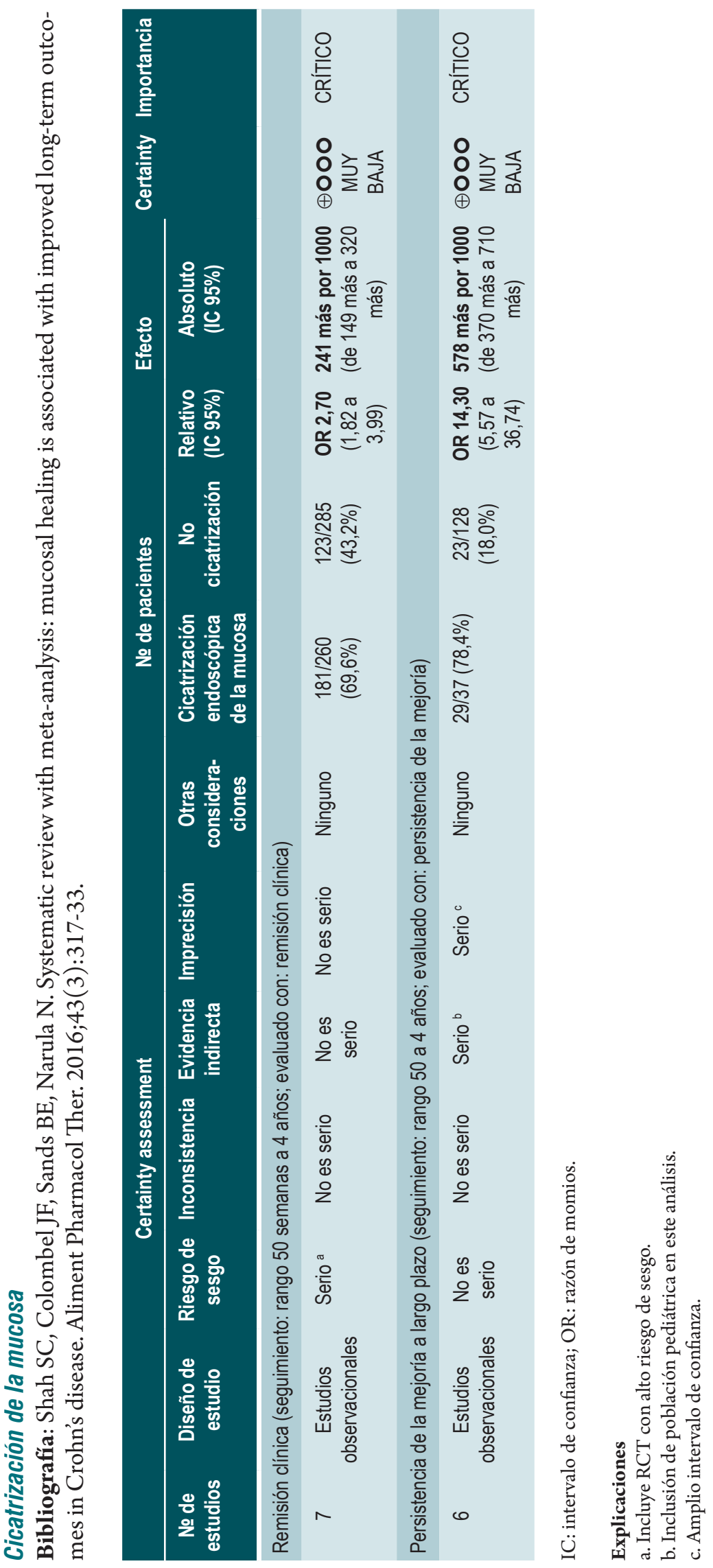




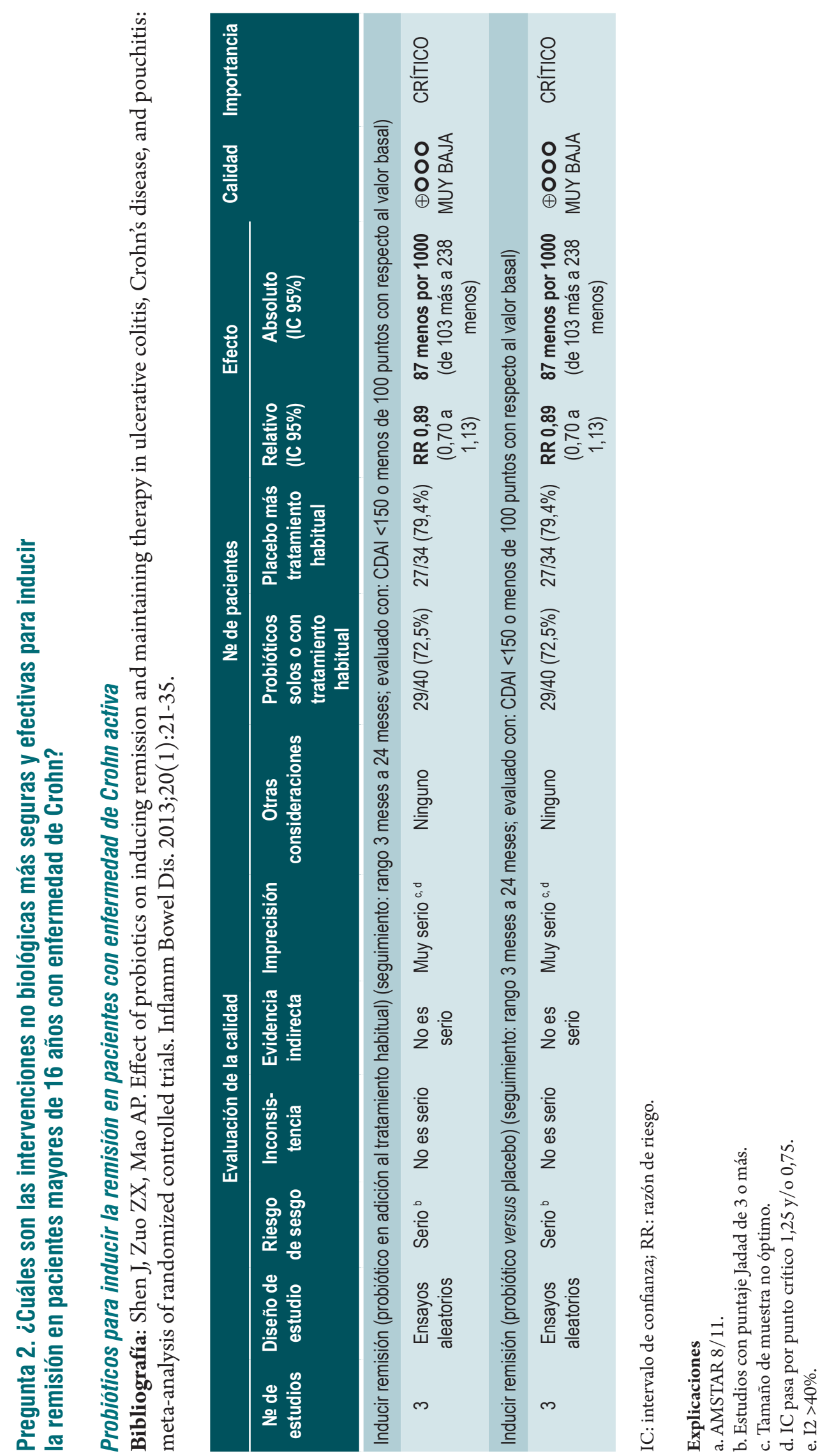









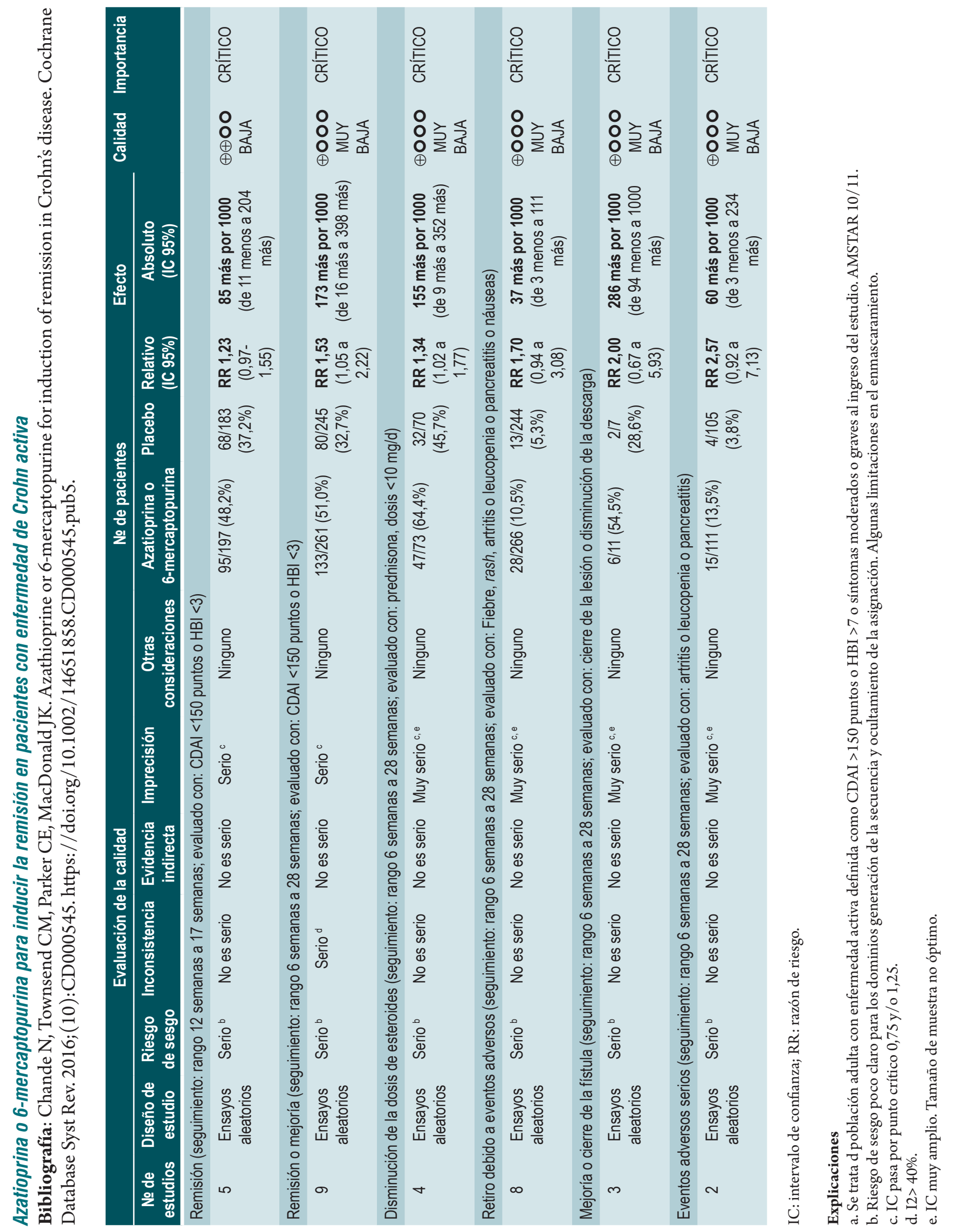




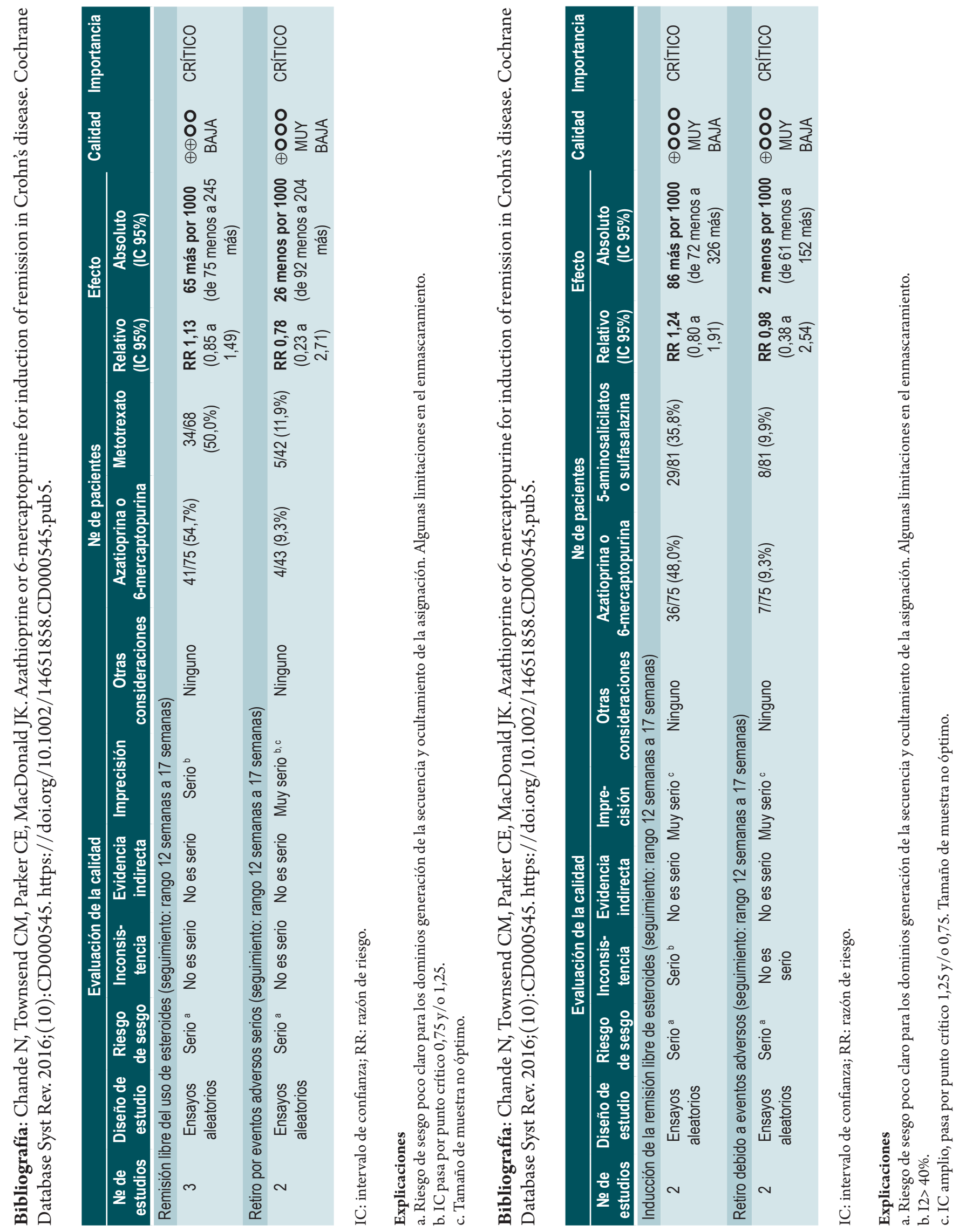




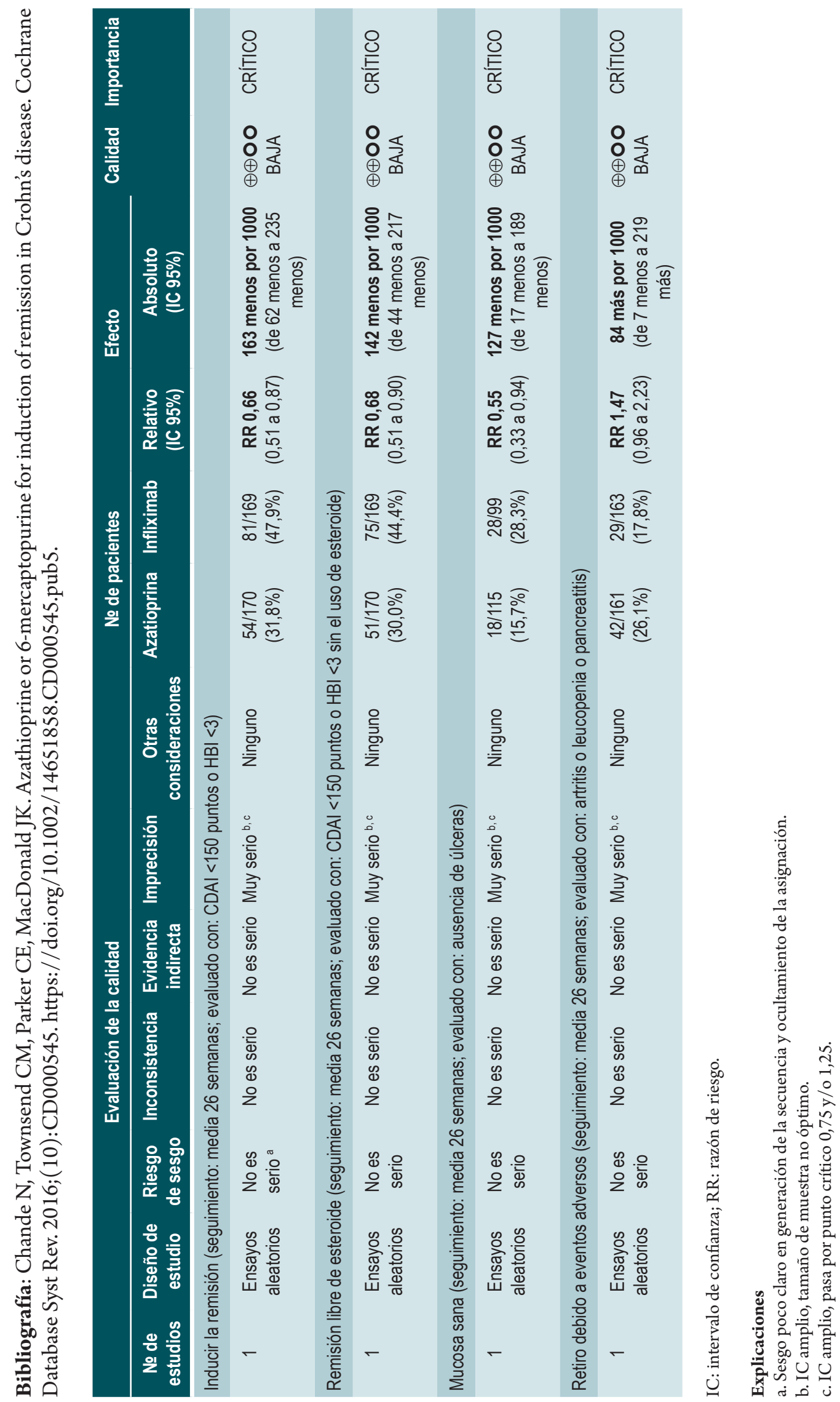




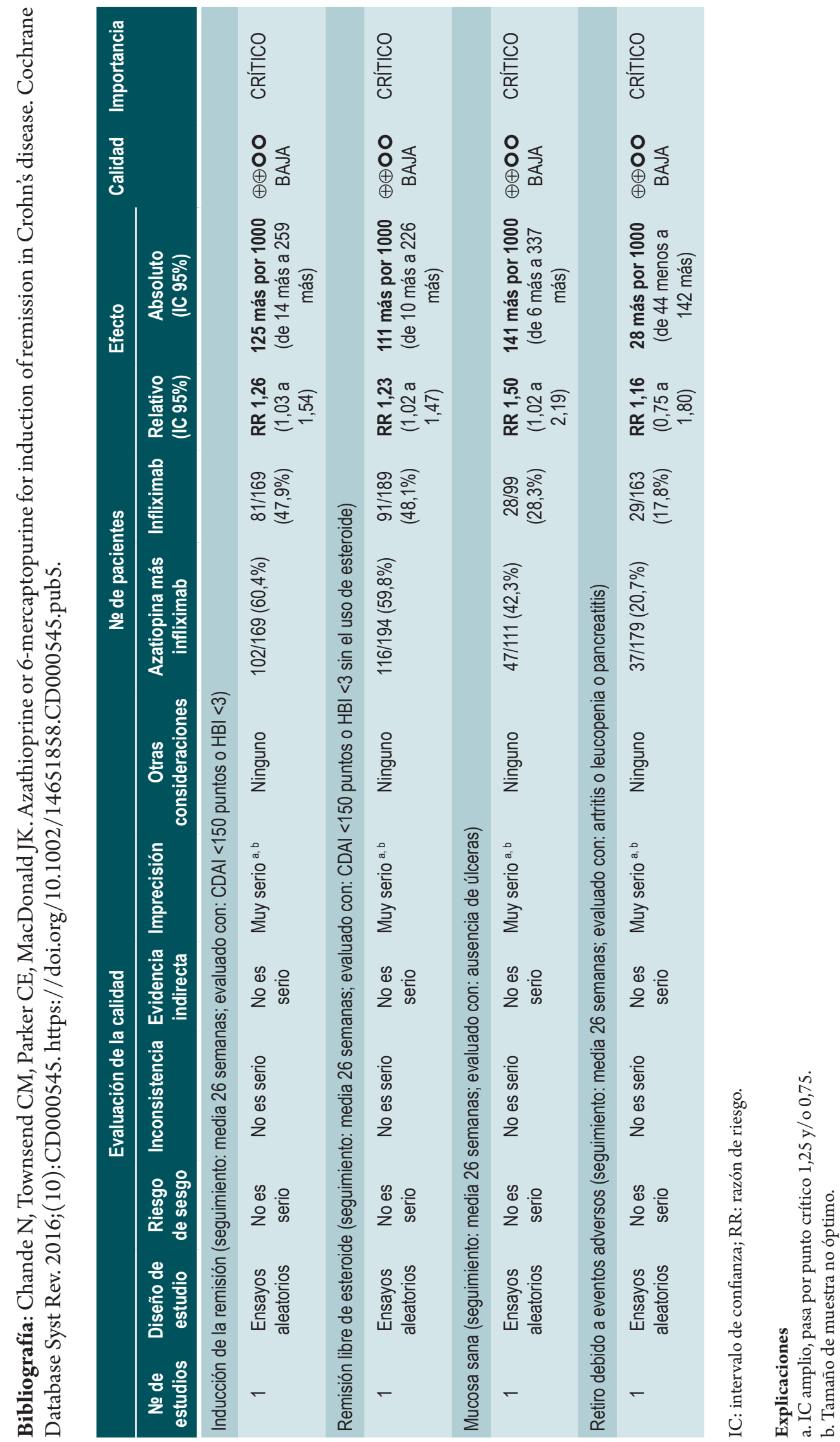




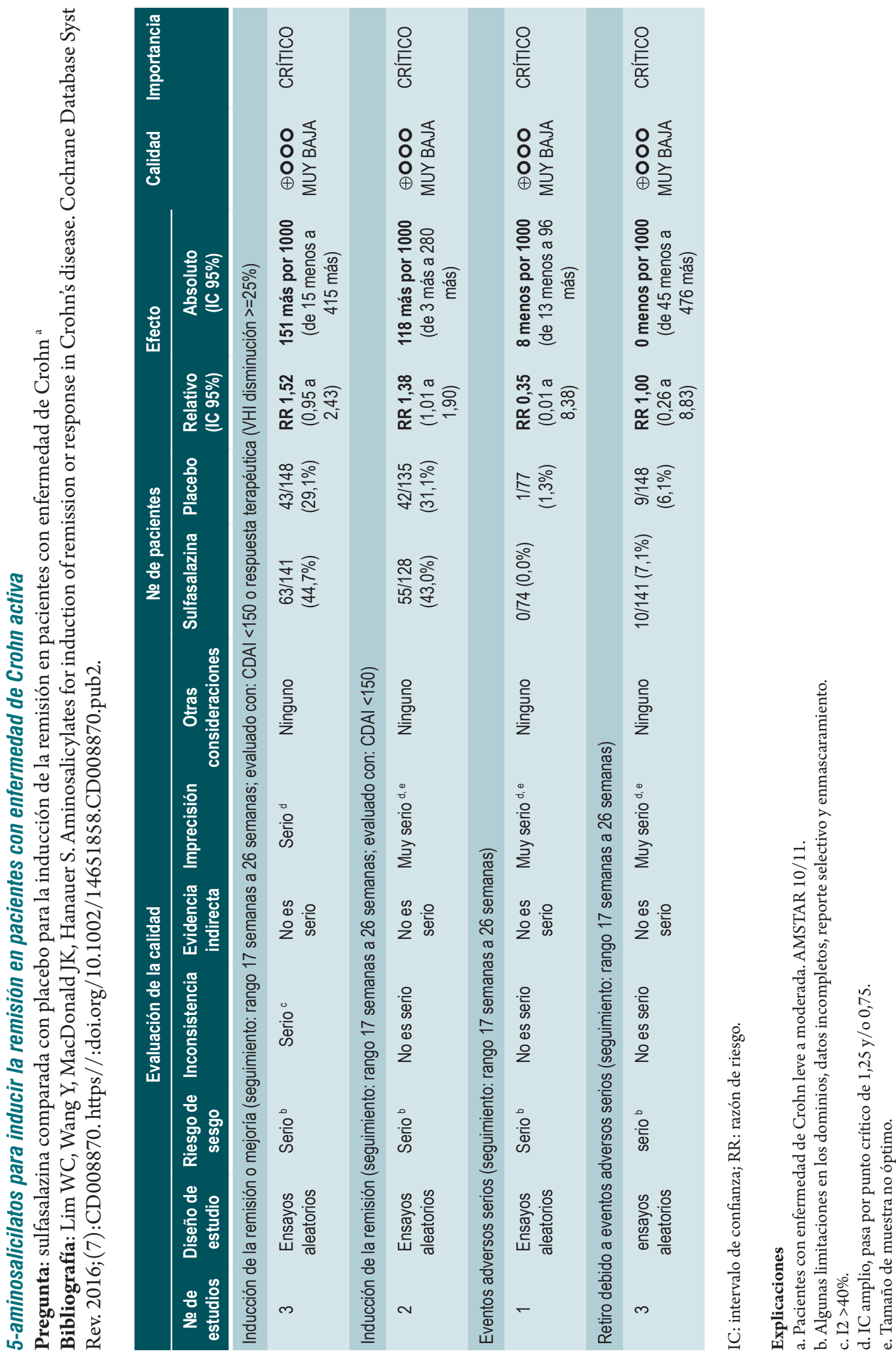




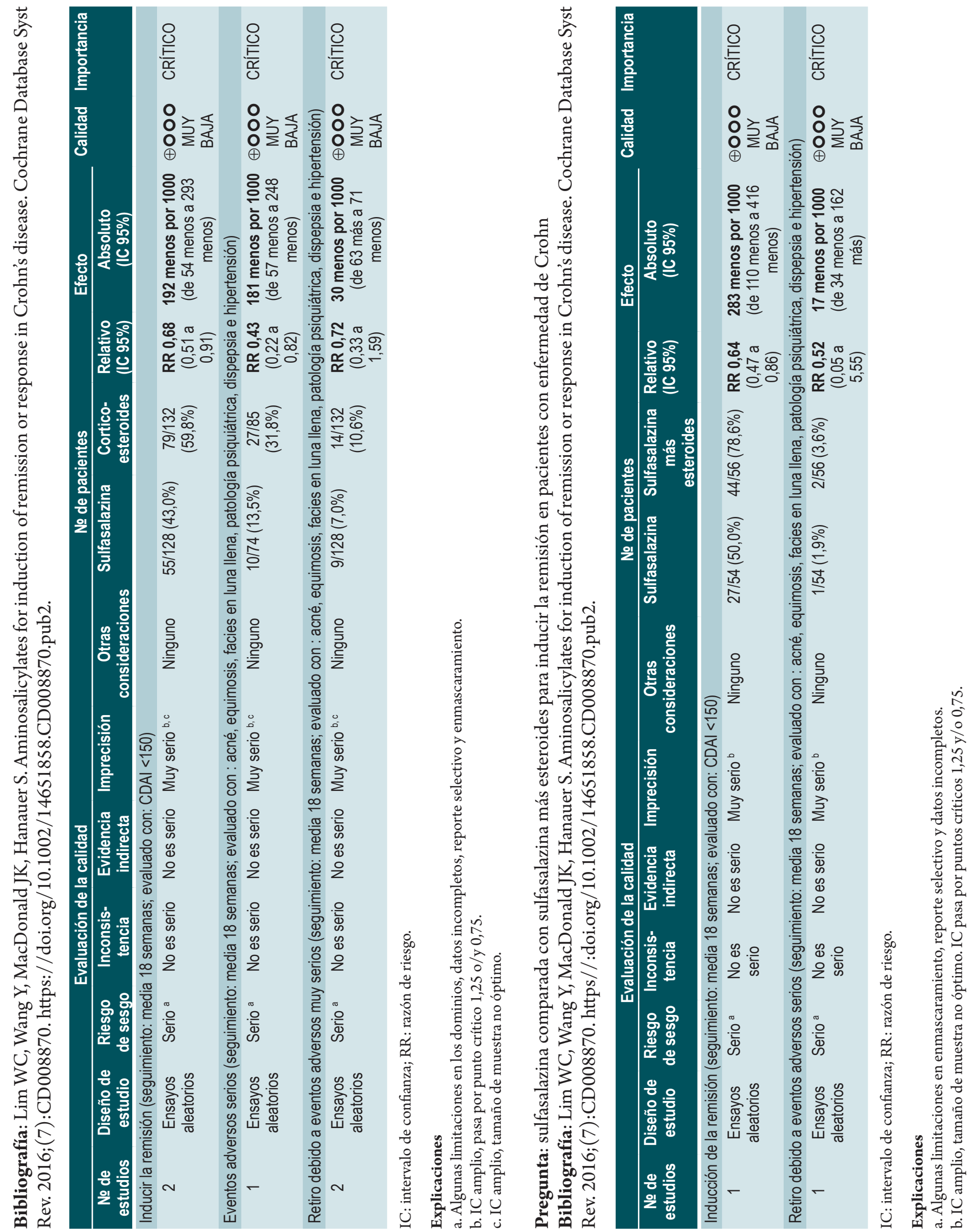




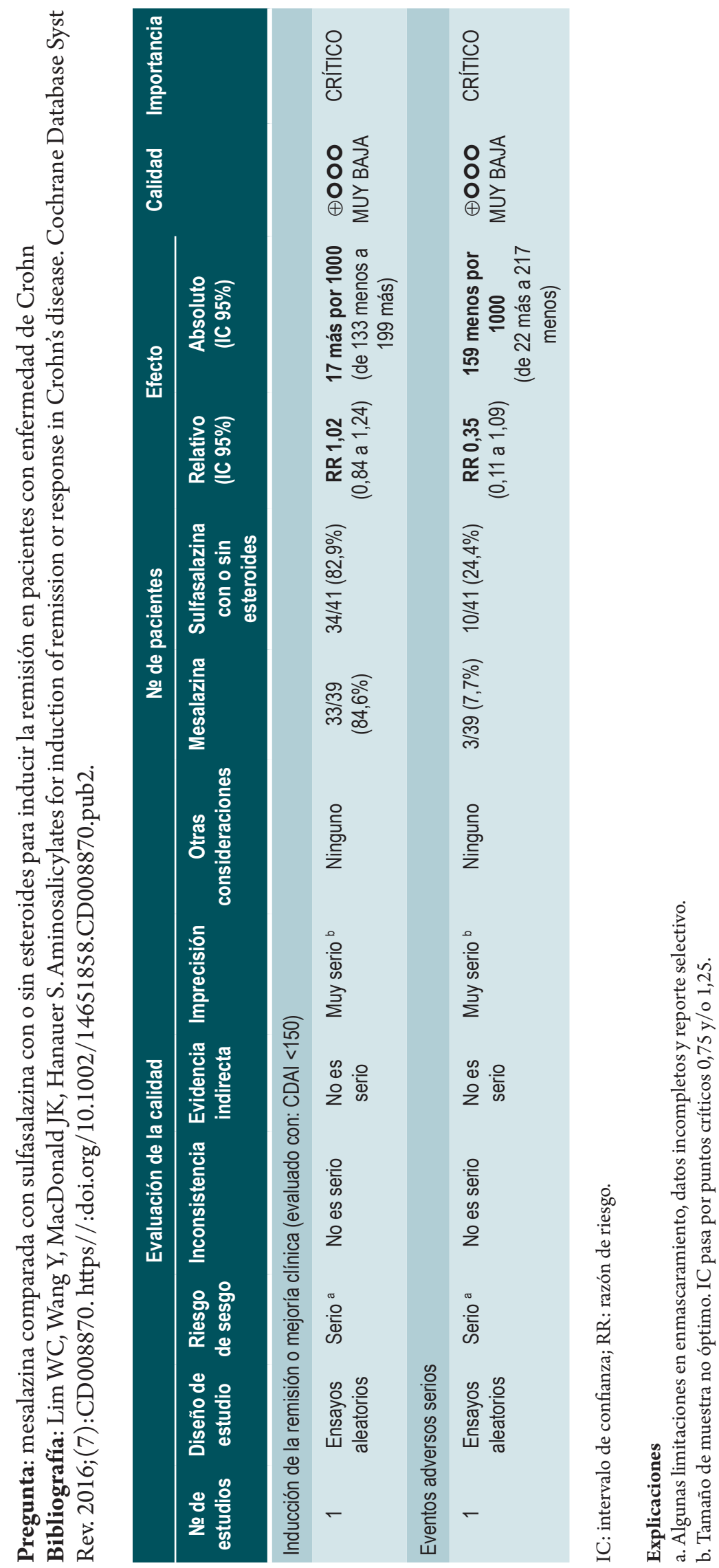









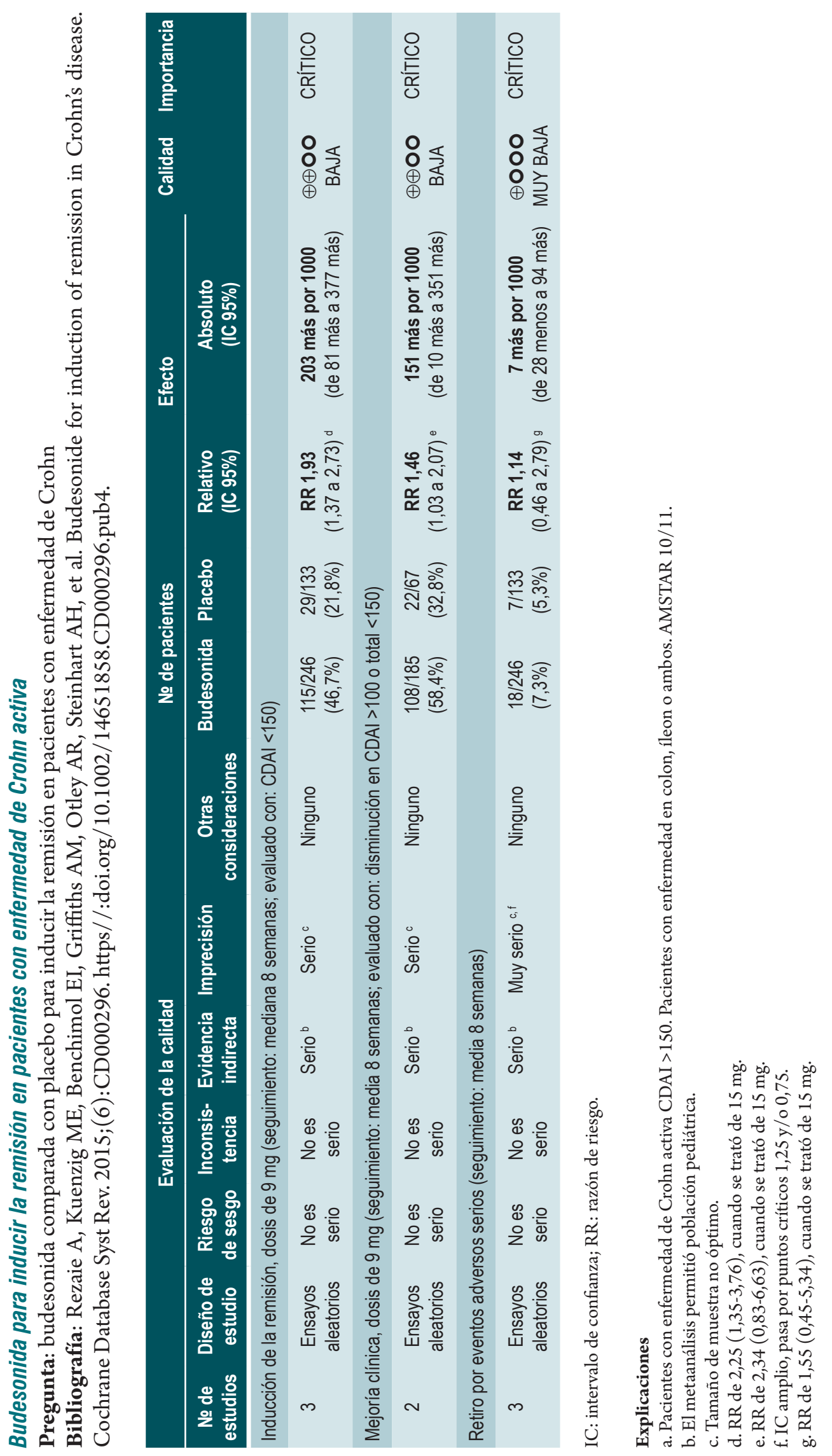




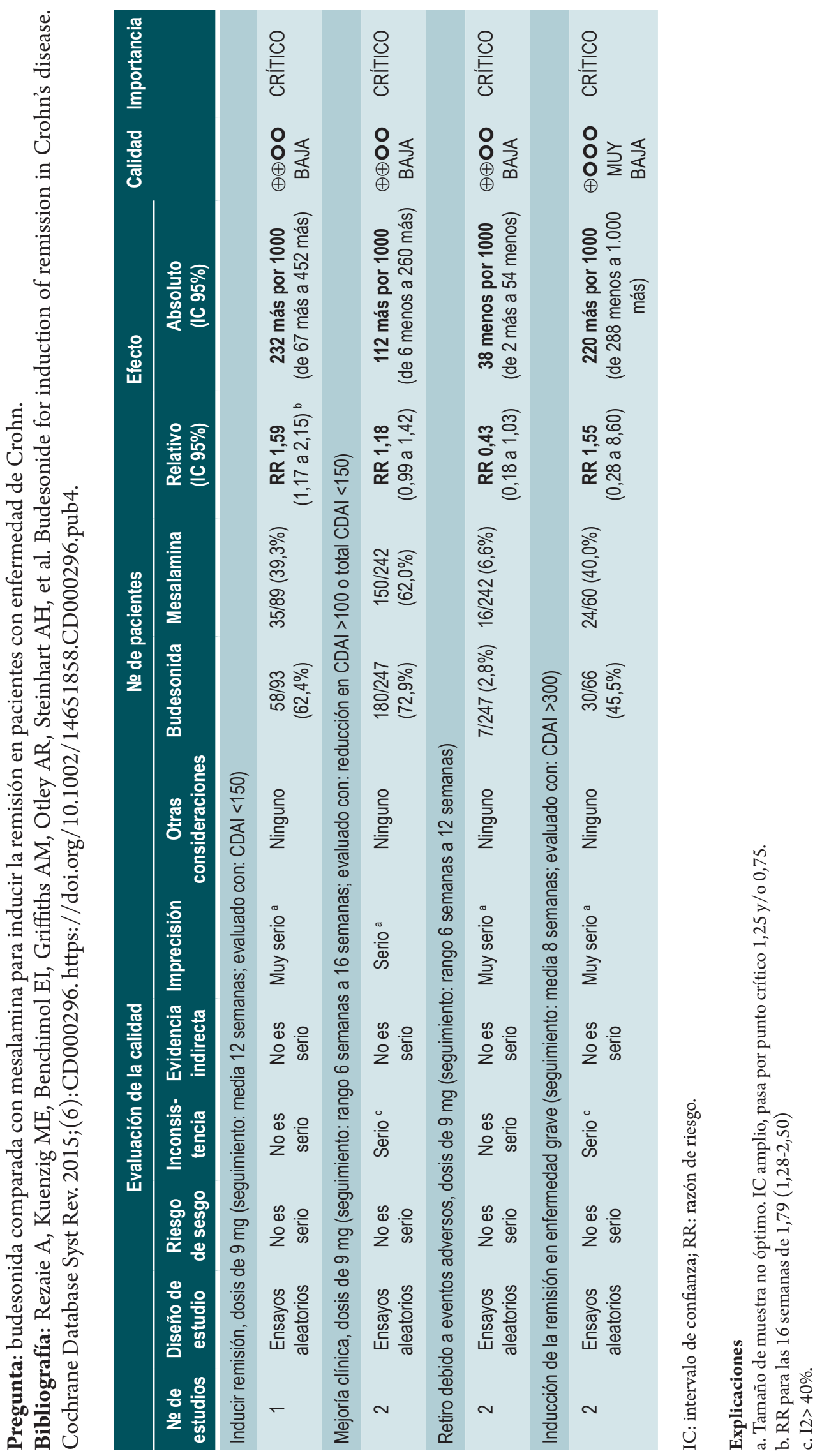




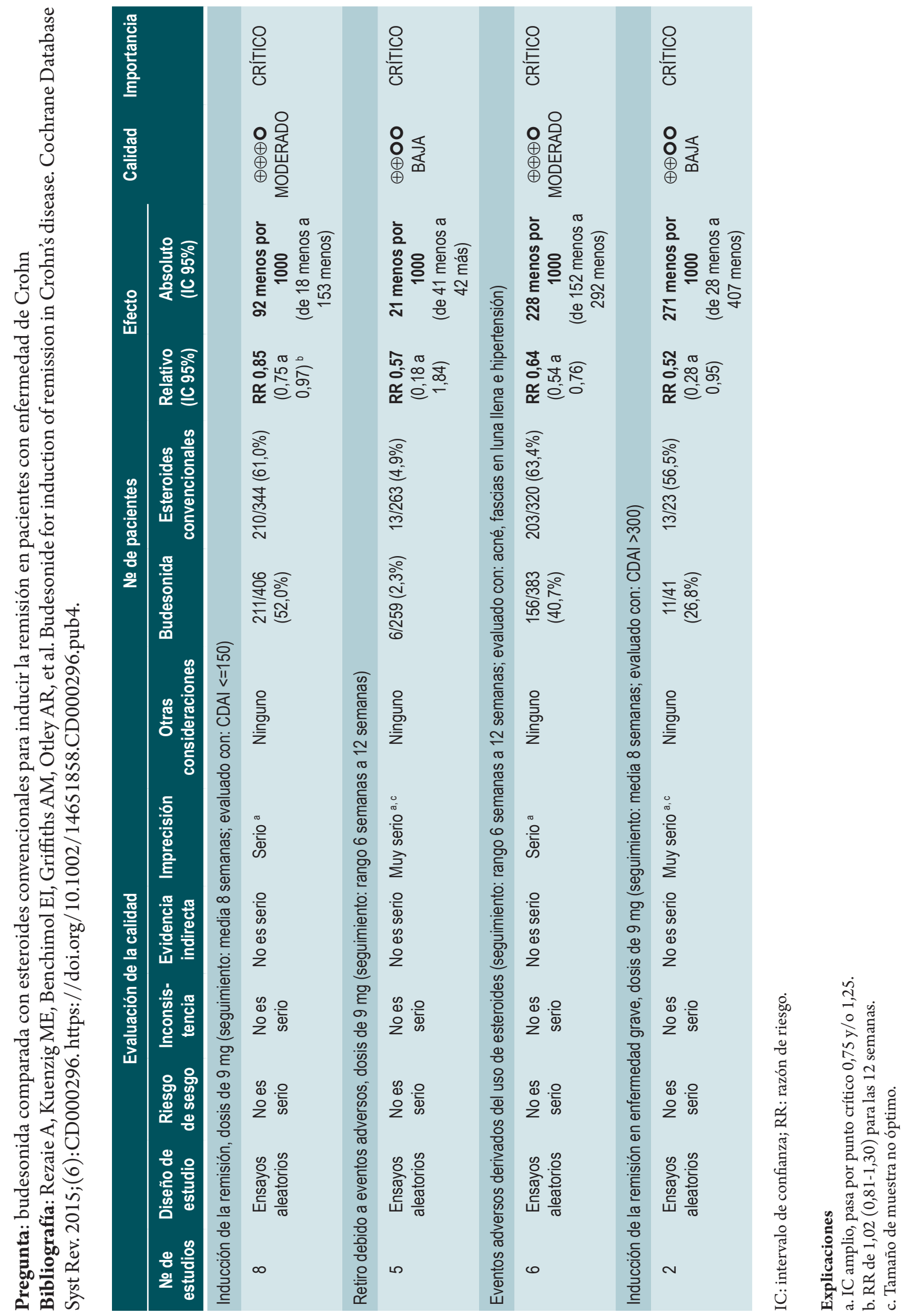




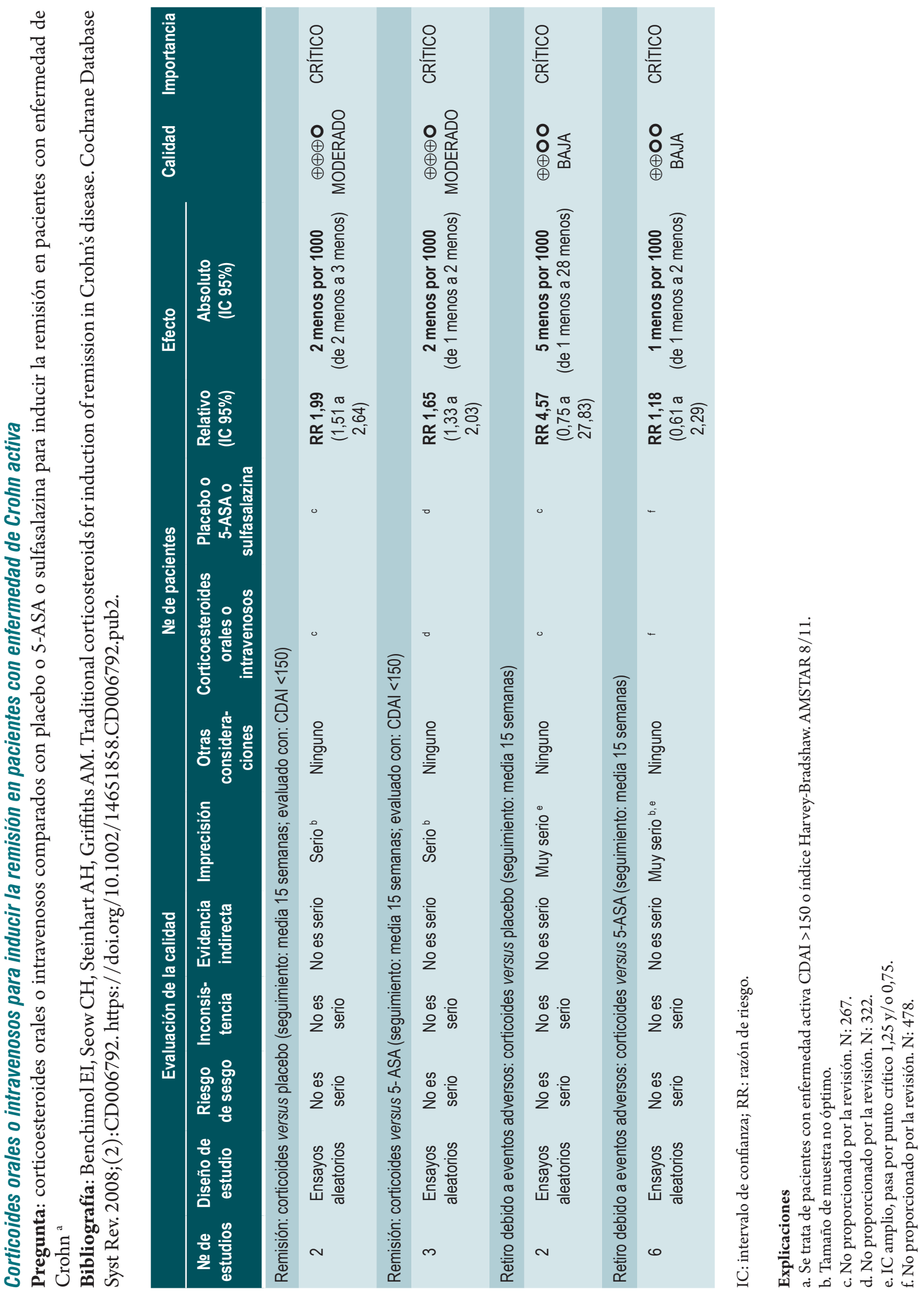




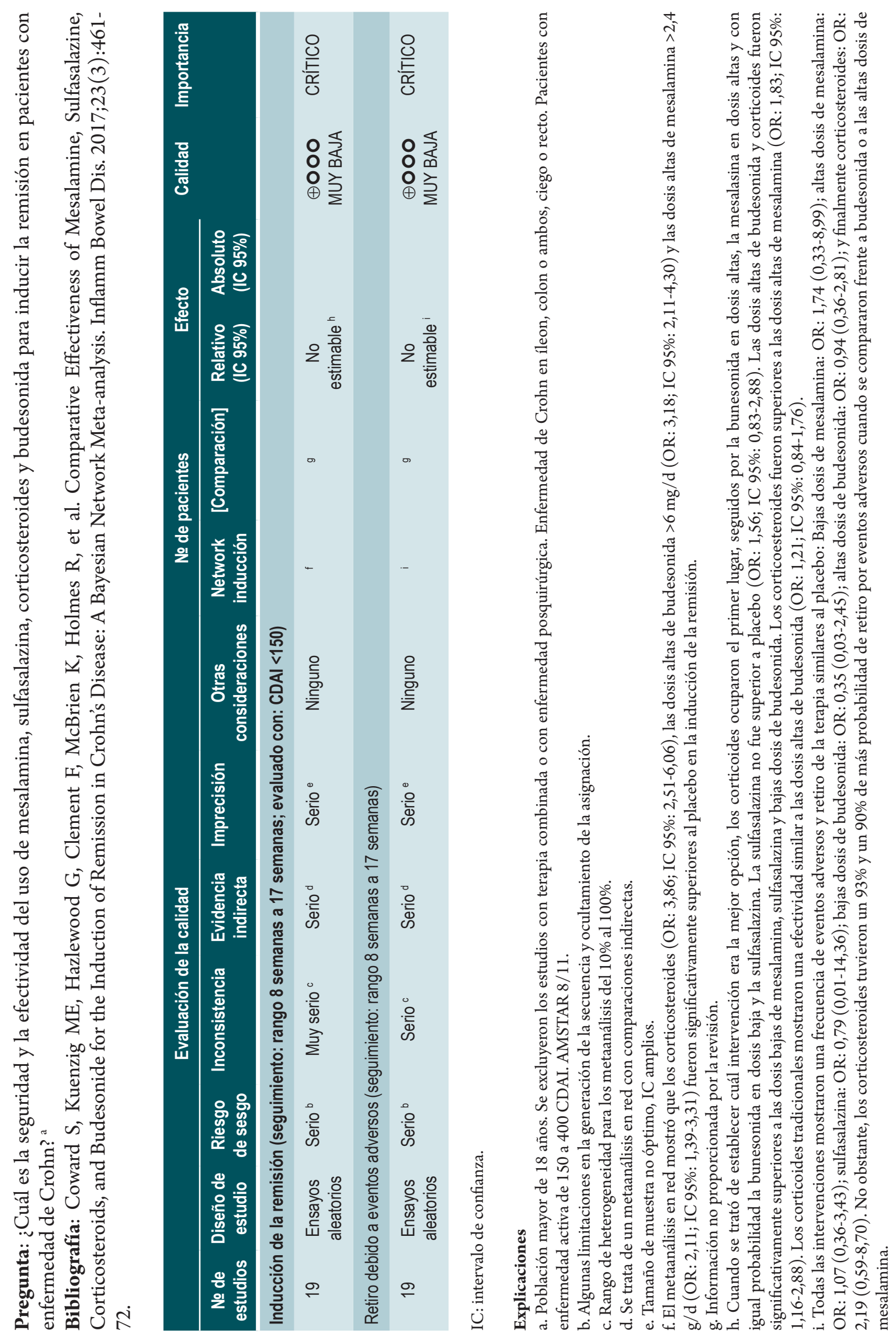




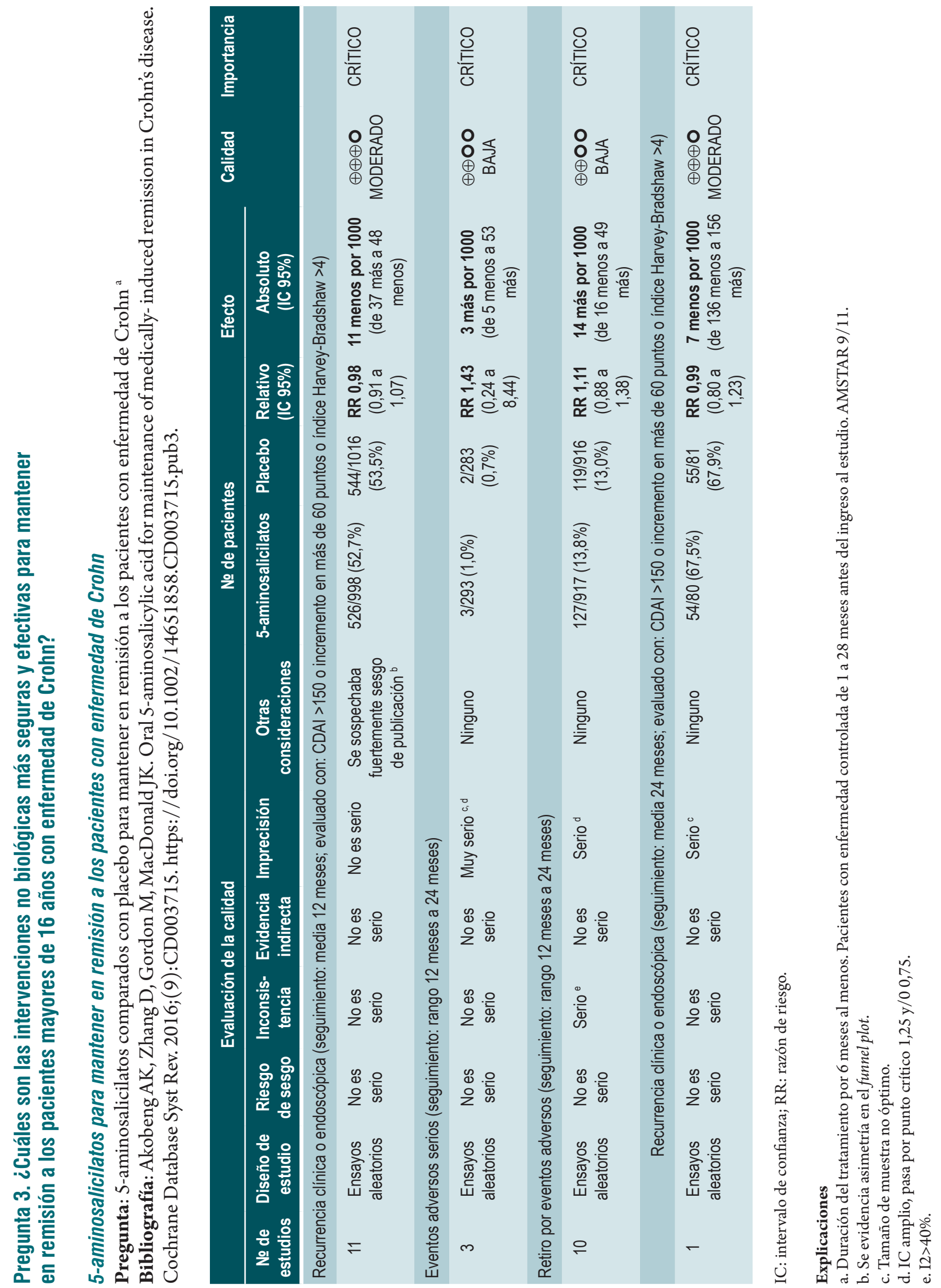




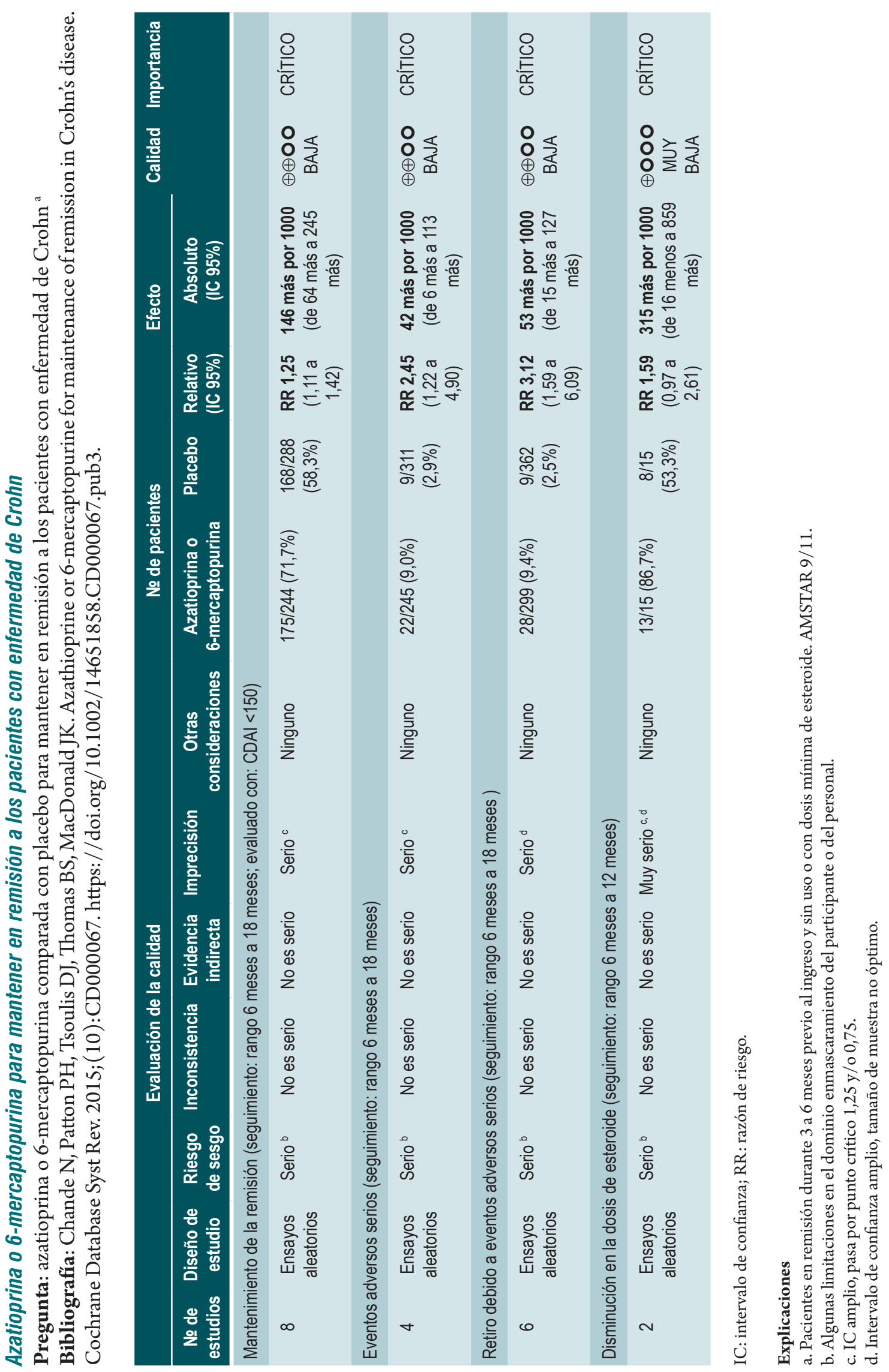




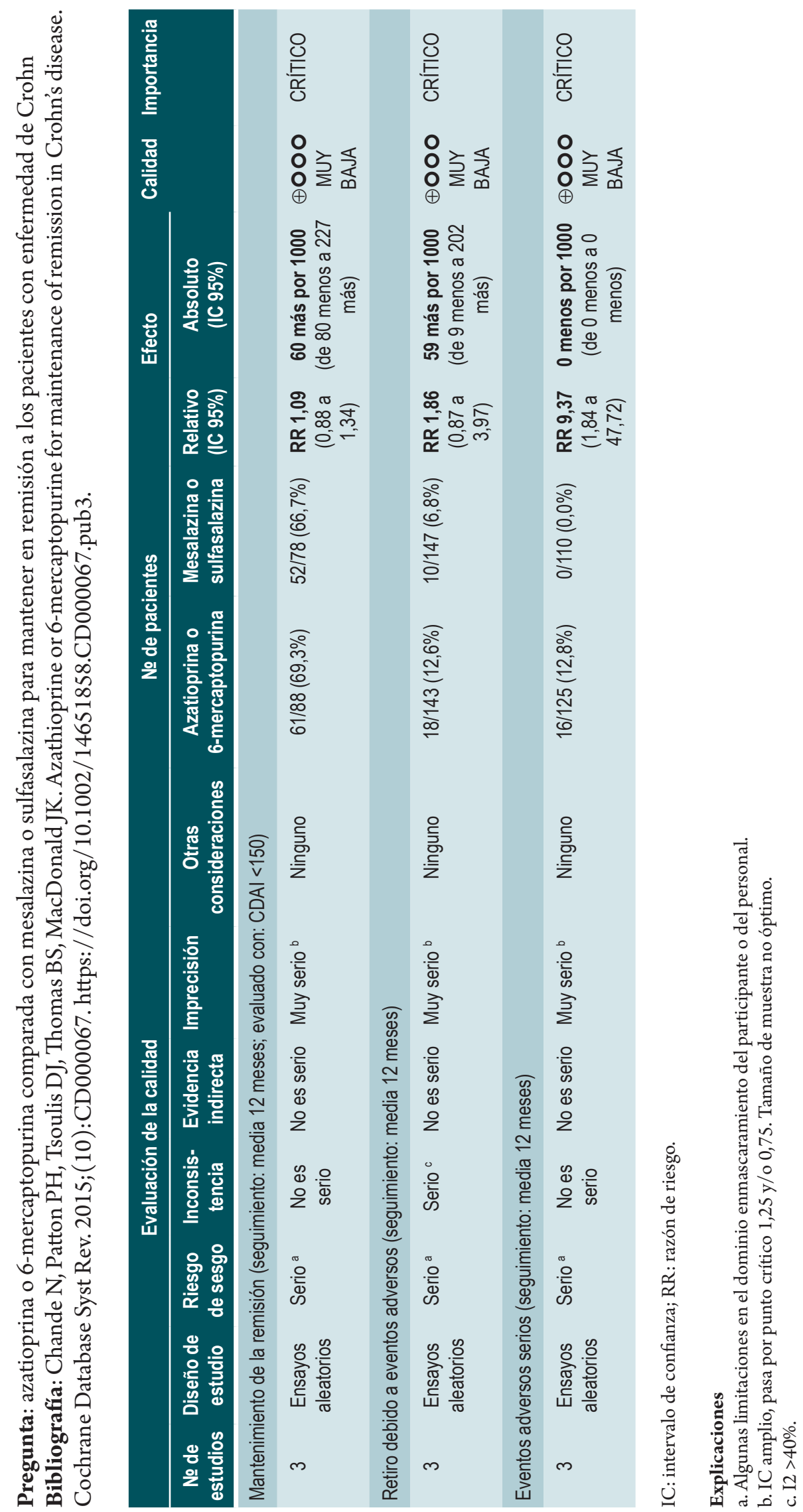




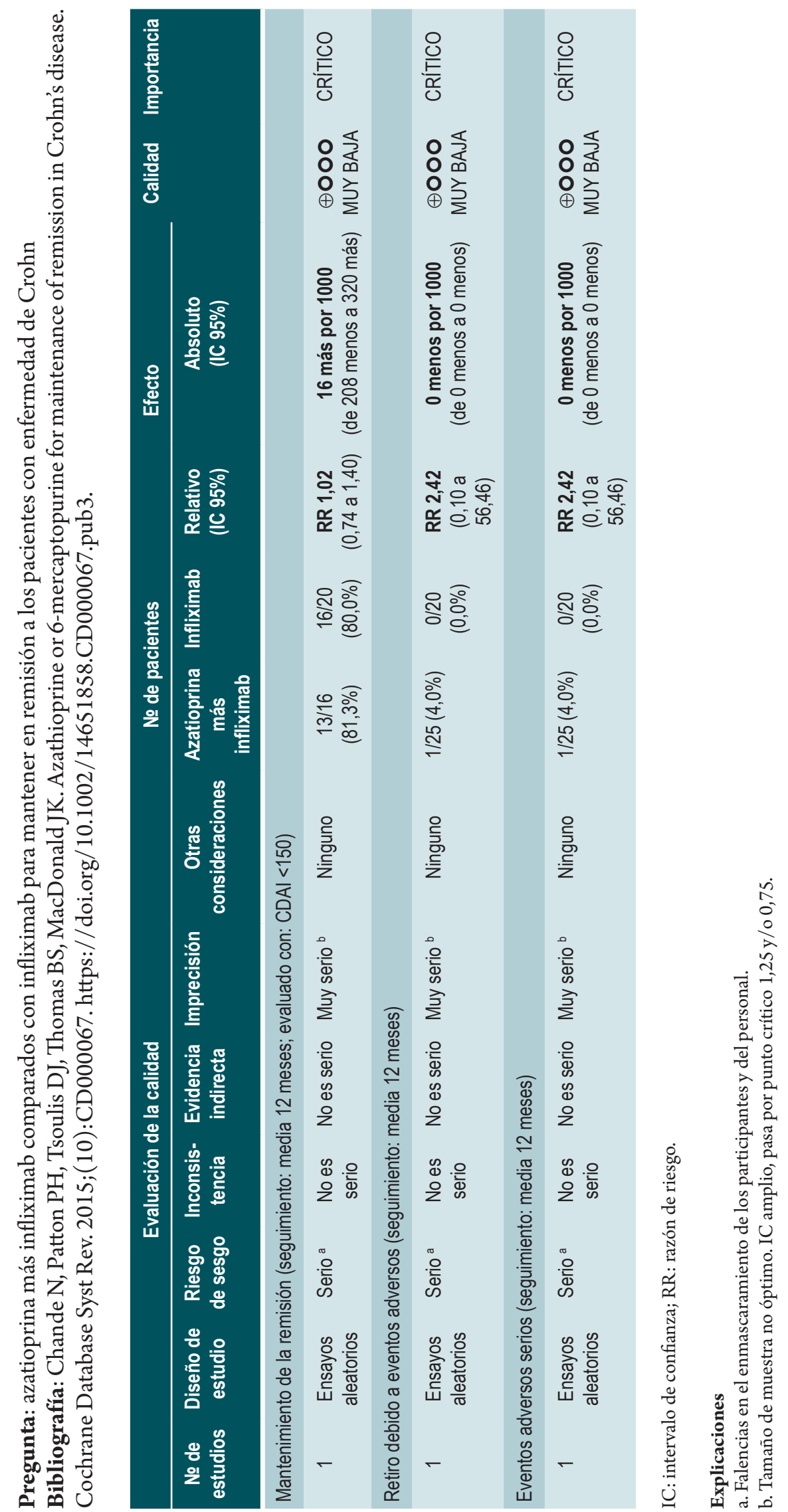




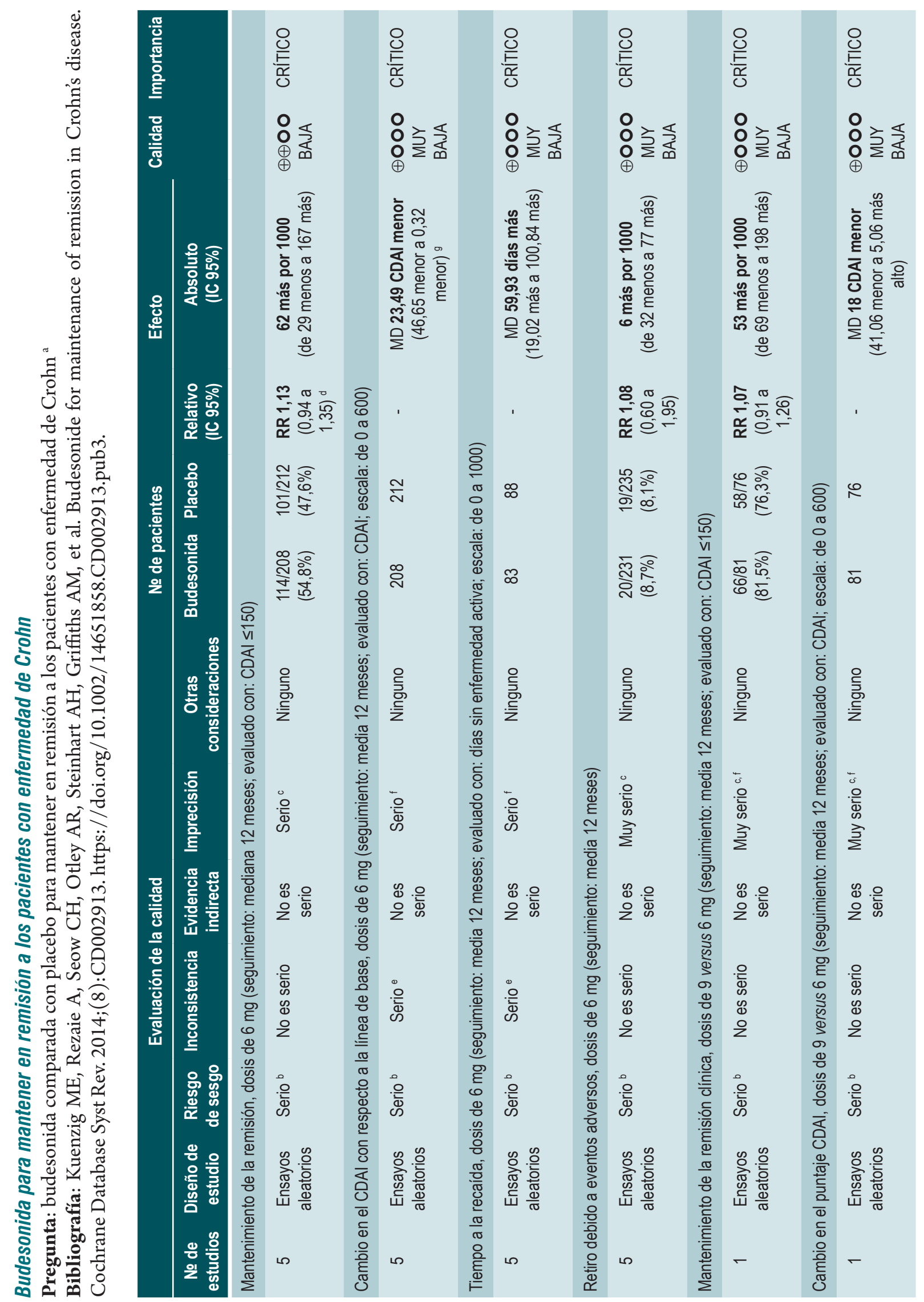




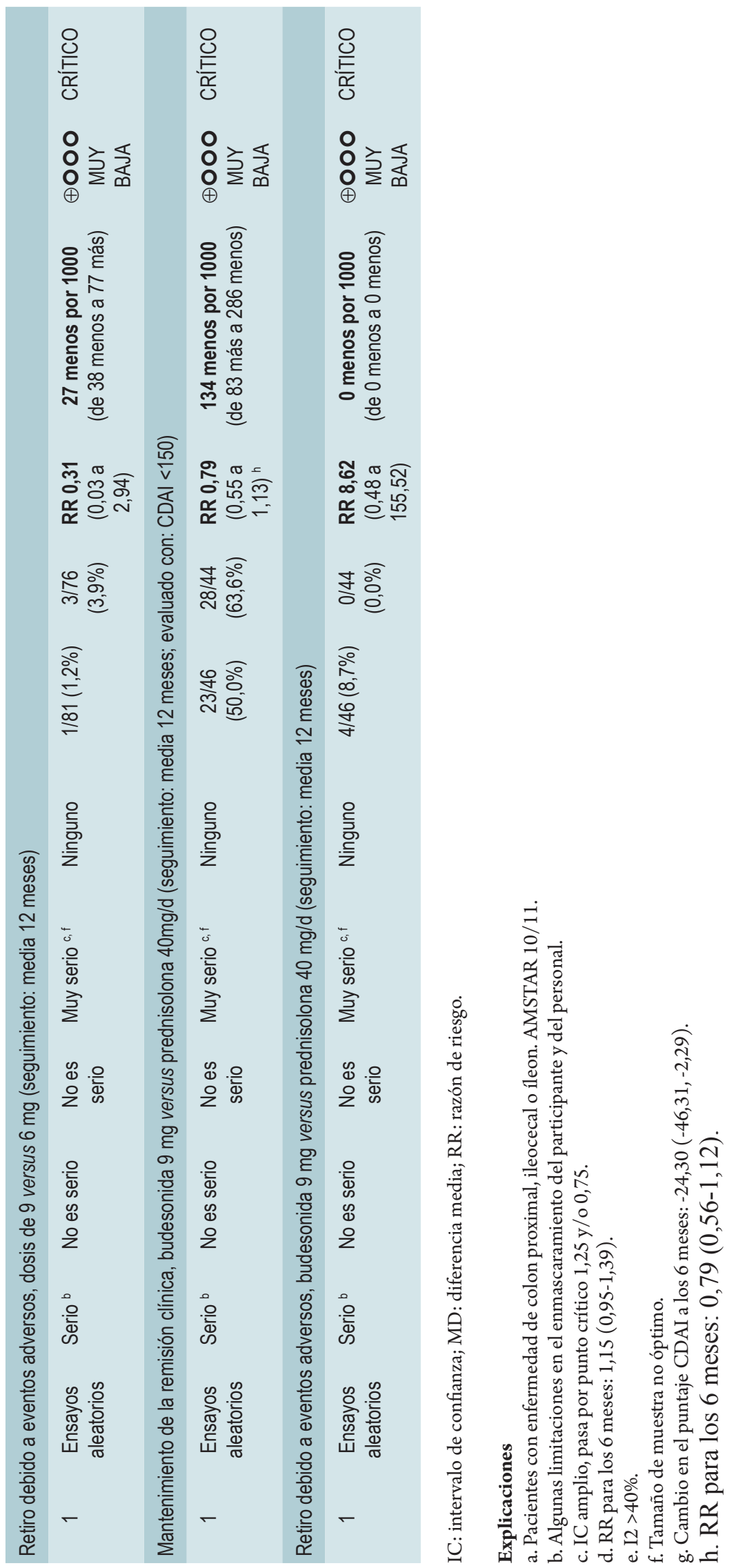




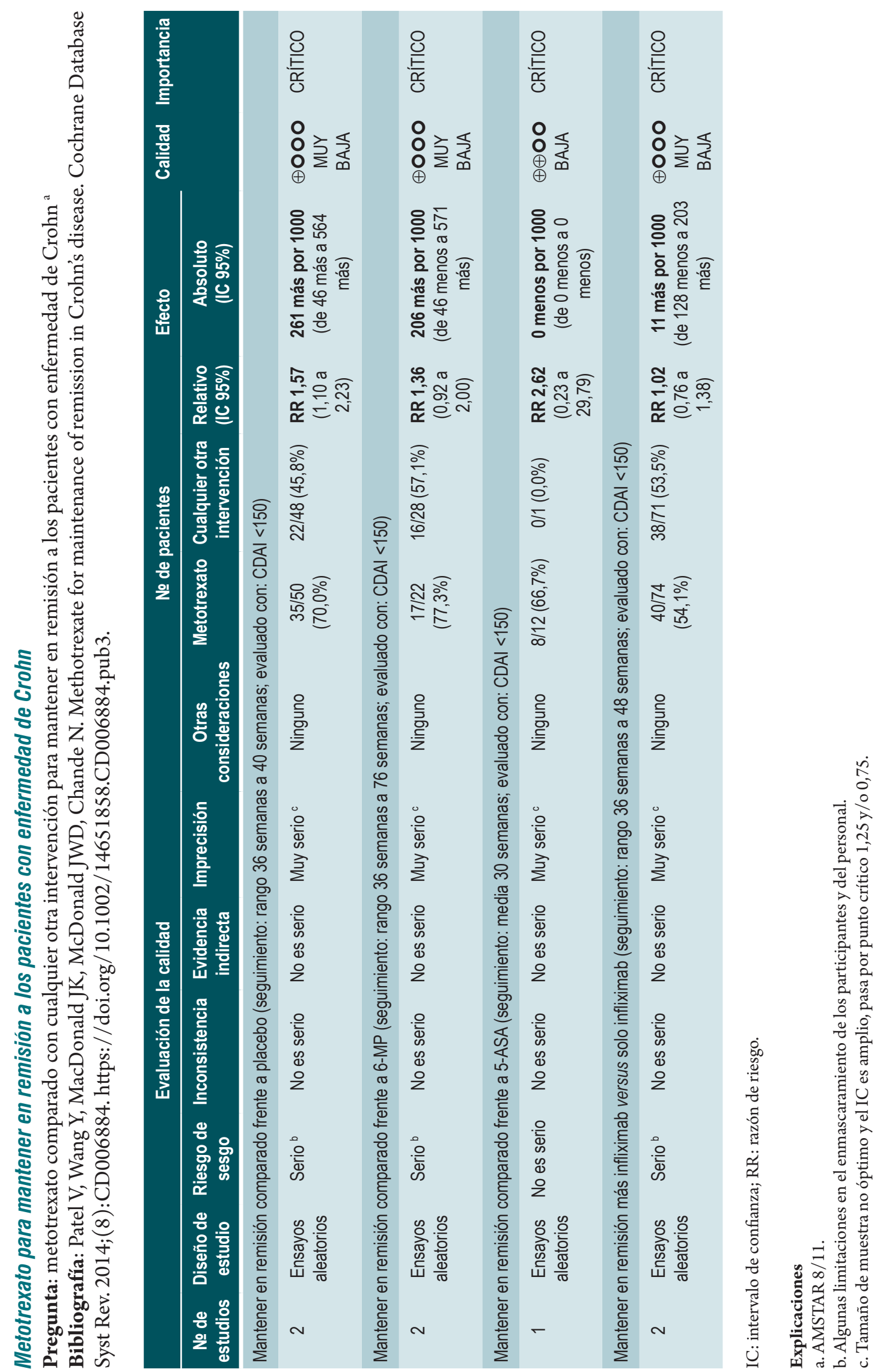




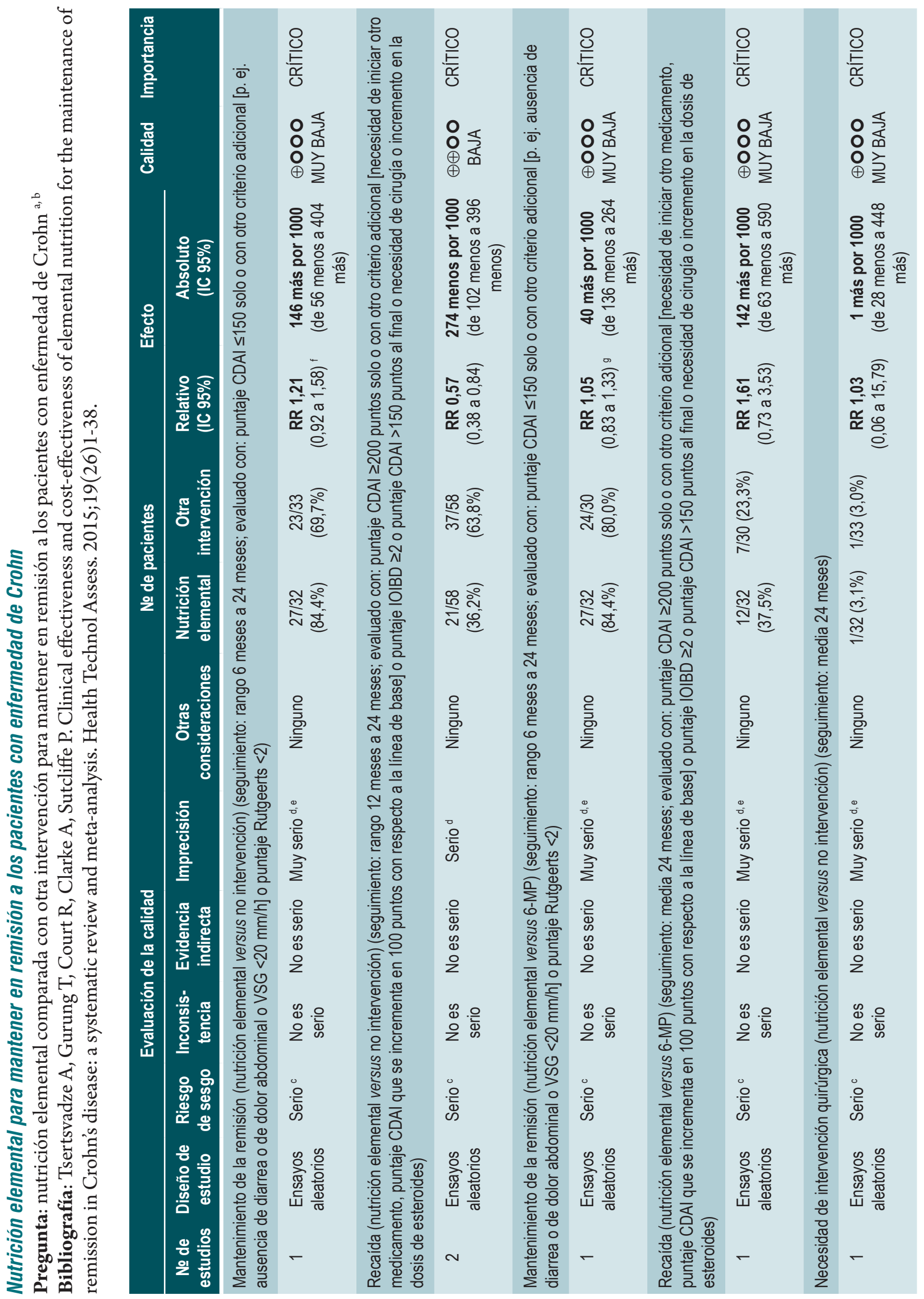



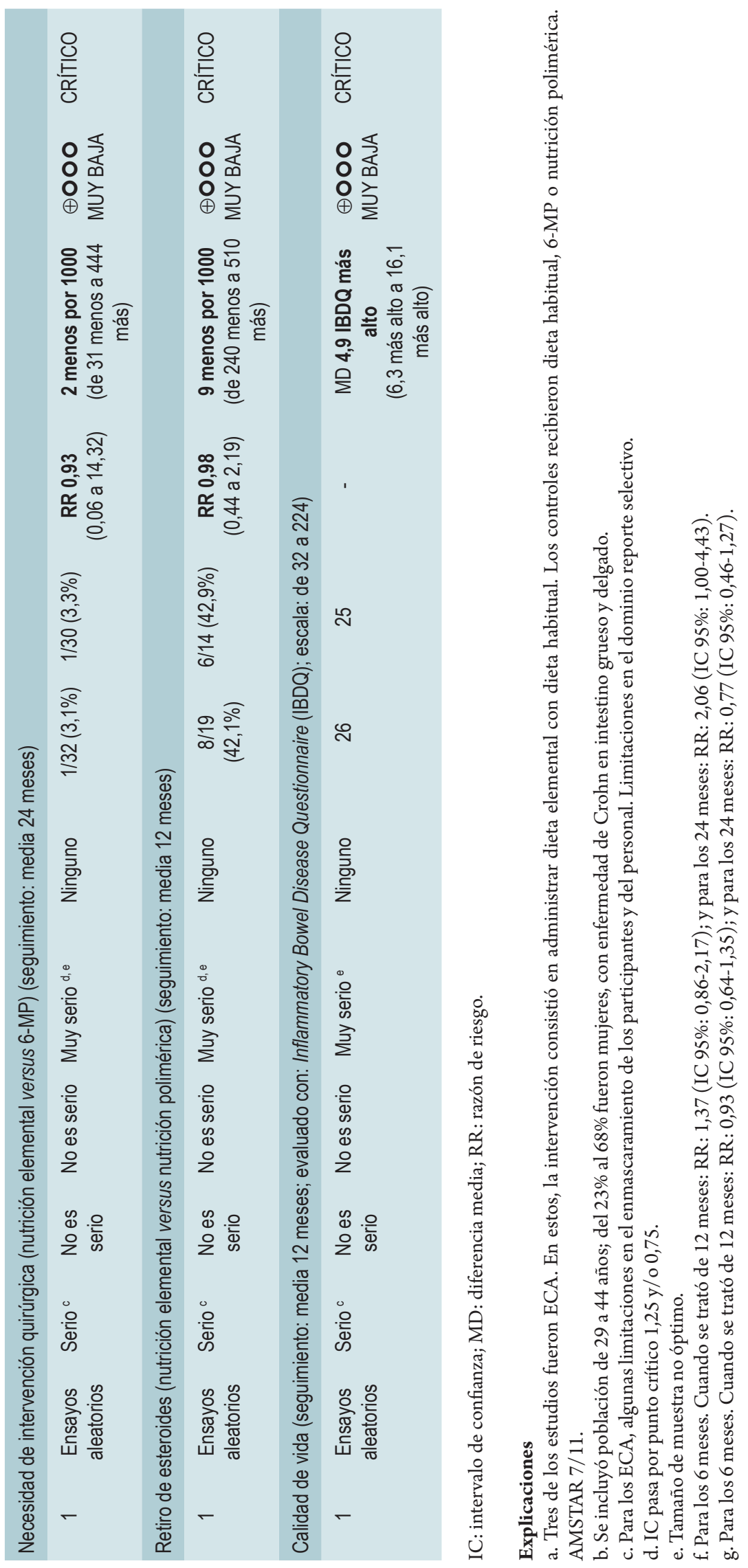







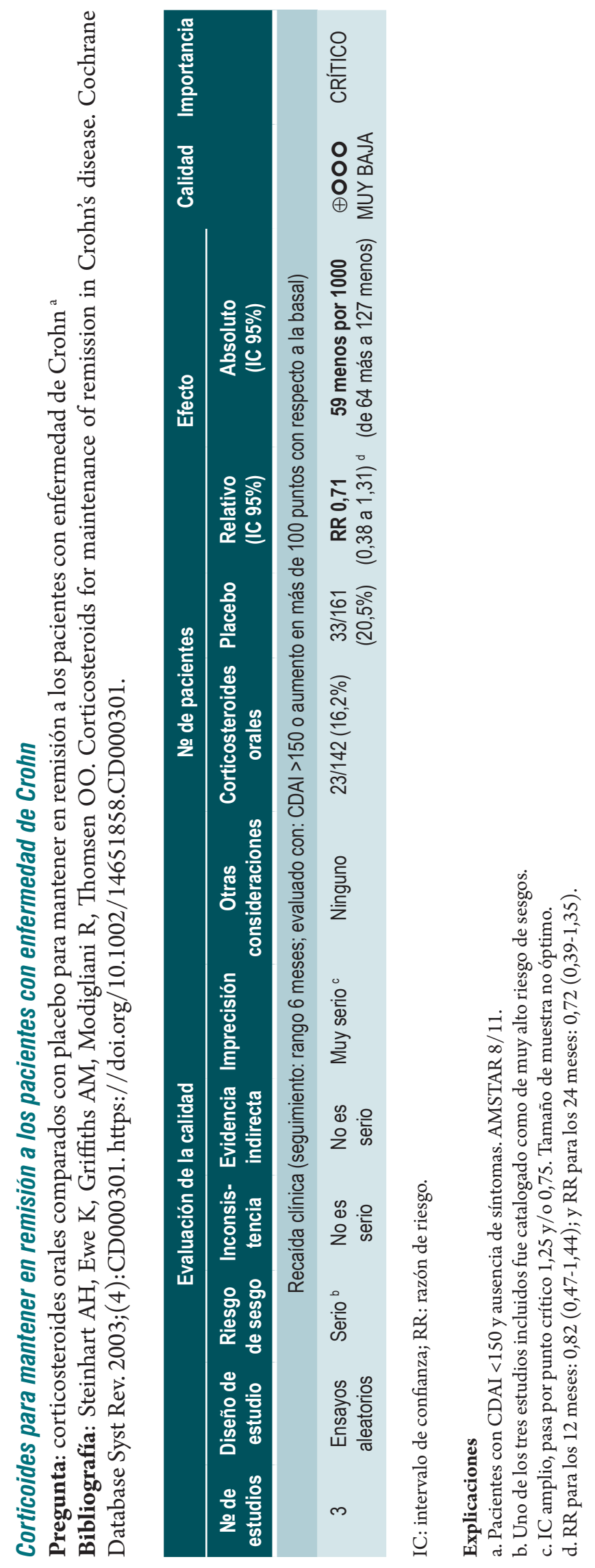




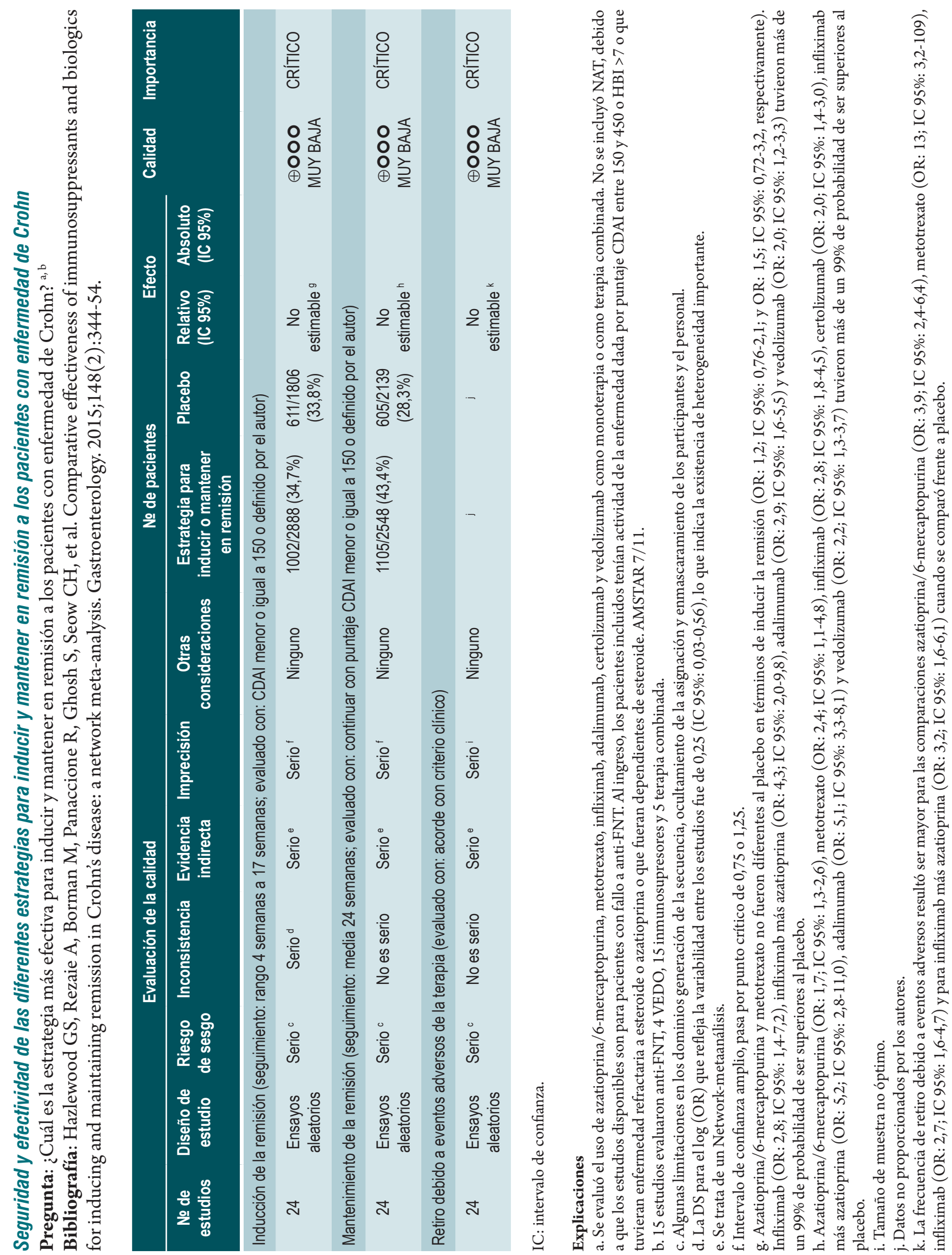



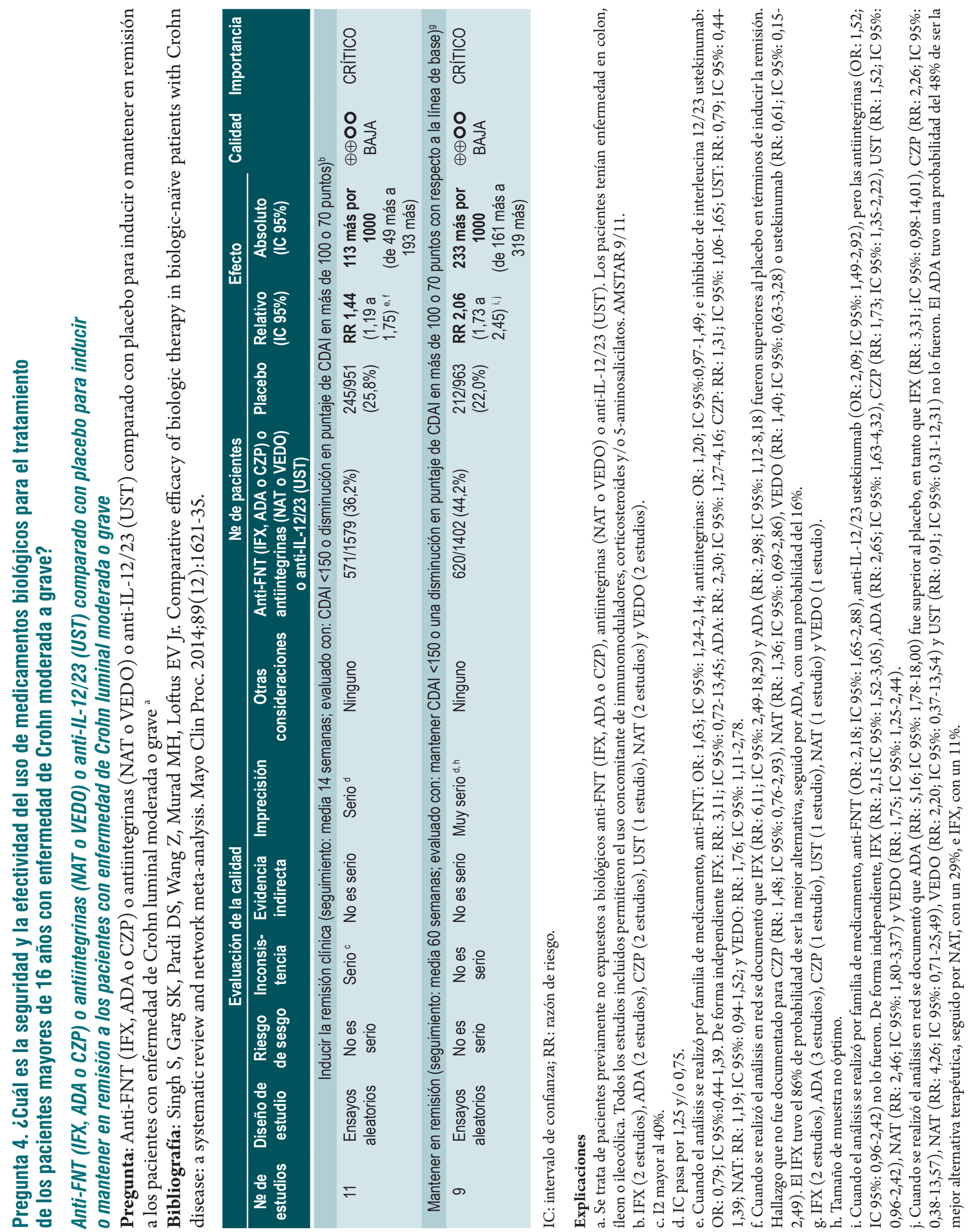


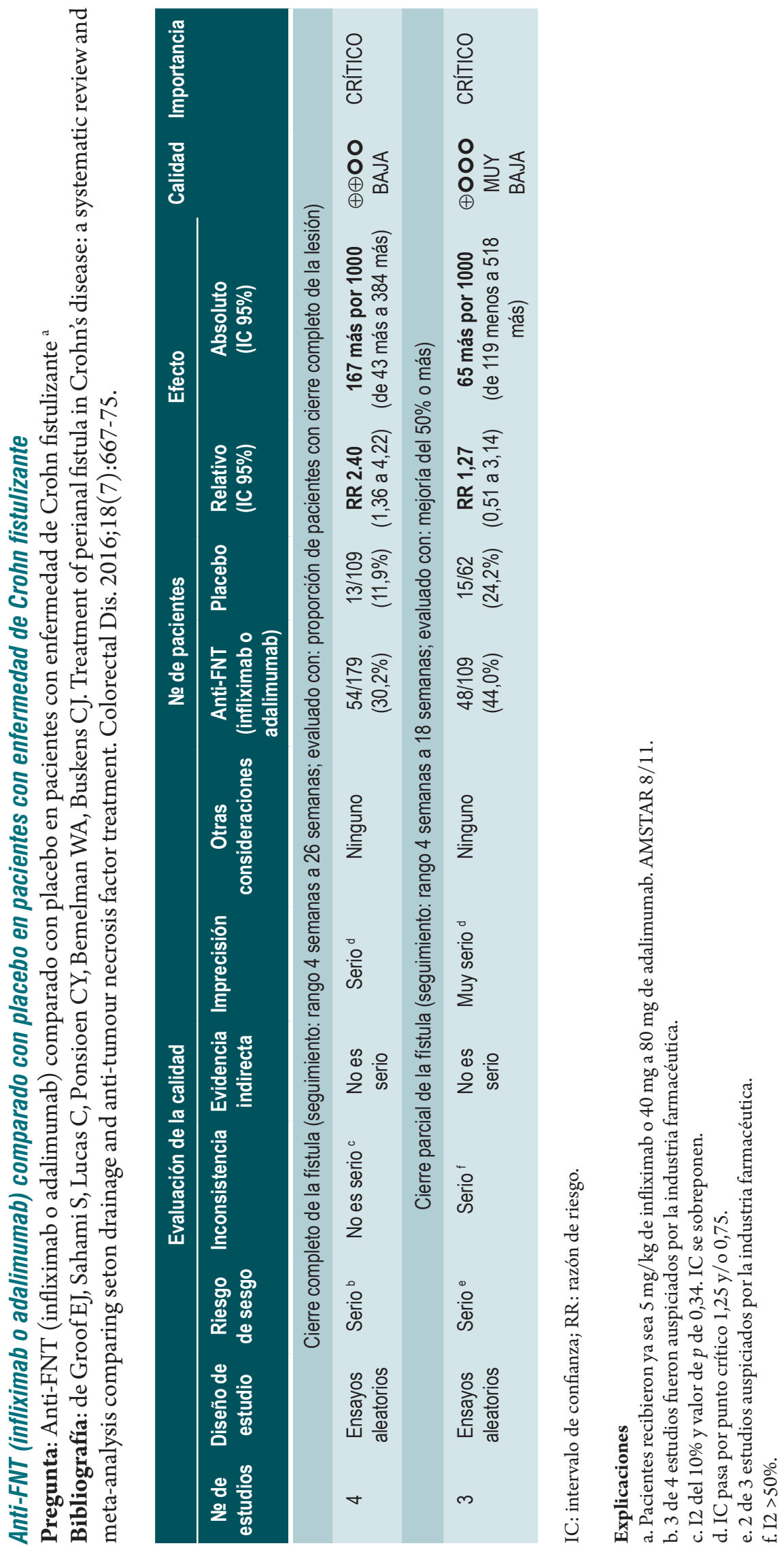




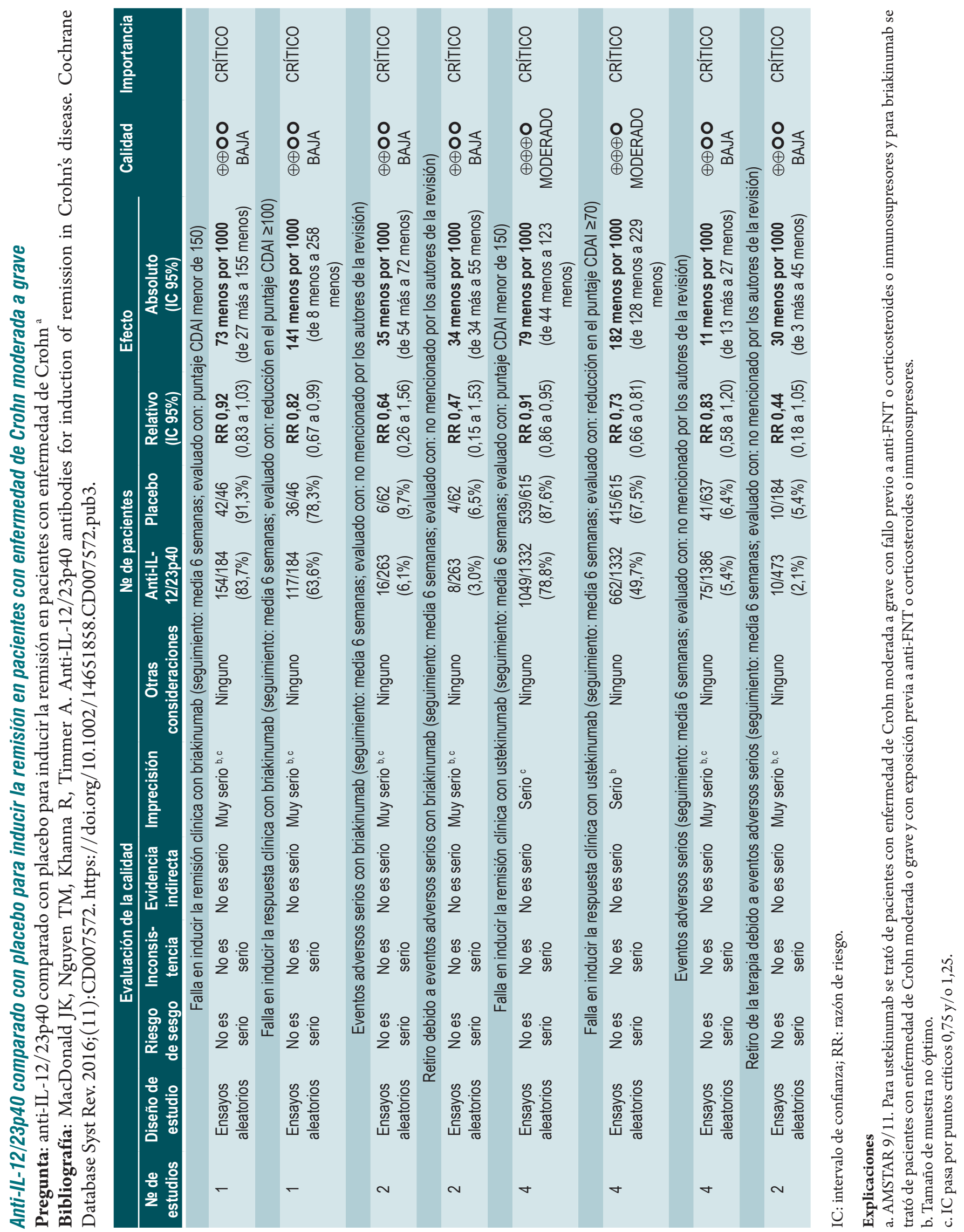




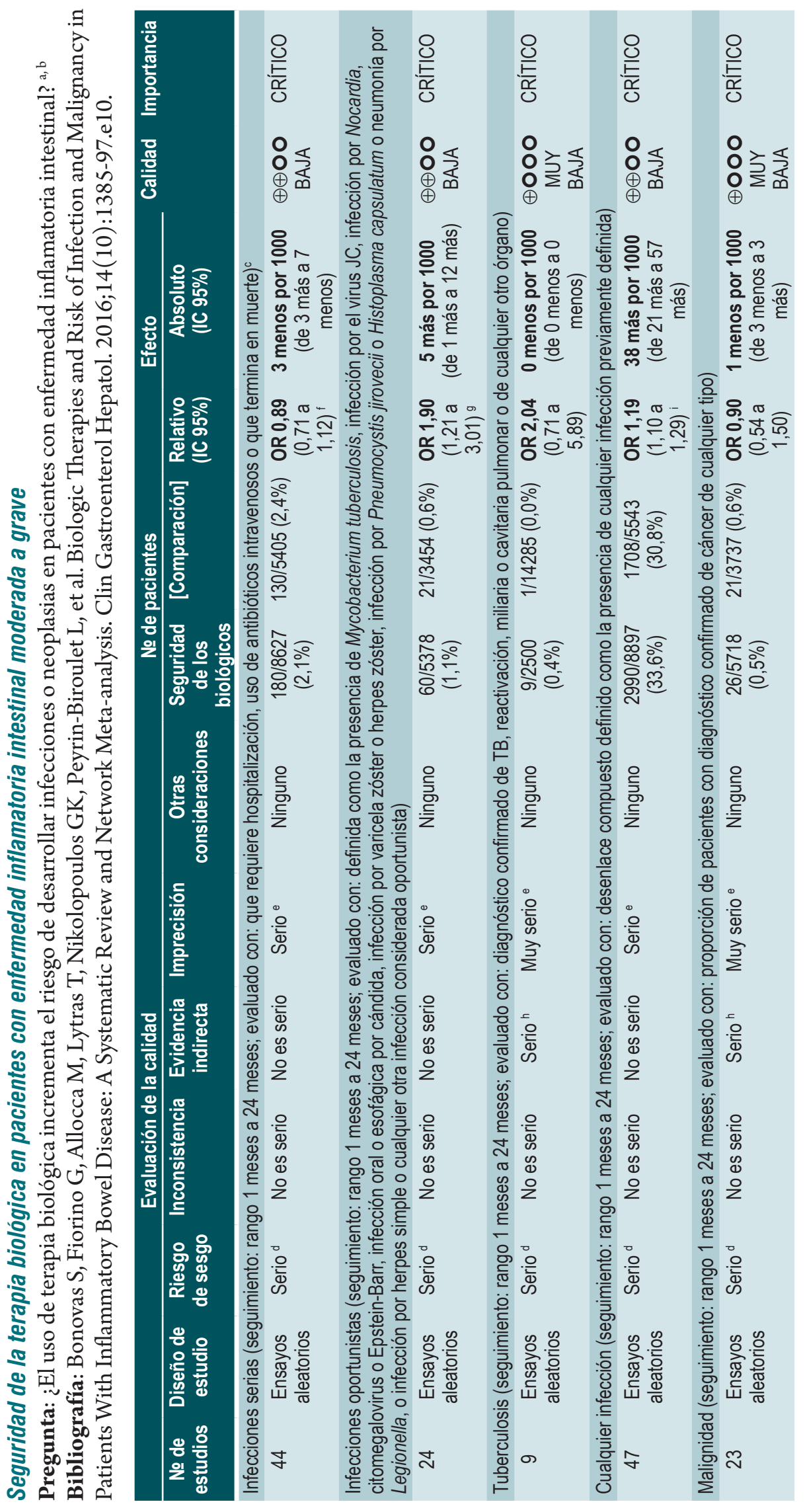






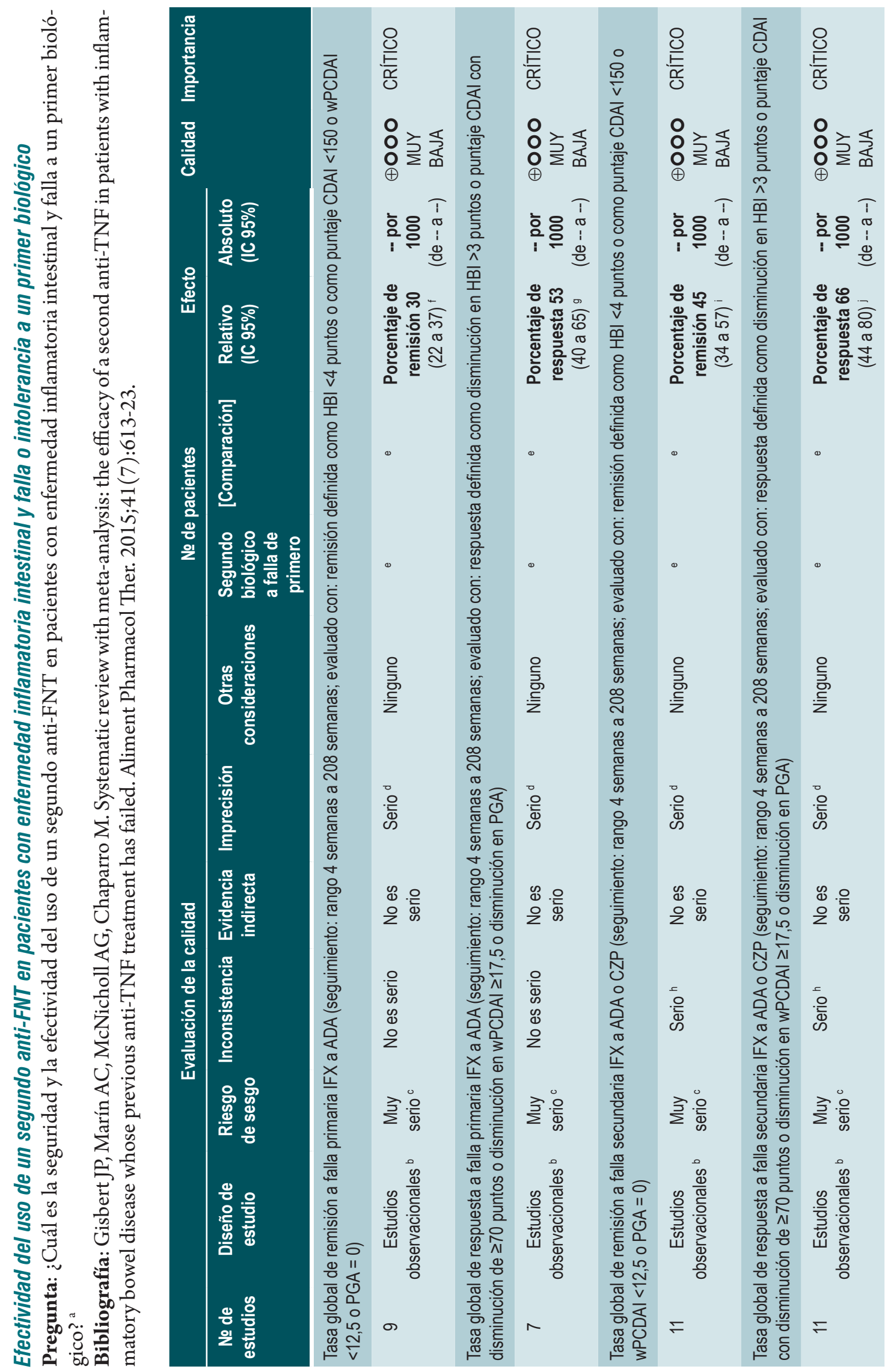




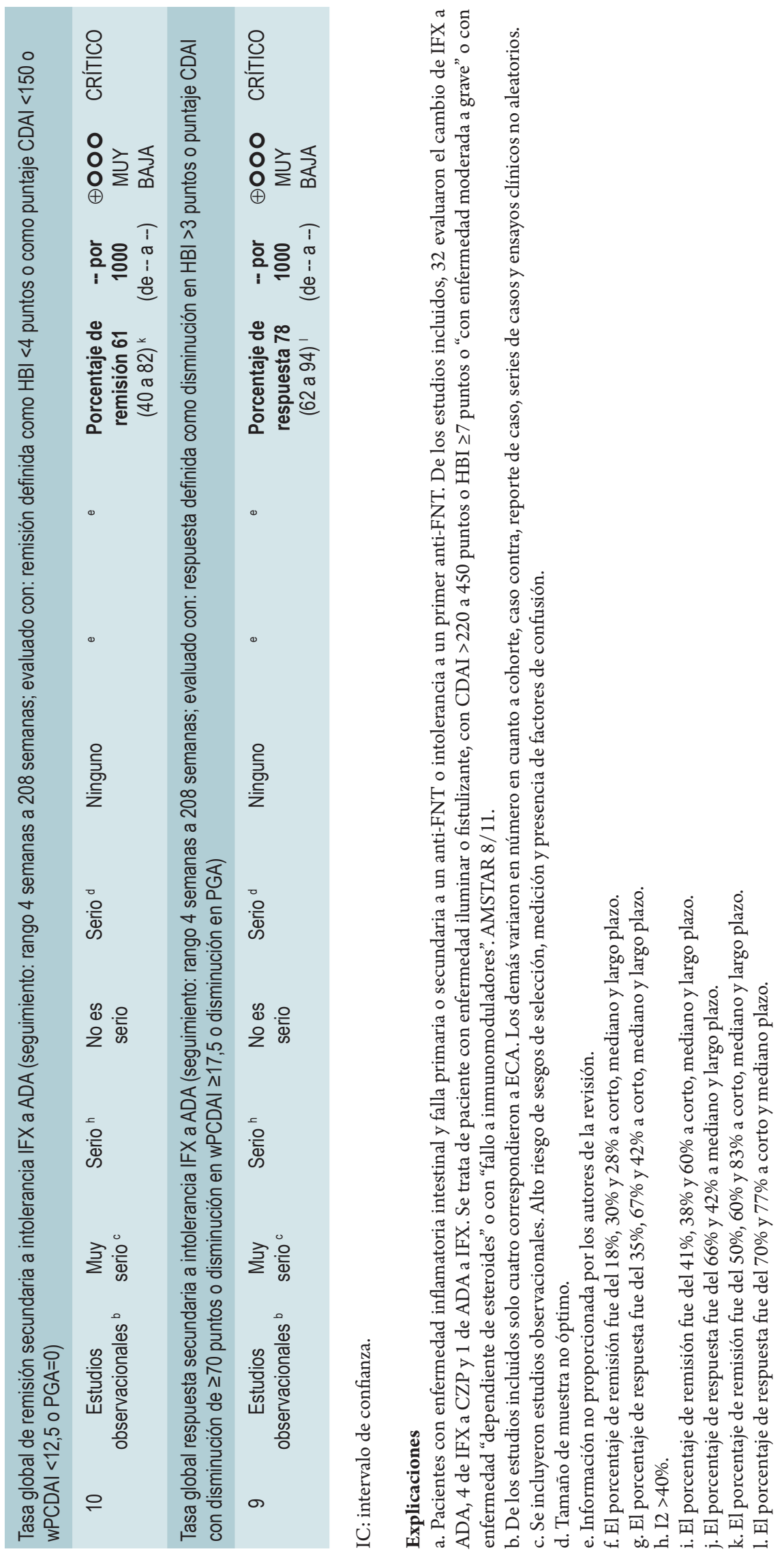




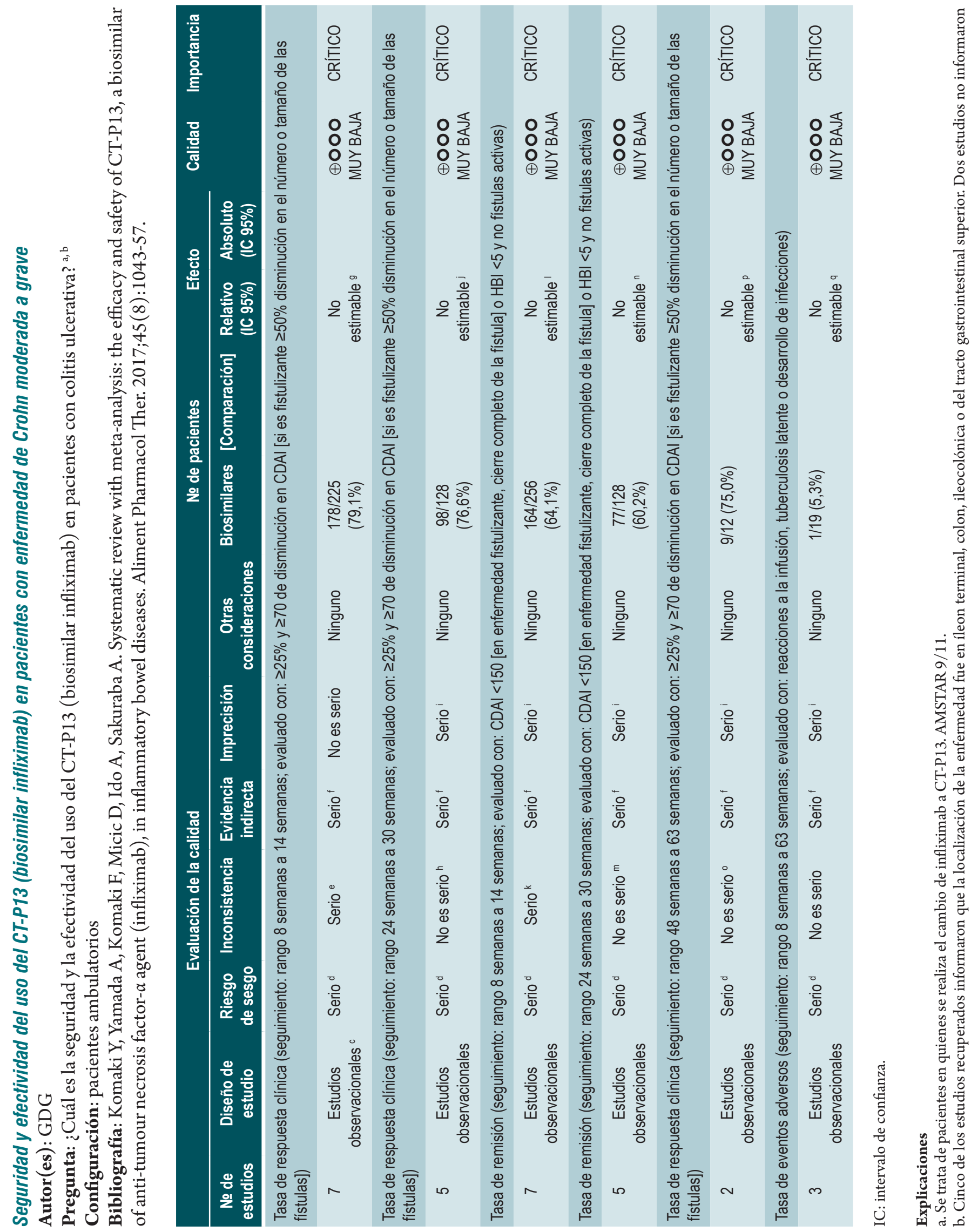



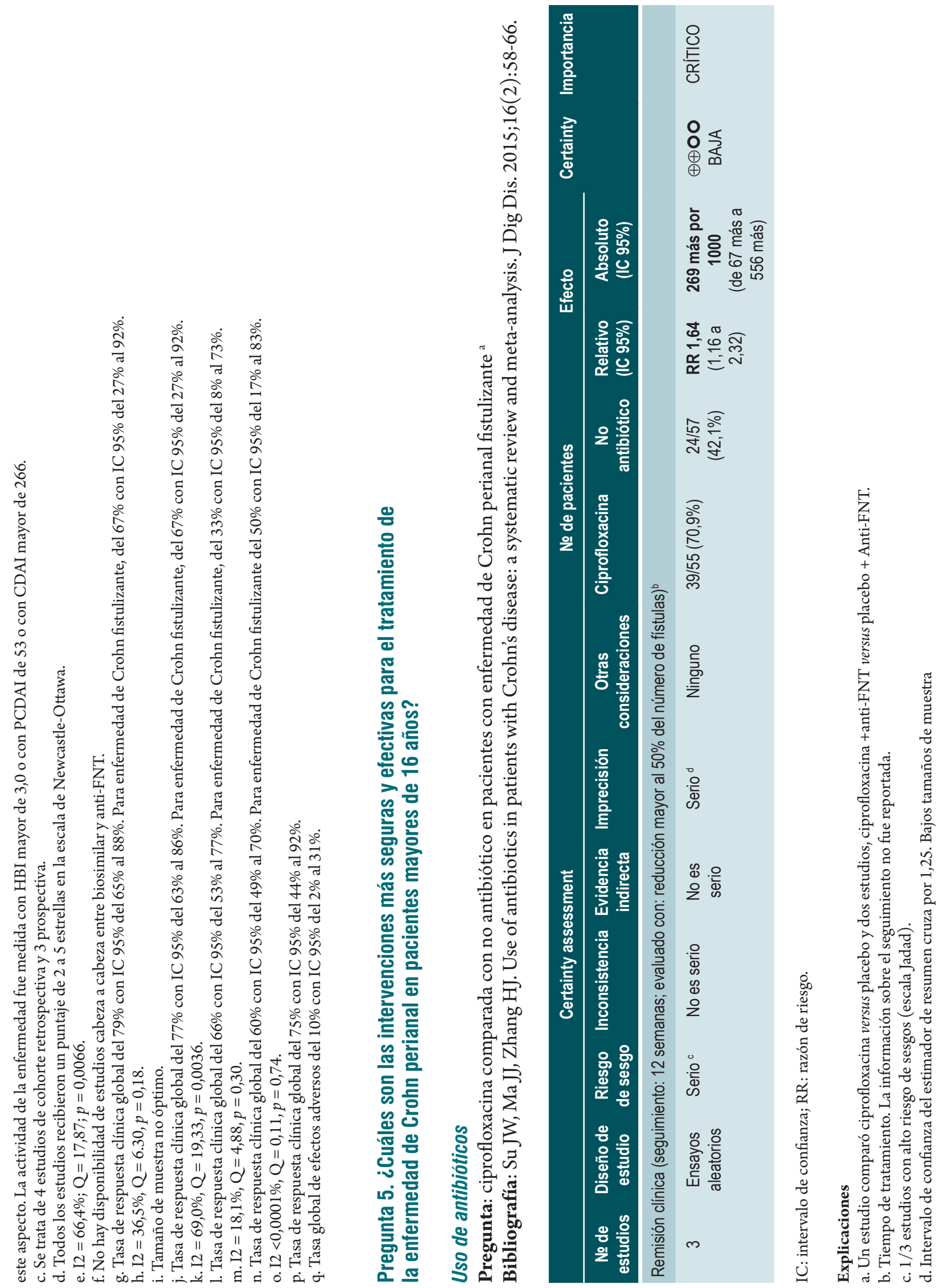







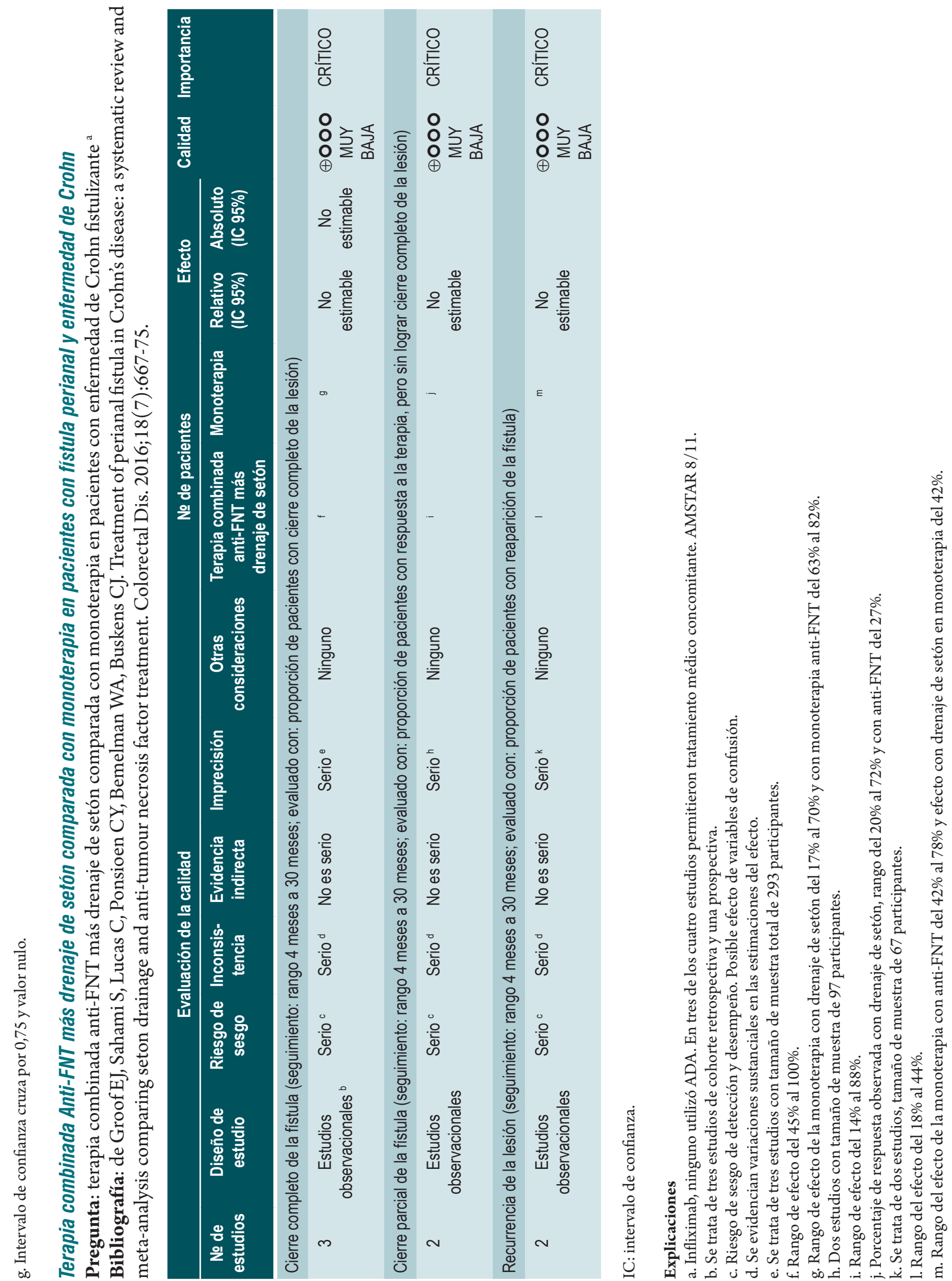




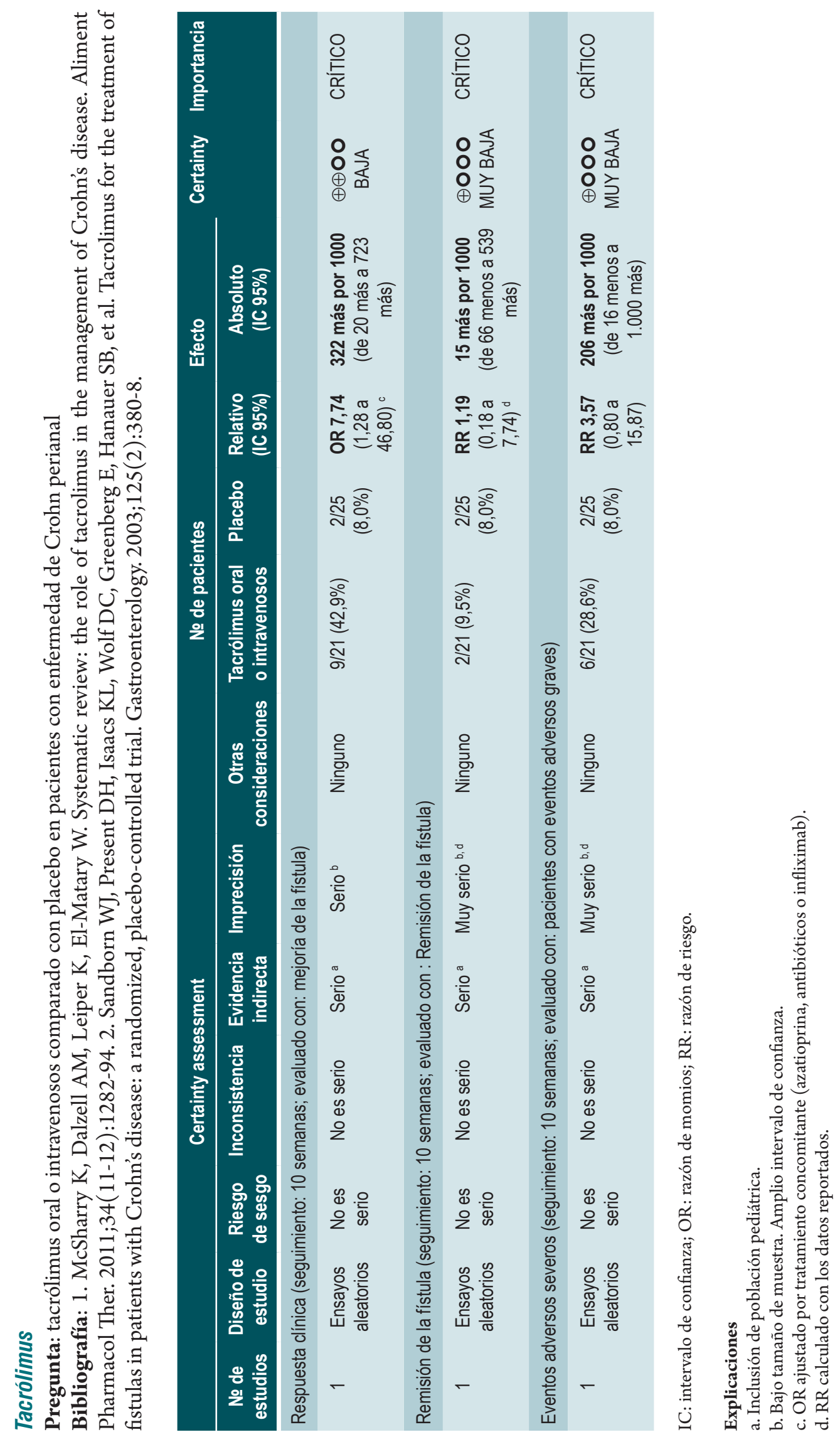




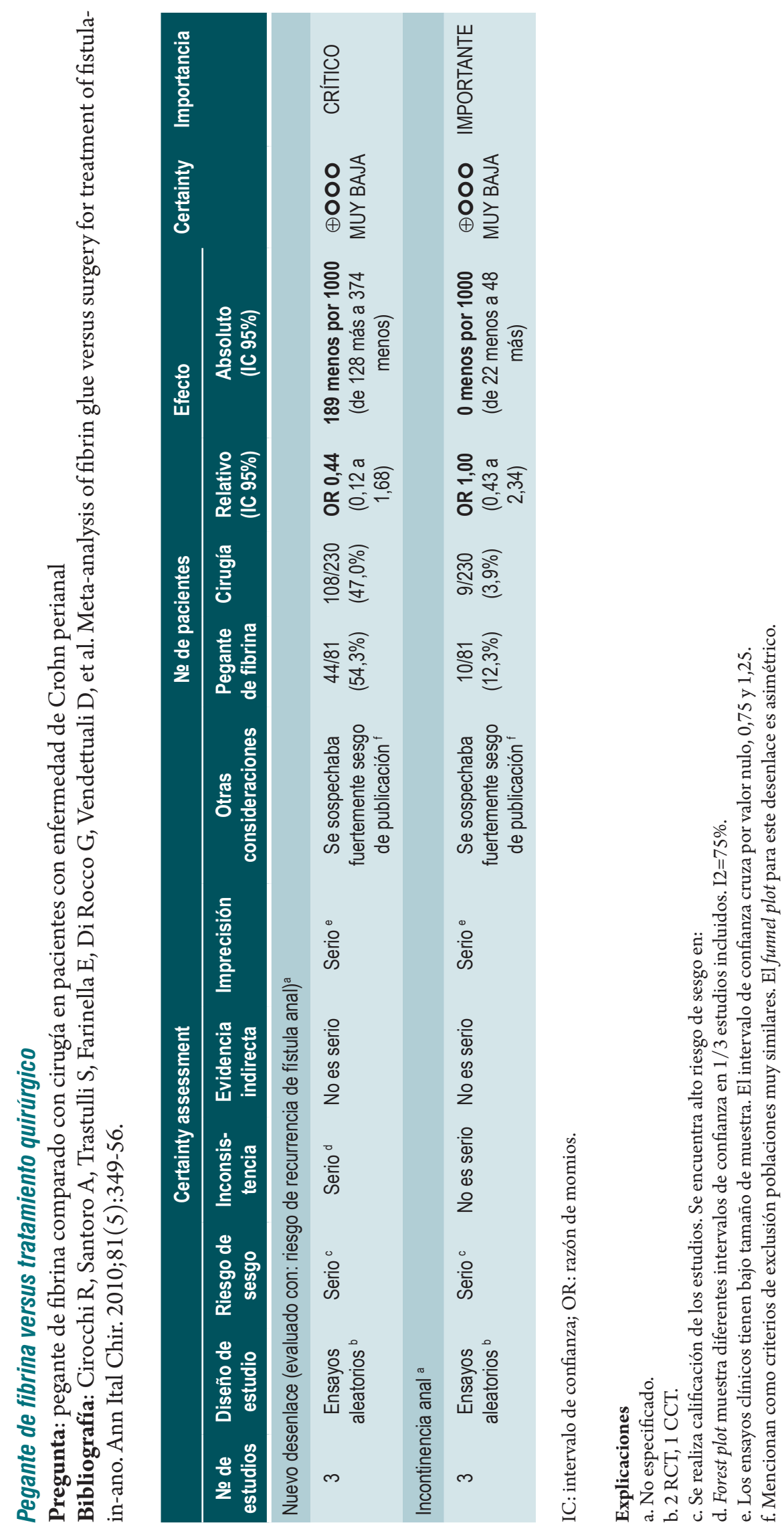




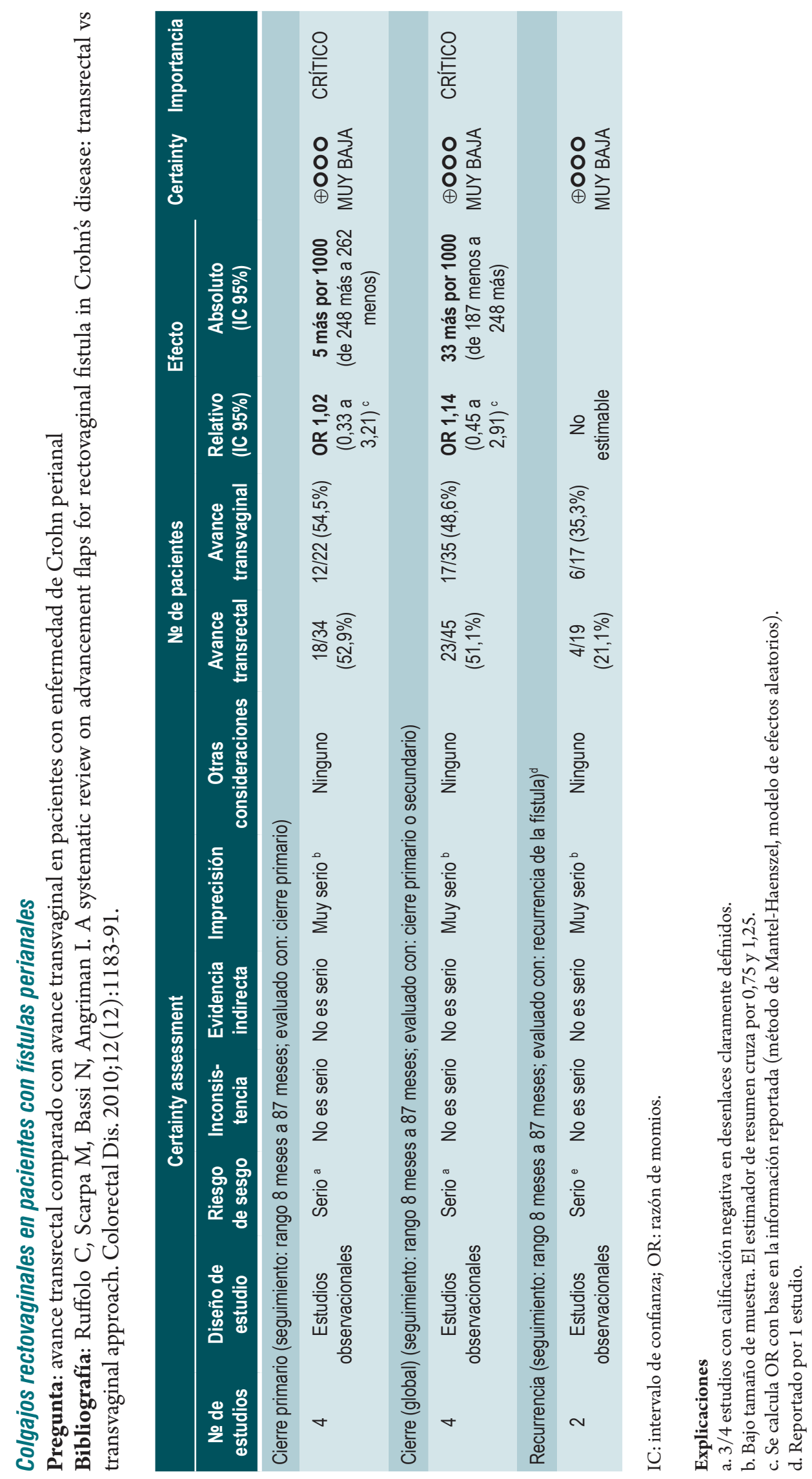




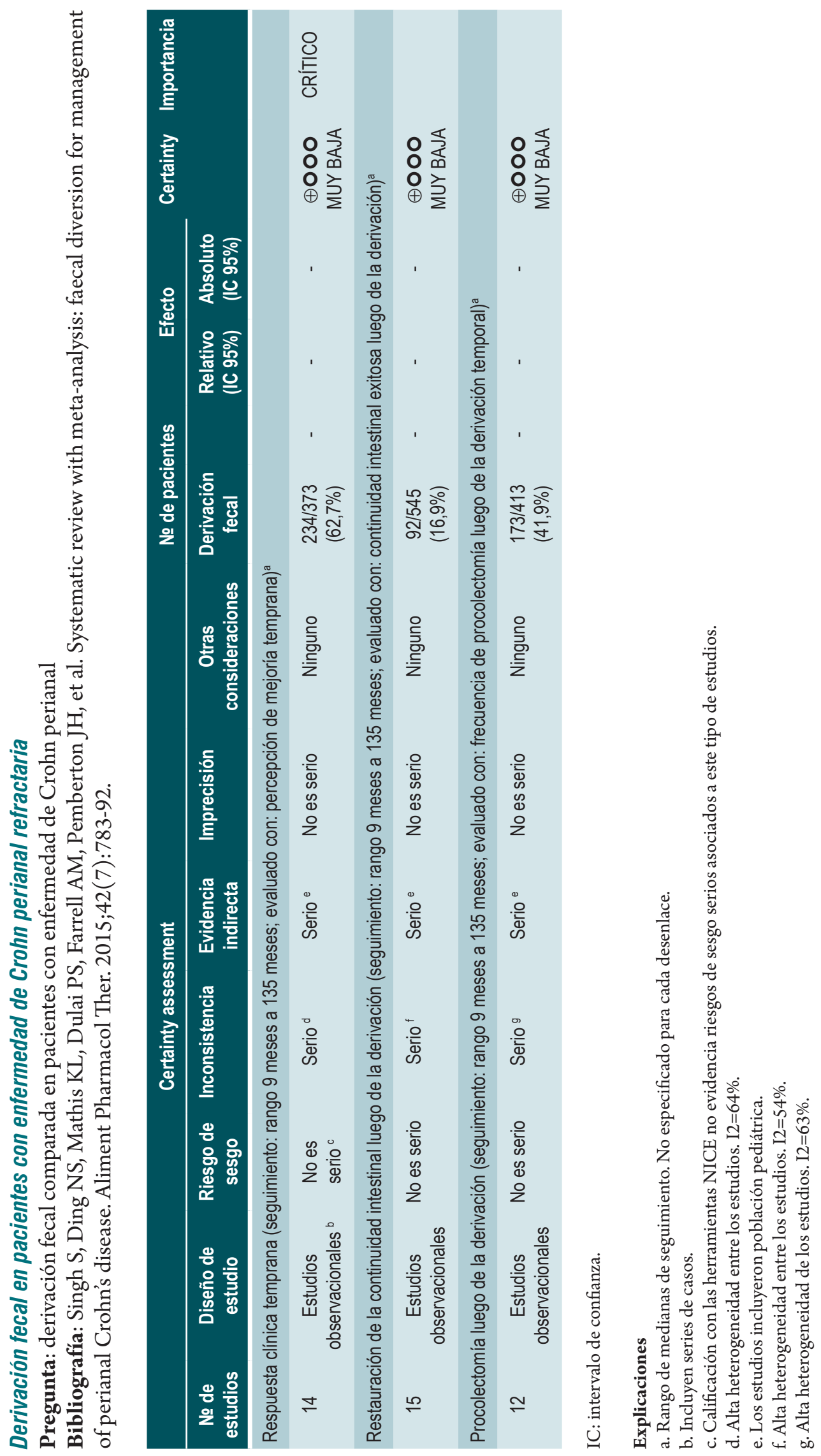




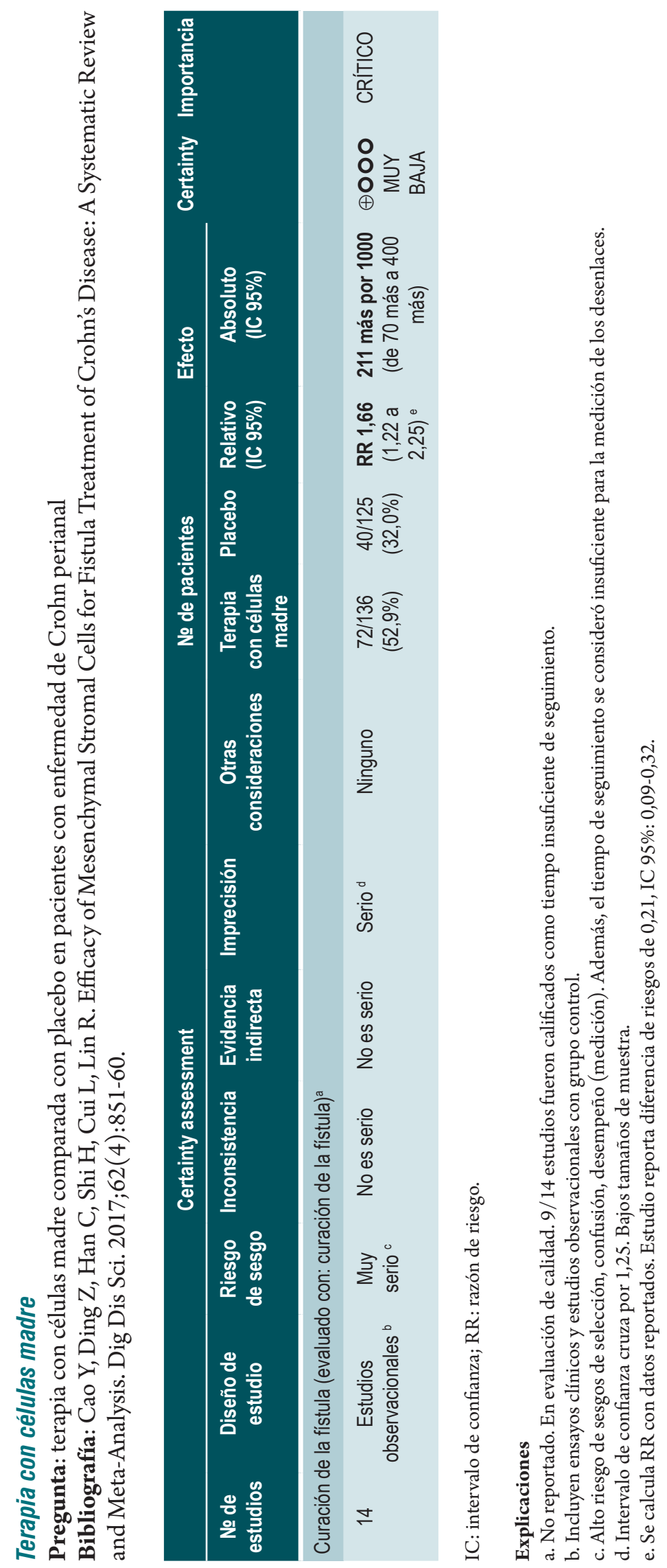




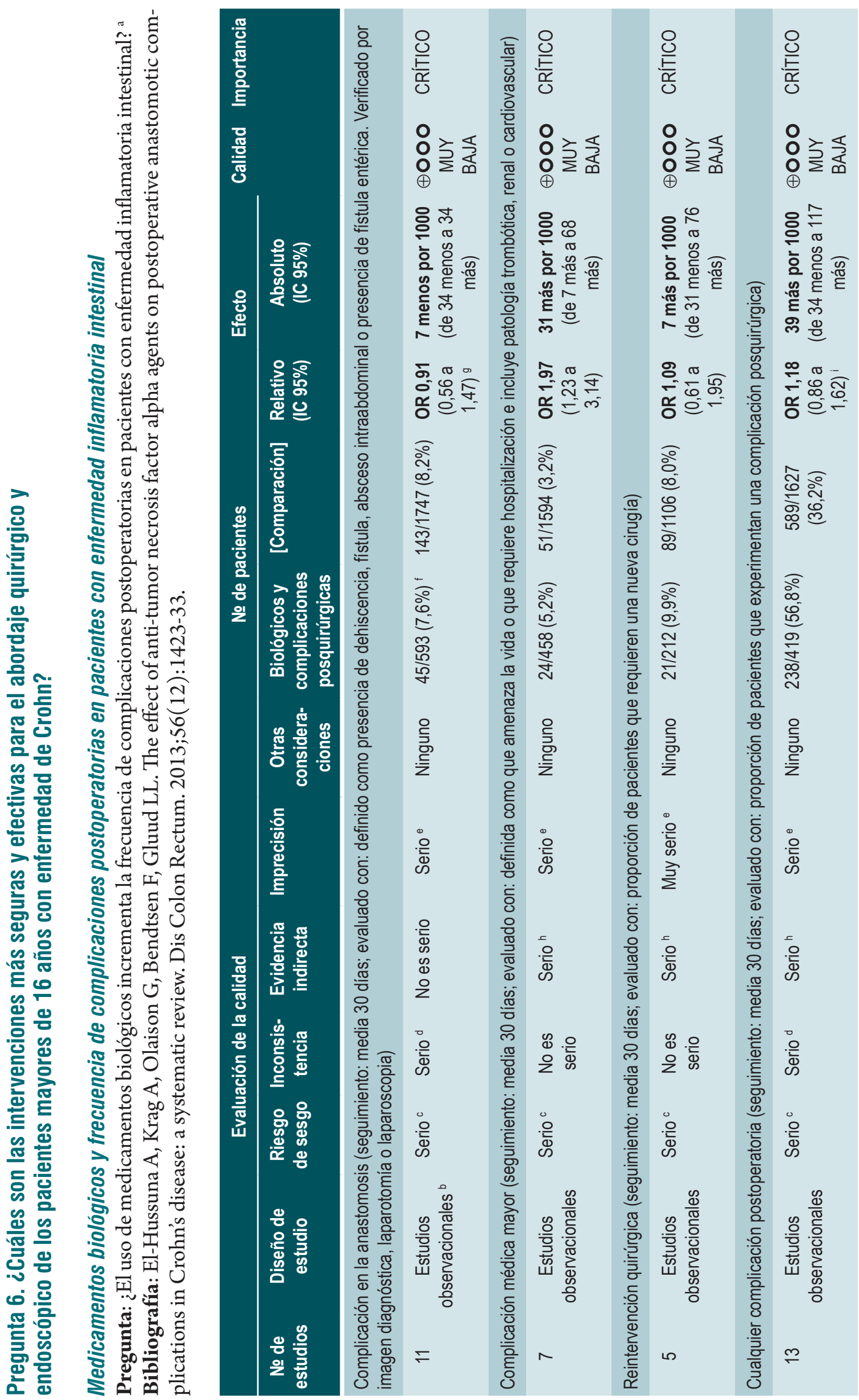




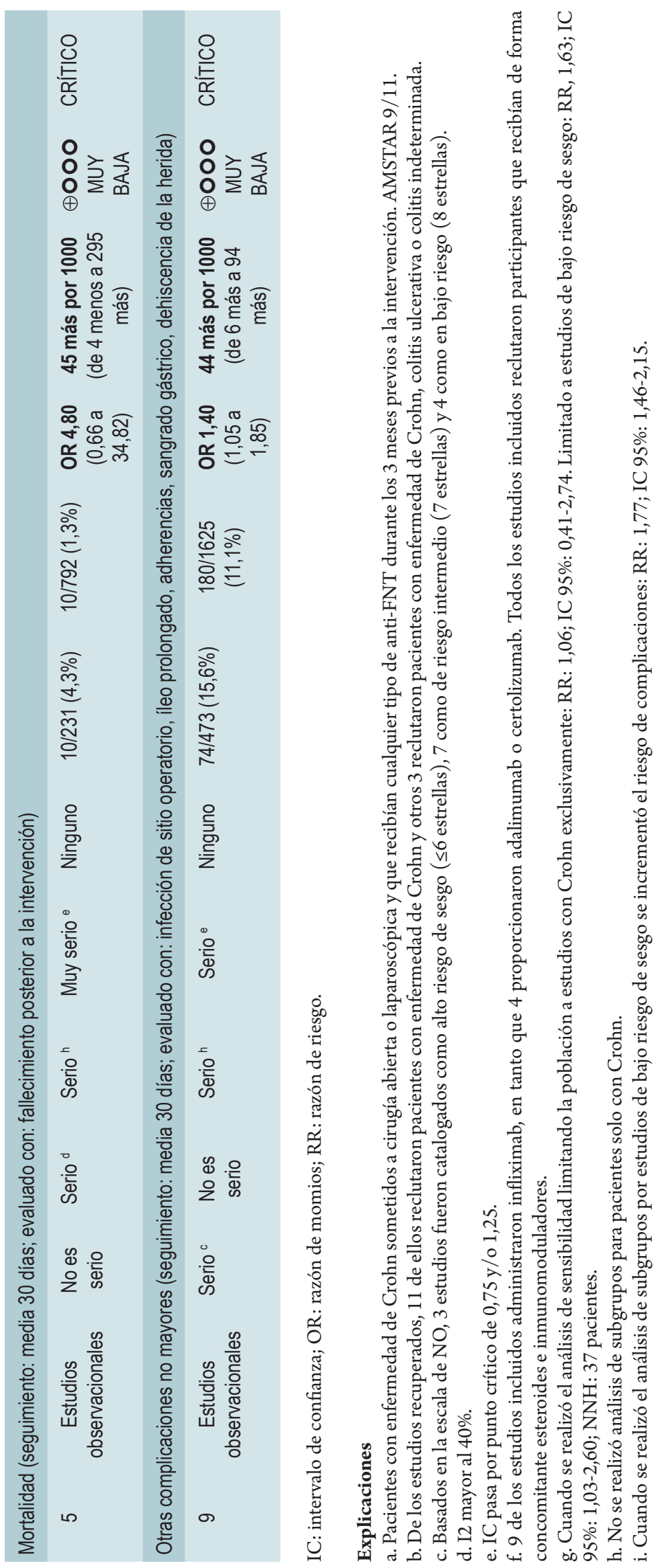




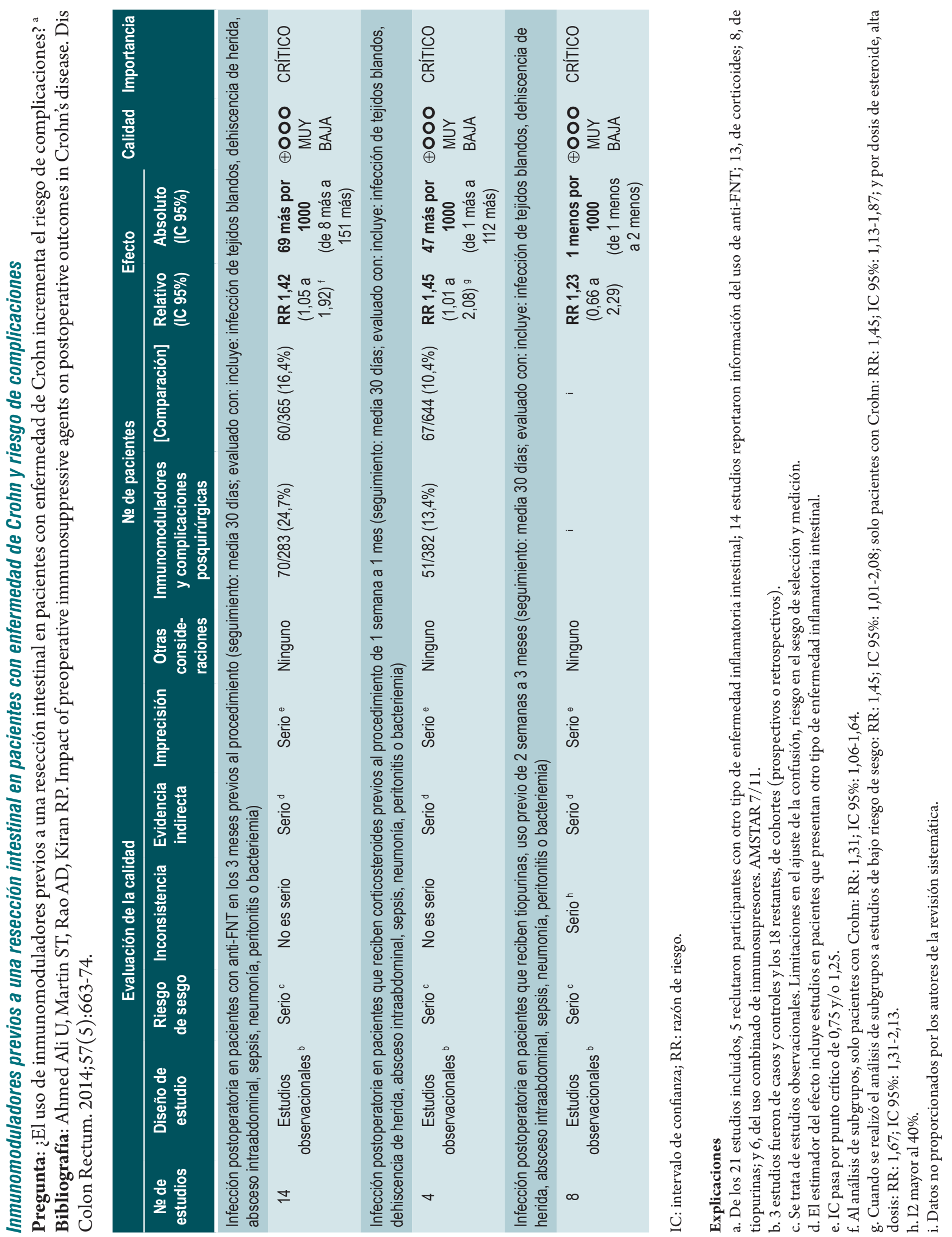




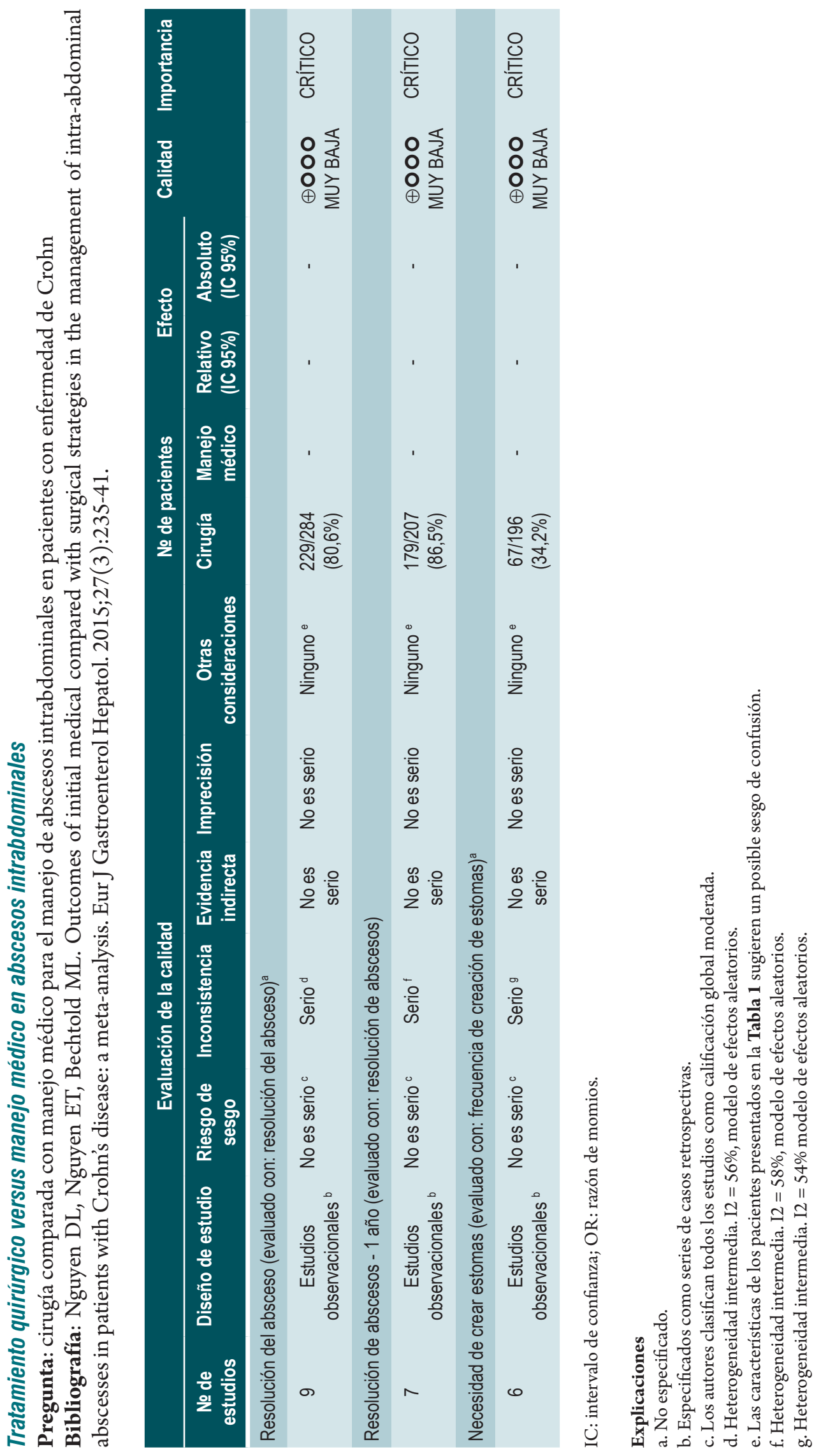




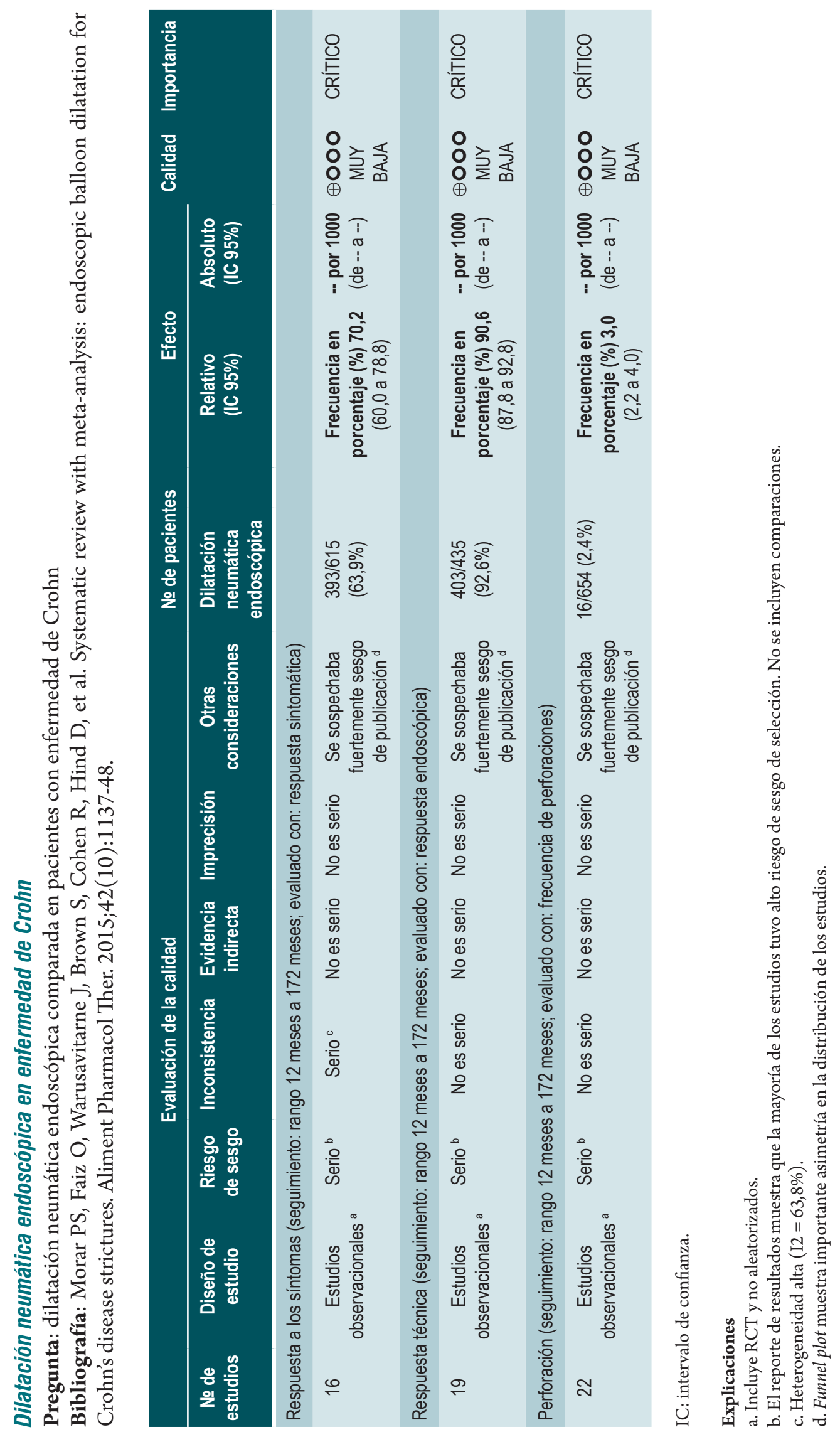









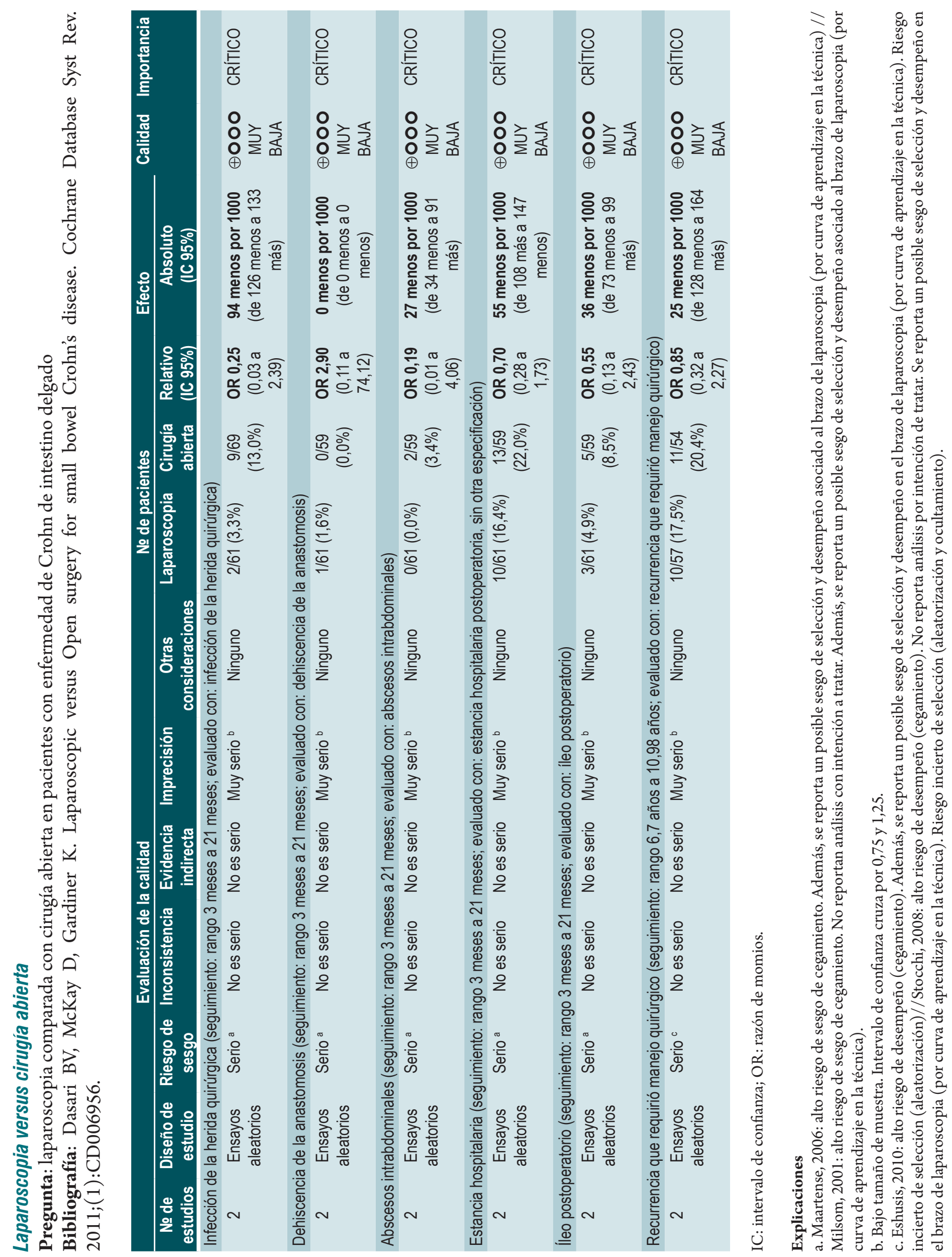




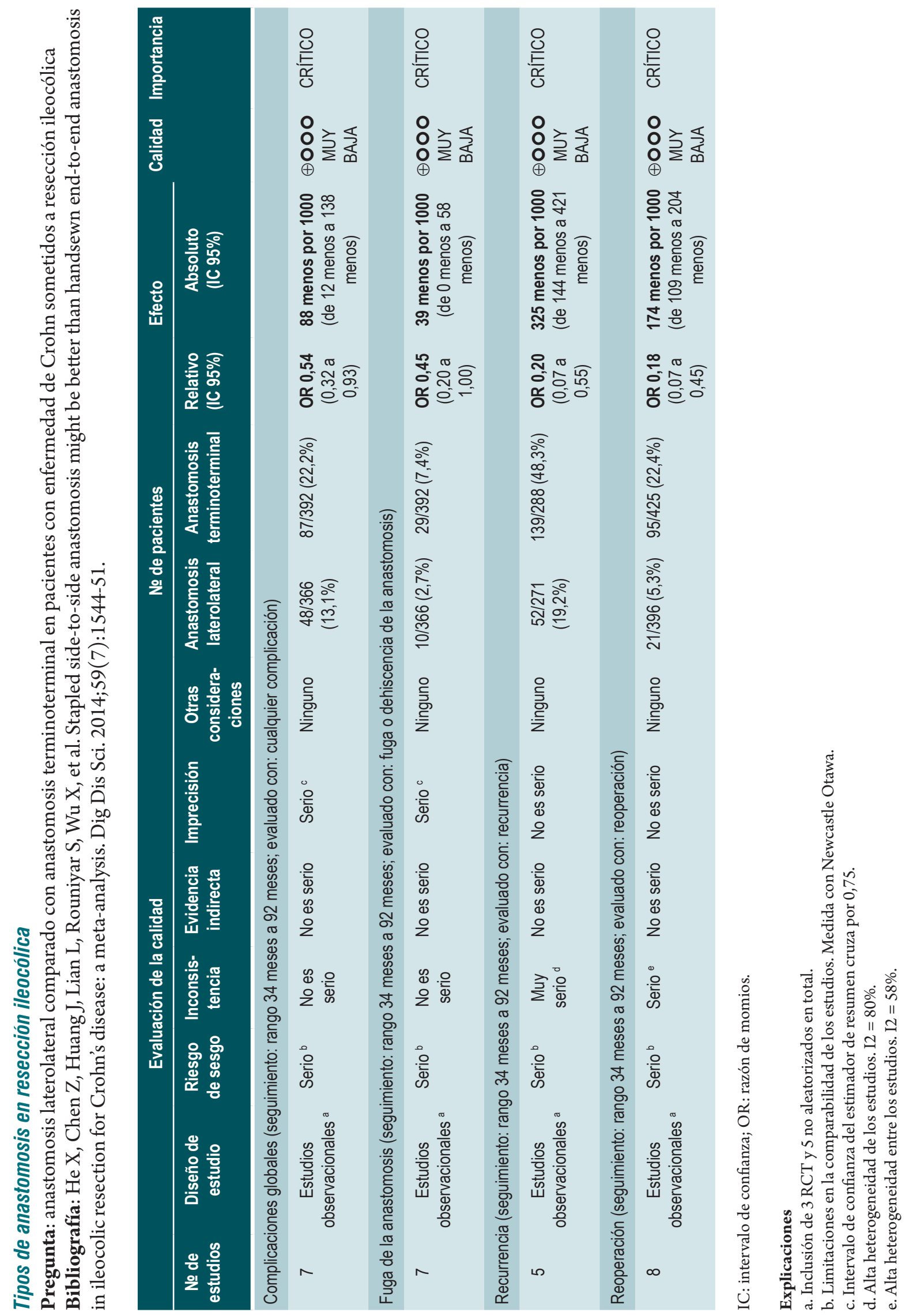






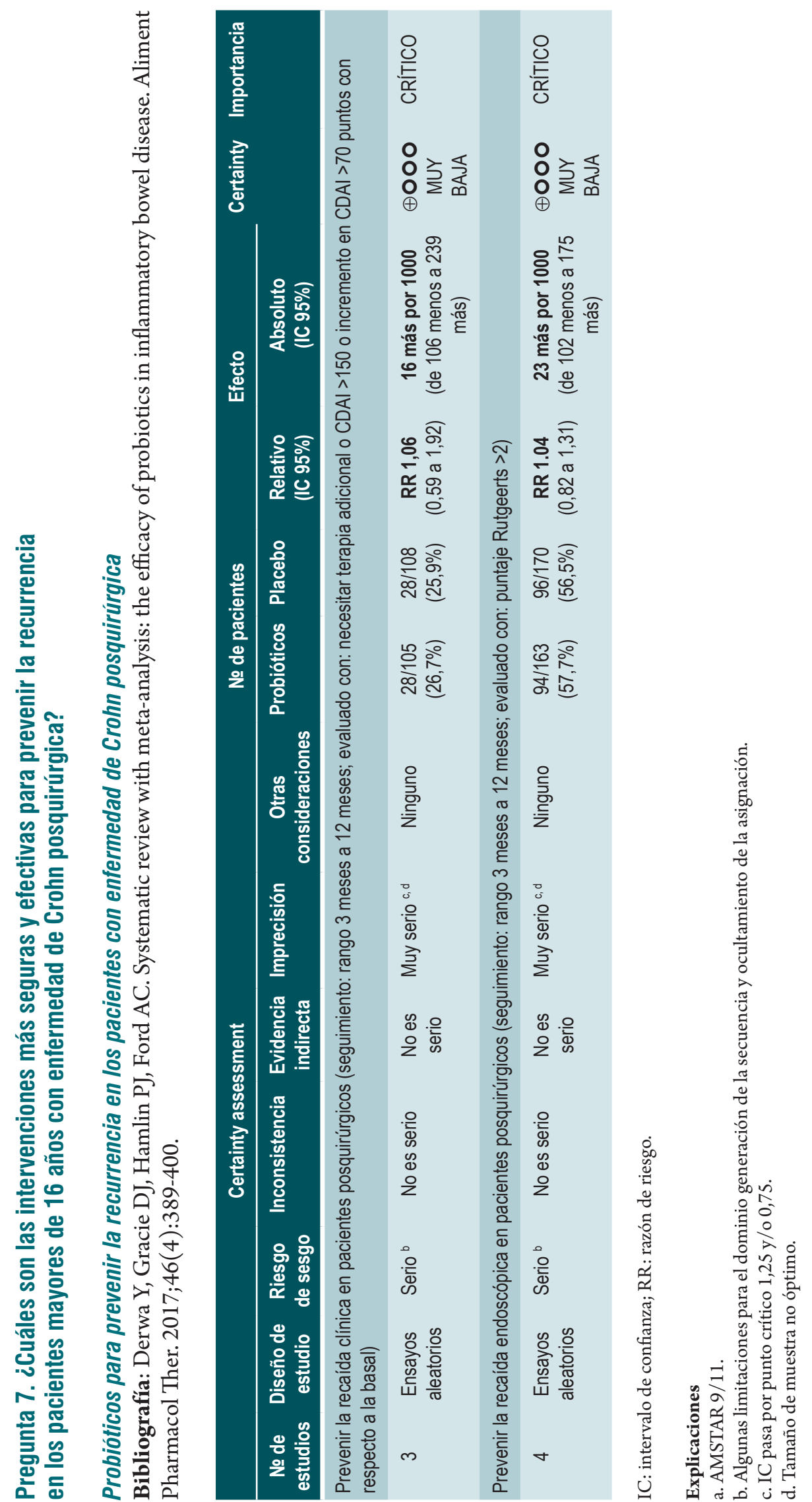





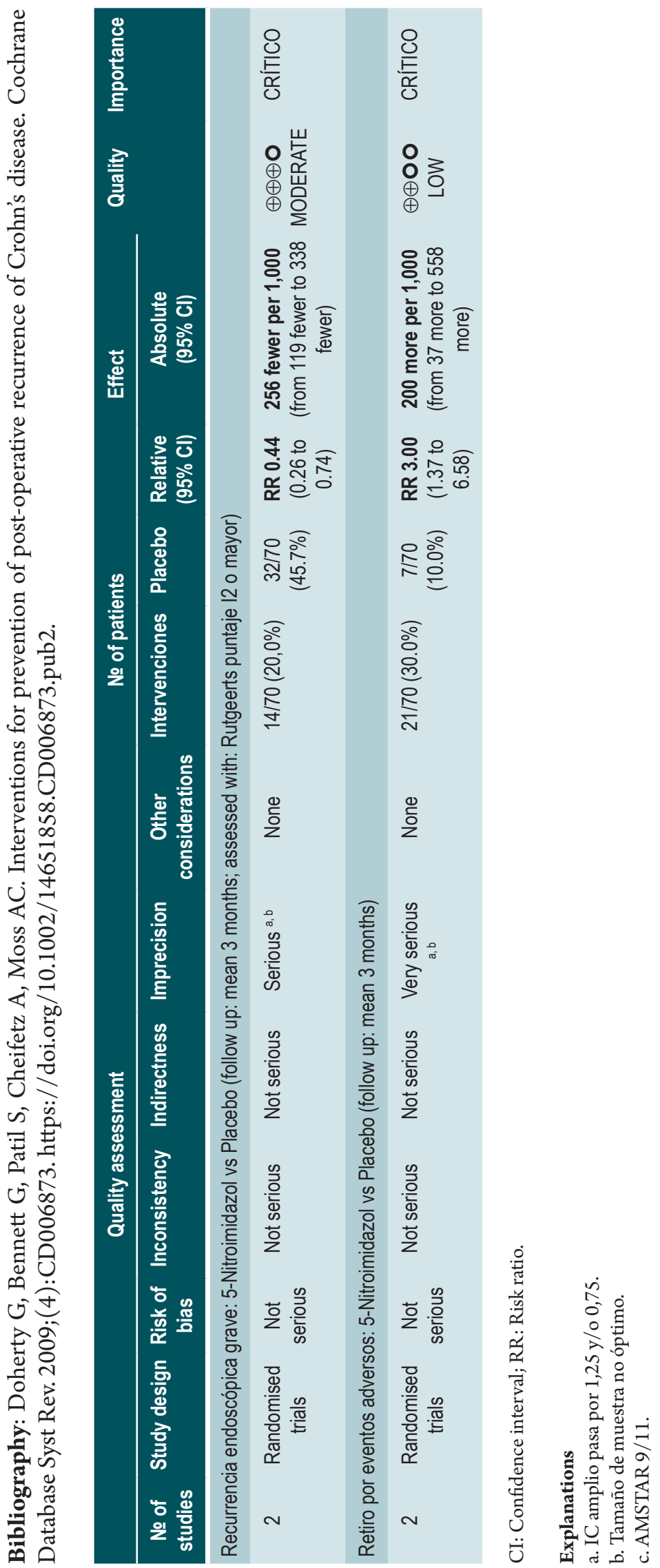







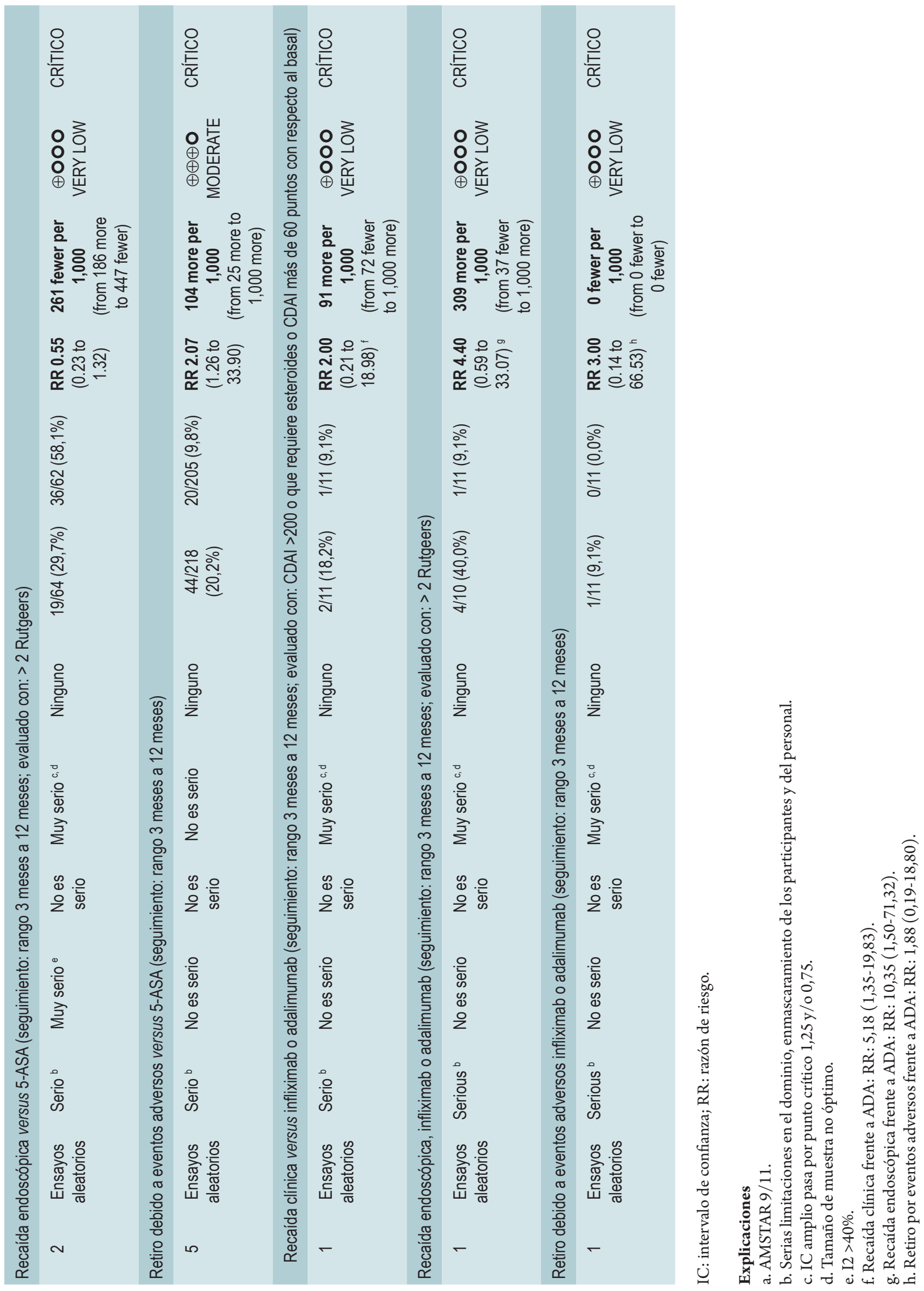














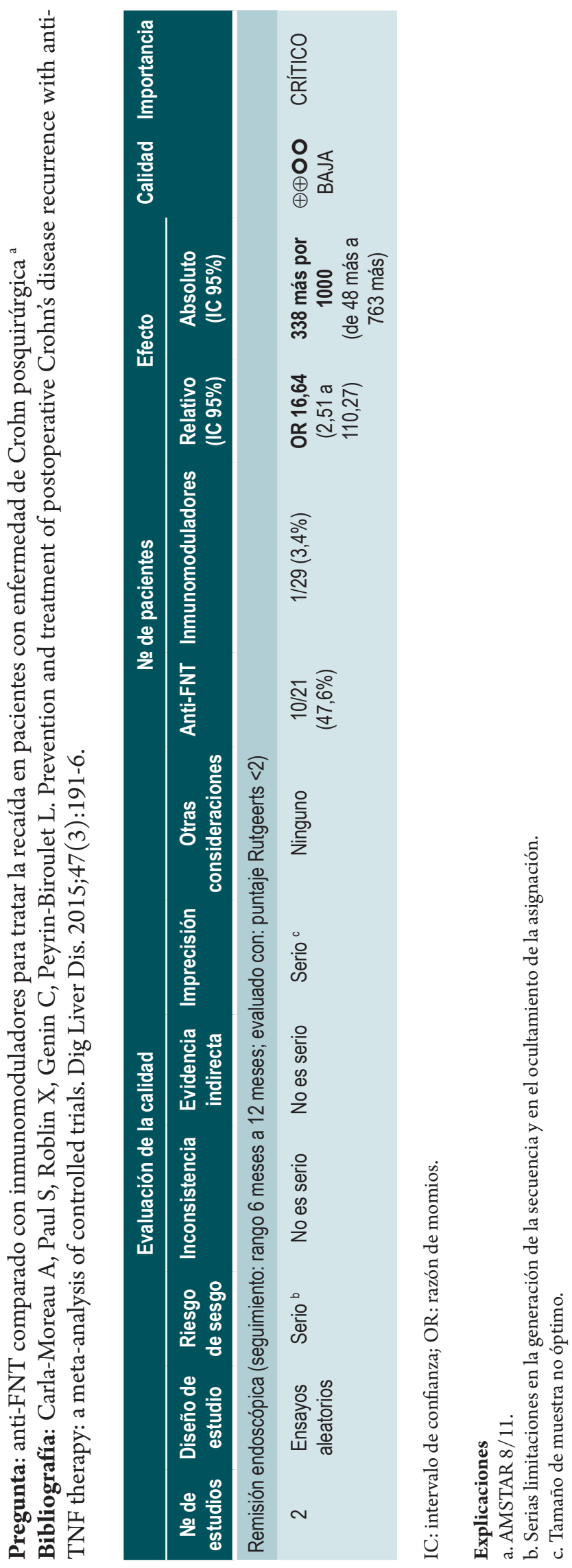




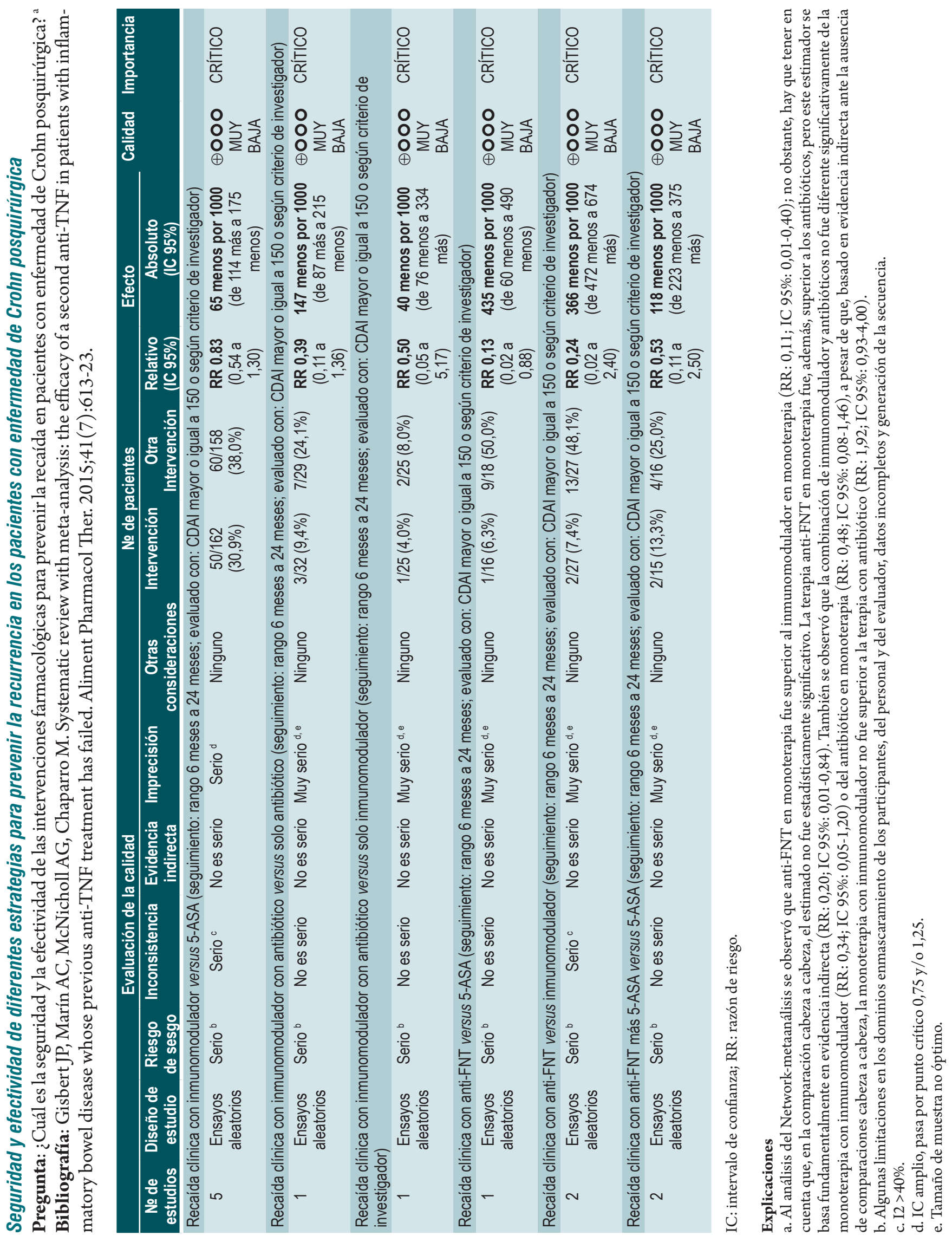




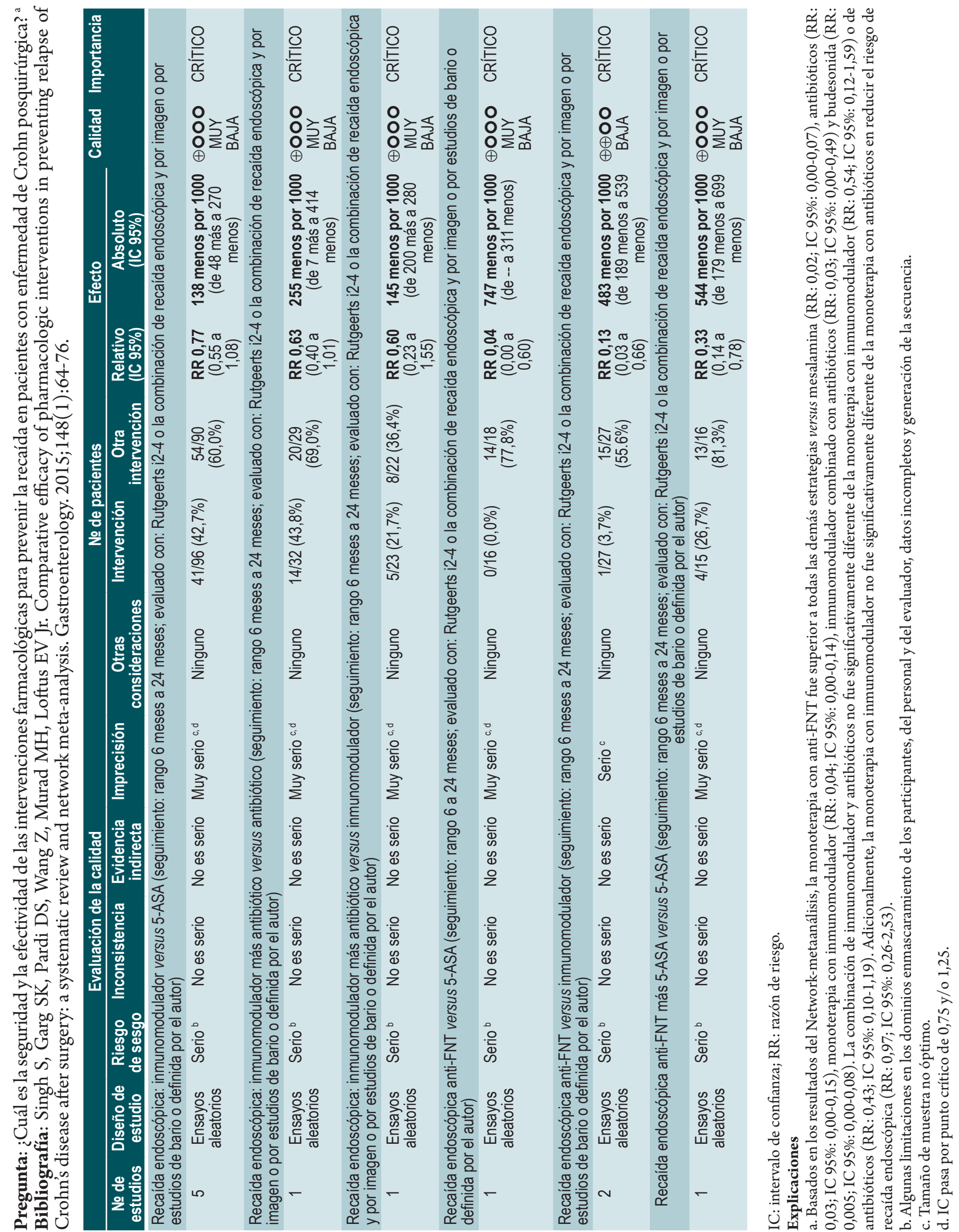




\section{REFERENCIAS}

1. Torres J, Mehandru S, Colombel JF, Peyrin-Biroulet L. Crohn's disease. Lancet. 2017;389(10080):1741-55. https://doi.org/10.1016/S0140-6736(16)31711-1

2. Ungaro R, Mehandru S, Allen PB, Peyrin-Biroulet $\mathrm{L}$, Colombel JF. Ulcerative colitis. Lancet. 2017;389(10080):1756-70. https://doi.org/10.1016/ S0140-6736(16)32126-2

3. de Souza HS, Fiocchi C. Immunopathogenesis of IBD: current state of the art. Nat Rev Gastroenterol Hepatol. 2016;13(1):13-27. https://doi.org/10.1038/nrgastro.2015.186

4. Rose NR, Bona C. Defining criteria for autoimmune diseases (Witebsky's postulates revisited). Immunol Today. 1993;14(9):426-30. https://doi. org/10.1016/0167-5699(93)90244-F

5. Behr MA, Divangahi M, Lalande JD. What's in a name? The (mis)labelling of Crohn's as an autoimmune disease. Lancet. 2010;376(9736):202-3. https://doi.org/10.1016/ S0140-6736(10)60282-6

6. Park H, Bourla AB, Kastner DL, Colbert RA, Siegel RM. Lighting the fires within: the cell biology of autoinflammatory diseases. Nat Rev Immunol. 2012;12(8):570-80. https://doi.org/10.1038/nri3261

7. Burisch J, Munkholm P. The epidemiology of inflammatory bowel disease. Scand J Gastroenterol 2015;50(8):942-51. https://doi.org/10.3109/00365521.2015.1014407

8. Molodecky NA, Soon IS, Rabi DM, Ghali WA, Ferris M, Chernoff $\mathrm{G}$, et al. Increasing incidence and prevalence of the inflammatory bowel diseases with time, based on systematic review. Gastroenterology. 2012;142(1):46-54. https://doi.org/10.1053/j.gastro.2011.10.001

9. Ng SC, Shi HY, Hamidi N, Underwood F, Tang W, Benchimol E, et al. Worldwide incidence and prevalence of inflammatory bowel disease in the 21st century: a systematic review of population-based studies. Lancet. 2017;390(10114):2769-78. https://doi.org/10.1016/ S0140-6736(17)32448-0

10. Kotze PG, Underwood F, Damiao AOMC, Panaccione R, Ng S, Kaplan G. Progression of Inflammatory Bowel Diseases Throughout Latin America and the Caribbean: a Systematic Review. Clin Gastroenterol Hepatol. 2020;18(2):304-12. https://doi.org/10.1016/j. cgh.2019.06.030

11. Quaresma AB, Kaplan GG, Kotze PG. The globalization of inflammatory bowel disease: the incidence and prevalence of inflammatory bowel disease in Brazil. Curr Opin Gastroenterol. 2019;35(4):259-64. https://doi. org/10.1097/MOG.0000000000000534

12. Yamamoto-Furusho JK, Sarmiento-Aguilar A, ToledoMauriño JJ, Bozada-Gutiérrez K, Bosques-Padilla F, Martínez-Vázquez $\mathrm{M}$, et al. Incidence and prevalence of inflammatory bowel disease in Mexico from a nationwide cohort study in a period of 15 years (2000-2017).
Medicine (Baltimore). 2019;98(27):e16291. https://doi. org/10.1097/MD.0000000000016291

13. Juliao F, Damas OM, Arrubla M, Calixto O, Camargo $\mathrm{J}$, Cruz L, et al. The prevalence of inflammatory bowel disease in Colombia is increasing: report on the national prevalente of IBD and description of IBD phenotype. Gastroenterology 2019;156(6):S-405. https://doi. org/10.1016/S0016-5085(19)37865-5

14. Arguello M, Archila P, Sierra F, Otero W. Enfermedad inflamatoria intestinal. Rev Col Gastroenterol. 1991;6(4):237-72.

15. Juliao Baños F, Ruiz Vélez MH, Flórez Arango JF, Donado Gómez JH, Marín Zuluaga JI, Monsalve Arango C, et al. Fenotipo e historia natural de la enfermedad inflamatoria intestinal en un centro de referencia en MedellínColombia. Rev Col Gastroenterol. 2010;25(3):240-51.

16. Reyes GA, Gil FL, Carvajal GD, Sánchez C, Aponte D, González C, et al. Enfermedad inflamatoria intestinal: características de fenotipo y tratamiento en un hospital universitario de Bogotá, Colombia. Rev Col Gastroenterol 2018;29 (1):11-8. https://doi. org $/ 10.22516 / 25007440.196$

17. Rojas CA, Sánchez-Londoño S, Rojas NE, Sepúlveda S, García J, Jiménez D, et al. Descripción clínico-epidemiológica de pacientes con enfermedad inflamatoria intestinal en una clínica de cuarto nivel en Cali. Rev Colomb Gastroenterol. 2020;35(2):166-73. https://doi. org $/ 10.22516 / 25007440.409$

18. Shivashankar R, Tremaine WJ, Harmsen WS, Loftus EV. Incidence and Prevalence of Crohn's Disease and Ulcerative Colitis in Olmsted County, Minnesota from 1970 Through 2010. Clin Gastroenterol Hepatol. 2017;15(6):857-63. https://doi.org/10.1016/j. cgh.2016.10.039

19. Enfermedades huérfanas [Internet]. Ministerio de Salud y Protección Social de Colombia; 2020. Disponible en: https://bit.ly/364B42h

20. Johnston RD, Logan RF. What is the peak age for onset of IBD? Inflamm Bowel Dis. 2008; 14(Suppl 2):S4-5. https:// doi.org/10.1002/ibd.20545

21. Maaser C, Sturm A, Vavricka SR, Kucharzik T, Fiorino G, Annese V, et al. ECCO-ESGAR Guideline for Diagnostic Assessment in IBD Part 1: Initial diagnosis, monitoring of known IBD, detection of complications. J Crohns Colitis. 2019;13(2):144-64. https://doi.org/10.1093/ecco-jcc/jjy113

22. Gomollon F, Dignass A, Annese V, Tilg H, Van Assche G, Lindsay JO, et al. 3rd European Evidence-based Consensus on the Diagnosis and Management of Crohn's Disease 2016: Part 1: Diagnosis and Medical Management. J Crohns Colitis. 2017;11(1):3-25. https://doi. org/10.1093/ecco-jcc/jjw168

23. Piovani D, Danese S, Peyrin-Biroulet L, Nikolopoulos GK, Lytras T, Bonovas S. Environmental Risk Factors for Inflammatory Bowel Diseases: An Umbrella Review of 
Meta-analyses. Gastroenterology. 2019;157(3):647-59. https://doi.org/10.1053/j.gastro.2019.04.016

24. Mosli MH, Zou G, Garg SK, Feagan SG, MacDonald JK, Chande N, et al. C-Reactive Protein, Fecal Calprotectin, and Stool Lactoferrin for Detection of Endoscopic Activity in Symptomatic Inflammatory Bowel Disease Patients: A Systematic Review and Meta-Analysis. Am J Gastroenterol. 2015;110(6):802-19. https://doi.org/10.1038/ ajg.2015.120

25. Van Rheenen PF, Van de Vijver E, Fidler V. Faecal calprotectin for screening of patients with suspected inflammatory bowel disease: diagnostic meta-analysis. BMJ. 2010;341:c3369. https://doi.org/10.1136/bmj.c3369

26. Menees SB, Powell C, Kurlander J, Goel A, Chey WD. A meta-analysis of the utility of C-reactive protein, erythrocyte sedimentation rate, fecal calprotectin, and fecal lactoferrin to exclude inflammatory bowel disease in adults with IBS. Am J Gastroenterol. 2015;110(3):444-54. https:// doi.org/10.1038/ajg.2015.6

27. Vermeire S, Peeters M, Vlietinck R, Joossens S, Den Hond E, Bulteel V, et al. Anti-Saccharomyces cerevisiae antibodies (ASCA), phenotypes of IBD, and intestinal permeability: a study in IBD families. Inflamm Bowel Dis. 2001;7(1):8-15. https://doi.org/10.1097/00054725200102000-00002

28. Annese V, Daperno M, Rutter MD, Amiot A, Bossuyt $\mathrm{P}$, East J, et al. European evidence-based consensus for endoscopy in inflammatory bowel disease. J Crohns Colitis. 2013;7(12):982-1018. https://doi.org/10.1016/j. crohns.2013.09.016

29. Magro F, Langner C, Driessen A, Ensari A, Geboes K, Mantzaris GJ, et al. European consensus on the histopathology of inflammatory bowel disease. J Crohns Colitis. 2013;7(10):827-51. https://doi.org/10.1016/j. crohns.2013.06.001

30. Panes J, Bouhnik Y, Reinisch W, Stoker J, Taylor SA, Baumgart DC, et al. Imaging techniques for assessment of inflammatory bowel disease: joint ECCO and ESGAR evidence-based consensus guidelines. J Crohns Colitis. 2013;7(7):556-85. https://doi.org/10.1016/j.crohns.2013.02.020

31. Silverberg MS, Satsangi J, Ahmad T, Arnott ID, Bernstein $\mathrm{CN}$, Brant SR, et al. Toward an integrated clinical, molecular and serological classification of inflammatory bowel disease: report of a Working Party of the 2005 Montreal World Congress of Gastroenterology. Can J Gastroenterol. 2005;19(Suppl A):5a-36a. https://doi. org/10.1155/2005/269076

32. Louis E, Collard A, Oger AF, Degroote E, Aboul Nasr El Yafi FA, Belaiche J. Behaviour of Crohn's disease according to the Vienna classification: changing pattern over the course of the disease. Gut. 2001;49(6):777-82. https:// doi.org/10.1136/gut.49.6.777

33. Frolkis AD, Dykeman J, Negrón ME, Debruyn J, Jette $\mathrm{N}$, Fiest KM, et al. Risk of surgery for inflammatory bowel diseases has decreased over time: a systematic review and meta-analysis of population-based studies. Gastroenterology. 2013;145(5):996-1006. https://doi. org/10.1053/j.gastro.2013.07.041

34. Buisson A, Chevaux JB, Allen PB, Bommelaer G, PeyrinBiroulet L. Review article: the natural history of postoperative Crohn's disease recurrence. Aliment Pharmacol Ther. 2012;35(6):625-33. https://doi.org/10.1111/j.13652036.2012.05002.x

35. Sandborn WJ. Crohn's disease evaluation and treatment: clinical decision tool. Gastroenterology. 2014;147(3):7025. https://doi.org/10.1053/j.gastro.2014.07.022

36. Torres J, Caprioli F, Katsanos KH, Lobatón T, Micic D, Zeronico M, et al. Predicting Outcomes to Optimize Disease Management in Inflammatory Bowel Diseases. J Crohns Colitis. 2016;10(12):1385-94. https://doi. org/10.1093/ecco-jcc/jjw116

37. Torres J, Bonovas S, Doherty G, Kucharzik T, Gisbert J, Raine T, et al. ECCO Guidelines on Therapeutics in Crohn's Disease: Medical Treatment. J Crohns Colitis. 2020;14(1):4-22. https://doi.org/10.1093/ecco-jcc/ jjz180

38. Shah SC, Colombel JF, Sands BE, Narula N. Systematic review with meta-analysis: mucosal healing is associated with improved long-term outcomes in Crohn's disease. Aliment Pharmacol Ther. 2016;43(3):317-33. https://doi. org/10.1111/apt.13475

39. Bouguen G, Levesque BG, Feagan BG, Kavanaugh A, Peyrin-Biroulet L, Colombel JF, et al. Treat to target: a proposed new paradigm for the management of Crohn's disease. Clin Gastroenterol Hepatol. 2015;13(6):1042-50. https://doi.org/10.1016/j.cgh.2013.09.006

40. Peyrin-Biroulet L, Sandborn W, Sands BE, Reinisch W, Bemelan W, Bryant R, et al. Selecting Therapeutic Targets in Inflammatory Bowel Disease (STRIDE): Determining Therapeutic Goals for Treat-to-Target. Am J Gastroenterol. 2015;110(9):1324-38. https://doi.org/10.1038/ ajg.2015.233

41. Colombel JF, D’haens G, Lee WJ, Petersson J, Panaccione R. Outcomes and Strategies to Support a Treat-to-target Approach in Inflammatory Bowel Disease: A Systematic Review. J Crohns Colitis. 2020;14(2):254-66. https://doi. org/10.1093/ecco-jcc/jjz131

42. Danese S, Vuitton L, Peyrin-Biroulet L. Biologic agents for IBD: practical insights. Nat Rev Gastroenterol Hepatol. 2015;12(9):537-45. https://doi.org/10.1038/nrgastro.2015.135

43. Côté-Daigneault J, Bouin M, Lahaie R, Colombel JF, Poitras P. Biologics in inflammatory bowel disease: what are the data? United European Gastroenterol J. 2015;3(5):419-28. https:// doi. org/10.1177/2050640615590302

44. Khanna R, Jairath V, Feagan BG. The Evolution of Treatment Paradigms in Crohn's Disease: Beyond Better Drugs. Gastroenterol Clin North Am. 2017;46(3):661-77. https://doi.org/10.1016/j.gtc.2017.05.010 
45. Fiorino G, Allocca M, Chaparro M, Coenen S, Fidalgo C, Younge L, et al. 'Quality of Care' Standards in Inflammatory Bowel Disease: A Systematic Review. J Crohns Colitis. 2019;13(1):127-37. https://doi. org/10.1093/ecco-jcc/jjy140

46. Farraye FA, Melmed GY, Lichtenstein GR, Kane SV. ACG Clinical Guideline: Preventive Care in Inflammatory Bowel Disease. Am J Gastroenterol. 2017;112(2):241-58. https://doi.org/10.1038/ajg.2016.537

47. Juliao-Baños F. Calidad en el manejo de enfermedad inflamatoria intestinal. Rev Col Gastroenterol. 2011; 26(3):211-20.

48. Bitton A, Vutcovici M, Lytvyak E, Kachan N, Bressler B, Jones J, et al. Selection of Quality Indicators in IBD: Integrating Physician and Patient Perspectives. Inflamm Bowel Dis. 2019;25(2):403-9. https://doi.org/10.1093/ $\mathrm{ibd} / \mathrm{izy} 259$

49. Jackson BD, De Cruz P. Quality of Care in Patients with Inflammatory Bowel Disease. Inflamm Bowel Dis. 2019;25(3):479-89. https://doi.org/10.1093/ibd/izy276

50. Rahier JF, Magro F, Abreu C, Armuzzi A, Ben-Horin $S$, Chowers Y, et al. Second European evidence-based consensus on the prevention, diagnosis and management of opportunistic infections in inflammatory bowel disease. J Crohns Colitis. 2014;8(6):443-68. https://doi. org/10.1016/j.crohns.2013.12.013

51. Hindryckx P, Novak G, Bonovas S, Peyrin-Biroulet L, Danese S. Infection Risk with Biologic Therapy in Patients with Inflammatory Bowel Disease. Clin Pharmacol Ther. 2017;102(4):633-41. https://doi.org/10.1002/cpt.791

52. Nguyen NH, Singh S, Sandborn WJ. Positioning Therapies in the Management of Crohn's Disease. Clin Gastroenterol Hepatol. 2020;18(6):1268-79. https://doi.org/10.1016/j. cgh.2019.10.035

53. Sulz MC, Burri E, Michetti P, Rogler G, Peyrin-Biroulet L, Seibold F; on behalf of the Swiss IBDnet, an official working group of the Swiss Society of Gastroenterology. Treatment Algorithms for Crohn's Disease. Digestion. 2020;101(Suppl 1):43-57. doi: 10.1159/000506364. Epub 2020 Mar 13. PMID: 32172251.

54. Brouwers MC, Kho ME, Browman GP, Burgers JS, Cluzeau F, Feder G, et al. AGREE II: advancing guideline development, reporting and evaluation in health care. CMAJ. 2010;182(18):E839-42. https://doi.org/10.1503/ cmaj.090449

55. Grupo de actualización de la Guía Metodológica para el desarrollo de Guías de Práctica Clínica con Evaluación Económica en el SGSSS Colombiano. Guía Metodológica para la elaboración de Guías de Práctica Clínica con Evaluación Económica en el Sistema General de Seguridad Social en Salud Colombiano: Ministerio de Salud y Protección Social; 2014. Disponible en: https://bit. ly/2I8nAdu

56. Shea BJ, Hamel C, Wells GA, Bouter LM, Kristjansson E, Grimshaw J, et al. AMSTAR is a reliable and valid measurement tool to assess the methodological quality of syste- matic reviews. J Clin Epidemiol. 2009;62(10):1013-20. https://doi.org/10.1016/j.jclinepi.2008.10.009

57. Higgins J, Altman D. Assessing risk of bias in included studies. En: Higgins J, Green S (editores). Cochrane Handbook for Systematic Reviews of Interventions. Londres: The Cochrane Collaboration; 2011.

58. Guyatt G, Oxman AD, Akl EA, Kunz R, Vist G, Brozek J, et al. GRADE guidelines: 1. Introduction-GRADE evidence profiles and summary of findings tables. J Clin Epidemiol. 2011;64(4):383-94. https://doi.org/10.1016/j.jclinepi.2010.04.026

59. National Institute for Health and Clinical Excellence. Crohn's disease: management in adults, children and young people. Disponible en: https://bit.ly/2I6zYe1

60. Bitton A, Dobkin PL, Edwardes MD, Sewitch MJ, Meddings JB, Rawal S, et al. Predicting relapse in Crohn's disease: a biopsychosocial model. Gut. 2008;57(10):138692. https://doi.org/10.1136/gut.2007.134817

61. Consigny Y, Modigliani R, Colombel JF, Dupas JL, Lemann M, Mary JY. A simple biological score for predicting low risk of short-term relapse in Crohn's disease. Inflamm Bowel Dis. 2006; 12(7):551-7. https://doi. org/10.1097/01.ibd.0000225334.60990.5b

62. Kallel L, Ayadi I, Matri S, Fekih M, Mahmoud NB, Feki M, et al. Fecal calprotectin is a predictive marker of relapse in Crohn's disease involving the colon: a prospective study. Eur J Gastroenterol Hepatol. 2010;22(3):340-5. https:// doi.org/10.1097/MEG.0b013e32832bab49

63. Mao R, Xiao YL, Gao X, Chen BL, He Y, Yang L, et al. Fecal calprotectin in predicting relapse of inflammatory bowel diseases: a meta-analysis of prospective studies. Inflamm Bowel Dis. 2012;18(10):1894-9. https://doi. org/10.1002/ibd.22861

64. Dulai PS, Peyrin-Biroulet L, Danese S, Sands B, Dignass A, Turner D, et al. Approaches to Integrating Biomarkers into Clinical Trials and Care Pathways as Targets for the Treatment of Inflammatory Bowel Diseases. Gastroenterology. 2019;157(4):1032-43. https://doi. org/10.1053/j.gastro.2019.06.018

65. Colombel JF, Panaccione R, Bossuyt P, Lukas M, Baert $\mathrm{F}$, Vaňásek T, et al. Effect of tight control management on Crohn $>$ s disease (CALM): a multicentre, randomised, controlled phase 3 trial. Lancet. 2018;390(10114):277989. https://doi.org/10.1016/S0140-6736(17)32641-7

66. Moore C, Corbett G, Moss AC. Systematic Review and Meta-Analysis: Serum Infliximab Levels During Maintenance Therapy and Outcomes in Inflammatory Bowel Disease. J Crohns Colitis. 2016;10(5):619-25. https://doi.org/10.1093/ecco-jcc/jjw007

67. Thomassin L, Armengol-Debeir L, Charpentier C, Bridoux V, Koning E, Savoye G, et al. Magnetic resonance imaging may predict deep remission in patients with perianal fistulizing Crohn $>\mathrm{s}$ disease. World J Gastroenterol. 2017;23(23):4285-92. https://doi.org/10.3748/wjg.v23. i23.4285 
68. Choi SH, Kim KW, Lee JY, Kim K, Park S. Diffusionweighted magnetic resonance enterography for evaluating bowel inflammation in Crohn $>\mathrm{s}$ disease: a systematic review and meta-analysis. Inflamm Bowel Dis. 2016;22(3):669-79. https://doi.org/10.1097/ MIB.0000000000000607

69. Allocca M, Danese S, Laurent V, Peyrin-Biroulet L. Use of Cross-Sectional Imaging for Tight Monitoring of Inflammatory Bowel Diseases. Clin Gastroenterol Hepatol. 2020;18(6):1309-23. https://doi.org/10.1016/j. cgh.2019.11.052

70. Niv Y. Small-bowel mucosal healing assessment by capsule endoscopy as a predictor of long-term clinical remission in patients with Crohn $>$ s disease: a systematic review and meta-analysis. Eur J Gastroenterol Hepatol. 2017;29(7):844-8. https://doi.org/10.1097/ MEG.0000000000000881

71. Shen J, Zuo ZX, Mao AP. Effect of probiotics on inducing remission and maintaining therapy in ulcerative colitis, Crohn $>$ s disease, and pouchitis: meta-analysis of randomized controlled trials. Inflamm Bowel Dis. 2014;20(1):21-35. https://doi.org/10.1097/01.MIB.0000437495.30052.be

72. Limketkai BN, Akobeng AK, Gordon M, Adepoju AA. Probiotics for induction of remission in Crohn $>\mathrm{s}$ disease. Cochrane Database Syst Rev. 2020;7(7):CD006634. https://doi.org/10.1002/14651858.CD006634.pub3

73. Su JW, Ma JJ, Zhang HJ. Use of antibiotics in patients with Crohn $>$ s disease: a systematic review and metaanalysis. J Dig Dis. 2015;16(2):58-66. https://doi. org/10.1111/1751-2980.12216

74. Townsend CM, Parker CE, MacDonald JK, Nguyen T, Jairath V, Feagan B, et al. Antibiotics for induction and maintenance of remission in Crohn $>\mathrm{s}$ disease. Cochrane Database Syst Rev. 2019;2(2):CD012730. https://doi. org/10.1002/14651858.CD012730.pub2

75. Chande N, Townsend CM, Parker CE, MacDonald JK. Azathioprine or 6-mercaptopurine for induction of remission in Crohn>s disease. Cochrane Database Syst Rev. 2016;10:Cd000545. https://doi.org/10.1002/14651858. CD000545.pub5

76. Lim WC, Wang Y, MacDonald JK, Hanauer S. Aminosalicylates for induction of remission or response in Crohn $>\mathrm{s}$ disease. Cochrane Database Syst Rev. 2016;7:CD008870. https://doi.org/10.1002/14651858. CD008870.pub2

77. McDonald JW, Wang Y, Tsoulis DJ, MacDonald JK, Feagan BG. Methotrexate for induction of remission in refractory Crohn>s disease. Cochrane Database Syst Rev. 2014(8): CD003459. https://doi.org/10.1002/14651858. CD003459.pub4

78. Rezaie A, Kuenzig ME, Benchimol EI, Griffiths AM, Otley AR, Steinhart AH, et al. Budesonide for induction of remission in Crohn $>\mathrm{s}$ disease. Cochrane Database Syst Rev. 2015(6): CD000296. https://doi. org/10.1002/14651858.CD000296.pub4
79. Benchimol EI, Seow CH, Steinhart AH, Griffiths AM. Traditional corticosteroids for induction of remission in Crohn $>$ s disease. Cochrane Database Syst Rev. 2008(2):CD006792. https://doi.org/10.1002/14651858. CD006792.pub2

80. Coward S, Kuenzig ME, Hazlewood G, Clement F, McBrien K, Holmes R, et al. Comparative Effectiveness of Mesalamine, Sulfasalazine, Corticosteroids, and Budesonide for the Induction of Remission in Crohn $>\mathrm{s}$ Disease: A Bayesian Network Meta-analysis. Inflamm Bowel Dis. 2017;23(3):461-72. https://doi.org/10.1097/ MIB.0000000000001023

81. Qiu Y, Li MY, Feng T, Feng R, Mao R, Chen BL, et al. Systematic review with meta-analysis: the efficacy and safety of stem cell therapy for Crohn $>$ s disease. Stem Cell Res Ther. 2017;8(1):136. https://doi.org/10.1186/ s13287-017-0570-x

82. Akobeng AK, Zhang D, Gordon M, MacDonald JK. Oral 5-aminosalicylic acid for maintenance of medicallyinduced remission in Crohn $>\mathrm{s}$ disease. Cochrane Database Syst Rev. 2016;9:CD003715. https://doi. org/10.1002/14651858.CD003715.pub3

83. Chande N, Patton PH, Tsoulis DJ, Thomas BS, MacDonald JK. Azathioprine or 6-mercaptopurine for maintenance of remission in Crohn $>\mathrm{s}$ disease. Cochrane Database Syst Rev. 2015(10):CD000067. https://doi. org/10.1002/14651858.CD000067.pub3

84. Kuenzig ME, Rezaie A, Seow CH, Otley AR, Steinhart AH, Griffiths AM, et al. Budesonide for maintenance of remission in Crohn>s disease. Cochrane Database Syst Rev. 2014(8):CD002913. https://doi.org/10.1002/14651858. CD002913.pub3

85. Patel V, Wang Y, MacDonald JK, McDonald JW, Chande N. Methotrexate for maintenance of remission in Crohn $>\mathrm{s}$ disease. Cochrane Database Syst Rev. 2014(8):CD006884. https://doi.org/10.1002/14651858.CD006884.pub3

86. Tsertsvadze A, Gurung T, Court R, Clarke A, Sutcliffe $P$. Clinical effectiveness and cost-effectiveness of elemental nutrition for the maintenance of remission in Crohn $>$ s disease: a systematic review and meta-analysis. Health Technol Assess. 2015;19(26):1-138. https://doi. org/10.3310/hta19260

87. Narula N, Dhillon A, Zhang D, Sherlock ME, Tondeur $\mathrm{M}$, Zachos M. Enteral nutritional therapy for induction of remission in Crohn $>$ s disease. Cochrane Database Syst Rev. 2018;4(4):CD000542. https://doi. org/10.1002/14651858.CD000542.pub3

88. Derwa Y, Gracie DJ, Hamlin PJ, Ford AC. Systematic review with meta-analysis: the efficacy of probiotics in inflammatory bowel disease. Aliment Pharmacol Ther. 2017;46(4):389-400. https://doi.org/10.1111/apt.14203

89. Steinhart AH, Ewe K, Griffiths AM, Modigliani R, Thomsen OO. Corticosteroids for maintenance of remission in Crohn $>$ s disease. Cochrane Database Syst Rev. 2003(4):CD000301. https://doi.org/10.1002/14651858. $\mathrm{CD} 000301$ 
90. Cottone M, Kohn A, Daperno M, Castiglione F, Annese $\mathrm{V}$, Orlando A. Advanced age is an independent risk factor for severe infections and mortality in patients given antitumor necrosis factor therapy for inflammatory bowel disease. Clin Gastroenterol Hepatol. 2011;9(1):30-5. https://doi.org/10.1016/j.cgh.2010.09.026

91. Singh S, Garg SK, Pardi DS, Wang Z, Murad MH, Loftus EV Jr. Comparative efficacy of biologic therapy in biologic-naïve patients with Crohn disease: a systematic review and network meta-analysis. Mayo Clin Proc. 2014;89(12):1621-35. https://doi.org/10.1016/j. mayocp.2014.08.019

92. Singh S, Fumery M, Sandborn WJ, Murad MH. Systematic review and network meta-analysis: first- and second-line biologic therapies for moderate-severe Crohn $>$ s disease. Aliment Pharmacol Ther. 2018;48(4):394-409. https:// doi.org/10.1111/apt.14852

93. Gisbert JP, Marin AC, McNicholl AG, Chaparro M. Systematic review with meta-analysis: the efficacy of a second anti-TNF in patients with inflammatory bowel disease whose previous anti-TNF treatment has failed. Aliment Pharmacol Ther. 2015;41(7):613-23. https://doi. org/10.1111/apt.13083

94. de Groof EJ, Sahami S, Lucas C, Ponsioen CY, Bemelman WA, Buskens CJ. Treatment of perianal fistula in Crohn $>\mathrm{s}$ disease: a systematic review and meta-analysis comparing seton drainage and anti-tumour necrosis factor treatment. Colorectal Dis. 2016;18(7):667-75. https://doi. org/10.1111/codi.13311

95. MacDonald JK, Nguyen TM, Khanna R, Timmer A. Anti-IL-12/23p40 antibodies for induction of remission in Crohn $>$ s disease. Cochrane Database Syst Rev. 2016;11:CD007572. https://doi.org/10.1002/14651858. CD007572.pub3

96. Davies SC, Nguyen TM, Parker CE, MacDonald JK, Jairath V, Khanna R. Anti-IL-12/23p40 antibodies for maintenance of remission in Crohn $>$ s disease. Cochrane Database Syst Rev. 2019;12(12):CD012804. https://doi. org/10.1002/14651858.CD012804.pub2

97. Bonovas S, Fiorino G, Allocca M, Lytras T, Nikolopoulos GK, Peyrin-Biroulet L, et al. Biologic Therapies and Risk of Infection and Malignancy in Patients with Inflammatory Bowel Disease: A Systematic Review and Network Metaanalysis. Clin Gastroenterol Hepatol. 2016;14(10):138597. https://doi.org/10.1016/j.cgh.2016.04.039

98. Singh S, Facciorusso A, Dulai PS, Jairath V, Sandborn WJ. Comparative Risk of Serious Infections with Biologic and/or Immunosuppressive Therapy in Patients with Inflammatory Bowel Diseases: A Systematic Review and Meta-Analysis. Clin Gastroenterol Hepatol. 2020;18(1):69-81. https://doi.org/10.1016/j. cgh.2019.02.044

99. Komaki Y, Yamada A, Komaki F, Micic D, Ido A, Sakuraba A. Systematic review with meta-analysis: the efficacy and safety of CT-P13, a biosimilar of anti-tumour necrosis factor-alpha agent (infliximab), in inflammatory bowel diseases. Aliment Pharmacol Ther. 2017;45(8):1043-57. https://doi.org/10.1111/apt.13990

100. Hazlewood GS, Rezaie A, Borman M, Panaccione R, Ghosh S, Seow CH, et al. Comparative effectiveness of immunosuppressants and biologics for inducing and maintaining remission in Crohn $>$ s disease: a network metaanalysis. Gastroenterology. 2015;148(2):344-54. https:// doi.org/10.1053/j.gastro.2014.10.011

101. Sands BE, Anderson FH, Bernstein CN, Chey WY, Feagan BG, Fedorak RN, et al. Infliximab maintenance therapy for fistulizing Crohn $>$ s disease. N Engl J Med. 2004;350(9):876-85. https://doi.org/10.1056/ NEJMoa030815

102. McSharry K, Dalzell AM, Leiper K, El-Matary W. Systematic review: the role of tacrolimus in the management of Crohn $>$ s disease. Aliment Pharmacol Ther. 2011;34(11-12):1282-94. https://doi.org/10.1111/ j.1365-2036.2011.04873.x

103. Sandborn WJ, Present DH, Isaacs KL, Wolf DC, Greenberg E, Hanauer SB, et al. Tacrolimus for the treatment of fistulas in patients with Crohn>s disease: a randomized, placebo-controlled trial. Gastroenterology. 2003;125(2):380-8. https://doi.org/10.1016/S00165085(03)00877-1

104. Cirocchi R, Santoro A, Trastulli S, Farinella E, Di Rocco $G$, Vendettuali D, et al. Meta-analysis of fibrin glue versus surgery for treatment of fistula-in-ano. Ann Ital Chir. 2010;81(5):349-56.

105. Ruffolo C, Scarpa M, Bassi N, Angriman I. A systematic review on advancement flaps for rectovaginal fistula in Crohn's disease: transrectal vs transvaginal approach. Colorectal Dis. 2010;12(12):1183-91. https://doi. org/10.1111/j.1463-1318.2009.02029.x

106. Singh S, Ding NS, Mathis KL, Dulai PS, Farrell AM, Pemberton JH, et al. Systematic review with meta-analysis: faecal diversion for management of perianal Crohn's disease. Aliment Pharmacol Ther. 2015;42(7):783-92. https://doi.org/10.1111/apt.13356

107. Cao Y, Ding Z, Han C, Shi H, Cui L, Lin R. Efficacy of Mesenchymal Stromal Cells for Fistula Treatment of Crohn's Disease: A Systematic Review and MetaAnalysis. Dig Dis Sci. 2017;62(4):851-60. https://doi. org/10.1007/s10620-017-4453-x

108. Lightner AL, Wang Z, Zubair AC, Dozois EJ. A Systematic Review and Meta-analysis of Mesenchymal Stem Cell Injections for the Treatment of Perianal Crohn's Disease: Progress Made and Future Directions. Dis Colon Rectum. 2018;61(5):629-40. https://doi.org/10.1097/ DCR.0000000000001093

109. Lee MJ, Parker CE, Taylor SR, Guizzetti L, Feagan B, Lobo A, et al. Efficacy of Medical Therapies for Fistulizing Crohn's Disease: Systematic Review and Meta-analysis. Clin Gastroenterol Hepatol. 2018;16(12):1879-92. https://doi.org/10.1016/j.cgh.2018.01.030

110. El-Hussuna A, Krag A, Olaison G, Bendtsen F, Gluud LL. The effect of anti-tumor necrosis factor alpha 
agents on postoperative anastomotic complications in Crohn's disease: a systematic review. Dis Colon Rectum. 2013;56(12):1423-33. https://doi.org/10.1097/ DCR.0b013e3182a48505

111. Qiu Y, Zheng Z, Liu G, Zhao X, He A. Effects of preoperative anti-tumour necrosis factor alpha infusion timing on postoperative surgical site infection in inflammatory bowel disease: A systematic review and meta-analysis. United Eur Gastroenterol J. 2019;7(9):1198-214. https://doi. org/10.1177/2050640619878998

112. Ahmed Ali U, Martin ST, Rao AD, Kiran RP. Impact of preoperative immunosuppressive agents on postoperative outcomes in Crohn's disease. Dis Colon Rectum. 2014;57(5):663-74. https://doi.org/10.1097/ DCR.0000000000000099

113. Nguyen DL, Nguyen ET, Bechtold ML. Outcomes of initial medical compared with surgical strategies in the management of intra-abdominal abscesses in patients with Crohn's disease: a meta-analysis. Eur J Gastroenterol Hepatol. 2015;27(3):235-41. https://doi.org/10.1097/ MEG.0000000000000273

114. Morar PS, Faiz O, Warusavitarne J, Brown S, Cohen R, Hind D, et al. Systematic review with meta-analysis: endoscopic balloon dilatation for Crohn's disease strictures. Aliment Pharmacol Ther. 2015;42(10):1137-48. https:// doi.org/10.1111/apt.13388

115. Reese GE, Purkayastha S, Tilney HS, von Roon A, Yamamoto T, Tekkis PP. Strictureplasty vs resection in small bowel Crohn's disease: an evaluation of short-term outcomes and recurrence. Colorectal Dis. 2007;9(8):68694. https://doi.org/10.1111/j.1463-1318.2006.01114.x

116. Dasari BV, McKay D, Gardiner K. Laparoscopic versus open surgery for small bowel Crohn's disease. Cochrane Database Syst Rev. 2011(1):CD006956. https://doi. org/10.1002/14651858.CD006956.pub2

117. He X, Chen Z, Huang J, Lian L, Rouniyar S, Wu X, et al. Stapled side-to-side anastomosis might be better than handsewn end-to-end anastomosis in ileocolic resection for Crohn's disease: a meta-analysis. Dig Dis Sci. 2014;59(7):1544-51. https://doi.org/10.1007/s10620014-3039-0

118. Tekkis PP, Purkayastha S, Lanitis S, Athanasiou T, Heriot AG, Orchard TR, et al. A comparison of segmental vs subtotal/total colectomy for colonic Crohn's disease: a meta-analysis. Colorectal Dis. 2006;8(2):82-90. https:// doi.org/10.1111/j.1463-1318.2005.00903.x

119. Doherty G, Bennett G, Patil S, Cheifetz A, Moss AC. Interventions for prevention of post-operative recurrence of Crohn's disease. Cochrane Database Syst Rev. 2009(4):CD006873. https://doi.org/10.1002/14651858. CD006873.pub2
120. Gordon M, Taylor K, Akobeng AK, Thomas AG. Azathioprine and 6-mercaptopurine for maintenance of surgically-induced remission in Crohn's disease. Cochrane Database Syst Rev. 2014(8):CD010233. https://doi. org/10.1002/14651858.CD010233.pub2

121. Gordon M, Naidoo K, Thomas AG, Akobeng AK. Oral 5-aminosalicylic acid for maintenance of surgically-induced remission in Crohn's disease. Cochrane Database Syst Rev. 2011(1):CD008414. https://doi. org/10.1002/14651858.CD008414.pub2

122. Nguyen DL, Solaimani P, Nguyen ET, Jamal MM, Bechtold ML. Anti-tumor necrosis factor alpha is more effective than conventional medical therapy for the prevention of postoperative recurrence of Crohn's disease: a meta-analysis. Eur J Gastroenterol Hepatol. 2014;26(10):1152-9. https://doi.org/10.1097/MEG.0000000000000178

123. Singh S, Garg SK, Pardi DS, Wang Z, Murad MH, Loftus EV, Jr. Comparative efficacy of pharmacologic interventions in preventing relapse of Crohn's disease after surgery: a systematic review and network meta-analysis. Gastroenterology. 2015;148(1):64-76. https://doi. org/10.1053/j.gastro.2014.09.031

124. Burr NE, Hall B, Hamlin PJ, Selinger CP, Ford AC, O’Connor A. Systematic Review and Network MetaAnalysis of Medical Therapies to Prevent Recurrence of Post-Operative Crohn's Disease. J Crohns Colitis. 2019;13(6):693-701. https://doi.org/10.1093/ecco-jcc/ jjy216

125. Carla-Moreau A, Paul S, Roblin X, Genin C, PeyrinBiroulet L. Prevention and treatment of postoperative Crohn's disease recurrence with anti-TNF therapy: a meta-analysis of controlled trials. Dig Liver Dis. 2015;47(3):191-6. https://doi.org/10.1016/j. dld.2014.11.005

126. McCombie AM, Mulder RT, Gearry RB. How IBD patients cope with IBD: a systematic review. J Crohns Colitis. 2013;7(2):89-106. https://doi.org/10.1016/j. crohns.2012.05.021

127. Ha FJ, Thong L, Khalil H. Quality of Life after Intestinal Resection in Patients with Crohn Disease: A Systematic Review. Dig Surg. 2017;34(5):355-63. https://doi. org/10.1159/000453590

128. Mahadev S, Young JM, Selby W, Solomon MJ. Quality of life in perianal Crohn's disease: what do patients consider important? Dis Colon Rectum. 2011;54(5):579-85. https://doi.org/10.1007/DCR.0b013e3182099d9e

129. Byrne CM, Solomon MJ, Young JM, Selby W, Harrison JD. Patient preferences between surgical and medical treatment in Crohn's disease. Dis Colon Rectum. 2007;50(5):586-97. https://doi.org/10.1007/s10350006-0847-0 